NÍCOLAS ALEXANDRE FAKHOURY

ESTUDO DA QUALIDADE DO AR INTERIOR EM AMBIENTES EDUCACIONAIS

São Paulo

2017 
NÍCOLAS ALEXANDRE FAKHOURY

ESTUDO DA QUALIDADE DO AR INTERIOR EM AMBIENTES EDUCACIONAIS

Dissertação apresentada para a Escola

Politécnica da Universidade de São Paulo para

obtenção do título de Mestre em Ciências

São Paulo 
NÍCOLAS ALEXANDRE FAKHOURY

\section{ESTUDO DA QUALIDADE DO AR INTERIOR EM AMBIENTES EDUCACIONAIS}

Dissertação apresentada para a Escola Politécnica da Universidade de São Paulo para obtenção do título de Mestre em Ciências

Área de concentração: Engenharia Mecânica de Energia e Fluidos

Orientador: Prof. Dr. Marcos de Mattos Pimenta

São Paulo 
Este exemplar foi revisado e corrigido em relação à versão original, sob responsabilidade única do autor e com a anuência de seu orientador.

São Paulo, de de

Assinatura do autor:

Assinatura do orientador:

Catalogação-na-publicação

Fakhoury, Nícolas Alexandre

Estudo da qualidade do ar interior em ambientes educacionais / N. A. Fakhoury -- versão corr. -- São Paulo, 2017.

$196 \mathrm{p}$.

Dissertação (Mestrado) - Escola Politécnica da Universidade de São Paulo. Departamento de Engenharia Mecânica.

1.Qualidade do ambiente interno 2.Poluição atmosférica 3.Ambiente educacional 4.Ventilação e ar condicionado I.Universidade de São Paulo. Escola Politécnica. Departamento de Engenharia Mecânica II.t. 


\section{DEDICATÓRIA}

Dedico este trabalho a minha família. 


\section{AGRADECIMENTOS}

A Deus, pela saúde e oportunidade.

À Natália, com amor e gratidão, por sua compreensão, carinho e apoio ao longo desse período.

À minha família, por todo incentivo e força sempre presentes.

Ao amigo Ricardo Correia, por toda ajuda e atenção na realização deste projeto.

Ao professor Dr. Antonio Luís de Campos Mariani, pelos ensinamentos, dedicação, estímulo e confiança ao longo de todo o projeto.

Ao professor Dr. Marcos de Mattos Pimenta, pela orientação, atenção e confiança presentes no processo de orientação.

Ao professor Dr. Celso Massatoshi Furukawa, pela colaboração com as aulas que foram laboratório da Qualidade do Ar Interior.

À equipe do Laboratório de Instrumentação, Douglas Silva, Eric Piaga e Guilherme Formon, pela ajuda e disponibilidade no período das medições.

À empresa BHP, pela instalação dos equipamentos de tratamento de ar indispensáveis para o projeto.

À empresa Conforlab, pela disponibilização dos equipamentos de medição que foram fundamentais para a realização desse trabalho. 


\section{RESUMO}

A Qualidade do Ambiente Interior (QAI) é um dos principais fatores que determina a funcionalidade, harmonia, conforto e produtividade em um edifício. A QAI afeta a saúde e o conforto dos ocupantes de um edifício, bem como a habilidade dos mesmos em realizar tarefas, influenciando diretamente na produtividade. Quando a QAI é boa, os ambientes se tornam lugares mais desejáveis para estar, trabalhar e aprender.

O ambiente de escolas e universidades pode exercer um impacto significativo na saúde e no aprendizado de crianças e estudantes universitários. A limitação da entrada de poluentes e contaminantes, bem como o fornecimento da quantidade adequada de ar externo filtrado e limpo, melhoram o desempenho acadêmico dos estudantes e não atinge a saúde dos mesmos.

Este trabalho apresenta medições de parâmetros físicos e químicos, $\mathrm{CO}_{2}, \mathrm{PM}_{2,5}, \mathrm{PM}_{10}$, temperatura de bulbo seco e umidade relativa, efetuadas em uma sala de aula do prédio de Engenharia Mecânica da Escola Politécnica da Universidade de São Paulo (EPUSP) os quais os estudantes e professores estavam sujeitos. As medidas foram tomadas no ambiente interno e externo a sala de aula, onde atividades teóricas e práticas eram realizadas. A vazão de ar externo, previamente filtrado, era variada para a redução dos contaminantes gerados internamente.

Constatou-se que os particulados $\mathrm{PM}_{2,5}$ e $\mathrm{PM}_{10}$ atingiram concentrações críticas de 6 e 30 vezes maiores do que o limite proposto pelas normas vigentes, respectivamente, bem como a concentração de $\mathrm{CO}_{2}$ que atingiu 3 vezes o limite recomendado. Porém, observou-se que o aumento da vazão de ar externo em aproximadamente $2200 \mathrm{~m}^{3} / \mathrm{h}$ foi suficiente para a diminuição da concentração de $\mathrm{PM}_{10}$ em 50\% nos primeiros 20 minutos. Apesar da diminuição da concentração, a vazão recomendada de ar externo por pessoa não foi suficiente para a concentração de material particulado atingir os limites aceitáveis.

Por fim, apresenta-se uma proposta de projeto detalhado de dois sistemas independentes de tratamento de ar que permitirão a realização de experimentos e estudos sobre a QAI, podendose variar a vazão de ar externo e a classe de filtragem da recirculação e da tomada de ar externo para dois laboratórios do Departamento de Engenharia Mecânica da EPUSP, que podem dar sequência aos estudos deste trabalho.

Palavras-chave: Qualidade do Ambiente Interno; poluição do ar; ventilação e ar condicionado; ambientes educacionais. 


\begin{abstract}
The Indoor Environmental Quality (IEQ) is one of the main factors that determines the functionality, harmony, comfort and productivity in a building. The IEQ affects the health and comfort of the occupants of a building, as well as the ability of them to perform tasks, influencing directly in productivity. When IEQ is good, the environments become more desirable places to be in, work and learn.

The indoor environment of schools and universities can have a significant impact on the health and learning of children and college students. The limitation of input of pollutants and contaminants, as well as providing the appropriate amount of filtered and clean outside air, improve the academic performance of students and does not affect the health of the same.

This paper presents measurements of physical and chemical parameters, $\mathrm{CO}_{2}, \mathrm{PM}_{2,5}, \mathrm{PM}_{10}$, dry bulb temperature and relative humidity, made in a classroom of the Mechanical Engineering building of the Polytechnic School of the University of São Paulo (EPUSP) which students and teachers were subject. The measurements were taken in the internal and external environment of the classroom, where theoretical and practical activities were conducted. The flow of outside air, previously filtered, was varied for the reduction of contaminants generated internally.

It was found that the particulate $\mathrm{PM}_{2,5}$ and $\mathrm{PM}_{10}$ achieved critical concentrations of 6 and 30 times greater than the limit proposed by the current standards, respectively, and that the concentration of $\mathrm{CO}_{2}$ reached 3 times the recommended limit. However, it was observed that increasing outside air flow of approximately $2200 \mathrm{~m}^{3} / \mathrm{h}$ was enough to decrease the concentration of $\mathrm{PM}_{10}$ in $50 \%$ at the first 20 minutes. Despite the decreased concentration, the recommended flow of outside air per person was not enough for the concentration of particulate matter reaches the acceptable limits.

Finally, a detailed project proposal is presented of two independent air treatment systems that will allow performing experiments and studies on the IEQ, being able to vary the flow of outside air and, the filters of the recirculation and external air intake for two laboratories of the Department of Mechanical Engineering of EPUSP, that can follow the studies of this work.
\end{abstract}

Keywords: Indoor Environmental Quality; air pollution; ventilation and air conditioning; educational environments. 


\section{LISTA DE FIGURAS}

Figura 2.1. Taxas de ventilação em escolas publicados na literatura dos Estados Unidos da América e da Europa (adaptado de DAISEY, ANGELL, APTE, 2003). 41

Figura 2.2. Média e Variação da concentração de $\mathrm{CO}_{2}$ nas escolas, na literatura científica dos Estados Unidos da América e do Canadá (adaptado de DAISEY, ANGELL, APTE, 2003). . 42

Figura 2.3. Desempenho no trabalho relativo a várias taxas de ventilação (adaptado de SEPPÄNEN et al., 2006) 44

Figura 2.4. Aumento do desempenho na realização de testes comparados com a remoção de uma fonte interna poluidora e do aumento da taxa de ventilação. 45

Figura 3.1. Layout da sala de aula A2. 53

Figura 3.2. Vista lateral interna da sala de aula A2. 53

Figura 3.3. Fotos da caixa de ventilação da sala de aula A2. Caixa de ventilação aberta com um estágio de filtragem (esquerda); Caixa de ventilação instalada (direita). 54

Figura 3.4. Difusores de ar externo instalados na sala de aula A2 ................................... 55

Figura 3.5. Posicionamento do medidor de vazão na saída do difusor para verificação da vazão de ar das caixas de ventilação. 56

Figura 3.6. Dados meteorológicos da CETESB de 17 de agosto de 2016 da cidade de São Paulo 57

Figura 3.7. Curva de calibração do medidor de vazão 58

Figura 3.8. Taxa de respiração, consumo de oxigênio e produção de $\mathrm{CO}_{2}$ em função do metabolismo (ABNT, 2008). 61

Figura 3.9. Taxa de renovação de ar mínima, por ocupante, em função da idade dos estudantes, para garantir concentração média diária de $\mathrm{CO}_{2}$ de 1000 ppm (adaptado de REHVA, 2010). 63 
Figura 3.10. Comparação do diâmetro do cabelo humano e de um grão de areia com as

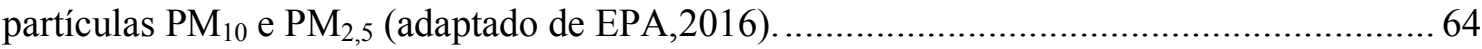

Figura 3.11. Termohigrômetro utilizado durante as medições.......................................... 65

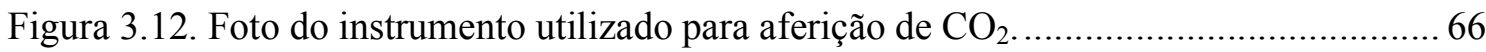

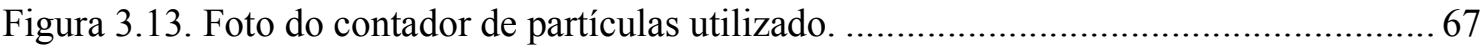

Figura 3.14. Tabela proposta por Bordini (2015) para tomada de medidas.......................... 68

Figura 3.15. Tabela utilizada para controle das medições. .................................................... 69

Figura 3.16. Instrumentação utilizada e posição de medição no ar externo .......................... 71

Figura 3.17. Instrumentação utilizada e posição de medição na sala A2 ............................. 71

Figura 4.1. Alunos e instrutores durante a atividade na Oficina de Brinquedos. .................. 75

Figura 4.2. Alunos e instrutores realizando atividade de usinagem na Oficina de Brinquedos. 76

Figura 4.3. Concentração de $\mathrm{CO}_{2}$ - Oficina de Brinquedos $(21 / 05 / 2016)$. ........................... 76

Figura 4.4. Concentração de $\mathrm{PM}_{10}$ - Oficina de Brinquedos (21/05/2016)......................... 77

Figura 4.5. Concentração de $\mathrm{PM}_{2,5}$ - Oficina de Brinquedos (21/05/2016) ......................... 78

Figura 4.6. Temperatura e umidade relativa - Oficina de Brinquedos $(21 / 05 / 2016) \ldots \ldots \ldots \ldots . . . .79$

Figura 4.7. Alunos e instrutores durante a aula teórica da Oficina de Robótica. ................... 80

Figura 4.8. Alunos durante a atividade prática na Oficina de Robótica. .............................. 81

Figura 4.9. Concentração de $\mathrm{CO}_{2}$ - Oficina de Robótica (11/05/2016).............................. 81

Figura 4.10. Concentração de $\mathrm{PM}_{10}$ - Oficina de Robótica (11/06/2016)............................. 82

Figura 4.11. Concentração de $\mathrm{PM}_{2,5}$ - Oficina de Robótica (11/06/2016) ........................... 83

Figura 4.12. Temperatura e umidade relativa - Oficina de Robótica $(11 / 06 / 2016) \ldots \ldots \ldots \ldots \ldots . . .84$ 
Figura 4.13. Arrumação da sala de aula A2 para a Oficina de Carrinhos de Rolimã. 86

Figura 4.14. Utilização da serra elétrica para confecção dos tampos das mesas 86

Figura 4.15. Concentração de $\mathrm{CO}_{2}$ - Aula de Eletrônica e arrumação da sala (21/10/2016). . 87

Figura 4.16. Concentração de $\mathrm{PM}_{10}$ - Aula de Eletrônica e arrumação da sala (21/10/2016). 88

Figura 4.17. Concentração de $\mathrm{PM}_{2,5}$ - Aula de Eletrônica e arrumação da sala (21/10/2016). 89

Figura 4.18. Temperatura e umidade relativa - Aula de Eletrônica e arrumação da sala $(21 / 10 / 2016)$. 90

Figura 4.19. Alunos e instrutores durante a atividade na Oficina de Carrinhos de Rolimã.... 91

Figura 4.20. Alunos e instrutores realizando atividade de usinagem na Oficina de Carrinhos de Rolimã. 92

Figura 4.21. Concentração de $\mathrm{CO}_{2}$ - Oficina de Carrinhos de Rolimã (22/10/2016)............ 92

Figura 4.22. Concentração de $\mathrm{PM}_{10}$ - Oficina de Carrinhos de Rolimã (22/10/2016). ........... 93

Figura 4.23. Concentração de $\mathrm{PM}_{2,5}$ - Oficina de Carrinhos de Rolimã (22/10/2016)........... 94

Figura 4.24. Temperatura e umidade relativa - Oficina de Carrinhos de Rolimã (22/10/2016).

Figura 4.25. Segundo dia de atividades da Oficina de Carrinhos de Rolimã 96

Figura 4.26. Alunos e instrutores durante as atividades do segundo dia da Oficina de Carrinhos de Rolimã. 97

Figura 4.27. Concentração de $\mathrm{CO}_{2}$ - Oficina de Carrinhos de Rolimã (23/10/2016). 97

Figura 4.28. Concentração de $\mathrm{PM}_{10}$ - Oficina de Carrinhos de Rolimã (23/10/2016)........... 98

Figura 4.29. Concentração de $\mathrm{PM}_{2,5}$ - Oficina de Carrinhos de Rolimã (23/10/2016). 99

Figura 4.30. Temperatura e umidade relativa - Oficina de Carrinhos de Rolimã (23/10/2016). 
Figura 4.31. Medição da aula teórica de Eletrônica. 101

Figura 4.32. Concentração de $\mathrm{CO}_{2}$ na sala de aula $\mathrm{A} 2$ do dia 17/08/2016. 102

Figura 4.33. Temperatura e umidade relativa na sala de aula A2 do dia 17/08/2016. 103

Figura 4.34. Concentração de $\mathrm{CO}_{2}$ na sala de aula A2 do dia 19/08/2016 105

Figura 4.35. Concentração de $\mathrm{PM}_{10}$ na sala de aula A2 do dia 19/08/2016........................ 106

Figura 4.36. Concentração de $\mathrm{PM}_{2,5}$ na sala de aula A2 do dia 19/08/2016....................... 107

Figura 4.37. Temperatura e umidade relativa na sala de aula A2 do dia 19/08/2016. ......... 108

Figura 4.38. Concentração de $\mathrm{CO}_{2}$ na sala de aula A2 do dia 22/08/2016......................... 109

Figura 4.39. Concentração de $\mathrm{PM}_{10}$ na sala de aula A2 do dia 22/08/2016.......................... 110

Figura 4.40. Concentração de $\mathrm{PM}_{2,5}$ na sala de aula A2 do dia 22/08/2016........................ 111

Figura 4.41. Temperatura e umidade relativa na sala de aula A2 do dia 22/08/2016.......... 112

Figura 4.42. Concentração de $\mathrm{CO}_{2}$ na sala de aula $\mathrm{A} 2$ do dia 24/08/2016........................ 113

Figura 4.43. Concentração de $\mathrm{PM}_{10}$ na sala de aula A2 do dia 24/08/2016........................ 114

Figura 4.44. Concentração de $\mathrm{PM}_{2,5}$ na sala de aula A2 do dia 24/08/2016....................... 115

Figura 4.45. Temperatura e umidade relativa na sala de aula A2 do dia 24/08/2016. ......... 116

Figura 4.46. Concentração de $\mathrm{CO}_{2}$ na sala de aula $\mathrm{A} 2$ do dia 26/08/2016......................... 117

Figura 4.47. Concentração de $\mathrm{PM}_{10}$ na sala de aula A2 do dia 26/08/2016........................ 118

Figura 4.48. Concentração de $\mathrm{PM}_{2,5}$ na sala de aula A2 do dia 26/08/2016....................... 119

Figura 4.49. Temperatura e umidade relativa na sala de aula A2 do dia 26/08/2016......... 120

Figura 4.50. Concentração de $\mathrm{CO}_{2}$ na sala de aula A2 do dia 24/10/2016......................... 122

Figura 4.51. Concentração de $\mathrm{PM}_{10}$ na sala de aula A2 do dia 24/10/2016......................... 123 
Figura 4.52. Concentração de $\mathrm{PM}_{2,5}$ na sala de aula A2 do dia 24/10/2016.

Figura 4.53. Temperatura e umidade relativa na sala de aula A2 do dia 24/10/2016. 125

Figura D.1. Layout dos laboratórios de Instrumentação (MT16) e Túneis de Vento (MT06) e ambientes contíguos 148

Figura D.2. Configuração na qual o ar externo é misturado com o ar de recirculação na caixa de mistura (BOLLIGER JR, MARIANI, 2006). 149

Figura D.3. Intercambiador de calor série ICV-DX (TROX, 2015) 152

Figura D.4. Filtro bolsa para dutos para os laboratórios (TROX, 2015c). 153

Figura D.5. Caixa de ventilação a ser utilizada nos laboratórios com gaveta para filtro (OTAM, 2015a). 155

Figura D.6. Ventilador de exaustão selecionado para operação no laboratório MT06 (OTAM, 2015b) 156

Figura D.7. Ventilador para exaustão localizada (OTAM, 2015b). 157

Figura D.8. Braço extrator modelo "Nederman Original” (NEDERMAN, 2015). 157

Figura D.9. Grelha de retorno modelo AR da TROX...................................................... 158

Figura D.10. Difusor selecionado para insuflamento de ar no laboratório MT06 (TROX,

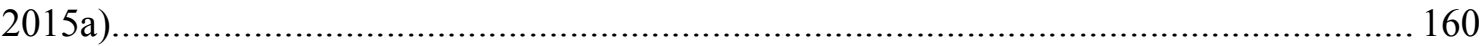

Figura D.11. Princípio de funcionamento do sistema Varyset......................................... 160 


\section{LISTA DE TABELAS}

Tabela 2.1. Efeitos da concentração de $\mathrm{O}_{2}$ (VERANI, 2003).......................................... 26

Tabela 2.2. Classificação das substâncias poluentes (CETESB, 2015)................................ 29

Tabela 2.3. Padrões nacionais de qualidade do ar estabelecidos pela resolução CONAMA

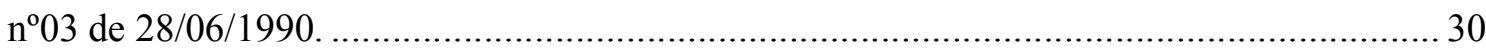

Tabela 2.4. Padrões estaduais de qualidade do ar (Decreto Estadual nº59113 de 23/04/2013).

Tabela 2.5. Critérios para episódios agudos de poluição do ar (Decreto Estadual nº59113 de

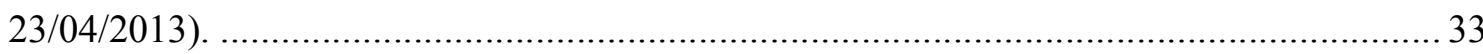

Tabela 2.6. Estrutura do índice de qualidade do ar (CETESB, 2015)................................ 34

Tabela 2.7. Qualidade do ar e efeitos à saúde (CETESB, 2015)...................................... 34

Tabela 2.8. Possíveis fontes de poluentes biológicos (Resolução nº9 de 16/01/2003, 2015).. 37

Tabela 2.9. Possíveis fontes de poluentes químicos (Resolução n ${ }^{\circ} 9$ de 16/01/2003, 2015)... 38

Tabela 3.1. Características técnicas dos equipamentos instalados. ..................................... 54

Tabela 3.2. Dados obtidos para verificação da vazão de ar externo das caixas de ventilação. 55

Tabela 3.3. Vazão de ar externo das caixas de ventilação. ................................................... 59

Tabela 3.4. Concentração de particulados na saída dos difusores das unidades de renovação.59

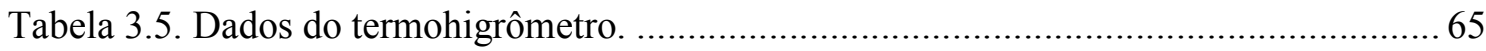

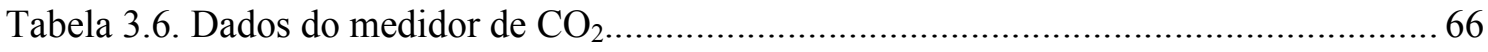

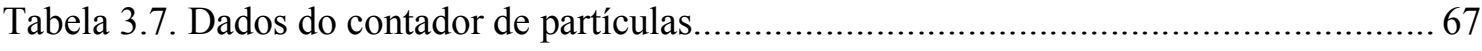

Tabela 3.8. Tabela resumo dos instrumentos utilizados e a posição de medição.................... 71 
Tabela 3.9. Valores de incerteza do tipo B 73

Tabela 3.10. Valores de incerteza expandida com um nível de confiança de 95,45\%.......... 73

Tabela 4.1. Variação da vazão de ar externo para a medição P1 ........................................ 75

Tabela 4.2. Variação da vazão de ar externo para a medição P2 ........................................ 80

Tabela 4.3. Variação da vazão de ar externo para a medição P3. ......................................... 85

Tabela 4.4. Variação da vazão de ar externo para a medição P4. ....................................... 91

Tabela 4.5. Variação da vazão de ar externo para a medição P5. ........................................ 96

Tabela 4.6. Variação da vazão de ar externo para a medição T1....................................... 101

Tabela 4.7. Variação da vazão de ar externo para a medição T2 ....................................... 104

Tabela 4.8. Variação da vazão de ar externo para a medição T3...................................... 109

Tabela 4.9. Variação da vazão de ar externo para a medição T4. ....................................... 113

Tabela 4.10. Variação da vazão de ar externo para a medição T5. .................................... 117

Tabela 4.11. Variação da vazão de ar externo para a medição T6..................................... 121

Tabela 5.1. Variação da concentração de particulado devido à ação de escrever com giz na

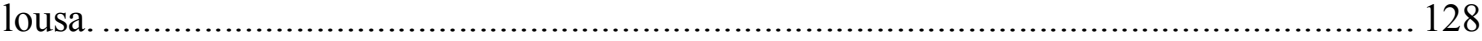

Tabela 5.2. Variação da concentração de material particulado no interior da sala devido ao

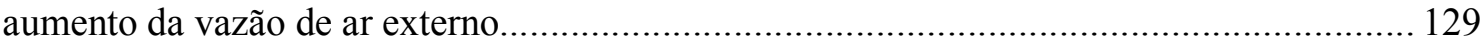

Tabela D.1. Carga térmica dos laboratórios de estudo de acordo com Rollo (2013)........... 148

Tabela D.2. Carga térmica total dos laboratórios (ROLLO, 2013)................................. 150

Tabela D.3. Vazões de ar para os laboratórios de estudo (ROLLO, 2013).......................... 150

Tabela D.4. Equipamentos selecionados para os laboratórios (TROX, 2015).................... 151

Tabela D.5. Tabela de seleção das caixas de ventilação para os laboratórios (OTAM, 2015a). 
Tabela D.6. Ventiladores de exaustão selecionados para os laboratórios (OTAM, 2015b). . 156

Tabela D.7. Faixas de vazões de trabalho para os difusores dos Laboratórios. 159

Tabela D.8. Tabela de seleção do difusor Tipo ADLQ com Varyset (TROX, 2015a).......... 159 


\section{LISTA DE ABREVIATURAS E SIGLAS}

\begin{tabular}{|c|c|}
\hline ANVISA & Agência Nacional de Vigilância Sanitária \\
\hline ASHRAE & American Society of Heating, Refrigerating and Air Conditioning Engineers \\
\hline AVAC & Aquecimento, Ventilação e Ar Condicionado \\
\hline CETESB & Companhia Ambiental do Estado de São Paulo \\
\hline CICPAA & Comissão Intermunicipal de Controle da Poluição das Águas e do Ar \\
\hline $\mathrm{CO}$ & Monóxido de Carbono \\
\hline $\mathrm{CO}_{2}$ & Dióxido de Carbono \\
\hline CONAMA & Conselho Nacional de Meio Ambiente \\
\hline CONSEMA & Conselho Estadual do Meio Ambiente \\
\hline $\mathrm{COV}$ & Compostos Orgânicos Voláteis \\
\hline COV-S & Compostos Orgânicos Semi Voláteis \\
\hline EPA & Environmental Protection Agency \\
\hline FMC & Fumaça \\
\hline $\mathrm{HC}$ & Hidrocarbonetos \\
\hline IBAMA & Instituto Brasileiro de Meio Ambiente \\
\hline ICIEE & International Center for Indoor Environment and Energy \\
\hline IEQ & Indoor Environmental Quality \\
\hline INMETRO & Instituto Nacional de Metrologia, Qualidade e Tecnologia \\
\hline MS & Ministério da Saúde \\
\hline MT06 & Laboratório de Tunéis de Vento \\
\hline MT16 & Laboratório de Instrumentação \\
\hline NO & Óxido de Nitrogênio \\
\hline $\mathrm{NO}_{2}$ & Dióxido de Nitrogênio \\
\hline $\mathrm{NOx}$ & Óxidos de Nitrogênio \\
\hline $\mathrm{O}_{2}$ & Oxigênio \\
\hline OMS & Organização Mundial da Saúde \\
\hline PM & Material Particulado \\
\hline $\mathrm{PM}_{10}$ & Partículas Inaláveis \\
\hline $\mathrm{PM}_{2,5}$ & Partículas Inaláveis Finas \\
\hline PTS & Partículas Totais em Suspensão \\
\hline QAI & Qualidade do Ambiente Interior \\
\hline RMSP & Região Metropolitana de São Paulo \\
\hline
\end{tabular}




$\begin{array}{ll}\mathrm{SED} & \text { Síndrome dos Edifícios Doentes } \\ \mathrm{SO}_{2} & \text { Dióxido de Enxofre } \\ \mathrm{UR} & \text { Umidade Relativa } \\ \mathrm{WHO} & \text { World Health Organization }\end{array}$




\section{LISTA DE SÍMBOLOS}

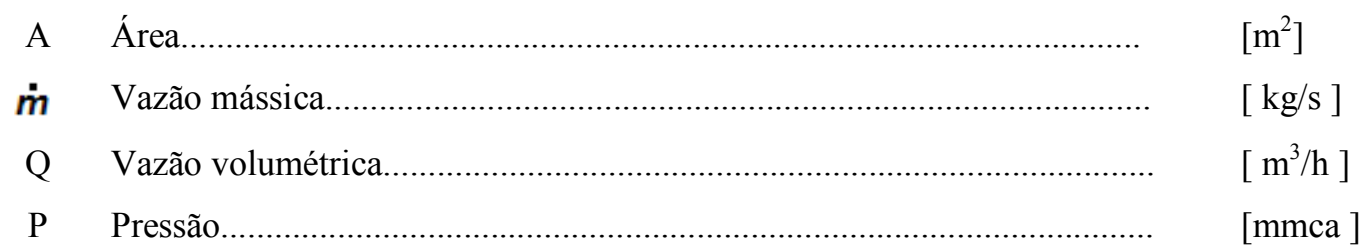

\section{Símbolos Gregos}

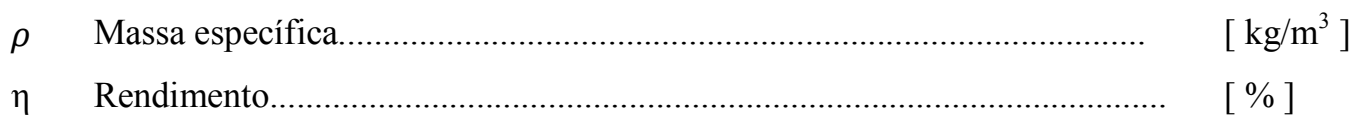

\section{Subscritos}

$\begin{array}{ll}A E & \text { Ar externo } \\ i & \text { Interno } \\ R & \text { Retorno } \\ \text { esc } & \text { Escape }\end{array}$




\section{SUMÁRIO}

1 INTRODUÇÃ

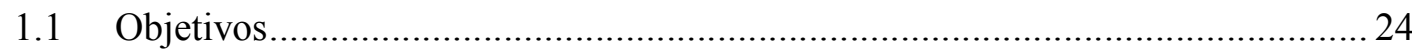

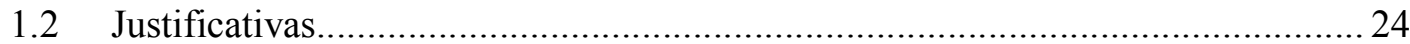

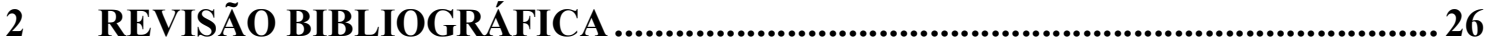

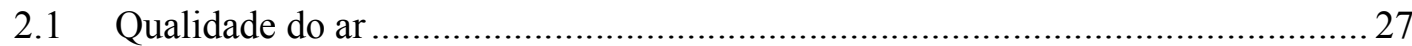

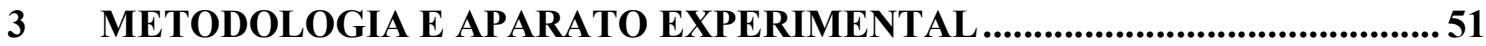

3.1 Sala de aula e equipamentos de condicionamento de ar adotados para avaliação de

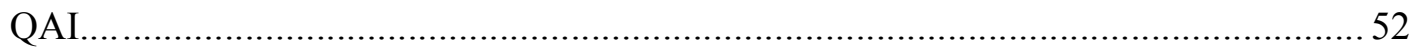

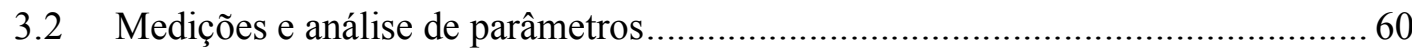

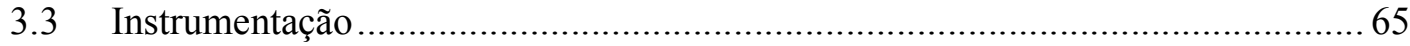

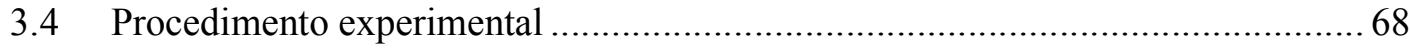

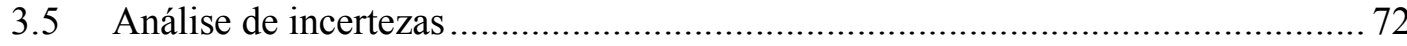

4 RESULTADOS DAS MEDIÇÕES E DISCUSSÃO DOS PARÂMETROS.......... 74

4.1 Medições na sala de aula A2 durante aulas práticas ........................................ 74

4.2 Medições na sala de aula A2 durante aulas teóricas ........................................ 101

5 ANÁLISE GERAL DOS RESULTADOS................................................. 126

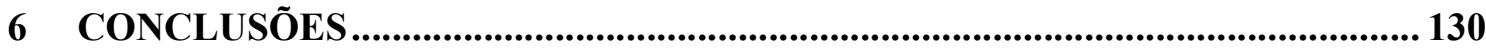

REFERÊNCIAS BIBLIOGRÁFICAS ................................................................. 131

Anexo A - Descrição dos poluentes .................................................................... 139

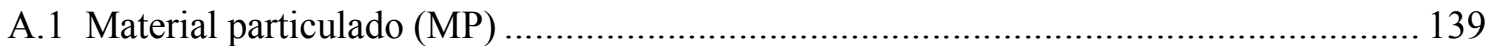

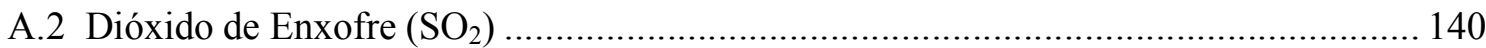

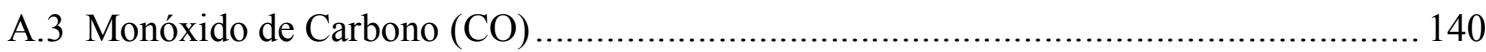

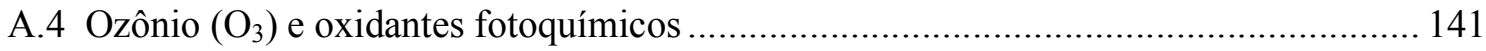

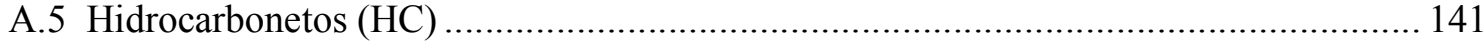

A.6 Óxido de Nitrogênio (NO) e Dióxido de Nitrogênio $\left(\mathrm{NO}_{2}\right)$....................................... 141

Anexo B - Tabelas da CETESB ................................................................................ 142

B.1 Qualidade do Ar e Efeitos sobre a Saúde (CETESB, 2015) .................................... 143 
B.2 Qualidade do Ar e Prevenção de Riscos à Saúde (CETESB, 2015) .......................... 144

Anexo C - Tabela da NBR 16401-3 (ABNT, 2008) ..................................................... 145

C.1 Concentração máxima de alguns poluentes do ambiente interior ............................. 145

Anexo D - Proposta de projeto de sistemas de tratamento de ar para futuros estudos de QAI 147

D.1 Laboratórios didáticos para estudo de QAI ..................................................... 147

D.2 Projeto dos sistemas de tratamento de ar para os laboratórios ................................... 150

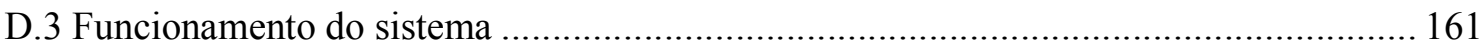

Anexo E - Projeto dos sistemas de VAC para os laboratórios ................................... 162

E.1 Fluxograma da casa de máquinas do Laboratório de Instrumentação (MT 16)............ 163

E.2 Fluxograma da casa de máquinas do Laboratório de Túneis de Vento (MT 06) .......... 164

E.3 Arranjo de dutos e equipamentos do Laboratório de Instrumentação (MT 16) ............ 165

E.4 Arranjo de dutos e equipamentos do Laboratório de Túneis de Vento (MT 06) .......... 166

E.5 Arranjo de dutos e equipamentos Cobertura .................................................. 167

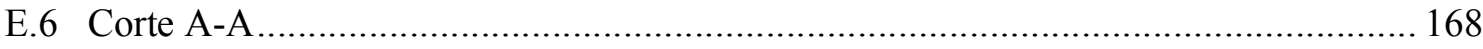

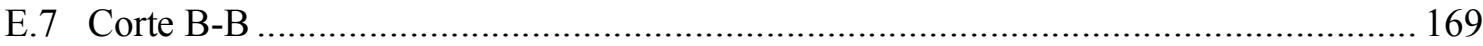

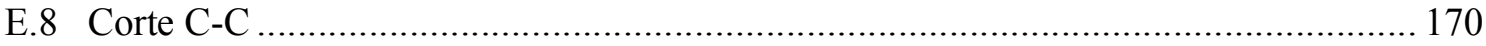

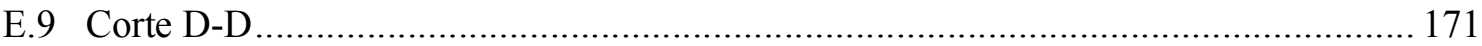

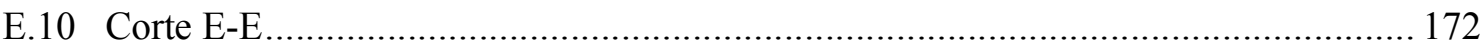

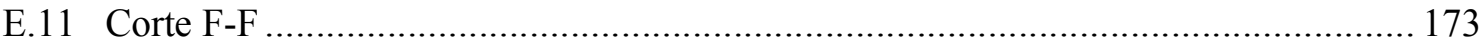

E.12 Vista da casa de máquinas do laboratório de Instrumentação (MT 16)..................... 174

E.13 Vista da casa de máquinas do laboratório de Túneis de Vento (MT 06) .................... 175

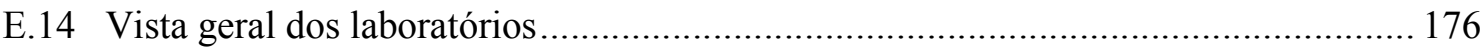

E.15 Tabela de componentes do sistema do laboratório (MT 16) ................................. 177

E.16 Tabela de componentes do sistema do laboratório (MT 06) .................................. 178

Anexo F - Tabelas de medições das aulas práticas....................................................... 179

F.1 Tabela da medição do dia 21/05/2016 ............................................................ 180

F.2 Tabela da medição do dia 11/06/2016 .................................................................... 181

F.3 Tabela da medição do dia 21/10/2016 ..................................................................... 182

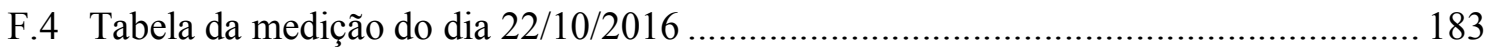

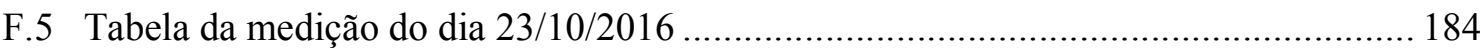

Anexo G - Tabelas de medições das aulas teóricas......................................................... 185 


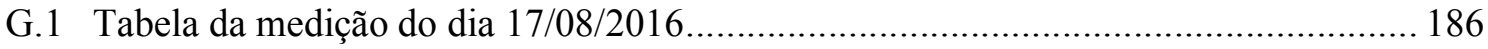

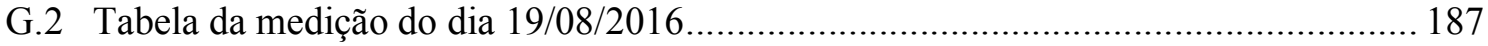

G.3 Tabela da medição do dia 22/08/2016 .................................................................... 188

G.4 Tabela da medição do dia 24/08/2016 .................................................................. 189

G.5 Tabela da medição do dia 26/08/2016 .............................................................. 190

G.6 Tabela da medição do dia 24/10/2016............................................................... 191

Anexo H - Gráficos das medições de Bordini (2015) ...................................................... 192

H.1 Concentração de $\mathrm{CO}_{2}$ na sala A2 durante a aula teórica (BORDINI, 2015) ................ 193

H.2 Concentração de $\mathrm{PM}_{10}$ na sala A2 durante a aula teórica (BORDINI, 2015)............... 194

H.3 Concentração de $\mathrm{CO}_{2}$ na sala A2 durante a Oficina de Carrinhos de Rolimã (BORDINI,

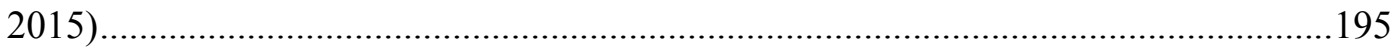

H.4 Concentração de $\mathrm{PM}_{10}$ na sala A2 durante a Oficina de Carrinhos de Rolimã (BORDINI, 2015) 


\section{INTRODUÇÃO}

Com o passar dos anos, o crescimento populacional nos centros urbanos se tornou muito expressivo e, consequentemente, acarretou em um aumento considerável das atividades necessárias para atender à população, como o transporte público, as indústrias e obras diversas. Com o aumento dessas atividades, as ações negativas do homem, como queimadas e devastação de áreas verdes tornam cada vez mais impuro o ar que nos circunda. Devido a estes fatores e, consequente observação do crescimento considerável de diversas fontes de poluentes atmosféricos, um dos objetos de discussões e de estudos que se tornou frequente é a poluição atmosférica.

Os poluentes atmosféricos provocam um grande impacto ambiental nos ecossistemas, acarretando em mudanças na qualidade do ar. Essa, por sua vez, reflete diretamente no homem, podendo influenciar no conforto, no desempenho em realizações de tarefas, e até mesmo na saúde humana. Sendo assim, uma maior atenção ao monitoramento da qualidade do ar se fez necessária, acarretando em várias políticas de controle de emissão de poluentes, e inúmeros estudos acerca desta temática.

Significativa porcentagem do tempo de vida do ser humano é passada em ambientes interiores, sejam eles residências, escolas, escritórios ou outros edifícios. Um estudo realizado em 1992 mostrou que um habitante urbano passa em média cerca de 87\% do seu tempo em ambientes interiores, e $6 \%$ em ambientes exteriores, sendo que os outros $7 \%$ seriam gastos na transição entre esses dois ambientes, como por exemplo no automóvel (JENKLINS et al., 1992). Isto significa que, na maior parte do tempo, estamos sujeitos a um ambiente artificial que é definido pelo espaço fechado do edifício. (PARKER, 1993).

A maioria das pessoas tende a acreditar que o ar que se respira no interior dos edifícios é mais limpo e saudável do que o ar externo. No entanto, é preciso considerar que a contaminação do ar atmosférico não está limitada apenas ao meio exterior, visto que uma quantidade significativa de emissão de contaminantes pode ocorrer em ambientes ocupacionais internos.

A Qualidade do Ar Interior está relacionada à contaminação do ar exterior que entra no edifício, da efíciência do sistema de Aquecimento, Ventilação e Ar Condicionado (AVAC) na remoção de contaminantes do ar, e das próprias atividades realizadas nas áreas internas, como 
poluição causada por materiais de construção, de equipamentos, e pelas próprias pessoas usuárias do ambiente (ANVISA, 2013).

Desde a crise de energia de 1970, as construções dos edifícios eram feitas para se ter cada vez mais um edifício vedado. Dessa forma, as pessoas conseguiam uma estratégia para economizar energia por meio da recirculação do ar interno, minimizando assim a necessidade de aquecimento ou de resfriamento do ar externo. Porém, essa estratégia trouxe consigo o enclausuramento de contaminantes em níveis não desejados no interior dos edifícios.

Em geral, as medições de poluentes atmosféricos são realizadas no ambiente externo, em estações de qualidade do ar. As concentrações obtidas para determinados poluentes, nestes casos, podem não representar bons indicadores das concentrações que existem no interior, tendo em vista que as mesmas não consideram fontes de emissão que existem exclusivamente em ambientes interiores (WALLACE et al., 1997).

A preocupação com a Qualidade do Ar Interior aumentou e começou a ser contemplada pelos organismos e entidades internacionais e nacionais. Em 1979, a Organização Mundial da Saúde (OMS) apresentou um relatório chamado Health aspects related to indoor air quality, no qual são referidas as crescentes preocupações com os poluentes e as fontes emissoras interiores (WORLD HEALTH ORGANIZATION, 1979).

É importante mencionar que o aumento na preocupação com a Qualidade do Ar Interior, não se refere apenas à poluição atmosférica, mas também com:

- os problemas de saúde, como a Síndrome do Edifício Doente, problema este que advém de condições desfavoráveis das construções, como a má ventilação, limpeza e manutenção inadequadas de equipamentos, gerando fatores que afetam a saúde dos usuários do ambiente;

- o desempenho de atividades, o que afeta diretamente na produtividade, como por exemplo, de trabalhadores, sendo que isto está diretamente relacionado com custo. Em um escritório onde existe digitação, por exemplo, onde se deseja uma produção rápida, problemas com Qualidade do Ar Interior podem diminuir o desempenho dos trabalhadores diminuindo o lucro final do empregador;

- o aprendizado de alunos, sendo que problemas de saúde e a diminuição no desempenho dos mesmos influencia diretamente na vida escolar. 
A concentração dos agentes contaminantes internos, decorrentes das condições da instalação, conservação dos ambientes e de agentes poluidores externos tornou-se um indicador da qualidade do ar em recintos fechados. Assim, a medida da concentração de agentes como Monóxido de Carbono ( $\mathrm{CO}$ ), Dióxido de Carbono $\left(\mathrm{CO}_{2}\right)$, Monóxido de Nitrogênio (NO), Dióxido de Nitrogênio $\left(\mathrm{NO}_{2}\right)$, partículas em suspensão, aldeídos, compostos orgânicos voláteis (COV), microorganimos pode ser usada para avaliar a taxa de ventilação, determinando a proporção de ar renovado que está misturado com o ar recirculado, bem como o tratamento do mesmo. Os citados agentes possuem a capacidade de agredir o ser humano, com sua sintomatologia vinculada à concentração e exposição observadas em ambientes fechados (FUJII, 2006).

Estudos recentes demonstraram associações entre a Qualidade do Ambiente Interno e a saúde e o desempenho de estudantes e funcionários nas escolas. As pesquisas que ligam a baixa Qualidade do Ar Interior aos problemas de saúde das crianças e o desempenho acadêmico reduzido mostram o papel fundamental que o ambiente interior de uma escola exerce no desempenho do aluno. As boas condições físicas da escola e a adequada ventilação do ar exterior podem reduzir a ausência dos alunos em sala e melhorar os resultados obtidos pelos mesmos em testes acadêmicos. É importante incorporar as melhores práticas para escolas saudáveis e sustentáveis em melhorias na eficiência energética e em novas maneiras de construção das escolas. (EPA, 2014).

Sendo assim, a melhor maneira de se buscar a Qualidade do Ar Interior é realizar a verificação das condições de ventilação das edificações, com a devida filtragem, e implantar sistemas de tratamento de ar com configurações energeticamente eficientes para a retirada de poluentes. 


\subsection{Objetivos}

O objetivo central deste trabalho é a realização de um estudo experimental para análise da Qualidade do Ar Interior em ambientes educacionais, monitorando um ambiente real da sala de aula A2 no prédio de Engenharia Mecânica da Escola Politécnica da Universidade de São Paulo (EPUSP).

Adotando como parâmetro importante para a Qualidade do Ar Interior a vazão de ar externo e sua filtragem, foi definida como meta a análise da influência da variação da vazão do ar exterior visando a redução de contaminantes no interior de ambientes de instituição de ensino, através de atividades experimentais.

Adicionalmente, objetiva-se a verificação da vazão de renovação vigente para o $\mathrm{CO}_{2}$, visando a concentração de material particulado $\mathrm{PM}_{2,5}$ e $\mathrm{PM}_{10}$. São verificadas a importância de estágios de filtragem no processo e a necessidade de medição da concentração de $\mathrm{PM}_{2,5}$.

\subsection{Justificativas}

A constante piora na qualidade do ar é um fator que facilmente pode ser observado em manchetes de jornais e revistas, bem como no meio acadêmico, pois tem gerado interesses nos estudos de pesquisadores e universitários.

A Agência de Proteção Ambiental (EPA) dos Estados Unidos incluiu a Qualidade do Ar Interior como um dos cinco maiores riscos para a saúde humana, provavelmente devido ao fato de que o ar interno ao ambiente pode estar de duas à cinco vezes mais poluído do que o ar externo (HAQUE, SHAKIL, AKHTER, 2013).

A ventilação inadequada que ocorre nos edifícios "selados" contribui com o aumento dos níveis de poluentes interiores, cuja diluição não se torna possível, visto que não ocorre a troca de ar necessária com a devida filtragem. O aumento dos níveis de poluentes, somados a altos níveis de temperatura e umidade, afeta a qualidade do ambiente, que afeta, diretamente, o conforto das pessoas, a saúde, e o desempenho na escola e no trabalho.

Dessa forma, o estudo voltado para a qualidade do ar interno, que adota como estudo de caso a sala de aula A2, é de fundamental importância, pois trata-se de um ambiente onde são realizadas atividades didáticas e experimentais que, muitas vezes, emitem poluentes internos. A sala não possuia ventilação mecânica e nem equipamentos para o tratamento do ar, 
dificultando a dissipação dos poluentes e, consequente, diminuição da concentração dos mesmos.

Os casos analisados representam situações, que permitem determinar a Qualidade do Ambiente Interior (QAI) em escolas, e possibilitam verificar os possíveis prejuízos aos usuários afetados. Essas situações estão presentes em vários países, afetando alunos, professores e outros ocupantes de ambientes educacionais. 


\section{REVISÃO BIBLIOGRÁFICA}

O ar é uma mistura gasosa determinante para a vida humana, sendo que é através da respiração que se permite a produção da energia que será utilizada na manutenção da vida e no desenvolvimento dos movimentos diversos de uma pessoa (BASTO, 2007).

Um adulto necessita em média de $14 \mathrm{~kg}$ de ar por dia, comparativamente a 1,4 kg de comida e $2 \mathrm{~L}$ de água. O composto ar é indispensável para a vida humana. Pode-se sobreviver durante 5 semanas sem comida, 5 dias sem água, mas não mais de 5 minutos sem ar. O ar é essencial aos sentidos da visão, do olfato, e da audição, sendo que a poluição a ele associada afeta os dois primeiros sentidos (STERN, 1977).

$\mathrm{O}$ ar como encontrado na atmosfera é composto de uma mistura de vários gases em contato com vapor de água. Juntamente a ele, podem ser encontrados em suspensão na atmosfera outros elementos tais como poeiras, pólens, cinzas, compostos orgânicos e microorganismos. A tabela 2.1 mostra os efeitos no homem devido à variação da concentração de oxigênio $\left(\mathrm{O}_{2}\right)$ no ar.

Tabela 2.1. Efeitos da concentração de $O_{2}$ (VERANI, 2003).

\begin{tabular}{|c|l|}
\hline \% vol. $\mathbf{O}_{\mathbf{2}}$ & Efeitos Fisiológicos \\
\hline 20,9 & Concentração normal \\
\hline 19,5 & Concentração mínima legal \\
\hline $19-16$ & Início de sonolência \\
\hline $16-12$ & $\begin{array}{l}\text { Perda de visão periférica, respiração intermitente, dificuldade de } \\
\text { coordenação, aumento do volume da respiração, aumento da frequência } \\
\text { cardíaca, redução da capacidade de pensar e agir }\end{array}$ \\
\hline $12-10$ & $\begin{array}{l}\text { Falta de raciocínio, pobre coordenação muscular sendo que o esforço } \\
\text { muscular leva à fadiga, que pode causar danos permanentes ao coração }\end{array}$ \\
\hline $10-6$ & $\begin{array}{l}\text { Náusea, vômito, incapacidade para movimentos vigorosos inconsciência } \\
\text { seguida por morte }\end{array}$ \\
\hline$<6$ & Respiração espasmática, movimentos convulsivos e morte em minutos \\
\hline
\end{tabular}




\subsection{Qualidade do ar}

O termo Qualidade do Ar Interior refere-se às características do ar no interior dos edifícios, o qual pode afetar a saúde humana, o conforto e o desempenho do trabalho. A qualidade do ar depende de alguns parâmetros:

- biológicos, como exemplo os fungos e bactérias;

- químicos, como exemplo o $\mathrm{CO}_{2}$ e aerodispersódeis;

- físicos, como exemplo a temperatura, umidade e velocidade do ar.

Esse termo, nos últimos anos, foi englobado por uma nova expressão, Indoor Environmental Quality (IEQ), traduzida como Qualidade do Ambiente Interior (QAI).

O comportamento da Qualidade do Ambiente Interno dos edifícios afeta a saúde, a produtividade e o bem estar dos ocupantes do edifício, ou seja, a Qualidade do Ar Interior, juntamente com os custos de vida e o consumo de energia (HEINZERLING et al, 2013).

Dadas as consequências nos seres humanos de uma baixa qualidade de ar interior, criou-se na OMS um termo para caracterizar as doenças que estão relacionadas com Qualidade do Ar Interior. Como exemplo, pode-se citar a Síndrome dos Edifícios Doentes (SED). O termo SED é usado para descrever situações nas quais pelo menos $20 \%$ dos usuários de um determinado edifício experimentam efeitos adversos à saúde e ao conforto, que normalmente tendem a desaparecem após curtos períodos de afastamento das pessoas afetadas, como por exemplo: irritação das mucosas, efeitos neurotóxicos, sintomas respiratórios e cutâneos, e alteração dos sentidos (OMS, 1999).

As características geralmente utilizadas para a avaliação da QAI incluem as quantidades/concentrações de poluentes no ar, bem como a temperatura e a umidade. Outros parâmetros utilizados, porém com menor frequência, são os poluentes em superfícies internas, a iluminação e as condições acústicas do ambiente. A taxa de fornecimento de ar exterior para um edifício, ou seja, a taxa de renovação de ar, é tratada como uma condição da QAI, pois a mesma exerce influência direta sobre a concentração de poluentes do ar interior. 


\subsubsection{Poluição atmosférica}

Segundo a Companhia Ambiental do Estado de São Paulo (CETESB, 2015), poluente atmosférico é toda e qualquer forma de matéria ou energia com intensidade e em quantidade, concentração, tempo de permanência ou características em desacordo com os níveis estabelecidos em legislação, e que tornem ou possam tornar o ar impróprio, nocivo ou ofensivo à saúde, inconveniente ao bem-estar público, danoso aos materiais, à fauna e à flora ou prejudicial à segurança, ao uso e gozo da propriedade e às atividades normais da comunidade.

A contaminação atmosférica ocorre devido à emissão de compostos perigosos a uma taxa que excede a capacidade natural que ela possui para transformar, precipitar, depositar ou diluir através do vento ou de outros movimentos do ar (YASSI, 2002).

Os efeitos na saúde relacionados com a poluição atmosférica foram estabelecidos a partir de episódios de contaminação do ar e estudos sobre a ocorrência de várias mortes registradas em Londres, em 1948 e 1952 (CETESB, 2015).

No Brasil, um exemplo de intensa poluição atmosférica ocorreu em Cubatão, na década de 1980, havendo naquela época uma grande repercussão negativa, em virtude do grande número de casos de adoecimento e mortes na região (FREITAS et al, 2004).

As primeiras iniciativas para monitorar a qualidade do ar ocorreram na Região Metropolitana de São Paulo (RMSP), no início dos anos de 1960, por iniciativa dos municípios de Santo André, São Bernardo do Campo, São Caetano do Sul e Mauá, levando a criação da Comissão Intermunicipal de Controle da Poluição das Águas e do Ar (CICPAA). As medições dos poluentes eram feitas mensalmente, por taxas de sulfatação, poeira sedimentável e corrosividade (CETESB, 2015).

O Governo do Estado de São Paulo criou a CETESB, que se responsabilizou desde a década de 80 pela vigilância e pelo controle da qualidade ambiental. As medidas de controle foram tomadas visando melhoria da qualidade do ar. O governo implantou um programa de controle em 1984, com o objetivo de reduzir ou eliminar os poluentes (COUTO, 2003).

O nível de poluição atmosférica é medido pela quantidade de substâncias poluentes presentes no ar. Em relação aos poluentes, são nomeadas duas categorias que interferem na qualidade do ar: o poluente primário e o secundário. Essas duas categorias possuem o intuito de 
melhorar a identificação das diversas substâncias presentes na atmosfera, dada sua grande variedade. Segundo a CETESB, os poluentes primários são aqueles emitidos diretamente pelas fontes de emissão. Já os poluentes secundários são aqueles formados na atmosfera através da reação química entre poluentes primários e componentes naturais da atmosfera.

As substâncias poluentes podem ser classificadas conforme a tabela 2.2.

Tabela 2.2. Classificação das substâncias poluentes (CETESB, 2015).

\begin{tabular}{|c|c|c|c|}
\hline $\begin{array}{l}\text { Compostos de } \\
\text { Enxofre }\end{array}$ & $\begin{array}{c}\text { Compostos de } \\
\text { Nitrogênio }\end{array}$ & $\begin{array}{l}\text { Compostos } \\
\text { Orgânicos }\end{array}$ & $\begin{array}{l}\text { Monóxido de } \\
\text { Carbono }\end{array}$ \\
\hline $\begin{array}{c}\mathrm{SO}_{2} \\
\mathrm{SO}_{3} \\
\text { Compostos de } \\
\text { enxofre reduzido: } \\
\left(\mathrm{H}_{2} \mathrm{~S}, \text { Mercaptanas, }\right. \\
\text { Dissulfeto de } \\
\text { carbono, etc. }) \\
\text { Sulfatos }\end{array}$ & $\begin{array}{c}\mathrm{NO} \\
\mathrm{NO}_{2} \\
\mathrm{NH}_{3} \\
\mathrm{HNO}_{3} \\
\text { nitratos }\end{array}$ & $\begin{array}{l}\text { Hidrocarbonetos } \\
\text { álcoois } \\
\text { Aldeídos } \\
\text { Cetonas } \\
\text { Ácidos } \\
\text { orgânicos }\end{array}$ & $\mathrm{CO}$ \\
\hline $\begin{array}{c}\text { Compostos } \\
\text { Halogenados } \\
\end{array}$ & $\begin{array}{l}\text { Metais } \\
\text { Pesados }\end{array}$ & $\begin{array}{c}\text { Material } \\
\text { Particulado }\end{array}$ & $\begin{array}{c}\text { Oxidantes } \\
\text { Fotoquímicos } \\
\end{array}$ \\
\hline $\begin{array}{c}\mathrm{HCl} \\
\mathrm{HF} \\
\text { Cloretos } \\
\text { Fluoretos }\end{array}$ & $\begin{array}{l}\mathrm{Pb} \\
\mathrm{Cd} \\
\mathrm{As} \\
\mathrm{Ni} \\
\text { Etc. }\end{array}$ & $\begin{array}{l}\text { Mistura de } \\
\text { compostos no } \\
\text { estado sólido } \\
\text { ou líquido }\end{array}$ & $\begin{array}{c}\mathrm{O}_{3} \\
\text { Formaldeído } \\
\text { Acroleína } \\
\text { PAN } \\
\text { Etc. }\end{array}$ \\
\hline
\end{tabular}

A medição sistemática da qualidade do ar é restrita a um número de poluentes, sendo que esses são definidos em função de sua importância e dos recursos disponíveis para seu acompanhamento (CETESB, 2015).

Por ser ampla a variedade dos poluentes existentes na atmosfera, adotou-se universalmente um grupo de poluentes que servem como indicadores de qualidade do ar, sendo esses escolhidos em razão da frequência de ocorrência e de seus efeitos adversos. O grupo é composto por Material Particulado (PM), Dióxido de Enxofre $\left(\mathrm{SO}_{2}\right)$, Monóxido de Carbono (CO), Oxidadentes Fotoquímicos como o Ozônio $\left(\mathrm{O}_{3}\right)$, Hidrocarbonetos $(\mathrm{HC})$, e os Óxidos de 
Nitrogênio $\left(\mathrm{NO}_{\mathrm{x}}\right)$. Uma breve descrição, da CETESB, sobre os poluentes pode ser observada no Anexo A.

Os padrões nacionais de qualidade do ar foram estabelecidos pelo Instituto Brasileiro de Meio Ambiente (IBAMA) e aprovados pelo Conselho Nacional de Meio Ambiente (CONAMA), por meio da Resolução CONAMA n03/1990. Através desta Resolução, ficam estabelecidos dois padrões de qualidade do ar, sendo o padrão primário e o secundário. Os padrões primários de qualidade do ar são as concentrações de poluentes que, ultrapassadas, poderão afetar a saúde da população. Os padrões secundários de qualidade do ar representam o objetivo a ser atingido mediante a estratégia de controle fixada pelos padrões de emissão, e deverão orientar a elaboração de Planos Regionais de Controle de Poluição do Ar (BRASIL, 1990).

No Brasil, o CONAMA adotou os mesmos padrões da Environmental Protection Agengy (EPA) dos Estados Unidos da América (FREITAS et AL, 2003).

Tabela 2.3. Padrões nacionais de qualidade do ar estabelecidos pela resolução CONAMA n03 de 28/06/1990.

\begin{tabular}{|c|c|c|c|c|}
\hline Poluente & $\begin{array}{c}\text { Tempo de } \\
\text { Amostragem }\end{array}$ & $\begin{array}{c}\text { Padrão } \\
\text { Primário } \\
\mu \mathrm{g} / \mathrm{m}^{3}\end{array}$ & $\begin{array}{c}\text { Padrão } \\
\text { Secundário } \\
\mu \mathrm{g} / \mathrm{m}^{3}\end{array}$ & $\begin{array}{l}\text { Método de } \\
\text { Medição }\end{array}$ \\
\hline $\begin{array}{c}\text { Partículas } \\
\text { totais em } \\
\text { suspensão }\end{array}$ & $\begin{array}{l}24 \text { horas }^{1} \\
\text { MGA }^{2}\end{array}$ & $\begin{array}{c}240 \\
80\end{array}$ & $\begin{array}{c}150 \\
60\end{array}$ & $\begin{array}{l}\text { Amostrador de } \\
\text { grandes volumes }\end{array}$ \\
\hline $\begin{array}{l}\text { Partículas } \\
\text { inaláveis }\end{array}$ & $\begin{array}{l}24 \text { horas }^{1} \\
\text { MAA }^{3}\end{array}$ & $\begin{array}{c}150 \\
50\end{array}$ & $\begin{array}{c}150 \\
50\end{array}$ & $\begin{array}{c}\text { Separação } \\
\text { inercial/filtração }\end{array}$ \\
\hline Fumaça & $\begin{array}{l}24 \text { horas }^{1} \\
\text { MAA }^{3}\end{array}$ & $\begin{array}{c}150 \\
60\end{array}$ & $\begin{array}{c}100 \\
40\end{array}$ & Refletância \\
\hline $\begin{array}{l}\text { Dióxido de } \\
\text { enxofre }\end{array}$ & $\begin{array}{l}24 \text { horas }^{1} \\
\text { MAA }^{3}\end{array}$ & $\begin{array}{c}365 \\
80\end{array}$ & $\begin{array}{c}100 \\
40\end{array}$ & Pararosanilina \\
\hline $\begin{array}{l}\text { Dióxido de } \\
\text { nitrogênio }\end{array}$ & $\begin{array}{l}1 \text { hora }^{1} \\
\text { MAA }^{3}\end{array}$ & $\begin{array}{l}320 \\
100\end{array}$ & $\begin{array}{l}190 \\
100\end{array}$ & Quimiluminescência \\
\hline $\begin{array}{l}\text { Monóxido } \\
\text { de carbono }\end{array}$ & $\begin{array}{l}1 \text { hora }^{1} \\
8 \text { horas }^{1}\end{array}$ & $\begin{array}{l}40.000 \\
10.000\end{array}$ & $\begin{array}{l}40.000 \\
10.000\end{array}$ & $\begin{array}{l}\text { Infravermelho não } \\
\text { dispersivo }\end{array}$ \\
\hline Ozônio & 1 hora $^{1}$ & 160 & 160 & Quimiluminescência \\
\hline
\end{tabular}

1- Não deve ser excedido mais que uma vez ao ano.

2- Média geométrica anual.

3- Média aritmética anual.

À luz dos conhecimentos científicos adquiridos até então, em 2005 a Organização Mundial de Saúde publicou um documento com uma revisão dos valores guia para os poluentes atmosféricos visando à proteção da saúde da população. Segundo a OMS, os padrões de 
qualidade do ar podem variar dependendo da abordagem adotada para balanceamento dos riscos à saúde humana, viabilidade técnica, considerações econômicas e vários fatores políticos e sociais que dependem do desenvolvimento e da capacidade do Estado em gerenciar a qualidade do ar. Assim sendo, os governos devem considerar as circunstâncias locais antes de adotarem os valores propostos como padrões nacionais (CETESB, 2015).

Baseando-se nas diretrizes estabelecidas pela OMS, em 2008, o Estado de São Paulo iniciou um processo de revisão dos padrões de qualidade do ar. Dessa forma, em 2013 ocorreu a publicação do Decreto Estadual n 59113 estabelecendo novos padrões de qualidade do ar por intermédio de um conjunto de metas gradativas e progressivas para que a poluição atmosférica seja reduzida a níveis desejáveis ao longo do tempo. No Decreto, os seguintes critérios podem ser observados:

- Metas Intermediárias (MI): estabelecidas como valores temporários a serem cumpridos em etapas, visando à melhoria gradativa da qualidade do ar no Estado de São Paulo, baseada na busca pela redução das emissões de fontes fixas e móveis, em linha com os princípios do desenvolvimento sustentável;

- Padrões Finais (PF): padrões determinados pelo melhor conhecimento científico para que a saúde da população seja preservada ao máximo em relação aos danos causados pela poluição atmosférica.

A tabela 2.4 apresenta os padrões de qualidade do ar estabelecidos no Decreto citado, sendo que os padrões vigentes estão assinalados em vermelho. 
em suspensão e chumbo. Para os demais poluentes, os padrões finais passam a valer a partir do final do prazo de duração do MI3.

Baseado na Resolução do CONAMA n03/90, a Legislação Estadual por meio do Decreto n ${ }^{\circ}$ 59113/2013 estabelece também critérios para episódios agudos de poluição do ar. A declaração dos estados de Atenção, Alerta e Emergência, além dos níveis de concentração ultrapassados, requer a previsão de condições meteorológicas desfavoráveis à dispersão dos poluentes.

Tabela 2.5. Critérios para episódios agudos de poluição do ar (Decreto Estadual n59113 de 23/04/2013).

\begin{tabular}{|c|c|c|c|}
\hline Parâmetros & Atenção & Alerta & Emergência \\
\hline $\begin{array}{c}\text { Partículas inaláveis finas } \\
\left(\mu \mathrm{g} / \mathrm{m}^{3}\right)-24 \mathrm{~h}\end{array}$ & 125 & 210 & 250 \\
\hline $\begin{array}{c}\text { Partículas inaláveis } \\
\left(\mu \mathrm{g} / \mathrm{m}^{3}\right)-24 \mathrm{~h}\end{array}$ & 250 & 420 & 500 \\
\hline $\begin{array}{c}\text { Dióxido de enxofre } \\
\left(\mu \mathrm{g} / \mathrm{m}^{3}\right)-24 \mathrm{~h}\end{array}$ & 800 & 1.600 & 2.100 \\
\hline $\begin{array}{c}\text { Dióxido de nitrogênio } \\
\left(\mu \mathrm{g} / \mathrm{m}^{3}\right)-1 \mathrm{~h}\end{array}$ & 1.130 & 2.260 & 3.000 \\
\hline $\begin{array}{c}\text { Monóxido de carbono } \\
(\mathrm{ppm})-8 \mathrm{~h}\end{array}$ & 15 & 30 & 40 \\
\hline $\begin{array}{c}\text { Ozônio } \\
\left(\mu \mathrm{g} / \mathrm{m}^{3}\right)-8 \mathrm{~h}\end{array}$ & 200 & 400 & 600 \\
\hline
\end{tabular}

Visando controlar o atendimento dos padrões estabelecidos, criou-se o sistema de monitoramento do ar, permitindo então o desenvolvimento da atividade de vigilância na área de saúde ambiental por meio da mensuração das concentrações de poluentes na atmosfera e consequentemente uma análise dos riscos e efeitos sobre a saúde da população (FREITAS, PEREIRA, SALDIVA, 1996).

Os critérios definiram índices de qualidade do ar, sendo esses uma ferramenta matemática desenvolvida para simplificar o processo de divulgação da qualidade do ar. Esse índice foi criado usando como base uma longa experiência desenvolvida nos EUA. Para cada poluente medido é calculado um índice, que é um valor adimensional. Dependendo do índice obtido, o ar recebe uma qualificação, que é uma nota para a qualidade do ar, além de uma cor, conforme apresentado na tabela 2.6 (CETESB, 2015). 
Tabela 2.6. Estrutura do índice de qualidade do ar (CETESB, 2015).

\begin{tabular}{|c|c|c|c|c|c|c|c|}
\hline Qualidade & Índice & $\begin{array}{c}\mathrm{MP}_{10} \\
\left(\mu \mathrm{g} / \mathrm{m}^{3}\right) \\
24 \mathrm{~h}\end{array}$ & $\begin{array}{c}\mathrm{MIP}_{2.5} \\
\left(\mu \mathrm{g} / \mathrm{m}^{3}\right) \\
24 \mathrm{~h}\end{array}$ & $\begin{array}{c}\mathrm{O}_{3} \\
\left(\mu \mathrm{g} / \mathrm{m}^{3}\right) \\
8 \mathrm{~h}\end{array}$ & $\begin{array}{c}\mathrm{CO} \\
(\mathrm{ppm}) \\
8 \mathrm{~h} \\
\end{array}$ & $\begin{array}{c}\mathrm{NO}_{2} \\
\left(\mu \mathrm{g} / \mathrm{m}^{3}\right) \\
1 \mathrm{~h} \\
\end{array}$ & $\begin{array}{c}\mathrm{SO}_{2} \\
\left(\mu \mathrm{g} / \mathrm{m}^{3}\right) \\
24 \mathrm{~h} \\
\end{array}$ \\
\hline N1 - Boa & $0-40$ & $0-50$ & $0-25$ & $0-100$ & $0-9$ & $0-200$ & $0-20$ \\
\hline N2 - Moderada & $41-80$ & $>50-100$ & $>25-50$ & $>100-130$ & $>9-11$ & $>200-240$ & $>20-40$ \\
\hline N3 - Ruim & $81-120$ & $>100-150$ & $>50-75$ & $>130-160$ & $>11-13$ & $>240-320$ & $>40-365$ \\
\hline $\begin{array}{l}\text { N4 - Muito } \\
\text { Ruim }\end{array}$ & $121-200$ & $>150-250$ & $>75-125$ & $>160-200$ & $>13-15$ & $>320-1130$ & $>365-800$ \\
\hline N5 - Péssima & $>200$ & $>250$ & $>125$ & $>200$ & $>15$ & $>1130$ & $>800$ \\
\hline
\end{tabular}

Esta qualificação do ar está associada a efeitos à saúde, portanto independe do padrão de qualidade em vigor. Sendo assim, a tabela 2.7 apresenta os efeitos à saúde associada com os índices.

Tabela 2.7. Qualidade do ar e efeitos à saúde (CETESB, 2015).

\begin{tabular}{|c|c|c|}
\hline Qualidade & Índice & Significado \\
\hline $\mathrm{N} 1-\mathrm{Boa}$ & $0-40$ & - \\
\hline N2 - Moderada & $41-80$ & $\begin{array}{l}\text { Pessoas de grupos sensíveis (crianças, idosos e pessoas com doenças } \\
\text { respiratórias e cardíacas) podem apresentar sintomas como tosse seca e } \\
\text { cansaço. A população, em geral, não é afetada. }\end{array}$ \\
\hline N3 - Ruim & $81-120$ & $\begin{array}{l}\text { Toda a população pode apresentar sintomas como tosse seca, cansaço, ardor } \\
\text { nos olhos, nariz e garganta. Pessoas de grupos sensíveis (crianças, idosos e } \\
\text { pessoas com doenças respiratórias e cardíacas) podem apresentar efeitos } \\
\text { mais sérios na saúde. }\end{array}$ \\
\hline $\begin{array}{c}\text { N4 - Muito } \\
\text { Ruim }\end{array}$ & $121-200$ & $\begin{array}{l}\text { Toda a população pode apresentar agravamento dos sintomas como tosse } \\
\text { seca, cansaço, ardor no olhos, nariz e garganta e ainda falta de ar e } \\
\text { respiração ofegante. Efeitos ainda mais graves à saúde de grupos sensíveis } \\
\text { (crianças, idosos e pessoas com doenças respiratórias e cardíacas). }\end{array}$ \\
\hline N5 - Péssima & $>200$ & $\begin{array}{l}\text { Toda a população pode apresentar sérios riscos de manisfetações de doenças } \\
\text { respiratórias e cardiovasculares. Aumento de mortes prematuras em pessoas } \\
\text { de grupos sensíveis. }\end{array}$ \\
\hline
\end{tabular}

A CETESB também apresenta uma tabela dos efeitos sobre a saúde identificados por estudos epidemiológicos desenvolvidos dentro e fora do país. Estes efeitos requerem medidas de prevenção que também são apresentados. No Anexo B, estas duas tabelas podem ser observadas.

Pesquisas realizadas em todo o mundo evidenciam que não existem níveis seguros de concentração de poluentes para a saúde humana, e que os padrões deveriam ser revisados e novas concentrações determinadas (SALDIVA, PEREIRA, BRAGA, 2002). Devido a 
pesquisas como essas, os órgãos responsáveis pela qualidade do ar estão sempre revisando decretos, portarias, e normas visando a saúde humana.

Segundo um estudo realizado por Arruda (2008) em Cubatão, foi verificado que em decorrência da poluição atmosférica, uma elevação da concentração de $\mathrm{PM}_{10}$, em sete dias, de $56,5 \mu \mathrm{g} / \mathrm{m}^{3}$ e de $\mathrm{O}_{3}$, em cinco dias, de $46,7 \mu \mathrm{g} / \mathrm{m}^{3}$, resultou em um aumento de $9,6 \%$ nas internações.

É estimado que aproximadamente $20 \%$ do número total de doenças registradas em países industrializados possam ser atribuídas a fatores ambientais e que os seres humanos mais vulneráveis, ou seja, os mais afetados são as crianças, idosos, pessoas economicamente desfavorecidas e mulheres em idade reprodutiva (SMITH et al., 1999).

Segundo Assunção (1997), a ventilação é importante no controle da SED pois, além de garantir a qualidade do ar em ambientes interiores alterando a presença de gases e partículas, também diminui os sintomas de doenças apresentados pelos usuários nas edificações.

\subsubsection{Poluição do ar interior}

As pessoas que vivem em áreas urbanas passam aproximadamente $90 \%$ do tempo em ambientes interiores, em casa ou no trabalho, em edifícios comerciais, em faculdades ou escolas. Esse fato gera um impacto significativo na saúde e produtividade, gerando uma preocupação mundial. Assim, nos últimos anos, pesquisadores estão explorando a relação entre a Qualidade do Ar Interior, saúde e produtividade.

As estimativas da OMS mostram que a poluição em ambientes internos ocasiona aproximadamente 2,8 milhões de mortes anuais, o que a torna um dos maiores fatores de mortalidade do mundo, causando 5,5\% de todas as mortes (MORAES, 2006). Trata-se de um percentual extremamente alto, que sustenta a decisão de considerar a poluição em ambientes internos um dos quatro problemas ambientais mais cruciais do mundo.

Os poluentes do ar interno são gerados principalmente por três fontes, sendo as biológicas que incluem os ácaros, animais domésticos, insetos, fungos, bactérias e vírus; as fontes químicas que incluem os gases e vapores; e as fontes físicas, sendo os materiais particulados e campos eletromagnéticos (PRADO, 2003). 
A preocupação com o consumo de energia foi um marco para a piora na Qualidade do Ar Interior, tendo em vista que os projetos antigos visavam pouca ou nenhuma renovação de ar em função da diminuição da carga térmica e, consequentemente melhora no consumo de energia. Em contrapartida, os poluentes internos gerados foram aumentando, agravando o desconforto dos usuários devido a piora na qualidade do ar.

Segundo Kosonen e Tan (2004), o nível de poluição do ar interno ao ambiente pode ser melhorado por meio de valores máximos de emissão de poluentes, a fim de não causar ou agravar doenças aos usuários e assegurar o melhor desempenho das atividades.

Através da observação da concentração máxima admissível e calculando a quantidade de ar externo necessário para sua diluição, o controle de uma fonte de poluição é garantido. Esta diluição exige grandes taxas de ar externo e, consequentemente, maiores gastos de energia. $\mathrm{O}$ processo de se evitar a dispersão dos poluentes químicos, físicos e biológicos do que adotar soluções corretivas se torna mais econômico (MORAES, 2006).

Preocupado com a situação dos edifícios, no Brasil, o Ministério da Saúde (MS) publicou a portaria $\mathrm{n}^{\mathrm{o}} 3523$ de 28 de Agosto de 1998 referente à qualidade do ar de interiores climatizados. A definição de Síndrome dos Edifícios Doentes é tratada nesta portaria como sendo o surgimento de sintomas comuns à população em geral, mas que em uma situação temporal, pode ser relacionado a um edifício em particular. Depois de alguns anos, a Agência Nacional de Vigilância Sanitária (ANVISA) publicou a resolução $n^{\circ} 9$ de 16 de Janeiro de 2003, a qual dispõe sobre os Padrões Referenciais de Qualidade do Ar Interior em Ambientes Climatizados Artificialmente, de uso público e coletivo, valores máximos recomendáveis para contaminação biológica, química e parâmetros físicos do ar interno.

De acordo com a resolução $\mathrm{n}^{\circ} 9$ da ANVISA, os valores máximos para contaminação química são de 1000 ppm de dióxido de carbono, como indicador de renovação de ar externo, recomendado para conforto e bem-estar, sendo este dado baseado na American Society of Heating, Refrigerating and Air Conditioning Engineers (ASHRAE) Standard 62 - Ventilation for Acceptable Indoor Air Quality de 2001; e $80 \mu \mathrm{g} / \mathrm{m}^{3}$ de aerodispersóides totais no ar, como indicador do grau de pureza do ar e limpeza do ambiente climatizado.

Nesta resolução da ANVISA, são disponibilizadas duas tabelas (2.8 e 2.9), nas quais pode-se verificar as possíveis fontes de poluentes biológicos e químicos. Segundo a ANVISA, 
recomenda-se o uso destas tabelas para fins de pesquisa e com o propósito de levantar dados sobre a realidade brasileira, assim como para avaliação e correção das situações encontradas.

Tabela 2.8. Possíveis fontes de poluentes biológicos (Resolução nº 9 de 16/01/2003, 2015).

\begin{tabular}{|c|c|c|}
\hline $\begin{array}{l}\text { Agentes } \\
\text { Biológicos }\end{array}$ & $\begin{array}{c}\text { Principais fontes em ambientes } \\
\text { interiores }\end{array}$ & $\begin{array}{l}\text { Principais Medidas de correção } \\
\text { em ambientes interiores }\end{array}$ \\
\hline Bactérias & $\begin{array}{l}\text { Reservatórios com água } \\
\text { estagnada, torres de resfriamento, } \\
\text { bandejas de condensado, } \\
\text { desumidificadores, } \\
\begin{array}{llr}\text { umidificadores, serpentinas } & \text { de } \\
\text { condicionadores de ar } & \text { e } \\
\text { superfícies úmidas e quentes. }\end{array}\end{array}$ & $\begin{array}{l}\text { Realizar a limpeza e a conservação } \\
\text { das torres de resfriamento; } \\
\text { higienizar os reservatórios e } \\
\text { bandejas de condensado ou manter } \\
\text { tratamento contínuo para elimar as } \\
\text { fontes; eliminar as infiltrações; } \\
\text { higienizar as superfícies. }\end{array}$ \\
\hline Fungos & $\begin{array}{l}\text { Ambientes úmidos e demais } \\
\text { fontes de multiplicação fúngica, } \\
\text { como materiais porosos } \\
\text { orgânicos úmidos, forros, paredes } \\
\text { e isolamentos úmidos; ar externo, } \\
\text { interior de condicionadores e } \\
\text { dutos sem manutenção, vasos de } \\
\text { terra com plantas. }\end{array}$ & $\begin{array}{l}\text { Corrigir a umidade ambiental; } \\
\text { manter sob controle rígido } \\
\text { vazamentos, infiltrações e } \\
\text { condensação de água; higienizar os } \\
\text { ambientes e componentes do } \\
\text { sistema de climatização ou manter } \\
\text { tratamento contínuo para eliminar } \\
\text { as fontes; eliminar materiais } \\
\text { porosos contaminados; eliminar ou } \\
\text { restrigir vasos de plantas com } \\
\text { cultivo em terra, ou substituir pelo } \\
\text { cultivo em água (hidroponia); } \\
\text { utilizar filtros G-1 na renovação do } \\
\text { ar externo. }\end{array}$ \\
\hline Protozoários & $\begin{array}{lrr}\text { Reservatórios } & \text { de } & \text { água } \\
\text { contaminada, } & \text { bandejas } & \text { e } \\
\text { umidificadores } & & \text { de } \\
\text { condicionadores } & & \text { sem } \\
\text { manutenção. } & & \\
\end{array}$ & $\begin{array}{l}\text { Higienizar o reservatório ou manter } \\
\text { tratamento contínuo para eliminar } \\
\text { as fontes. }\end{array}$ \\
\hline Vírus & Hospedeiro humano. & $\begin{array}{l}\text { Adequar o número de ocupantes } \\
\text { por } \mathrm{m}^{2} \text { de área com aumento da } \\
\text { renovação de ar; evitar a presença } \\
\text { de pessoas infectadas nos ambientes } \\
\text { climatizados. }\end{array}$ \\
\hline Algas & $\begin{array}{l}\text { Torres de resfriamento e bandejas } \\
\text { de condensado. }\end{array}$ & $\begin{array}{l}\text { Higienizar os reservatórios e } \\
\text { bandejas de condensado ou manter } \\
\text { tratamento contínuo para eliminar } \\
\text { as fontes. }\end{array}$ \\
\hline Pólen & Ar externo. & $\begin{array}{l}\text { Manter filtragem de acordo com } \\
\text { NBR-6401 da ABNT. }\end{array}$ \\
\hline Artrópodes & Poeira caseira. & $\begin{array}{l}\text { Higienizar as superfícies fixas e } \\
\text { mobiliário, especialmente os } \\
\text { revestidos com tecidos e tapetes; } \\
\text { restrigir ou elimar o uso desses } \\
\text { revestimentos. }\end{array}$ \\
\hline Animais & Roedores, morcegos e aves. & $\begin{array}{l}\text { Restringir o acesso, controlar os } \\
\text { roedores, os morcegos, ninhos de } \\
\text { aves e respectivos excrementos. }\end{array}$ \\
\hline
\end{tabular}


Tabela 2.9. Possíveis fontes de poluentes químicos (Resolução nº de 16/01/2003, 2015).

\begin{tabular}{|c|c|c|}
\hline $\begin{array}{l}\text { Agentes } \\
\text { químicos }\end{array}$ & $\begin{array}{l}\text { Principais fontes em } \\
\text { ambientes interiores }\end{array}$ & $\begin{array}{c}\text { Principais medidas de correção em ambientes } \\
\text { interiores }\end{array}$ \\
\hline $\mathrm{CO}$ & $\begin{array}{l}\text { Combustão (cigarros, } \\
\text { queimadores de fogões e } \\
\text { veículos automotores). }\end{array}$ & $\begin{array}{l}\text { Manter a captação de ar exterior com baixa } \\
\text { concentração de poluentes; restrigir as fontes de } \\
\text { combustão; manter a exaustão em áreas em que } \\
\text { ocorre combustão; eliminar a infiltração de CO } \\
\text { proveniente de fontes externas; restrigir o } \\
\text { tabagismo em áreas fechadas. }\end{array}$ \\
\hline $\mathrm{CO}_{2}$ & $\begin{array}{l}\text { Produtos de metabolismo } \\
\text { humano e combustão. }\end{array}$ & $\begin{array}{l}\text { Aumentar a renovação de ar externo; restringir } \\
\text { as fontes de combustão e o tabagismo em áreas } \\
\text { fechadas; eliminar a infiltração de fontes } \\
\text { externas. }\end{array}$ \\
\hline $\mathrm{NO}_{2}$ & Combustão. & $\begin{array}{l}\text { Restrigir as fontes de combustão; manter a } \\
\text { exaustão em áreas em que ocorre combustão; } \\
\text { impedir a infiltração de } \mathrm{NO}_{2} \text { proveniente de } \\
\text { fontes externas; restrigir o tabagismo em áreas } \\
\text { fechadas. }\end{array}$ \\
\hline $\mathrm{O}_{3}$ & $\begin{array}{l}\text { Máquinas copiadoras e } \\
\text { impressoras a laser. }\end{array}$ & $\begin{array}{l}\text { Adotar medidas específicas para reduzir a } \\
\text { contaminação dos ambientes interiores, com } \\
\text { exaustão do ambiente ou enclausuramento em } \\
\text { locais exclusivos para os equipamentos que } \\
\text { apresentem grande capacidade de produção de } \\
\mathrm{O}_{3} \text {. }\end{array}$ \\
\hline Formaldeído & $\begin{array}{l}\text { Materiais de acabamento, } \\
\text { mobiliário, rola, } \\
\text { produtos de limpeza } \\
\text { domissanitários. }\end{array}$ & $\begin{array}{l}\text { Selecionar os materiais de construção, } \\
\text { acabamento e mobiliário que possuam ou } \\
\text { emitam menos formaldeído; usar produtos } \\
\text { domissanitários que não contenham } \\
\text { formaldeído. }\end{array}$ \\
\hline $\begin{array}{c}\text { Material } \\
\text { particulado }\end{array}$ & Poeira e fibras. & $\begin{array}{l}\text { Manter filtragem de acordo com NBR- } 6402 \text { da } \\
\text { ABNT; evitar isolamento termo-acústico que } \\
\text { possa emitir fibras minerais, orgânicas ou } \\
\text { sintéticas para o ambiente climatizado; reduzir } \\
\text { as fontes internas e externas; higienizar as } \\
\text { superfícies fixas e mobiliários sem o uso de } \\
\text { vassouras, escovas ou espanadores; selecionar } \\
\text { os materiais de construção e acabamento com } \\
\text { menor porosidade; adotar medidas específicas } \\
\text { para reduzir a contaminação dos ambientes } \\
\text { interiores (vide biológicos); restrigir o } \\
\text { tabagismo em áreas fechadas. }\end{array}$ \\
\hline COS-V & $\begin{array}{l}\text { Cera, mobiliário, } \\
\text { produtos usados em } \\
\text { limpeza } \\
\text { domissanitários, } \\
\text { solventes, materiais de } \\
\text { revestimento, tintas, } \\
\text { colar, etc. }\end{array}$ & $\begin{array}{l}\text { Selecionar os materiais de construção, } \\
\text { acabamento, mobiliário; usar produtos de } \\
\text { limpeza e domissanitários que não contenham } \\
\text { COV ou que não apresentem alta taxa de } \\
\text { volatilização e toxicidade. } \\
\text { Eliminar a contaminação por fontes pesticidas, } \\
\text { inseticidas e a queima de combustíveis; manter } \\
\text { a captação de ar exterior afastada de poluentes }\end{array}$ \\
\hline & $\begin{array}{l}\text { Queima de combustíveis } \\
\text { e utilização de pesticidas. }\end{array}$ & \\
\hline
\end{tabular}


Nos edifícios, os poluentes podem ser provenientes do ambiente externo, ou podem ter sido gerados dentro do próprio ambiente (internos). Nos dois casos, existe uma ampla variedade de tipos e origens dos poluentes, podendo ser utilizadas as tabelas da ANVISA como guia orientativo das fontes dos poluentes, a fim de controlá-los e assegurar a qualidade do ar interiror.

A norma brasileira ABNT NBR 16401-3 traz em seu anexo, uma tabela com as concentrações máximas de alguns poluentes do ambiente interior. $\mathrm{O}$ anexo lista alguns poluentes químicos comuns e indica as concentrações consideradas aceitáveis por diversas entidades internacionais. A norma diz que os valores indicados têm caráter informativo, não sendo obrigatório sua medição ou acompanhamento periódico. A tabela reproduzida da norma é apresentada no Anexo C.

\subsubsection{QAI em escolas}

Os estudos relacionados à Qualidade do Ar Interior em escolas estão presentes em todo o mundo, devido a duas razões principais:

- As escolas públicas, em relação a outros tipos de edifícios, são vistas como propensas a ter deficiências ambientais devido à escassez financeira que contribui para operação e manutenção inadequadas (U.S. GENERAL ACCOUNTING OFFICE, 1995).

- As crianças são mais suscetíveis para alguns poluentes ambientais do que os adultos, uma vez que respiram maiores volumes de ar em relação aos seus pesos corporais, e seus tecidos e órgãos estão em fase de crescimento (LANDRIGAN, 1998; FAUSTMAN et al, 2000). Contribuindo, jovens, sejam eles crianças ou adoslecentes, passam a maioria do tempo em ambientes internos como escolas e universidades. Efeitos ambientais adversos sobre a aprendizagem e desempenho dos alunos nas escolas pode ter consequências tanto imediatas, como ao longo da vida, para os próprios alunos e para a sociedade.

Um estudo norueguês, desenvolvido por Myhrvold e Olesen (1997), foi realizado em oito escolas abrangendo 35 salas de aula, e baseou-se na medição do tempo de reação em testes padrões para avaliar a concentração e a cautela dos estudantes para diferentes vazões de ar de 
renovação. Para vazões de ar externo de $12 \mathrm{~L} / \mathrm{s}$ por aluno, por exemplo, as reações foram $5,4 \%$ mais rápidas quando comparadas com as reações para uma vazão de 3,8 L/s por pessoa.

Lee e Chang (2000) desenvolveram um estudo em cinco escolas de Hong Kong que possuíam sistema de climatização. Nelas foram realizadas medições de umidade relativa (UR), $\mathrm{CO}_{2}$, $\mathrm{SO}_{2}, \mathrm{NO}, \mathrm{NO}_{2}, \mathrm{PM}_{10}$, e contagem bacteriana. $\mathrm{O}$ objetivo do estudo era a avaliação do cumprimento da legislação em vigor. Eles destacaram as concentrações de $\mathrm{PM}_{10}$ e de $\mathrm{CO}_{2}$, como sendo os compostos mais preocupantes. Em relação as concentrações de $\mathrm{PM}_{10}$, eles concluíram que a média de concentrações de material particulado inalável no interior das salas de aula ultrapassava, em várias ocasiões, o valor legislado e que, a concentração máxima atingida excedeu em aproximadamente $1000 \mu \mathrm{g} / \mathrm{m}^{3}$ do valor legislado, que era de uma média $180 \mu \mathrm{g} / \mathrm{m}^{3}$ por um período de 24 horas. Para as concentrações de $\mathrm{CO}_{2}$, eles observaram que o limite imposto de 1000 ppm pela legislação era várias vezes excedida nas salas de aula com sistemas de ar condicionado, devido à grande deficiência de ventilação externa. Eles constataram que durante os períodos de aula, ou seja, de maior ocupação das salas, as concentrações de $\mathrm{CO}_{2}$ chegavam a atingir valores da ordem de 5900 ppm.

Uma revisão da literatura feita por Daisey, Angell e Apte (2003) sobre a Qualidade do Ar Interior, buscou identificar os problemas de saúde em escolas relatadas até 1999 devido a ventilação interna das mesmas, e os sintomas de saúde relacionados com os edifícios. Foram coletados os dados existentes sobre as taxas de ventilação, $\mathrm{CO}_{2}$ e outros contaminantes do ar interior. Os dados de ventilação obtidos e $\mathrm{CO}_{2}$ indicam, claramente, que a ventilação nas escolas é inadequada em muitas salas de aula, acarretando problemas de saúde. O levantamento obtido por eles pode ser observado nas figuras 2.1 e 2.2, retiradas do estudo. 


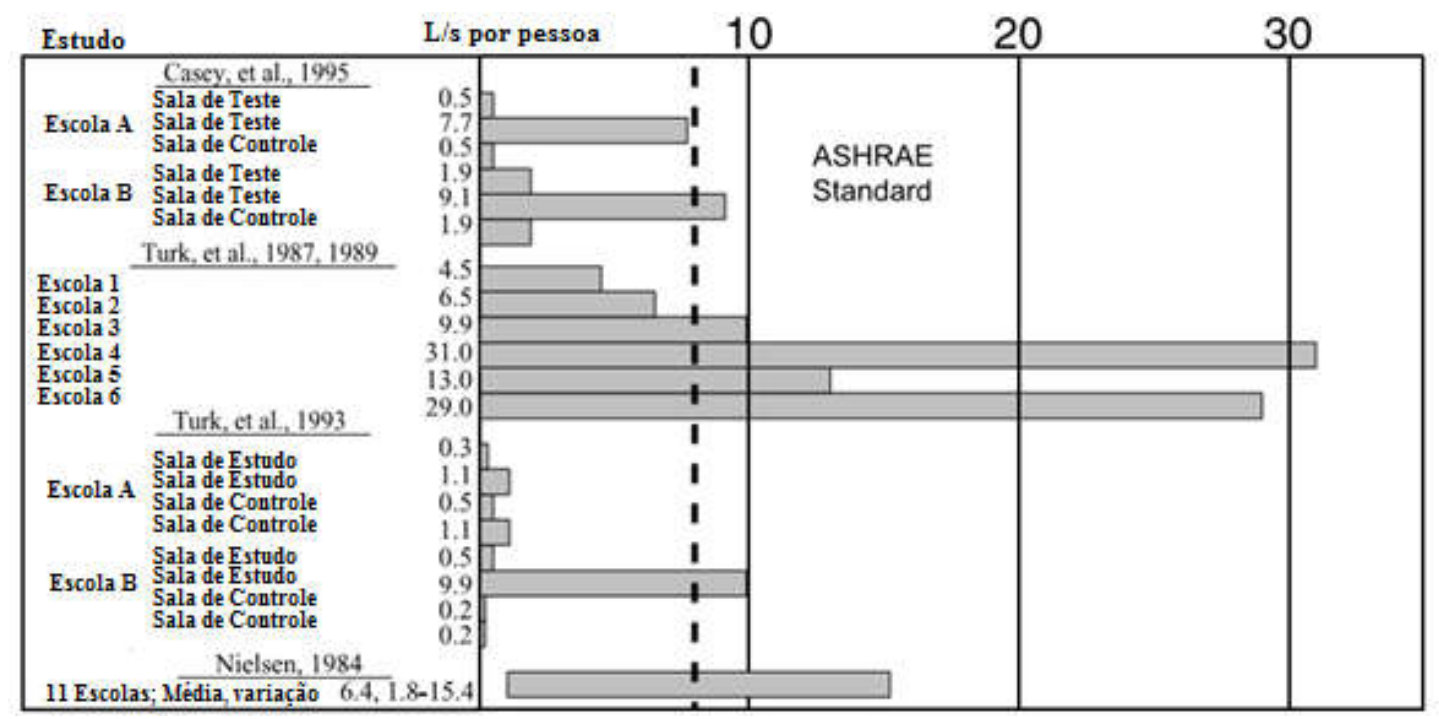

Figura 2.1. Taxas de ventilação em escolas publicados na literatura dos Estados Unidos da América e da Europa (adaptado de DAISEY, ANGELL, APTE, 2003).

Pode ser observado na figura 2.1 que várias escolas possuem ventilação inadequada, abaixo dos $7 \mathrm{~L} / \mathrm{s}$ por pessoa exigido pela ASHRAE Standard 62-1999. Já na figura 2.2, pode ser observada a concentração média de $\mathrm{CO}_{2}$ nos ambientes, sendo muito acima dos 1000 ppm, nível máximo recomendado pela ASHRAE Standard 62-1999. 


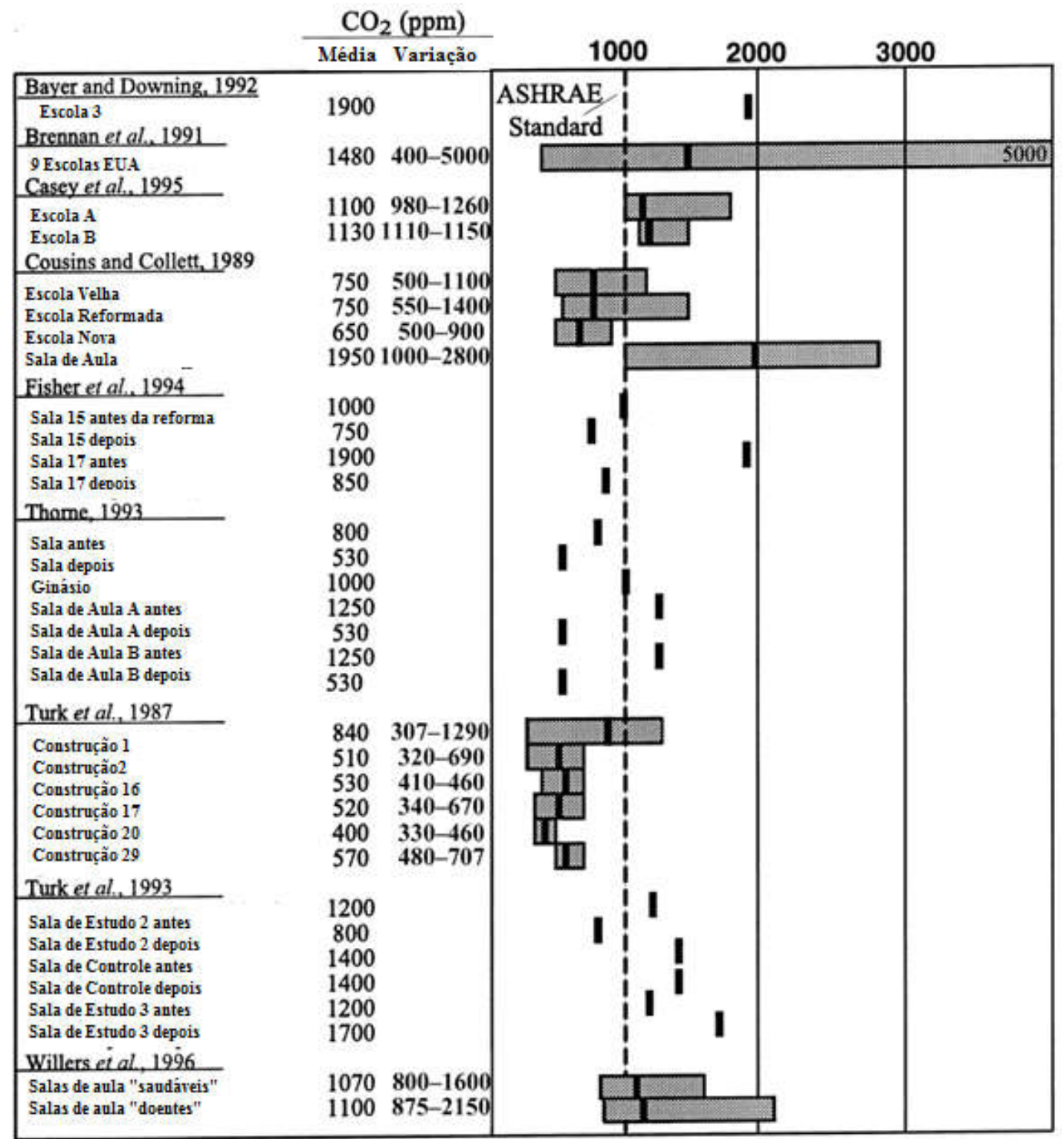

Figura 2.2. Média e Variação da concentração de $\mathrm{CO}_{2}$ nas escolas, na literatura científica dos Estados Unidos da América e do Canadá (adaptado de DAISEY, ANGELL, APTE, 2003).

No Japão, um estudo (ITO et al., 2006a; ITO et al., 2006b;) realizado com estudantes universitários em salas de aula e laboratórios buscou avaliar o desempenho em exames padrões de acordo com a variação da taxa de ventilação e da temperatura do ambiente. Em três testes executados, um sobre teoria e os outros dois envolvendo memorização, os alunos aumentaram o desempenho nos testes em 5,4\%, 8,7\% e 5,8\%, respectivamente, quando submetidos a um aumento de 0,8 para $7,5 \mathrm{~L} / \mathrm{s}$ por pessoa na taxa de ventilação. Por se tratar da análise de um edifício apenas ventilado, sem condicionamento de ar, a temperatura das 
salas permaneceu em aproximadamente $3^{\circ} \mathrm{C}$ acima da temperatura de conforto quando submetidas à baixas vazões de ar, sendo constatado neste caso, uma máxima temperatura de $27,5^{\circ} \mathrm{C}$, para mostrar também o efeito da temperatura na redução do desempenho. Dessa forma, esses dois estudos não fornecem apenas informações de como a taxa de ventilação afeta o desempenho quando a temperatura é mantida constante, mas indicam o efeito combinado da taxa de ventilação e da temperatura no desempenho de estudantes.

Um estudo realizado por Valente et al. (2010) sobre a exposição diária de crianças para $\mathrm{PM}_{10}$ no interior de salas de aula, em diferentes estações do ano, indicaram que as concentrações do material particulado foram muito mais elevadas dentro das salas de aula do que no ambiente exterior. Variações da concentração dependendo da época do ano também foram encontradas, sendo que os valores se apresentaram mais altos no verão.

Uma pesquisa dinamarquesa realizada em 4 salas de aula, Wargocki e Wyon (2007a e 2007b), se baseou na realização de alguns testes escolares, desde leitura até matemática, que foram ensinados no decorrer do ano letivo. Foram avaliadas a velocidade e a precisão no desempenho das tarefas realizadas. No estudo, eles obtiveram um aumento de $8 \%$ na resolução das atividades quando a taxa de ventilação era dobrada. Já, na estatística de número de erros, eles concluíram que não houve influências significativas da taxa de ventilação para os testes submetidos aos estudantes.

Na cidade de Lisboa, um estudo realizado em 14 escolas (PEGAS et al.,2010) visou avaliar a concentração de vários poluentes internos e externos. Os parâmetros de conforto, como temperatura e umidade relativa, também foram monitorados junto com as concentrações de monóxido e dióxido de carbono, os compostos orgânicos voláteis totais e os materiais microbiológicos. Nos resultados, eles mostraram que os valores obtidos no estudo indicavam que as concentrações de $\mathrm{CO}_{2}$ e material microbiológico ultrapassavam os valores impostos pela legislação portuguesa para Qualidade do Ar Interior. Para os COV, eles obtiveram valores superiores no ambiente interno quando comparados com o externo, concluindo que existiam fontes destes poluentes internamente.

Um estudo norte americano, desenvolvido por Haverinen-Shaughnessy, Moschandreas e Shaughnessy (2011), verificou a atuação dos alunos das salas de aula da $5^{\text {a }}$ série de 100 escolas em testes acadêmicos padrões para verificação de desempenho. Em 87 salas de aula, as taxas de ventilação existentes eram menores que os $7 \mathrm{~L} / \mathrm{s}$ por pessoa requeridos pela legislação em vigor no momento do estudo (ASHRAE, 2004). Os resultados mostraram que a 
porcentagem de alunos que passaram no teste padrão de matemática aumentou em 2,9\% para cada aumento de $1 \mathrm{~L} / \mathrm{s}$ na taxa de ventilação. Para os testes de leitura, o aumento foi de $2,7 \%$ para o mesmo aumento da taxa de ventilação. A análise foi controlada de acordo com o estado socioeconômico dos alunos, e se os mesmos já estudavam ou não nas atuais escolas. No estudo, eles concluem também que, quando comparados os resultados das 100 salas de aula, verificou-se o aumento no desempenho para os dois testes, à medida que a taxa de ventilação era aumentada. Porém, para taxas de ventilação maiores que $7 \mathrm{~L} / \mathrm{s}$ por aluno, os resultados eram incertos, não podendo verificar melhora no desempenho.

Seppänen et al. (2006) conduziram uma análise estatística de dados disponíveis de estudos, a fim de avaliar como a taxa de ventilação afeta o desempenho no trabalho em escritórios. Além disso, realizaram uma análise para verificar como a taxa de ventilação nas escolas afeta a concentração e a atenção, e determinar a relação entre a taxa de ventilação e a execução do trabalho, cujos resultados podem ser observados na figura 2.3 .

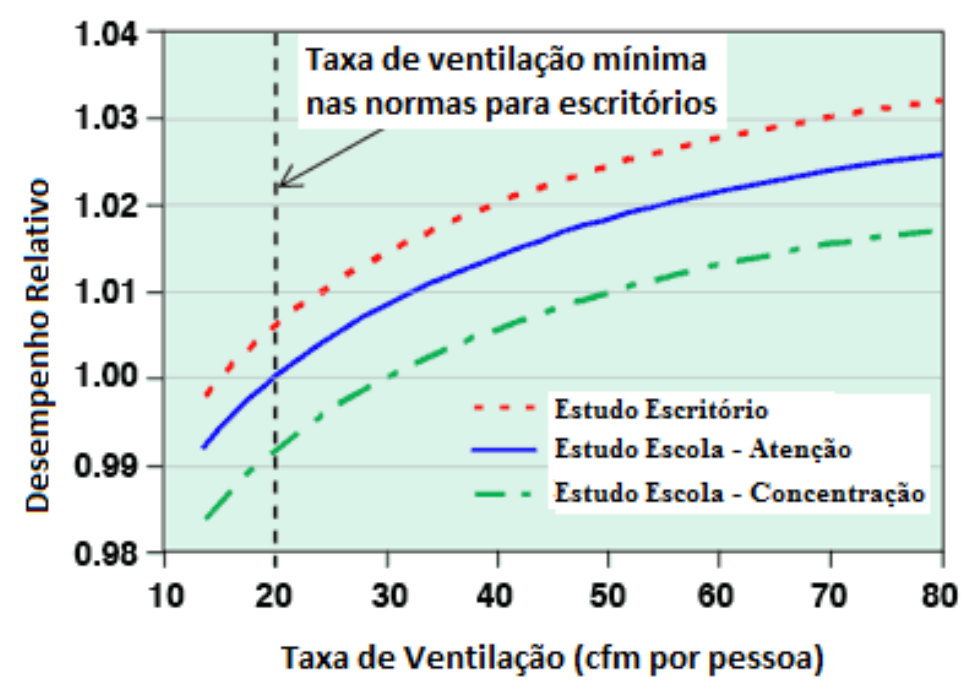

Figura 2.3. Desempenho no trabalho relativo a várias taxas de ventilação (adaptado de SEPPÄNEN et al., 2006).

O desempenho, avaliado pela velocidade e pela precisão da execução, de tarefas típicas melhorou com o aumento da taxa de ventilação. Para as taxas iniciais de ventilação entre 14 e $30 \mathrm{cfm}$ (aproximadamente 23,8 e $51 \mathrm{~m}^{3} / \mathrm{h}$ ) por pessoa, o desempenho médio aumenta aproximadamente $0,8 \%$ para cada $10 \mathrm{cfm}$ (aproximadamente $17 \mathrm{~m}^{3} / \mathrm{h}$ ) por pessoa de aumento 
na taxa de ventilação. Já, para taxas de ventilação superiores, o aumento no desempenho médio é menor, cerca de $0,3 \%$ para cada $10 \mathrm{cfm}$ por pessoa. $\mathrm{O}$ autor afirma que para taxas de ventilação menores que $14 \mathrm{cfm}$ por pessoa, o aumento no desempenho deve ser provável. No entanto, dados suficientes não estavam disponíveis para confirmar a hipótese do mesmo (SEPPÄNEN et al., 2006).

Outros estudos relativos a poluentes interiores, taxa de ventilação e desempenho podem ser observados na figura 2.4. Em dois dos estudos, Wargocki et al. (1999 e 2002) mostram os efeitos da retirada de uma fonte de poluição interna (carpete com 20 anos de uso) no desempenho de trabalhadores. Eles se basearam na combinação de desempenho na digitação e em testes de leitura. Em outro estudo, Wargocki et al. (2000) mostram o aumento do desempenho na realização de testes de criatividade com o aumento da taxa de ventilação.

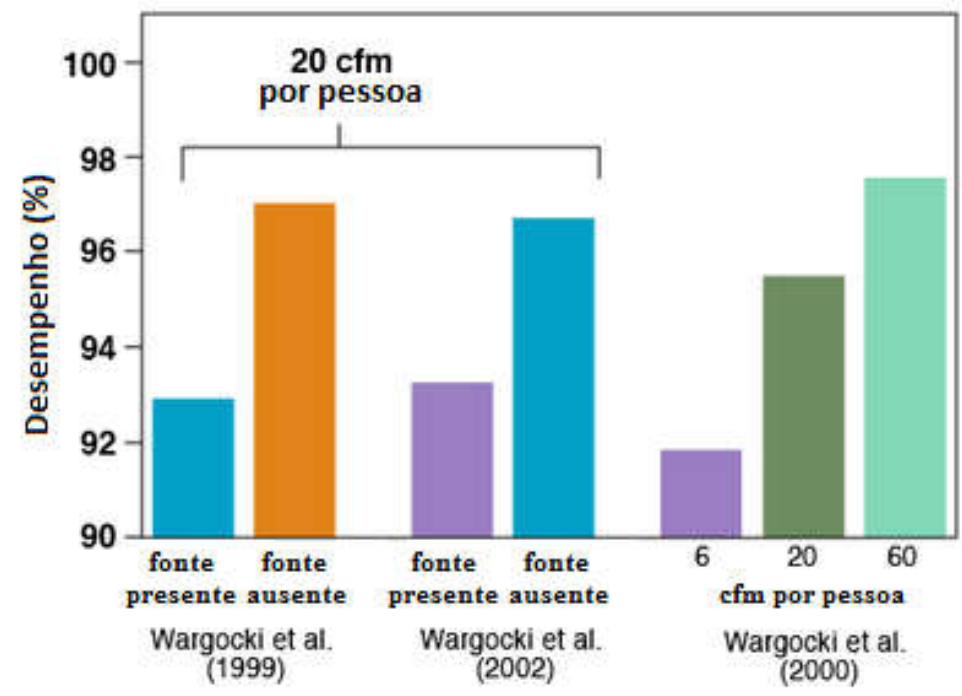

Figura 2.4. Aumento do desempenho na realização de testes comparados com a remoção de uma fonte interna poluidora e do aumento da taxa de ventilação.

Estudos relacionados ao efeito da luz natural no desempenho de estudantes, ou seja, relacionados a Qualidade do Ambiente Interior (QAI), foram realizados pelo Lawrence Berkeley National Laboratory. Um caso estudado em uma escola localizada no sul da Califórnia indicou que estudantes que estavam em salas com mais incidência de luz natural, durante um ano, progrediram 20\% mais rápido na compreensão de matemática e $26 \%$ mais rápido na compreensão de testes de leitura quando comparados com aqueles com a mínima 
exposição à luz natural. Analogamente, estudantes em salas de aula com áreas de janelas maiores, apresentaram um progresso de $15 \%$ mais rápido em matemática e $23 \%$ mais rápido em leitura do que aqueles que estudavam em salas de aula com pequena área de janela. Estudantes em espaços com claraboias bem projetadas se aprimoraram $20 \%$ mais rápido do que estudantes em áreas sem claraboias.

Com o intuito de avaliar a relação entre QAI em escolas do ensino fundamental da Finlândia, e a saúde e o desempenho acadêmico de estudantes da sexta série, foi realizado um estudo para verificação de qual sintoma prevalecia em relação a QAI. O estudo foi realizado utilizando dados coletados por um questionário de saúde, compreendendo 37 questões. O questionário de saúde foi enviado a todos os alunos da $6^{\mathrm{a}}$ série em uma amostra de 355 escolas de ensino fundamental. As condições ambientais interiores foram avaliadas com medidas da taxa de ventilação e condições térmicas das salas de aula em uma amostra de 56 escolas. No total, 297 escolas do ensino fundamental responderam o questionário de saúde, obtendo um total de 4248 questionários devolvidos (taxa de resposta estimado de 62,6\%). Os sintomas mais comuns semanais no semestre foram fadiga $(7,7 \%)$, nariz entupido $(7,3 \%)$, e dor de cabeça $(5,5 \%)$. Outros sintomas relatados foram chiado, tosse com chiado, e febre acima de $37^{\circ} \mathrm{C}$. Os relatos diários mais frequentes dos fatores que influenciam na QAI das salas de aula foram ruído, sendo 11,0\%, e ar abafado (má Qualidade do Ar Interior) de 7,0\%, juntamente com a alta temperatura interior e poeira ou sujeira. As reclamações sobre a QAI foi correlacionada com temperaturas médias elevadas e as taxas de ventilação inadequada nas salas de aula (TURUNEN et al., 2014).

Outros estudos sugerem que uma Qualidade do Ar Interior inadequada pode levar a uma redução da atenção por parte dos ocupantes, reduzindo a sua capacidade de efetuar tarefas como cálculos, uso da memória e outras funções que necessitam de concentração, interferindo no desempenho escolar (MENDELL, HEATH, 2005; SHAUGHNESSY et al., 2006).

Nas escolas da República da Sérvia, existem problemas que muitas vezes estão ligados a Qualidade do Ar Interior, devido a poluição do ar exterior, construção e manutenção predial impróprias, limpeza e ventilação natural inadequadas. A parcela da população de crianças na idade escolar, entre 7 e 14 anos, representa 7,5\% da população total, sendo que com 10 anos, a criança já apresenta asma. Uma pesquisa realizada na cidade de Belgrado, que está classificada na média da lista de cidades da República da Sérvia de crianças com asma, 
mostra que $9 \%$ das crianças que frequentam a escola no primário já apresentam casos de asma. (REPUBLIC OF SERBIA, 2012).

Os poluentes interiores podem agravar doenças como a asma ou outra alergia que produzem sintomas na saúde, ou até mesmo levam à ausência do aluno na aula. Esses fatores prejudicam o mesmo quanto à aprendizagem, ou levam ao uso de medicamentos que afetam no desempenho. A asma é a principal causa de faltas escolares das doenças crônicas, responsável por $20 \%$ de ausências no ensino fundamental e médio (RICHARDS, 1986).

Outro estudo nas escolas da Sérvia teve como objetivo a investigação da qualidade do ar e a caracterização da concentração de poluição nos ambientes interiores e exteriores das escolas. As medições foram realizadas continuamente no ambiente interno e externo por um período de 10 dias. Foi constatado, em uma sala de aula, que a concentração de material particulado com diâmetro de até $10 \mu \mathrm{m}\left(\mathrm{PM}_{10}\right)$ foi maior no ambiente interno em relação ao exterior (JOVANOVIC et al., 2014).

Mendell e Heath (2005) realizaram um amplo levantamento da literatura, o qual merece destaque, para saber se a qualidade do ambiente interno realmente influencia no desempenho dos estudantes em escolas. Os trabalhos considerados foram os que apresentavam como critério de desempenho os testes educacionais e testes neurocomportamentais, que segundo eles, são mais objetivos e que independentemente das limitações, são mais precisos do que avaliações subjetivas de desempenho. Literaturas que utilizavam a diminuição na presença em sala de aula como prejuízo, também foram consideradas, uma vez que os problemas de saúde podem acarretar na ausência do aluno, e do professor, influenciando no desempenho por prejudicar o aprendizado, diminuindo o tempo de aula para transferência verbal e visual de informações por parte do professor para os alunos. Os poluentes considerados foram os biológicos, químicos e partículas, originários em ambientes fechados ou ao ar livre. As características dos sistemas de climatização dos edifícios considerados incluem práticas de controle de poluição, tais como ventilação ou filtragem que pode reduzir ou diluir contaminantes interiores. No que diz respeito às relações dos poluentes e condições térmicas com o desempenho ou presença, Mendell e Heath evidenciaram os seguintes pontos:

- Relação entre as concentrações internas mais elevadas de dióxido de nitrogênio, a partir de fontes de combustão interna, à diminuição da participação de crianças nas escolas; 
- Relação entre as concentrações elevadas de gases poluentes (ozônio e monóxido de carbono), medida ao ar livre que entra no ambiente interno, à diminuição da participação de crianças nas escolas;

- Relação entre exposição ao pólen à diminuição no desempenho de adultos alérgicos;

- Provas não conclusivas sobre as relações entre as concentrações de COV, fungos, bactérias e poeira com o desempenho;

- Provas não conclusivas sobre a relação temperatura e desempenho, com mais resultados associando temperaturas mais altas acima da zona de conforto com diminuição do desempenho em adultos e crianças (os efeitos de temperaturas mais frias que trazem benefícios e, os riscos de sistemas de ar condicionado contaminados podem explicar essas inconsistências);

- Provas não conclusivas sobre a relação da umidade relativa do ar com o desempenho em escritórios e escolas;

- Provas escassas que aumentando a umidade relativa dentro da zona de conforto melhora a frequência escolar.

No que diz respeito às relações das características dos sistemas de AVAC com o desempenho ou presença, Mendell e Heath evidenciam os seguintes pontos:

- Relação da presença de tapetes velhos à diminuição no desempenho de estudantes universitários em escritórios e laboratórios;

- Relação de que o aumento da limpeza em escritórios reduz a ausência dos adultos devido a doenças, mas não influenciam no desempenho;

- Provas ligando as taxas de ventilação de ar externo inadequadas com a redução da presença de adultos em escritórios;

- Provas ligando as taxas de ventilação de ar externo inadequadas com a redução do desempenho por trabalhadores adultos em escritórios, e pelos alunos nas escolas;

- Provas escassas de que a remoção de partículas aumenta o desempenho e diminui a ausência de trabalhadores em escritório;

- Provas fracas de que melhores condições físicas das instalações, edifícios maiores, e presença de ar condicionado melhoram o desempenho de crianças em idade escolar; 
- Evidências conflitantes para a umidificação: se ela aumenta ou diminui a ausência de trabalhadores em escritório ou crianças em idade escolar.

O objetivo deste trabalho era resumir o conhecimento disponível relevante para ambientes internos quanto ao desempenho e a presença de adultos e crianças em seus ambientes interiores, como escritórios e escolas, respectivamente. As conclusões forneceram evidências sugestivas de que certas condições comumente encontrados em escolas e escritórios, tais como taxas de ventilação baixa, apresentam efeitos adversos sobre a saúde e o desempenho do indivíduo, tanto no trabalho, como em escolas. Assim, estes resultados da investigação tornam um forte argumento para ações de prevenção e mitigação em ambientes interiores, como ventilação exterior adequada, controle de umidade, evitar a exposição interior para materiais microbiológicos e químicos considerados como possíveis causadores de efeitos adversos (MENDELL e HEATH, 2003).

\subsubsection{QAI e a Produtividade}

William Fisk do Lawrence Berkeley National Laboratory na Califórnia foi um dos primeiros pesquisadores a examinar os efeitos da qualidade do ambiente interior na saúde e na produtividade. Em um estudo, Fisk (2002a) estabeleceu um patamar para quantificar os benefícios trazidos pelo aumento da QAI e demonstrou os impactos econômicos anuais no aumento da produtividade. Em seus resultados, ele mostrou que aumentando a QAI pode-se:

- Reduzir os sintomas da SED em $20 \%$ a $50 \%$, com uma economia estimada de $\$ 10$ à $\$ 100$ bilhões de dólares;

- Reduzir a ocorrência de asma em até $25 \%$, aproximadamente, com uma economia estimada de $\$ 1$ à $\$ 4$ bilhões de dólares;

- Reduzir outras doenças respiratórias em $23 \%$ a $76 \%$, com uma economia estimada de \$6 à \$14 bilhões de dólares; e

- Aumentar a produtividade do trabalhador em 0,5\% a 5\%, com uma economia estimada de \$20 à \$200 bilhões de dólares.

Em uma pesquisa em 100 edifícios de escritórios norte americanos, verificou-se que $23 \%$ dos trabalhadores vivenciaram sintomas frequentes da SED, como doenças respiratórias, alergias e asma. O impacto acaba sendo escondido nos dias de doença, com menor produtividade e 
custos médicos. Porém, o impacto econômico é enorme, com uma redução estimada da produtividade em torno de $2 \%$ no país, o que resulta em um custo anual para os Estados Unidos de aproximadamente $\$ 60$ bilhões de dólares ( FISK, 2002b).

Segundo um estudo de Hedge (2004), baixas temperaturas em ambientes de trabalho impactam negativamente na produtividade. Ele mostra, com seus estudos que trabalhadores em ambientes de escritório muito frios não só cometem mais erros, mas aumentam o custo da hora de trabalho em $10 \%$.

Segundo três estudos separados conduzidos por Wargocki (2002), do International Center for Indoor Environment and Energy (ICIEE), a produtividade aumenta no mínimo 5\% através da melhora na Qualidade do Ar Interior.

Um estudo da Finlândia realizado por Seppänen e Fisk (2005) mostra o desenvolvimento de um modelo conceitual para estimar o custo efetivo baseado na melhoria da QAI. No estudo, o modelo apresentou uma diminuição de $2 \%$ na produtividade para cada aumento de temperatura do ambiente entre $25^{\circ} \mathrm{C}$ e $32^{\circ} \mathrm{C}$. O desempenho ótimo de produtividade ocorreu quando a temperatura do ambiente estava em aproximadamente $22^{\circ} \mathrm{C}$.

Um estudo da universidade de Waseda, no Japão, publicado por Tanabe (2005), relatou os efeitos do conforto térmico no desempenho de realização de tarefas e fadiga. No Japão, é recomendado por lei que os edifícios com escritórios possuam termostatos programados em $28^{\circ} \mathrm{C}$ no verão. $\mathrm{O}$ estudo concluiu que a produtividade diminui em $2 \%$ quando a temperatura média interna aumenta em $1{ }^{\circ} \mathrm{C}$. Esse estudo também apresentou que o controle da velocidade do ar individual foi capaz de reduzir a percepção de fadiga mental pelos trabalhadores.

Um estudo realizado por Olesen (2005) indicou que a melhoria no conforto térmico, redução de poluentes interiores, e melhoria na taxa de ventilação podem aumentar a produtividade de $5 \%$ a $10 \%$. A pesquisa também mostra que uma redução de $10 \%$ da satisfação em relação à QAI, resulta em uma queda de $1 \%$ na produtividade. 


\section{METODOLOGIA E APARATO EXPERIMENTAL}

Neste capítulo são apresentadas as etapas seguidas no desenvolvimento do trabalho.

Inicialmente verificou-se, através da revisão da literatura sobre a qualidade do ar exterior e interior de ambientes, que a literatura científica disponível indica um aumento aproximado de $5 \%$ a $10 \%$ no desempenho dos alunos com o aumento das taxas de ventilação de ar externo para as salas de aula. Nos estudos dos diferentes autores, as taxas de ventilação, em mais da metade das escolas, se mostraram menores do que as taxas especificadas nas normas vigentes. Dessa maneira, verifica-se que o aumento nas taxas de ventilação do ar externo pode ser significativo e essencial para melhorar o desempenho dos alunos.

A concentração de $\mathrm{CO}_{2}$ se mostrou, em alguns estudos, acima do valor especificado, sendo que está diretamente relacionada à taxa de ventilação, ou seja, com o número de renovações do ar do ambiente. A partir do aumento da taxa de ventilação que se faz necessário nas escolas, como visto nos estudos anteriores, a diluição do $\mathrm{CO}_{2}$ poderá ser observada. Dessa forma, busca-se uma concentração de $\mathrm{CO}_{2}$ abaixo das normas vigentes, para consequente melhora no desempenho acadêmico.

Outro poluente que se apresentou várias vezes acima, tanto dos valores vigentes para ambientes internos, como quando comparados ao ambiente externo, foi o $\mathrm{PM}_{10}$. Este, decorrente muitas vezes da própria atividade humana, pode ser trazido também do ambiente externo. Além disso, pode ser observado no manual da REHVA (2011) que foi demonstrado que as nanopartículas ou partículas ultrafinas influenciam extremamente no sistema respiratório, sendo que existe uma relação direta entre as partículas finas $\mathrm{PM}_{2,5} \mathrm{e}$ o aumento da mortalidade devido à doenças respiratórias e cardiovasculares. Para isso, uma filtragem adequada deve ser prevista para diminuição da exposição humana ao poluente em ambientes internos.

Com base neste dados, a segunda etapa do projeto foi a escolha de um ambiente escolar, onde diversos tipos de atividades eram realizadas, possibilitando a avaliação da QAI, bem como os equipamentos de condicionamento de ar e ventilação necessários a serem instalados. 
Após a determinação do local e dos equipamentos a serem utilizados para a avaliação da QAI, definiu-se a instrumentação a ser utilizada para as medições, a incerteza dos instrumentos, bem como as técnicas envolvidas no processo de medição.

Em seguida, estabeleceu-se o procedimento experimental a ser empregado durante as medições, para a avaliação de QAI do local escolhido.

\subsection{Sala de aula e equipamentos de condicionamento de ar adotados para avaliação de QAI}

$\mathrm{O}$ ambiente escolar adotado neste trabalho é à sala de aula $\mathrm{A} 2$ do prédio de Engenharia Mecânica da Escola Politécnica da Universidade de São Paulo. Esta sala de aula é um ambiente importante por se tratar de um local onde são realizadas atividades experimentais e didáticas, tanto teóricas como práticas. Essas atividades desempenhadas na sala geram poluentes internos que podem afetar a saúde dos usuários e diminuir o desempenho dos alunos na realização das atividades acadêmicas. Contribuindo para o problema, a sala de aula está situada na cidade de São Paulo, onde a qualidade do ar externo pode vir a não ser boa devido à grande contaminação do ar atmosférico.

A sala de aula A2 não possuía equipamentos para condicionamento do ar, sendo utilizadas apenas as janelas e a porta para ventilação natural, sem nenhum tratamento prévio do ar externo. Bordini (2015) mediu no interior deste ambiente a concentração de $\mathrm{CO}_{2}$ e de $\mathrm{PM}_{10}$,

juntamente com a variação temperatura de bulbo seco e da umidade relativa, verificando o comportamento dos mesmos em função do tempo para a sala com as janelas e porta abertas.

Já, para o presente estudo, alguns equipamentos de condicionamento de ar foram instalados a fim de possibilitar a verificação da influência da vazão de ar externo nas concentrações de $\mathrm{CO}_{2}, \mathrm{PM}_{10}$ e $\mathrm{PM}_{2,5}$.

As figuras 3.1 e 3.2 a seguir representam a planta e uma vista lateral interna da sala A2, respectivamente. As mesmas ilustram os equipamentos para condicionadomento do ar, caixas de ventilação de ar externo e unidades evaporadoras, instalados para o aprimoramento da qualidade do ar interno. 


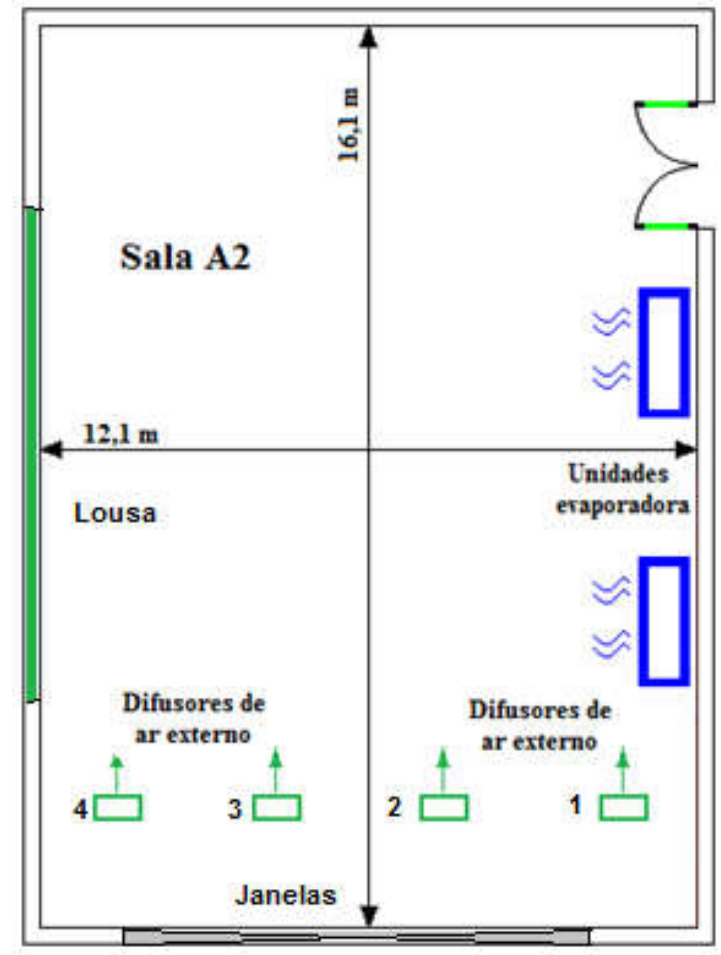

Figura 3.1. Layout da sala de aula A2.

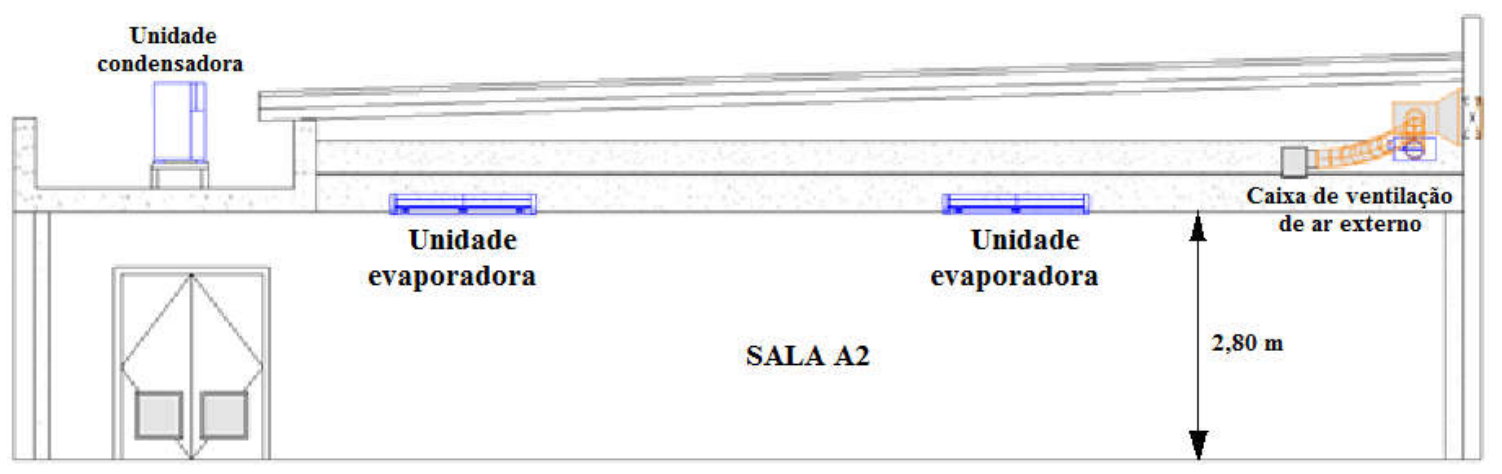

Figura 3.2. Vista lateral interna da sala de aula A2.

As unidades de condicionamento de ar instaladas na sala de aula A2, compostas pelas unidades evaporadoras (duas no total) e condensadoras, são responsáveis apenas pelo controle de temperatura do ambiente. Já, as caixas de ventilação de ar externo (quatro no total), desempenham um papel fundamental no presente estudo, que é o de proporcionar um tratamento prévio do ar externo para suprimento da sala de aula. 
As caixas de ventilação que foram utilizadas são compostas basicamente de um ventilador e 2 estágios de filtragem, sendo um filtro grosso classe G4 e um filtro médio classe M5, conforme norma NBR 16101 (ABNT, 2012).

As características técnicas dos equipamentos instalados podem ser observadas na tabela a seguir.

Tabela 3.1. Características técnicas dos equipamentos instalados.

\begin{tabular}{|c|c|c|c|c|}
\hline \multicolumn{2}{|c|}{ CAIXAS DE VENTILAÇÃO } & \multicolumn{2}{c|}{ UNIDADES DE CONDICIONAMENTO DE AR } \\
\hline Fabricante & MULTIVAC & Unidade & Evaporadora & Condensadora \\
\hline Modelo & CFM 1000 & Fabricante & CARRIER & CARRIER \\
\hline $\begin{array}{c}\text { Vazão máxima } \\
\left(\mathbf{m}^{\mathbf{3}} \mathbf{\text { hh }} \text { já com o }\right. \\
\text { filtro G4 }\end{array}$ & 1000 & Modelo & 42 XQM48C5 & 38 CQEP048535MC \\
\hline $\begin{array}{c}\text { Pressão máxima } \\
\text { (Pa) }\end{array}$ & 620 & $\begin{array}{c}\text { Capacidade } \\
(\mathbf{k W})\end{array}$ & 14 & 14 \\
\hline Filtros (classe) & G4 + M5 & $\begin{array}{c}\text { Vazão de ar } \\
\left(\mathbf{m}^{\mathbf{3}} / \mathbf{h}\right)\end{array}$ & 1785 & 6420 \\
\hline
\end{tabular}

Uma das caixas de ventilação e os difusores de ar externo instalados na sala de aula A2 podem ser observados nas figuras 3.3 e 3.4 .

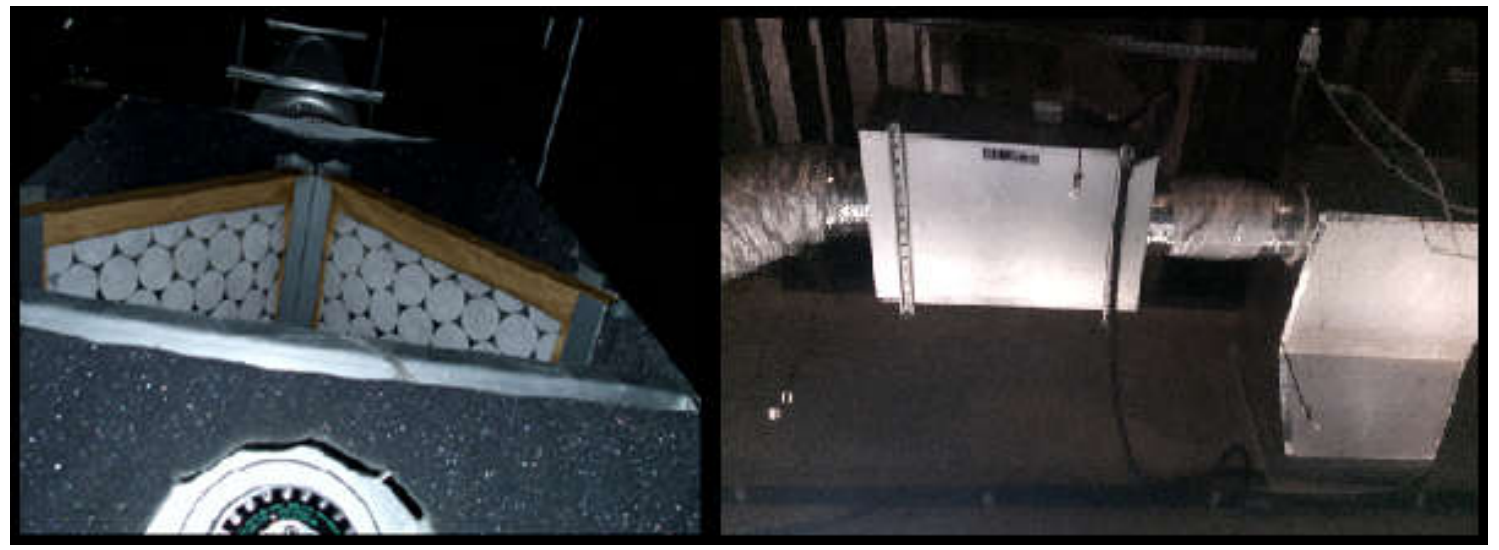

Figura 3.3. Fotos da caixa de ventilação da sala de aula A2. Caixa de ventilação aberta com um estágio de filtragem (esquerda); Caixa de ventilação instalada (direita). 


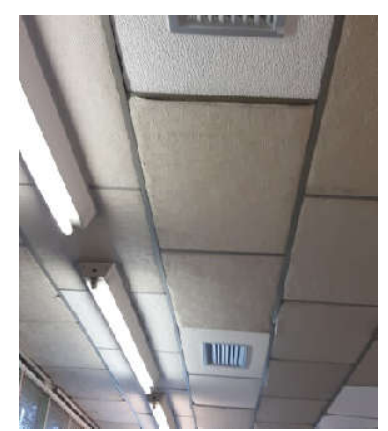

Figura 3.4. Difusores de ar externo instalados na sala de aula A2.

Para verificação da vazão de ar externo proporcionada pelas caixas de ventilação nos ensaios, uma avaliação da vazão e da filtragem foi realizada. Para isso, foi feita uma medição prévia da vazão de cada unidade por meio de uma medidor de vazão tipo coifa, modelo CFM-80 da marca Shortridge, figura 3.5. A temperatura de bulbo seco (TBS) e a umidade relativa (UR) do ar durante o procedimento também foram verificados.

As caixas de ventilação foram previamente numeradas, sendo que a número 1 é a mais próxima da parede do fundo da sala e a 4 da lousa. Os dados obtidos durante o procedimento estão indicados na tabela 3.2 a seguir.

Tabela 3.2. Dados obtidos para verificação da vazão de ar externo das caixas de ventilação.

\begin{tabular}{|c|c|c|c|}
\hline Caixa de ventilação & Vazão medida (l/s) & TBS $\left({ }^{\circ} \mathbf{C}\right)$ & UR (\%) \\
\hline 1 & 160 & 21,6 & 58,2 \\
\hline 2 & 160 & 21,4 & 59,7 \\
\hline 3 & 155 & 21,1 & 59,9 \\
\hline 4 & 155 & 21 & 60,3 \\
\hline
\end{tabular}




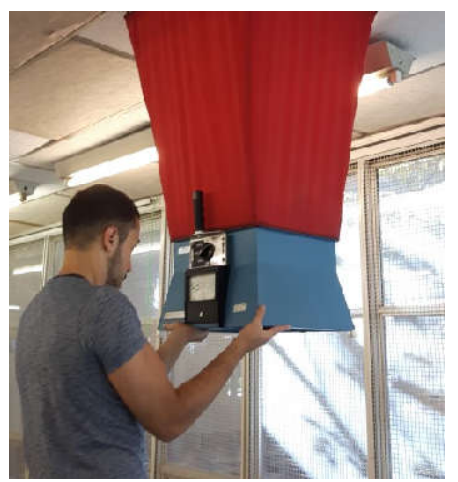

Figura 3.5. Posicionamento do medidor de vazão na saída do difusor para verificação da vazão de ar das caixas de ventilação.

Para cálculo da massa específica do ar, partiu-se do cálculo da pressão de vapor $\left(P_{v}\right)$, a qual pode ser calculada em função da temperatura de bulbo seco $(T)$ por meio da equação (1) retirada de Bolliger Jr. e Mariani (2012):

$$
P_{v}=\sum_{i=0}^{6} C_{i} \cdot T^{i} \quad\left(\text { para } 0{ }^{\circ} \mathrm{C}<\mathrm{T}<50^{\circ} \mathrm{C}\right)
$$

$$
\begin{aligned}
\text { com } 0 & =0,611217421 \\
\mathrm{C} 1 & =0,0444268992 \\
\mathrm{C} 2 & =1,42440863 \mathrm{E}-03 \\
\mathrm{C} 3 & =2,70506969 \mathrm{E}-05 \\
\mathrm{C} 4 & =2,77940283 \mathrm{E}-07 \\
\mathrm{C} 5 & =2,6287086 \mathrm{E}-09 \\
\mathrm{C} 6 & =1,07210619 \mathrm{E}-12
\end{aligned}
$$

Determinada a pressão de vapor, a umidade específica $(\omega)$ pode ser calculada em função da temperatura de bulbo seco e umidade relativa (UR).

$$
\omega(U R ; T B S)=\frac{0,622 \cdot\left(\frac{U R}{100}\right) \cdot P_{v}(T B S)}{P-\left(\frac{U R}{100}\right) \cdot P_{v}(T B S)}
$$


sendo $P$ a pressão atmosférica no local, obtida pela CETESB no horário da medição dos valores. $\mathrm{O}$ valor considerado foi de $92,6 \mathrm{kPa}$, conforme figura a seguir.

\begin{tabular}{|c|c|c|c|c|c|c|c|}
\hline Hora & $\begin{array}{c}\text { Velocidade } \\
\text { do Vento } \\
\mathrm{m} / \mathrm{s}\end{array}$ & $\begin{array}{l}\text { Direção do } \\
\text { Vento } \\
\text { Setor }\end{array}$ & $\begin{array}{c}\text { Temperatura } \\
{ }^{\circ} \mathrm{C}\end{array}$ & $\begin{array}{c}\text { Umidade } \\
\text { Relativa } \\
\%\end{array}$ & $\begin{array}{c}\text { Pressão } \\
\text { Atmosférica } \\
\text { mbar }\end{array}$ & $\begin{array}{c}\text { Radiação } \\
\text { UVA } \\
\text { W/m }\end{array}$ & $\begin{array}{c}\text { Radiação } \\
\text { Global } \\
\mathrm{W} / \mathrm{m}^{2}\end{array}$ \\
\hline $01: 00$ & 1.7 & $\mathrm{~N}$ & 18.0 & 76 & 925 & 0.0 & 0 \\
\hline $02: 00$ & 2.5 & NNE & 18.2 & 73 & 924 & 0.0 & 0 \\
\hline $03: 00$ & 2.3 & $\mathrm{~N}$ & 18.2 & 73 & 924 & 0.0 & 0 \\
\hline $04: 00$ & 2.4 & $\mathrm{~N}$ & 17.8 & 74 & 924 & 0.0 & 0 \\
\hline $05: 00$ & 1.8 & $\mathrm{~N}$ & 17.4 & 75 & 924 & 0.0 & 0 \\
\hline $06: 00$ & 1.4 & $N$ & 16.9 & 77 & 924 & 0.0 & 0 \\
\hline $07: 00$ & 1.1 & w & 17.0 & 76 & 925 & 0.2 & 7 \\
\hline $08: 00$ & 1.0 & WSW & 17.7 & 75 & 926 & 3.8 & 131 \\
\hline 09:00 & 2.4 & $\mathrm{~N}$ & 19.8 & 64 & 926 & 12.6 & 289 \\
\hline $10: 00$ & 2.1 & NNE & 22.6 & 56 & 926 & 21.4 & 491 \\
\hline $11: 00$ & 4.0 & NW & 24.1 & 54 & 926 & 29.9 & 709 \\
\hline $12: 00$ & 4.5 & NW & 25.8 & 47 & 926 & 33.8 & 806 \\
\hline $13: 00$ & 5.0 & WNW & 27.1 & 40 & 925 & 34.5 & 812 \\
\hline $14: 00$ & 4.9 & NW & 27.9 & 36 & 924 & 31.7 & 753 \\
\hline $15: 00$ & 4.8 & NW & 28.5 & 36 & 923 & 24.9 & 594 \\
\hline $16: 00$ & 4.8 & NW & 29.0 & 34 & 923 & 16.0 & 436 \\
\hline $17: 00$ & 3.6 & WNW & 29.0 & 35 & 923 & 7.1 & 213 \\
\hline $18: 00$ & 2.6 & WNW & 28.1 & 38 & 923 & 1.4 & 41 \\
\hline $19: 00$ & 1.7 & NW & 26.7 & 43 & 924 & 0.0 & 0 \\
\hline $20: 00$ & 1.3 & NW & 25.5 & 48 & 925 & 0.0 & 0 \\
\hline $21: 00$ & 4.1 & $s$ & 19.1 & 73 & 927 & 0.0 & 0 \\
\hline $22: 00$ & 2.1 & SSE & 18.4 & 78 & 928 & 0.0 & 0 \\
\hline $23: 00$ & 2.8 & SSE & 18.2 & 80 & 928 & 0.0 & 0 \\
\hline $24: 00$ & 2.0 & $E$ & 17.5 & 88 & 928 & 0.0 & 0 \\
\hline
\end{tabular}

Figura 3.6. Dados meteorológicos da CETESB de 17 de agosto de 2016 da cidade de São Paulo.

Retirado de http://sistemasinter.cetesb.sp.gov.br/Ar/php/ar_dados_horarios_Metrl.php em 18 de agosto de 2016.

Por final, obtem-se a massa específica $(\rho)$ em função da temperatura de bulbo seco, da umidade absoluta e da pressão atmosférica através da equação (3) a seguir.

$$
\rho(T B S ; \omega ; P)=\frac{1}{\frac{0,28705(5+27 \gtreqless)}{P} \cdot\left(1+\frac{\omega}{0,622}\right)}
$$

O valor da massa específica obtida pelos dados adquiridos é de, aproximadamente, $1,089 \mathrm{~kg} / \mathrm{m}^{3}$ para as 4 caixas de ventilação.

Para o cálculo da vazão de ar externo, a curva de calibração pelo Instituto de Pesquisas Tecnológicas (IPT) do medidor foi utilizada, sendo adicionada a mesma, uma linha de 
tendência polinomial de $2^{\mathrm{a}}$ ordem. Os resultados da calibração apresentados estão referidos às condições de pressão atmosférica de $101,325 \mathrm{kPa}$ e temperatura de $21^{\circ} \mathrm{C}$. A incerteza na determinação, segundo o IPT, é inferior a $\pm 1,5 \%$ do valor medido. A figura 3.7 apresenta a curva de calibração com a linha de tendência estabelecida.

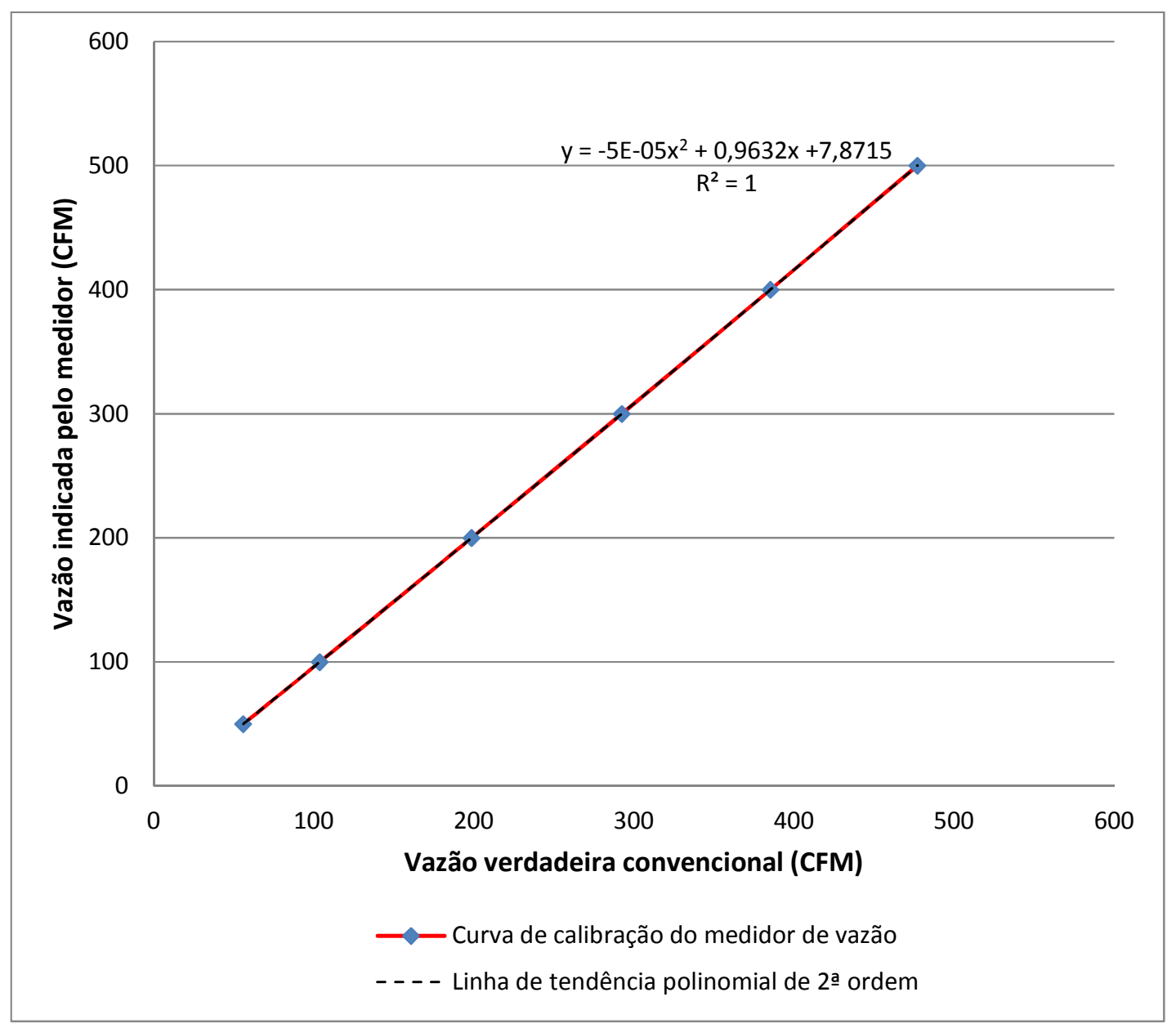

Figura 3.7. Curva de calibração do medidor de vazão.

Utilizando a curva de calibração da figura 3.7, da massa específica calculada para as condições de TBS e UR do horário da medição, a vazão de ar externo para cada unidade de renovação pode ser dada conforme a tabela 3.3. 
Tabela 3.3. Vazão de ar externo das caixas de ventilação.

\begin{tabular}{|c|c|c|c|c|}
\hline \multirow{2}{*}{$\begin{array}{c}\text { Caixa de } \\
\text { ventilaçãa }\end{array}$} & \multirow{2}{*}{$\begin{array}{c}\text { Vazão medida } \\
(\mathbf{l} / \mathbf{s})\end{array}$} & \multicolumn{2}{|c|}{ Vazão corrigida com a curva de calibração } & \multirow{2}{*}{$\begin{array}{l}\text { Vazão mássica } \\
\text { corrigida }(\mathrm{kg} / \mathrm{s})\end{array}$} \\
\hline & & $(\mathbf{l} / \mathbf{s})$ & $\left(\mathrm{m}^{3} / \mathbf{h}\right)$ & \\
\hline 1 & 160 & 155 & 558 & 0,169 \\
\hline 2 & 160 & 155 & 558 & 0,169 \\
\hline 3 & 155 & 150,5 & 542 & 0,164 \\
\hline 4 & 155 & 150,5 & 542 & 0,164 \\
\hline
\end{tabular}

Também analisou-se a concentração de particulados no insuflamento de ar externo da sala, ou seja, na saída dos difusores das unidades de renovação. O objetivo dessa medição foi a verificação das caixas de filtragem quanto a um possível escape de ar dos filtros, no interior das caixas de filtragem. Dessa forma, evita-se que uma parcela de ar externo seja insuflado na sala sem uma filtragem prévia.

Foram verificadas as concentrações de $\mathrm{PM}_{2,5}$ e $\mathrm{PM}_{10}$ nos quatro difusores e no ar exterior. As medidas foram tomadas por um tempo de 1 minuto e 30 segundos para cada ponto. A tabela 3.4 apresenta os dados da medição.

Tabela 3.4. Concentração de particulados na saída dos difusores das unidades de renovação.

\begin{tabular}{|c|c|c|c|c|c|c|c|c|c|c|}
\hline \multicolumn{4}{|c|}{ Sala de aula A2 } & \multicolumn{5}{c|}{$\begin{array}{c}\text { Instrumentação utilizada: } \\
\text { Contador de partículas Graywolf PC-3016A }\end{array}$} \\
\hline Local & \multicolumn{2}{|c|}{ Difusor 1 } & \multicolumn{2}{|c|}{ Difusor 2 } & \multicolumn{2}{c|}{ Difusor 3 } & \multicolumn{2}{c|}{ Difusor 4 } & \multicolumn{2}{c|}{ Ar externo } \\
\hline $\begin{array}{c}\text { Material } \\
\text { particulado }\end{array}$ & $\mathbf{P M}_{\mathbf{2 , 5}}$ & $\mathbf{P M}_{\mathbf{1 0}}$ & $\mathbf{P M}_{\mathbf{2 , 5}}$ & $\mathbf{P M}_{\mathbf{1 0}}$ & $\mathbf{P M}_{\mathbf{2 , 5}}$ & $\mathbf{P M}_{\mathbf{1 0}}$ & $\mathbf{P M}_{\mathbf{2 , 5}}$ & $\mathbf{P M}_{\mathbf{1 0}}$ & $\mathbf{P M}_{\mathbf{2 , 5}}$ & $\mathbf{P M}_{\mathbf{1 0}}$ \\
\hline \multirow{2}{\text{Valor}}{$\begin{array}{c}\text { medido } \\
\left(\boldsymbol{\mu g} / \mathbf{m}^{\mathbf{3}}\right)\end{array}$} & 6,05 & 7,71 & 6,79 & 9,73 & 6,74 & 9,92 & 6,98 & 11,14 & 10,48 & 40,01 \\
\cline { 2 - 12 } & 6,52 & 8,65 & 6,53 & 8,53 & 6,05 & 8,63 & 6,67 & 9,54 & 9,97 & 34,02 \\
\cline { 2 - 11 } & 7,54 & 6,59 & 9,25 & 6,78 & 9,46 & 6,96 & 9,98 & 10,26 & 48,33 \\
\hline
\end{tabular}




\subsection{Medições e análise de parâmetros}

No presente trabalho são medidos alguns parâmetros, para análise e comparação dos seus níveis na sala de aula, com e sem o tratamento de ar projetado. Os parâmetros escolhidos para medição foram a temperatura de bulbo seco e umidade relativa, que podem ser considerados essenciais para o conforto dos usuários, a concentração de dióxido de carbono, a qual pode causar sonolência nos alunos, e a concentração de material particulado, a qual é responsável por desconforto e problemas na saúde dos ocupantes.

\subsubsection{Temperatura de bulbo seco e umidade relativa}

A temperatura de bulbo seco e a umidade relativa são parâmetros que serão medidos para verificar se o sistema de tratamento do ar instalado atende aos níveis necessários para o conforto dos usuários.

A temperatura e a umidade, por se tratarem de parâmetros de conforto, devem estar de acordo com a norma, sendo que a parte 2 da NBR 16401 (ABNT, 2008) recomenda para o verão, uma temperatura operativa e umidade relativa dentro da zona delimitada por:

- $22,5^{\circ} \mathrm{C}$ a $25,5^{\circ} \mathrm{C}$ e umidade relativa de $65 \%$.

- $23,0^{\circ} \mathrm{C}$ a $26,0^{\circ} \mathrm{C}$ e umidade relativa de $35 \%$.

Para o inverno, a norma recomenda uma temperatura operativa e umidade relativa dentro da zona delimitada por:

- $21,0^{\circ} \mathrm{C}$ a $23,5^{\circ} \mathrm{C}$ e umidade relativa de $60 \%$.

- $\quad 21,5^{\circ} \mathrm{C}$ a $24,0^{\circ} \mathrm{C}$ e umidade relativa de $30 \%$.

Já, segundo a resolução no 9 de 16 de janeiro de 2003 da ANVISA, a faixa recomendável de operação das temperaturas de bulbo seco, nas condições internas para verão, deve variar de $23^{\circ} \mathrm{C}$ a $26^{\circ} \mathrm{C}$, com a faixa máxima de operação de $26,5^{\circ} \mathrm{C}$ a $27^{\circ} \mathrm{C}$. Para o inverno, a faixa recomendável deverá variar entre $20^{\circ} \mathrm{C}$ e $22^{\circ} \mathrm{C}$.

A faixa recomendável para a umidade relativa, segundo a mesma resolução, para o verão, deverá estar entre $40 \%$ a $65 \%$. Para o inverno, de $35 \%$ a $65 \%$. 


\subsubsection{Dióxido de carbono}

O dióxido de carbono $\left(\mathrm{CO}_{2}\right)$ é um dos parâmetros medidos e utilizado como um dos indicadores de qualidade do ar.

Como forma de sustentação do metabolismo, o organismo consome oxigênio e produz o $\mathrm{CO}_{2}$ e vapor de água, eliminados pela respiração. A norma ABNT NBR 16401 traz em seu anexo uma figura mostrando que a taxa de oxigênio consumido e de $\mathrm{CO}_{2}$ produzido depende da taxa de respiração correspondente ao nível de atividade física, portanto do metabolismo. A figura está representada a seguir (figura 3.8).

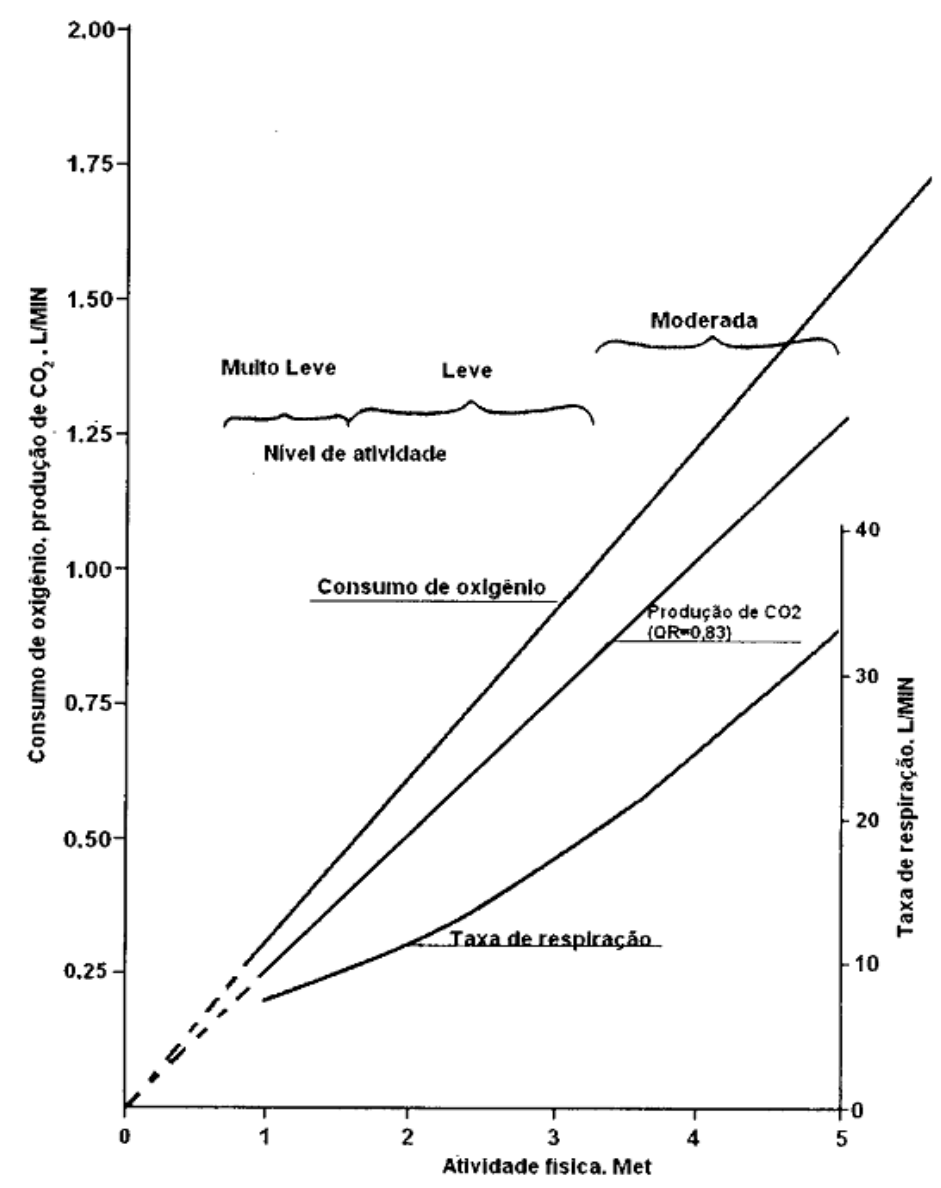

Figura 3.8. Taxa de respiração, consumo de oxigênio e produção de $\mathrm{CO}_{2}$ em função do metabolismo (ABNT, 2008).

$\mathrm{O} \mathrm{CO}_{2}$ é emitido pela respiração acompanhado da emissão de outros efluentes biológicos humanos, como os odores, também resultados da atividade metabólica das pessoas. Sendo 
assim, uma concentração de $\mathrm{CO}_{2}$ no recinto, acima da concentração no ar exterior, é considerado um indicador válido do nível de poluição produzido pelas pessoas (ABNT, 2008).

Segundo a NBR 16401 (ABNT, 2008), a concentração máxima aceitável de $\mathrm{CO}_{2}$ no ambiente interno é de 1000 ppm no recinto, e é citada como critério de qualidade de ar. A concentração de $\mathrm{CO}_{2}$ no ar exterior é assumida em 300 ppm arbitrariamente, sendo que este valor oscila normalmente entre 400 ppm e 600 ppm. Uma medição acima de 1000 ppm não indica, segundo a NBR 16401 (ABNT, 2008), que o critério não é satisfeito, desde que a medição não ultrapasse em mais de 700 ppm a concentração de ar exterior.

Já, para a resolução $\mathrm{n}^{\circ} 9$ da ANVISA, os valores máximos recomendáveis para conforto e bem estar para a concentração de $\mathrm{CO}_{2}$ é de 1000 ppm como indicador de renovação de ar externo. É recomendado uma vazão de renovação de ar externo de $27 \mathrm{~m}^{3} / \mathrm{h}$ pela mesma resolução.

O manual da REHVA (Federação de Associações Europeias de Aquecimento, Ventilação e Ar Condicionado) apresenta uma curva da taxa de renovação de ar externo recomendada, dependendo da idade de aprendizagem dos estudantes, para atingir uma concentração máxima de 1000 ppm de $\mathrm{CO}_{2}$. A figura 3.9 representa a curva. 


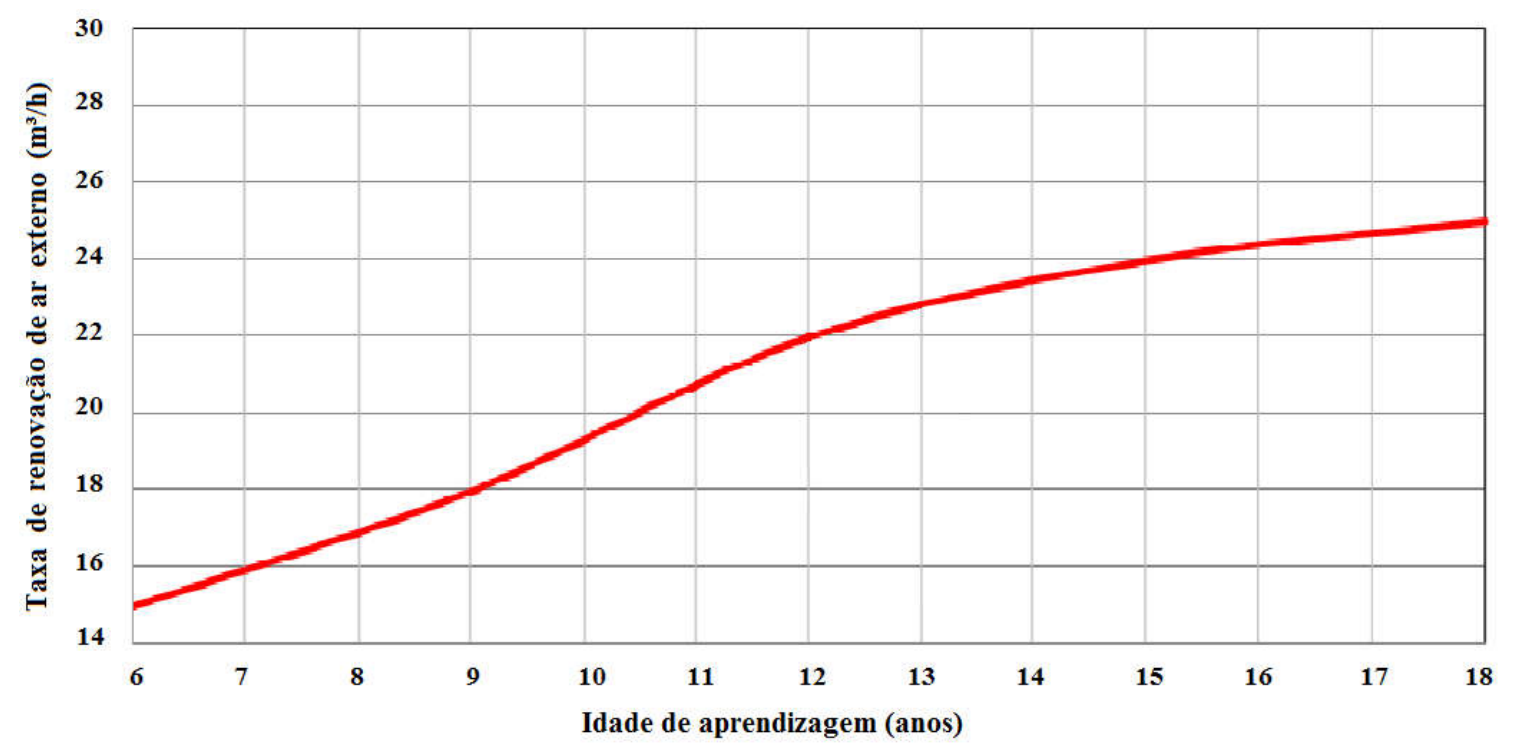

Figura 3.9. Taxa de renovação de ar mínima, por ocupante, em função da idade dos estudantes, para garantir concentração média diária de $\mathrm{CO}_{2}$ de 1000 ppm (adaptado de REHVA, 2010).

\subsubsection{Material particulado}

O material particulado também será um dos parâmetros medidos e analisados no presente estudo visando a Qualidade do Ar Interior.

A poluição por partículas, também chamado de material particulado ou PM, é uma mistura de sólidos e de gotículas de líquido que flutuam no ar. Algumas partículas são liberadas diretamente de uma fonte específica, enquanto outras se formam em reações químicas na atmosfera. As partículas possuem uma ampla gama de tamanhos. Partículas inferiores ou iguais a 10 micrômetros de diâmetro $\left(\mathrm{PM}_{10}\right)$ são tão pequenas que podem chegar aos pulmões, podendo causar sérios problemas de saúde (EPA, 2014).

As partículas finas ( $\left(\mathrm{PM}_{2,5}\right)$ são de 2,5 micrômetros de diâmetro ou menores, e só podem ser vistas com um microscópio. As partículas finas são produzidas a partir de todos os tipos de combustão, incluindo veículos automotivos, usinas de energia, queima de madeira residencial, incêndios florestais, queimadas agrícolas e alguns processos industriais (EPA, 2014).

A figura 3.10 apresenta uma comparação do tamanho dos particulados $\mathrm{PM}_{10}$ e $\mathrm{PM}_{2,5}$ com o fio de cabelo humano e um grão de areia. 


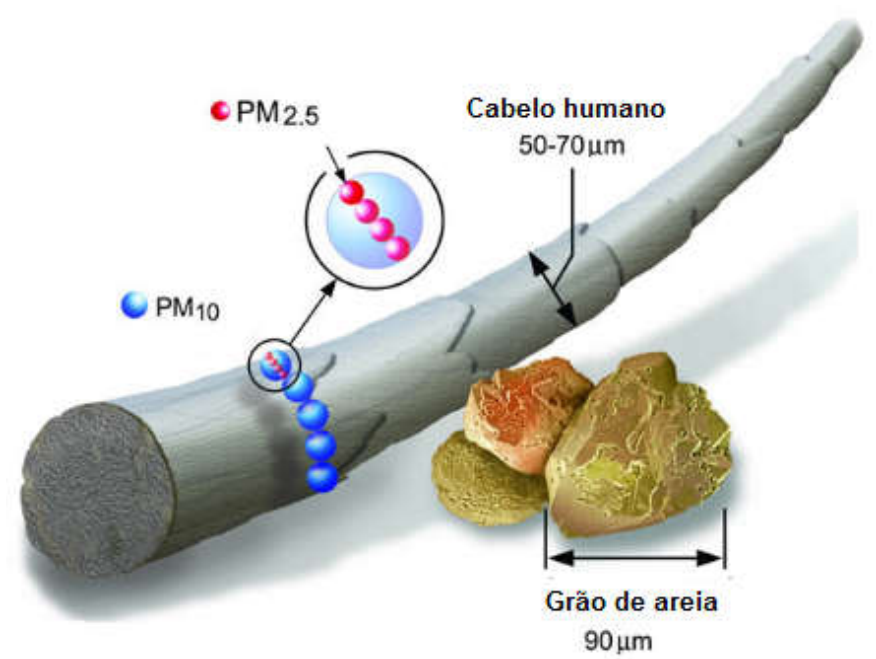

Figura 3.10. Comparação do diâmetro do cabelo humano e de um grão de areia com as partículas $\mathbf{P M}_{10} \mathrm{e}$ PM $_{2,5}$ (adaptado de EPA,2016).

Esses poluentes são um dos principais causadores de problemas de saúde, como irritação de olhos, nariz e garganta, doenças respiratórias, crises de asma, as quais afetam vários ocupantes de edifícios doentes (WORLD HEALTH ORGANIZATION, 2005).

Os particulados provenientes da degradação do material sólido, de poeira, processos industriais, queima de combustível e fragmentação do papel podem ser encontrados no ambiente externo, e em fontes internas. Sendo assim, uma boa taxa de ventilação externa ajuda na diluição desse particulado quando gerado internamente, porém traz consigo o material particulado do ar externo, caso não haja tratamento prévio.

A concentração de particulados $\mathrm{PM}_{10}$ e $\mathrm{PM}_{2,5}$ serão os parâmetros relativos a materiais em suspensão no ar que serão medidos no interior da sala de aula A2 e comparados com as concentrações no ar exterior.

A parte 3 da NBR 16401 (ABNT, 2008) limita à $50 \mu \mathrm{g} / \mathrm{m}^{3}$ a concentração máxima de $\mathrm{PM}_{10}$ no ambiente interior.

A Organização Mundial da Saúde estabelece níveis médios em 24 horas para $\mathrm{PM}_{10}$ limitados à $50 \mu \mathrm{g} / \mathrm{m}^{3}$ e para $\mathrm{PM}_{2,5}$ limitados à $25 \mu \mathrm{g} / \mathrm{m}^{3}$. Apesar do $\mathrm{PM}_{10}$ ser a medida mais amplamente divulgada e também o indicador de relevância para a maioria dos dados epidemiológicos, por vários estudos e razões, as diretrizes de qualidade do ar da Organização Mundial da Saúde para PM são baseadas em estudos que usam $\mathrm{PM}_{2,5}$ como um indicador. Os valores de 
referência para $\mathrm{o} \quad \mathrm{PM}_{2,5}$ são obtidos através dos valores de orientação do $\mathrm{PM}_{10}$ correspondentes por aplicação de uma razão $\mathrm{PM}_{2,5} / \mathrm{PM}_{10}$ de 0,5 (WORLD HEALTH ORGANIZATION, 2005).

\subsection{Instrumentação}

A instrumentação utilizada durante as medições é descrita a seguir:

\section{- Termohigrômetro:}

Para medição da temperatura de bulbo seco (TBS) e da umidade relativa (UR) da sala de aula A2 utilizou-se o termohigrômetro HOMIS modelo 974. A descrição do medidor e a imagem do mesmo podem ser observadas na tabela 3.4 e figura 3.11 .

Tabela 3.5. Dados do termohigrômetro.

\begin{tabular}{|c|l|l|}
\hline Modelo & \multicolumn{2}{|l|}{ HOMIS modelo 974} \\
\hline & Temperatura & Umidade relativa \\
\hline Faixa de Medição & $0{ }^{\circ} \mathrm{C}$ a $50{ }^{\circ} \mathrm{C}$ & $0 \%$ a $100 \%$ de UR \\
\hline Exatidão & $0,5^{\circ} \mathrm{C}$ & $\pm 2 \%$ de UR \\
\hline Resolução & $0,01^{\circ} \mathrm{C}$ & $0,01 \%$ de UR \\
\hline
\end{tabular}

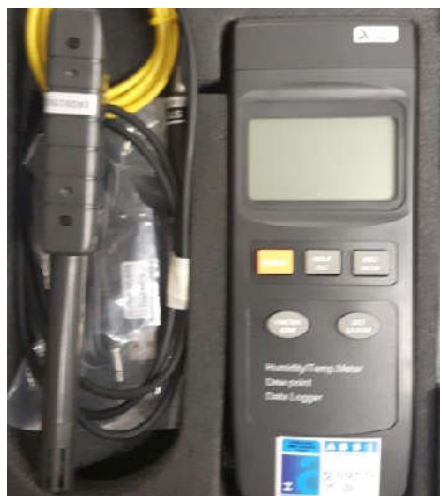

Figura 3.11. Termohigrômetro utilizado durante as medições. 
- Medidor de $\mathrm{CO}_{2}$ :

$\mathrm{O}$ instrumento utilizado para medição das concentrações de $\mathrm{CO}_{2}$ foi o sensor portátil Testo 535 (figura 3.12), com o funcionamento através de um sensor infravermelho. Os dados do medidor são apresentados na tabela 3.5 a seguir.

Tabela 3.6. Dados do medidor de $\mathrm{CO}_{2}$.

\begin{tabular}{|c|c|c|}
\hline Modelo & \multicolumn{2}{|c|}{ Testo 535} \\
\hline Faixa de Medição & 0 a $5000 \mathrm{ppm}$ & 5001 a $9999 \mathrm{ppm}$ \\
\hline Exatidão & $\begin{array}{c} \pm(75 \mathrm{ppm}+3 \% \\
\text { do valor medido })\end{array}$ & $\begin{array}{c} \pm(150 \mathrm{ppm}+5 \% \\
\text { do valor medido })\end{array}$ \\
\hline Resolução & \multicolumn{2}{|c|}{$1 \mathrm{ppm}$} \\
\hline
\end{tabular}

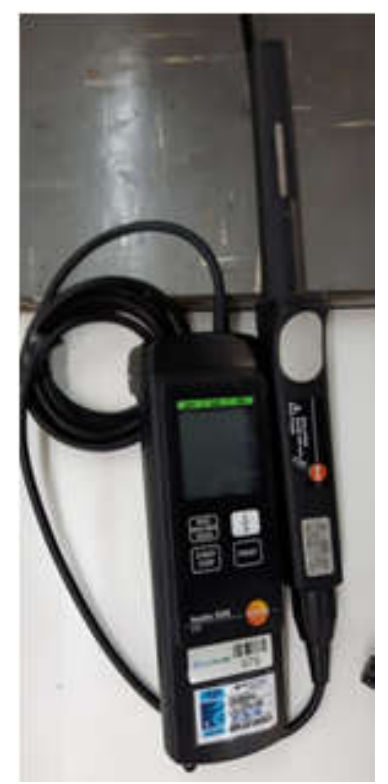

Figura 3.12. Foto do instrumento utilizado para aferição de $\mathrm{CO}_{2}$. 
- Contador de partículas:

Para a aferição das concetrações de $\mathrm{PM}_{10}$ e $\mathrm{PM}_{2,5}$ utilizou-se o contador de partículas portátil Graywolf PC-3016A (figura 3.13), com funcionamento a dispersão ótica. Os dados relativos ao contador podem ser verificados na tabela 3.6 a seguir.

Tabela 3.7. Dados do contador de partículas.

\begin{tabular}{|c|c|}
\hline Modelo & Graywolf PC-3016A \\
\hline Faixa de Medição & $4 \times 10^{6}$ partículas $/ \mathrm{ft}^{3}$ \\
\hline Exatidão & $\pm 5 \%$ do valor medido \\
\hline Resolução & $0,01 \mu \mathrm{g} / \mathrm{m}^{3}$ \\
\hline
\end{tabular}

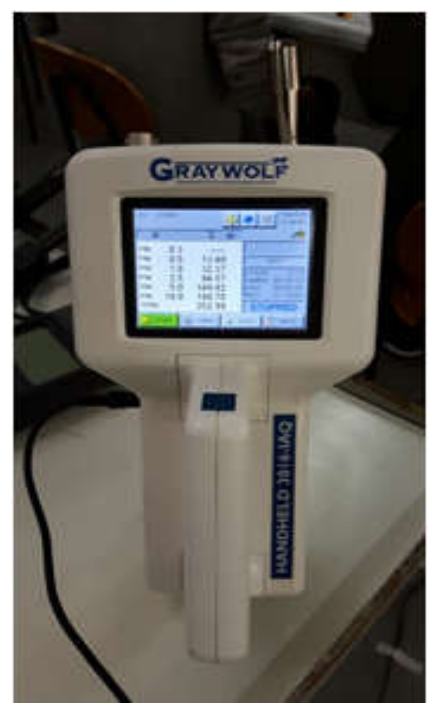

Figura 3.13. Foto do contador de partículas utilizado. 


\subsection{Procedimento experimental}

No presente trabalho desejou-se verificar a influência da variação da vazão do ar externo na concentração de $\mathrm{CO}_{2}, \mathrm{PM}_{2,5}$ e $\mathrm{PM}_{10}$ durante atividades teóricas e práticas na sala de aula $\mathrm{A} 2$ do prédio de Engenharia Mecânica da Escola Politécnica da Universidade de São Paulo, além de compará-las com as concentrações obtidas por Bordini (2015).

Em seu estudo, Bordini (2015) propôs o seguinte procedimento experimental:

a) No horário em que ocorrem as aulas, tomaram-se medidas a cada 15 minutos das concentrações de $\mathrm{CO}_{2}, \mathrm{PM}_{10}$, temperatura de bulbo seco e umidade relativa no interior e no exterior do ambiente.

b) A cada medida tomada, comentava-se sobre qualquer evento que poderia influenciar sobre as medições das variáveis controladas.

A figura 3.14 à seguir mostra o esqueleto da tabela proposta por Bordini (2015) em seu estudo.

\begin{tabular}{|c|c|}
\hline Data: & \\
\hline Dia da Semana: & \\
\hline Laboratório & \\
\hline
\end{tabular}

\begin{tabular}{|c|c|c|c|c|c|c|c|c|c|}
\hline \multirow{2}{*}{ Hora } & \multicolumn{2}{|c|}{$\mathrm{Conc} \mathrm{CO}_{2}[\mathrm{ppm}]$} & \multicolumn{2}{|c|}{ Conc. MP $[\mu \mathrm{g} / \mathrm{m} 3]$} & \multicolumn{2}{|c|}{ TBS $[\mathrm{OC}]$} & \multicolumn{2}{|c|}{ UR [\%] } & \multirow{2}{*}{ Comentário } \\
\hline & Int. & Ext. & Int. & Ext. & Int. & Ext. & Int. & Ext. & \\
\hline 07:00 & & & & & & & & & \\
\hline 07:15 & & & & & & & & & \\
\hline 07:30 & & & & & & & & & \\
\hline $07: 45$ & & & & & & & & & \\
\hline 08:00 & & & & & & & & & \\
\hline $08: 15$ & & & & & & & & & \\
\hline 08:30 & & & & & & & & & \\
\hline $08: 45$ & & & & & & & & & \\
\hline 09:00 & & & & & & & & & \\
\hline 09:15 & & & & & & & & & \\
\hline 09:30 & & & & & & & & & \\
\hline $09: 45$ & & & & & & & & & \\
\hline 10:00 & & & & & & & & & \\
\hline
\end{tabular}

Figura 3.14. Tabela proposta por Bordini (2015) para tomada de medidas.

O presente estudo utilizou-se da proposta de Bordini (2015) com algumas diferenças: 
a) Além das concentrações de $\mathrm{PM}_{10}$ e $\mathrm{CO}_{2}$, da temperatura de bulbo seco e umidade relativa, tomou-se a medida da concentração de $\mathrm{PM}_{2,5}$.

b) A vazão de ar externo era variada ligando-se um maior número de caixas de ventilação de ar externo (figura 3.1). A vazão de ar externo era aumentada com o acionamento das caixas de ventilação. O número de unidades de ar externo ligadas e o momento do acionamento variaram de acordo com o experimento.

c) A tomada de medidas era feita a cada 10 minutos no decorrer das aulas.

Sendo assim, a tabela para preenchimento dos dados pode ser observada na figura 3.15.

\begin{tabular}{|c|c|c|c|c|c|c|c|c|c|c|c|}
\hline \multicolumn{12}{|c|}{ Data: } \\
\hline \multicolumn{12}{|c|}{ Dia da semana: } \\
\hline \multicolumn{12}{|c|}{ Local: } \\
\hline \multirow{2}{*}{ Hora } & \multicolumn{2}{|c|}{ Conc. de $\mathrm{CO}_{2}$} & \multicolumn{2}{|c|}{$\mathrm{PM}_{10}[\mu \mathrm{g} / \mathrm{m} 3]$} & \multicolumn{2}{|c|}{$\mathrm{PM}_{2,5}[\mu \mathrm{g} / \mathrm{m} 3]$} & \multicolumn{2}{|c|}{ TBS $\left[{ }^{\circ} \mathrm{C}\right]$} & \multicolumn{2}{|c|}{ UR [\%] } & \multirow{2}{*}{ Comentários } \\
\hline & Interno & Externo & Interno & Externo & Interno & Externo & Interno & Externo & Interno & Externo & \\
\hline \multicolumn{12}{|l|}{$7 \mathrm{~h} 30$} \\
\hline \multicolumn{12}{|l|}{$7 \mathrm{~h} 40$} \\
\hline \multicolumn{12}{|l|}{$7 \mathrm{~h} 50$} \\
\hline \multicolumn{12}{|l|}{$8 \mathrm{~h} 00$} \\
\hline \multicolumn{12}{|l|}{$8 \mathrm{~h} 10$} \\
\hline $8 \mathrm{~h} 20$ & & & & & & & & & & & \\
\hline
\end{tabular}

Figura 3.15. Tabela utilizada para controle das medições.

Para o número de pontos de medição e o posicionamento dos mesmos, utilizou-se a resolução $\mathrm{n}^{\circ} 9$ da ANVISA de 16 de Janeiro de 2003 que traz quatro normas técnicas a respeito da amostragem de alguns parâmetros da Qualidade do Ar Interior.

Para o dióxido de carbono $\left(\mathrm{CO}_{2}\right)$, a norma técnica de número 2 da resolução supracitada trata sobre o método de amostragem e análise da concentração de $\mathrm{CO}_{2} \mathrm{em}$ ambientes interiores. A norma diz que os pontos amostrais deverão ser distribuídos uniformemente e coletados com o amostrador localizado na altura de $1,5 \mathrm{~m}$ do piso, no centro do ambiente ou zona ocupada. Outrossim, a norma define que, para uma área construída de até $1000 \mathrm{~m}^{2}$, deve-se utilizar um ponto de amostragem, no mínimo.

Para a amostragem e análise da concentração de aerodispersóides em ambientes interiores, a norma técnica de número 4 da resolução $n^{\circ} 9$ da ANVISA também informa que os pontos amostrais deverão ser distribuídos uniformemente e coletados com o amostrador localizado na 
altura de $1,5 \mathrm{~m}$ do piso, no centro do ambiente ou zona ocupada e que para uma área construída de até $1000 \mathrm{~m}^{2}$ deve-se utilizar um ponto de amostragem no mínimo.

Já, segundo o guia técnico (APAMBIENTE, 2009), para as medições de $\mathrm{PM}_{10}$, quando possível, deve-se respeitar os seguintes critérios de posicionamento do amostrador:

- os amostradores deverão estar há pelo menos 0,5 m das paredes, janelas, divisórias, e de outras superfícies verticais;

- os amostradores não devem estar diretamente abaixo ou em frente aos difusores de abastecimento de ar, unidades de difusão, ventoinhas, ou aquecedores, etc;

- os amostradores não devem ser posicionados a menos de $1 \mathrm{~m}$ de fontes de material particulados, tais como fotocopiadoras, impressoras ou fumo de cigarros, etc;

- a entrada de ar do amostrador deverá distar de 1,5 \pm 0,5 m acima do chão.

Segundo a NBR 9547 (ABNT, 2007), o número total de amostradores em um ambiente deve obedecer à seguinte equação:

$$
N_{i}=0,15 \cdot \sqrt{A_{i}}
$$

sendo $N_{i}$ o número de posições na zona a ser metida e $A_{i}$ a área desta.

A tabela a seguir apresenta um resumo da instrumentação utilizada nas medições e as posições da medição. As figuras a seguir mostram os instrumentos nas hastes de medição, no ar externo e no interior da sala A2. 
Tabela 3.8. Tabela resumo dos instrumentos utilizados e a posição de medição.

\begin{tabular}{|l|l|l|}
\hline $\begin{array}{c}\text { Parâmetro } \\
\text { medido }\end{array}$ & Instrumento utilizado & \multicolumn{1}{c|}{ Posição de medição } \\
\hline $\mathrm{CO}_{2}$ & Testo 535 & $1,5 \mathrm{~m}$ do piso. Centro da sala de aula A2 e ar externo \\
\hline $\mathrm{PM}_{2,5}$ e PM & Graywolf PC-3016A & $1,5 \mathrm{~m}$ do piso. Centro da sala de aula A2 e ar externo \\
\hline TBS e UR & HOMIS modelo 974 & $1,5 \mathrm{~m}$ do piso. Centro da sala de aula A2 e ar externo \\
\hline
\end{tabular}

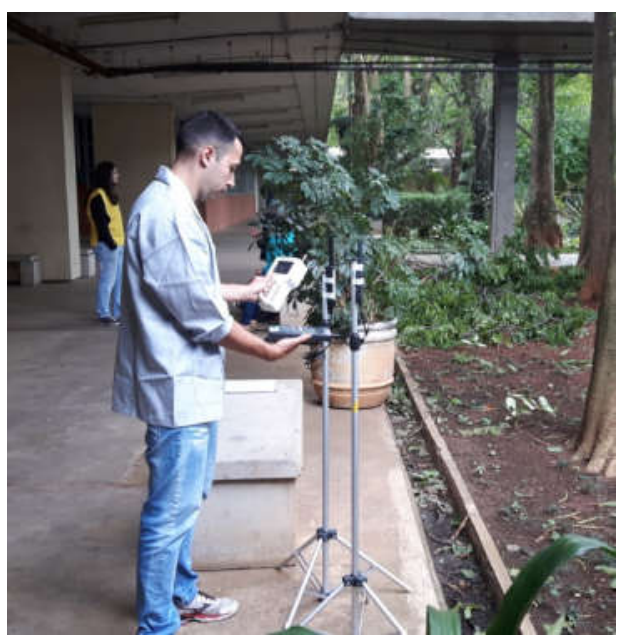

Figura 3.16. Instrumentação utilizada e posição de medição no ar externo

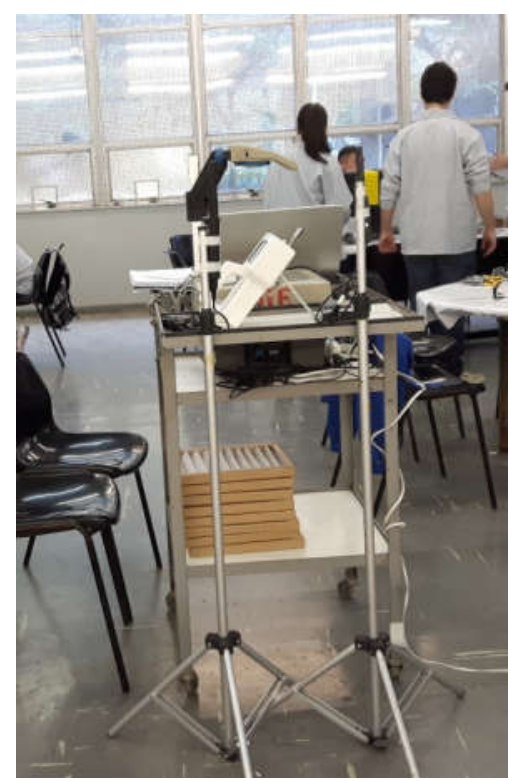

Figura 3.17. Instrumentação utilizada e posição de medição na sala A2. 


\subsection{Análise de incertezas}

Este item trata da análise das incertezas das medições realizadas. Informações relativas à exatidão e resolução dos instrumentos utilizados são descritas no item 3.3.

Para realização da análise das incertezas foi utilizado o Guia para a expressão de incerteza de medição do INMETRO (INMETRO, 2012).

Segundo o INMETRO (2012), a incerteza de medição é um parâmetro que está associado ao resultado de uma medição. Este parâmetro caracteriza a dispersão dos valores que podem ser atribuídos ao mensurando.

Dois métodos de avaliação de incerteza são discutidos no guia do INMETRO, que podem ser do tipo A e do tipo B. A avaliação do tipo A utiliza-se de uma análise estatística de uma série de observações. A avaliação do tipo B é realizada por outros meios que não sejam a análise estatística. (INMETRO, 2012).

Como os parâmetros avaliados durante as medições realizadas na sala de aula não possuem um comportamento definido, podendo variar com qualquer modificação da atividade desempenhada pelos ocupantes do ambiente, utilizou-se apenas da análise de incerteza do tipo B para avaliação das medidas. Outrossim, nenhuma medida com concentrações controladas foi realizada para obtenção da incerteza do tipo A.

Para a determinação da incerteza do tipo B, o parâmetro utilizado foi a exatidão dos instrumentos, conforme descrito no item 3.3.

Segundo o INMETRO (2012), pode ser possível afirmar que a probabilidade de que um valor medido esteja dentro de um intervalo $a$ - até $a+$ seja igual a um, e a probabilidade de estar fora dele ser zero. Sendo assim, se não há conhecimento sobre os valores possíveis medidos dentro do intervalo, pode-se supor que os valores medidos estejam em qualquer lugar dentro deste intervalo. Para o caso, utilizou-se uma distribuição, a priori, retangular dos valores medidos dentro do intervalo. Dessa forma, a incerteza do tipo B $\left(u_{B}\right)$ pode ser escrita como:

$$
u_{B}^{2}=\frac{\left(a_{+}-a_{-}\right)^{2}}{12}
$$


Se a diferença entre os limites, $a+$ e $a$ - for designado por $2 a$, então a equação (4) torna-se:

$$
u_{B}^{2}=\frac{a^{2}}{3}
$$

Utilizando-se dos valores da exatidão dos instrumentos do item 3.3 e da equação (5), a incerteza do tipo B dos instrumentos calculada pode ser observada na tabela a seguir.

Tabela 3.9. Valores de incerteza do tipo B

\begin{tabular}{|c|c|c|}
\hline Instrumento & \multicolumn{2}{|c|}{ Incerteza do tipo B } \\
\hline Contador de partículas & \multicolumn{2}{|c|}{ $\pm 2,9 \%$ do valor medido } \\
\hline Medidor de $\mathrm{CO}_{2}$ & \multicolumn{2}{|c|}{$\pm(43 \mathrm{ppm}+1,7 \%$ do valor medido $)$} \\
\hline Termohigrômetro & $\pm 0,29^{\circ} \mathrm{C}$ & $\pm 1,1 \%$ de UR do valor medido \\
\hline
\end{tabular}

Os valores das incertezas dos instrumentos apresentadas acima podem ser alterados de acordo com o nível de confiança adotado. Para isso, o INMETRO (2012) utiliza-se da incerteza expandida, definindo um intervalo em torno do resultado com o qual se espera abranger uma grande fração da distribuição dos valores, que podem ser atribuídos ao mensurando.

Para as medições realizadas, utiliza-se de uma fator de abrangência sendo igual a 2 (dois), o qual equivale a um nível de confiança de $95,45 \%$. Dessa forma, a incerteza expandida para os instrumentos utilizados pode ser observada na tabela a seguir.

Tabela 3.10. Valores de incerteza expandida com um nível de confiança de $95,45 \%$.

\begin{tabular}{|c|c|c|}
\hline Instrumento & \multicolumn{2}{|c|}{ Incerteza expandida } \\
\hline Contador de partículas & \multicolumn{2}{|c|}{ $\pm 5,8 \%$ do valor medido } \\
\hline Medidor de $\mathrm{CO}_{2}$ & \multicolumn{2}{|c|}{$\pm(86 \mathrm{ppm}+3,4 \%$ do valor medido $)$} \\
\hline Termohigrômetro & $\pm 0,58^{\circ} \mathrm{C}$ & $\pm 2,2 \%$ de UR do valor medido \\
\hline
\end{tabular}




\section{RESULTADOS DAS MEDIÇÕES E DISCUSSÃO DOS PARÂMETROS}

Neste capítulo são apresentados os dados obtidos durante as medições realizadas na sala de aula A2. Durante as medições, a vazão de ar externo era variada de acordo com o experimento proposto, quando do aumento da concentração de particulados no interior da sala de aula, ou em horários fixos. Uma programação prévia do horário, para o aumento da vazão de renovação, não era possível de ser realizada, pois as atividades realizadas internamente, as quais aumentavam a concentração de material particulado, não podiam ser previstas.

Os resultados foram separados para aulas teóricas $(\mathrm{T})$ e aulas práticas $(\mathrm{P})$. A separação devese ao fato de que, nas aulas práticas, ocorre uma geração diferente de particulados através dos processos de usinagem e fabricação de protótipos.

As incertezas dos instrumentos utilizados nas medições foram ser desprezadas, tendo em vista que as concentrações dos poluentes obtidas foram altas, não interferindo na análise dos resultados.

\subsection{Medições na sala de aula A2 durante aulas práticas}

Nos itens a seguir apresentam-se os dados obtidos em medições realizadas durante aulas com atividades práticas (similares a laboratórios) no interior da sala de aula A2, e uma análise destes dados. As medições que possuiam atividade prática ocorreram em cinco dias distintos. As tabelas com os valores obtidos, para cada parâmetro, podem ser visualizadas no Anexo G.

\subsubsection{Medição P1 - Sábado (21/05/16) - Oficina de Brinquedos}

A primeira medição na sala de aula A2 ocorreu no dia 21/05/2016 (sábado) durante uma atividade teórica e prática realizada pelo Programa Poli Cidadã em parceria com o CAM (Centro Acadêmico da Mecânica e Mecatrônica). Esta atividade denominada "Oficina de Brinquedos" é realizada por alunos da Escola Politécnica da Universidade de São Paulo (EPUSP) com objetivo de auxiliar crianças a manufaturar um braço hidráulico. As medições, durante a atividade, foram realizadas no período das $10 \mathrm{~h} 00$ às $16 \mathrm{~h} 00$ do dia 21 de maio, sábado. 
Para esta medição, as janelas da sala de aula foram mantidas fechadas e a porta aberta durante todo o experimento. As medidas dos parâmetros internos e externos foram tomadas a cada 10 minutos. A vazão de ar externo foi variada de acordo com a tabela a seguir.

Tabela 4.1. Variação da vazão de ar externo para a medição P1.

\begin{tabular}{|c|c|}
\hline Intervalo & Vazão $\left(\mathbf{m}^{\mathbf{3}} / \mathbf{h}\right)$ \\
\hline $10 \mathrm{~h} 00$ às $14 \mathrm{~h} 15$ & 1100 \\
\hline $14 \mathrm{~h} 20$ às $15 \mathrm{~h} 00$ & 1658 \\
\hline $15 \mathrm{~h} 10$ às $16 \mathrm{~h} 00$ & 1100 \\
\hline
\end{tabular}

Durante a atividade, alguns instrutores (alunos da EPUSP) entravam e saiam da sala mantendo uma média aproximada de 44 pessoas no interior da sala de aula. Atividades de usinagem (lixamento e furação de madeira) foram realizadas pelos alunos durante a oficina.

As imagens a seguir mostram os alunos e os instrutores durante a atividade do Programa Poli Cidadã.

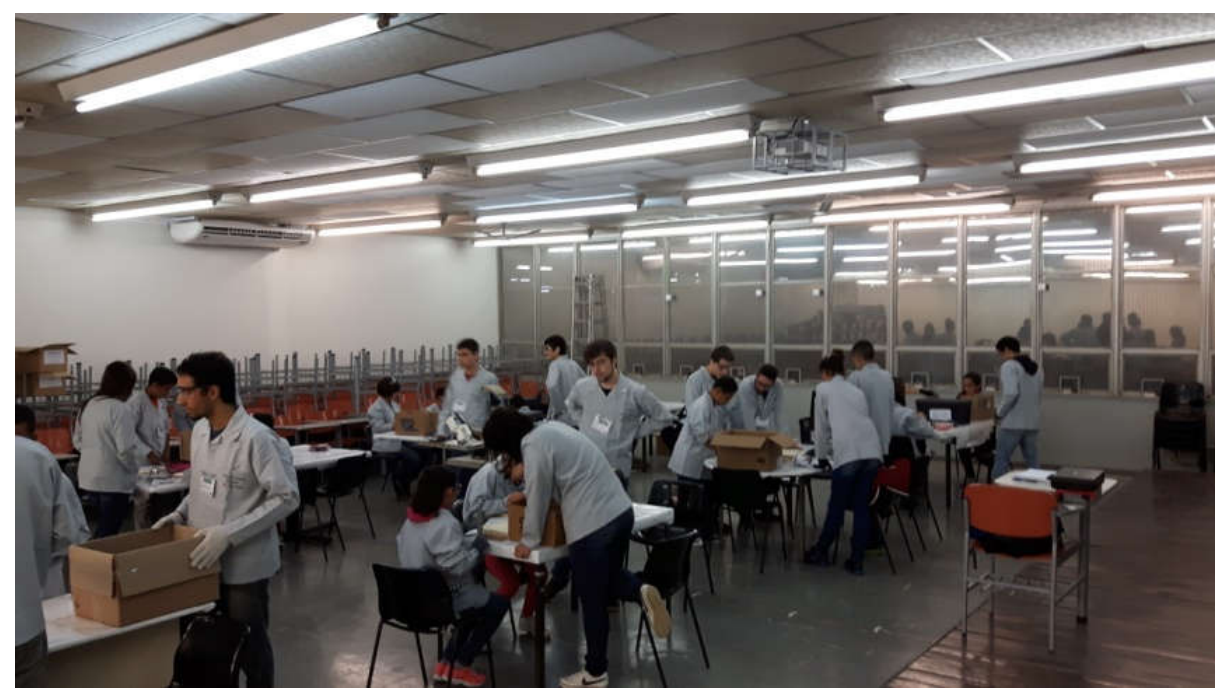

Figura 4.1. Alunos e instrutores durante a atividade na Oficina de Brinquedos. 


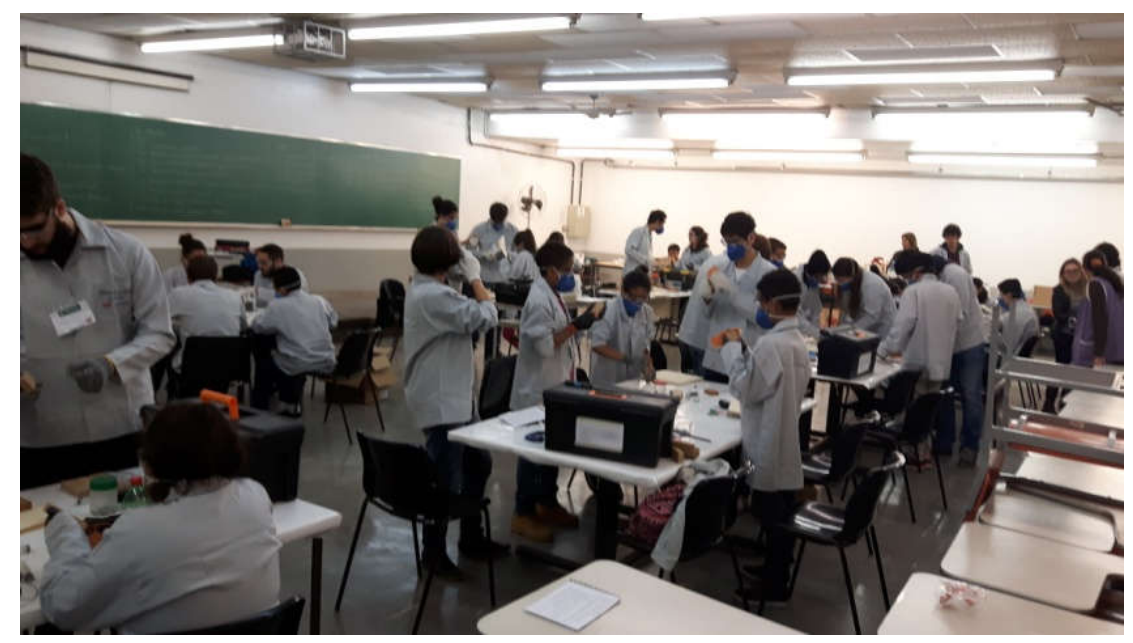

Figura 4.2. Alunos e instrutores realizando atividade de usinagem na Oficina de Brinquedos.

Os dados obtidos na medição prática $\mathrm{P} 1$ para a concentração de $\mathrm{CO}_{2}, \mathrm{PM}_{10}, \mathrm{PM}_{2,5}$ e TBS e UR podem ser observados nas figuras 4.3, 4.4, 4.5 e 4.6, respectivamente.

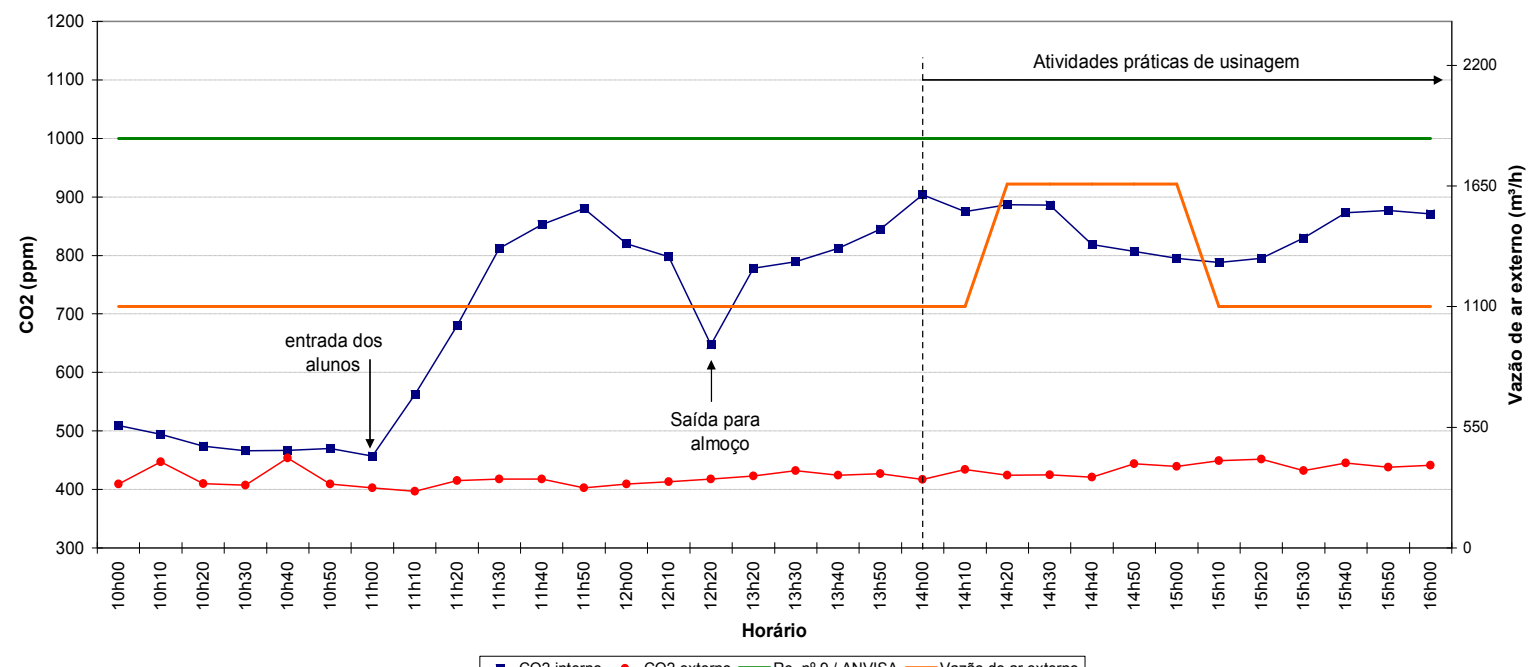

Figura 4.3. Concentração de $\mathrm{CO}_{2}$ - Oficina de Brinquedos (21/05/2016).

Nota-se que em nenhum momento a concentração de $\mathrm{CO}_{2}$ no interior do ambiente ultrapassou os 1000 ppm sugeridos pela resolução da ANVISA. Percebe-se, no entanto, o aumento da 
concentração de $\mathrm{CO}_{2}$ a partir do momento em que a sala torna-se ocupada, indicando a presença de uma fonte geradora de $\mathrm{CO}_{2}$.

Tendo em vista que quanto maior o metabolismo do indivíduo, maior a quantidade de $\mathrm{CO}_{2}$ que ele exala (figura 3.7), espera-se que ocorra um aumento na concentração de $\mathrm{CO}_{2}$ quando do desenvolvimento de atividades de usinagem. Este fato foi verificado por Bordini (2015) nas suas medições na sala de aula A2 porém apenas com ventilação natural pelas janelas e portas. Na presente medição verifica-se que o aumento da vazão de ar externo foi suficiente para diminuir em aproximadamente $100 \mathrm{ppm}$ a concentração de $\mathrm{CO}_{2}$ no interior da sala, mesmo com o desenvolvimento das atividades de usinagem, ou seja, aumento do metabolismo dos ocupantes.

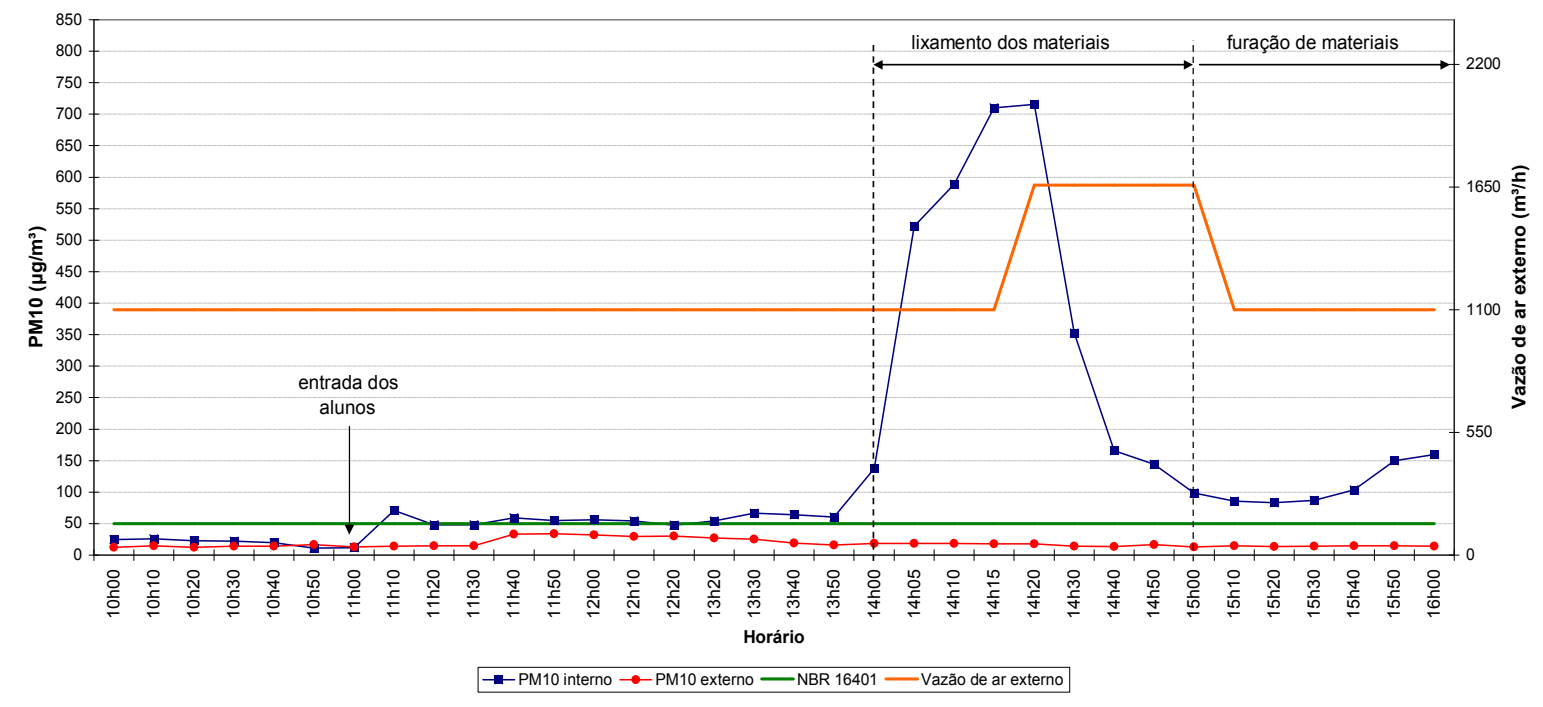

Figura 4.4. Concentração de $\mathrm{PM}_{10}$ - Oficina de Brinquedos (21/05/2016).

Para a concentração de particulado $\mathrm{PM}_{10}$ (figura 4.4) nota-se que as concentrações sempre se encontraram próximas ao limite aceitável de $50 \mu \mathrm{g} / \mathrm{m}^{3}$ pela NBR 16401 (ABNT, 2008) antes das atividades de usinagem. No entanto, quando do início das atividades de usinagem, as concentrações de $\mathrm{PM}_{10}$ chegaram em quatorze vezes o limite aceitável. Verifica-se que o aumento da vazão de ar externo (de $1100 \mathrm{~m}^{3} / \mathrm{h}$ para $1650 \mathrm{~m}^{3} / \mathrm{h}$ aproximadamente) foi suficiente para diminuir em aproximadamente $86 \%$, após 40 minutos do aumento da vazão, a 
concentração de $\mathrm{PM}_{10}$ no interior da sala de aula $\mathrm{A} 2$, mesmo com as atividades de usinagem mantidas.

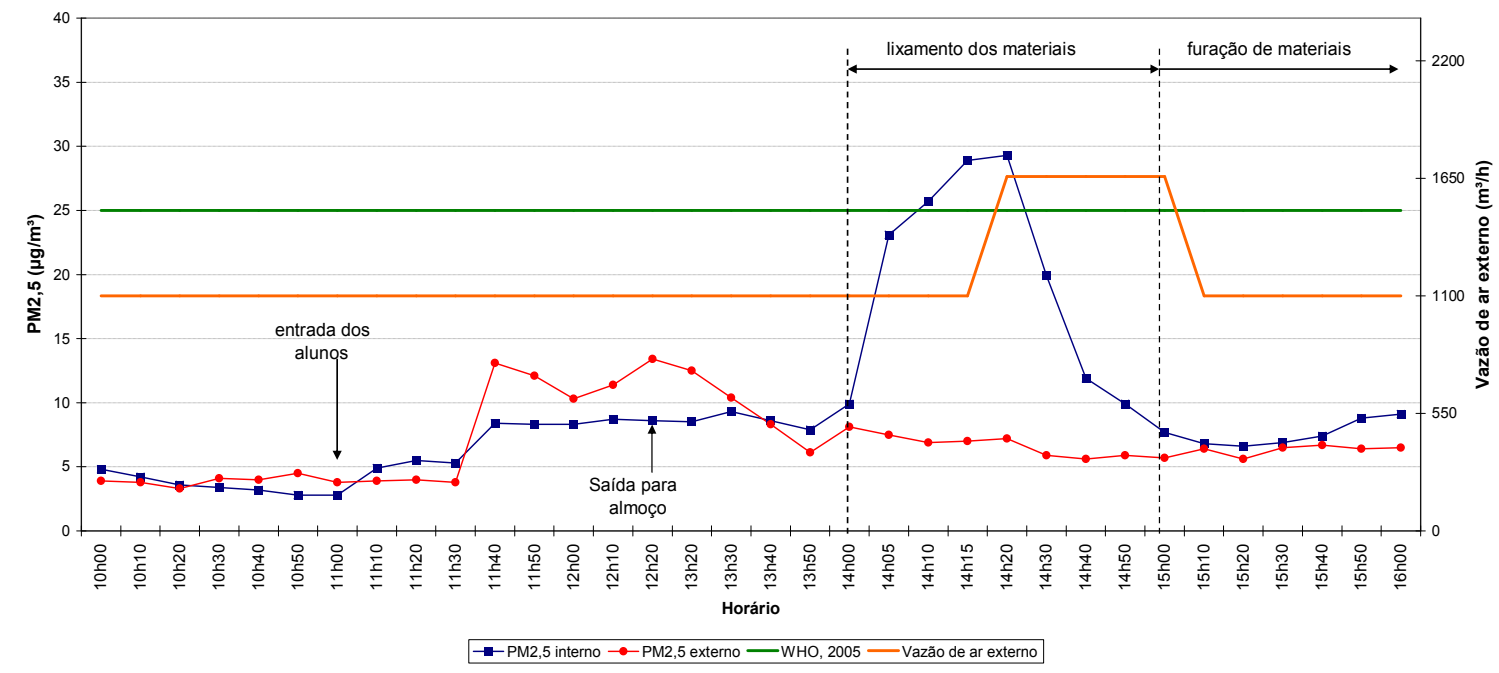

Figura 4.5. Concentração de $P M_{2,5}$ - Oficina de Brinquedos (21/05/2016)

Para a concentração de particulado $\mathrm{PM}_{2,5}$ (figura 4.5), os dados se apresentaram abaixo do limite aceitável de $25 \mu \mathrm{g} / \mathrm{m}^{3}$ pela Organização Mundial da Saúde (World Health Organization, 2005) antes das atividades de usinagem. Após o início das atividades de usinagem, as concentrações de $\mathrm{PM}_{2,5}$ chegaram a ultrapassar o limite aceitável em aproximadamente 20\%. Assim como foi constatado com o PM $_{10}$, verificou-se que com o aumento da vazão de ar externo (de $1100 \mathrm{~m}^{3} / \mathrm{h}$ para $1650 \mathrm{~m}^{3} / \mathrm{h}$ aproximadamente), as concentrações de $\mathrm{PM}_{2,5}$ no interior da sala de aula A2 diminuiram em aproximadamente 73\%, após 40 minutos do aumento da vazão, e ficaram dentro do limite aceitável, mesmo com as atividades de usinagem mantidas. Algo importante que não se verificou no estudo de Bordini (2015), já que ele utilizou apenas ventilação natural, é a influência dos filtros na tomada de ar externo. Podese observar que, em alguns momentos, a concentração de material particulado no interior do ambiente era menor do que a do ar externo, mesmo com geração interna de particulados. 


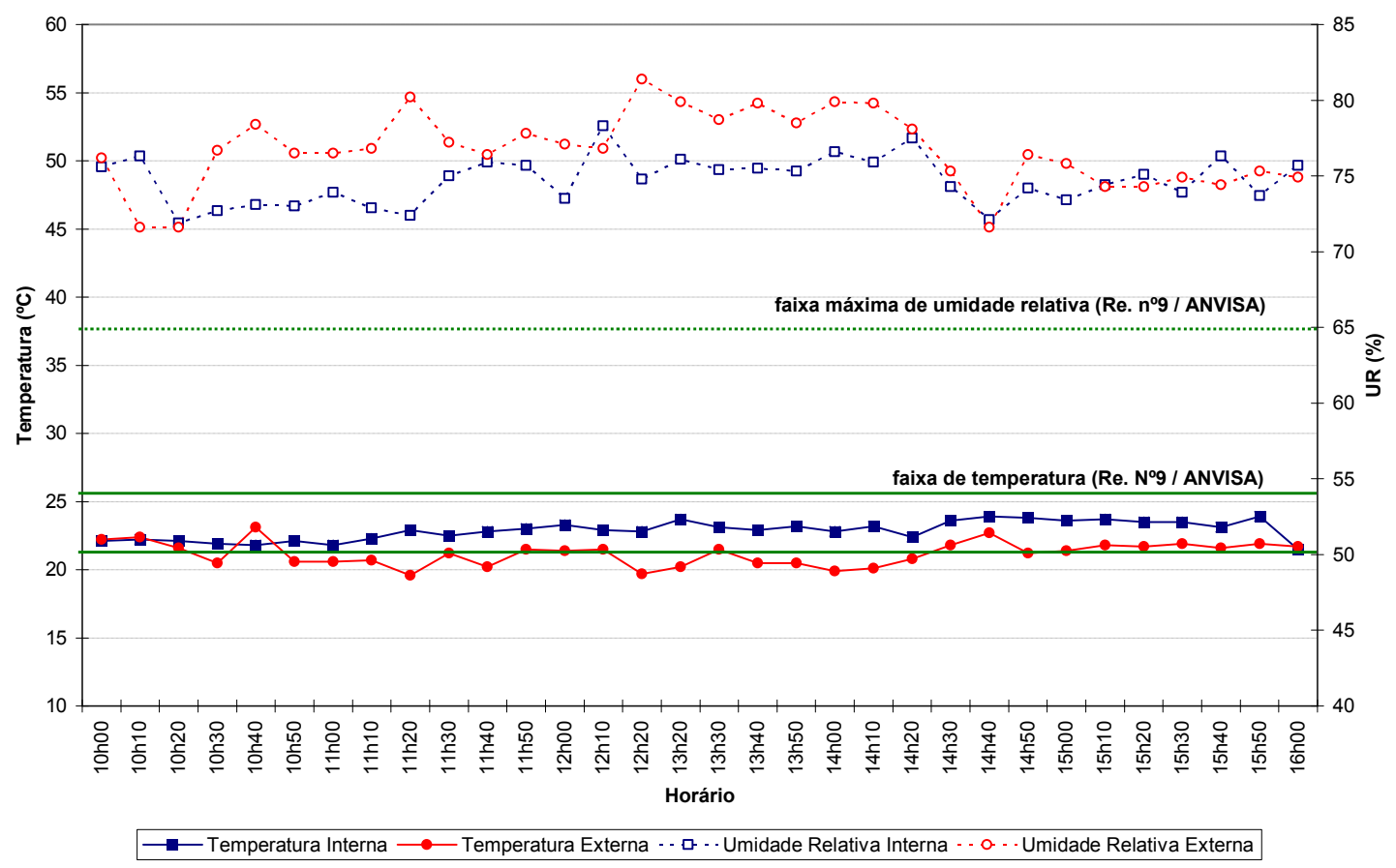

Figura 4.6. Temperatura e umidade relativa - Oficina de Brinquedos (21/05/2016).

Verifica-se na figura 4.6 que a temperatura no interior da sala de aula se manteve adequada durante todo o experimento. A umidade relativa, por sua vez, ficou bem acima do imposto na resolução número 9 da ANVISA.

\subsubsection{Medição P2 - Sábado (11/06/16) - Oficina de Robótica}

A segunda medição na sala de aula A2 ocorreu no dia 11/06/2016 (sábado) durante uma atividade teórica e prática realizada para alunos surdos em linguagem de sinais, libra. A mesma, denominada "Oficina de Robótica", possuia uma parte teórica sobre engenharia elétrica e, posteriormente, era manufaturado um carrinho. As medições foram realizadas no período das 8 horas às 13 horas e 20 minutos do sábado.

Para esta medição, as janelas da sala de aula foram mantidas fechadas e a porta aberta durante todo o experimento. Da mesma forma que a primeira medição, as medidas dos parâmetros internos e externos foram tomadas a cada 10 minutos. A vazão de ar externo foi variada de acordo com a tabela a seguir. 
Tabela 4.2. Variação da vazão de ar externo para a medição P2.

\begin{tabular}{|c|c|}
\hline Intervalo & Vazão $\left(\mathbf{m}^{\mathbf{3}} / \mathbf{h}\right)$ \\
\hline $08 \mathrm{~h} 00$ às $09 \mathrm{~h} 50$ & 0 \\
\hline $10 \mathrm{~h} 00$ às $10 \mathrm{~h} 50$ & 558 \\
\hline $11 \mathrm{~h} 00$ às $11 \mathrm{~h} 40$ & 1100 \\
\hline $11 \mathrm{~h} 50$ às $12 \mathrm{~h} 20$ & 2200 \\
\hline $12 \mathrm{~h} 30$ às $13 \mathrm{~h} 20$ & 558 \\
\hline
\end{tabular}

O número de ocupantes no interior da sala de aula foi de 12 pessoas durante o experimento. Atividades de usinagem foram realizadas pelos alunos durante a oficina para confecção do carrinho.

As imagens a seguir mostram os alunos e os instrutores durante a atividade da Oficina de Robótica.

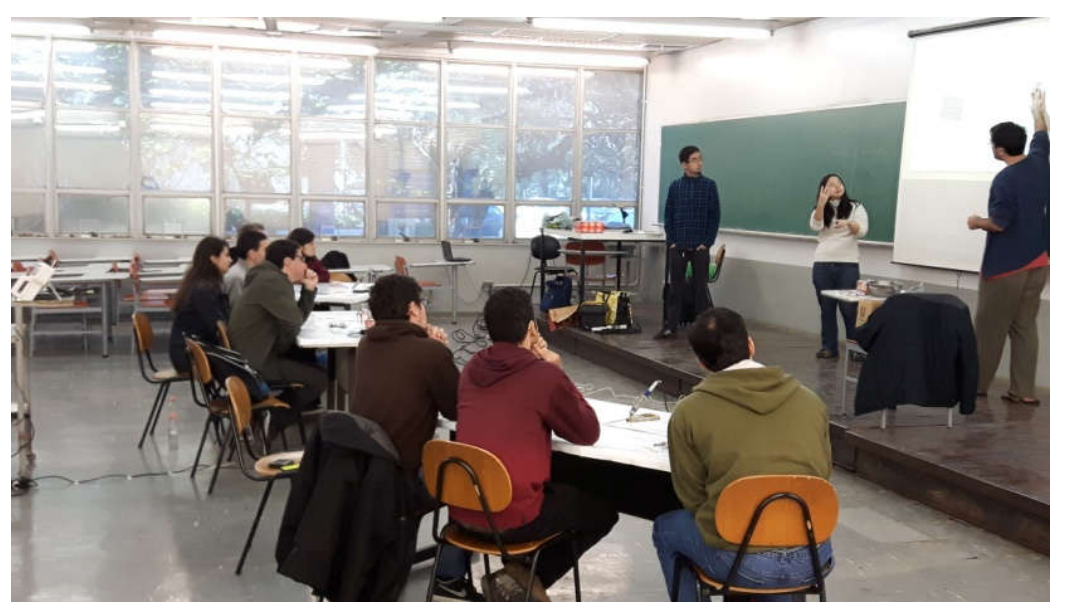

Figura 4.7. Alunos e instrutores durante a aula teórica da Oficina de Robótica. 


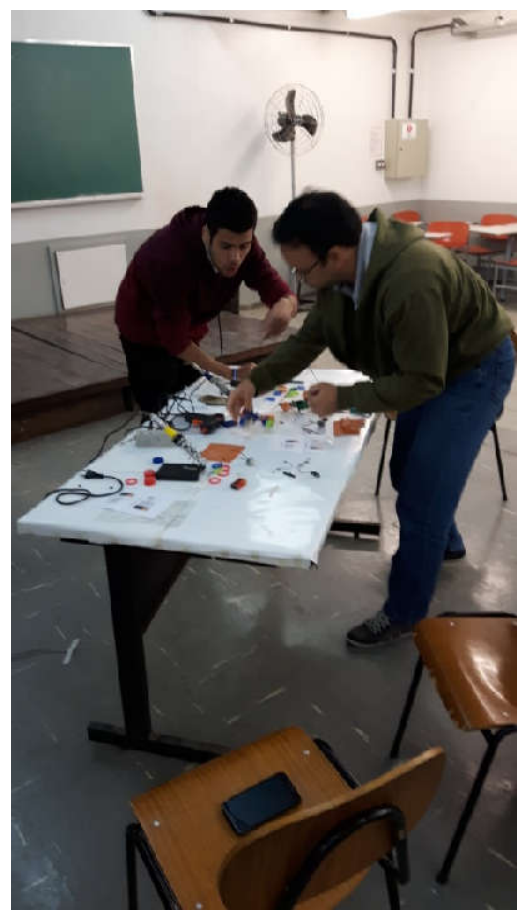

Figura 4.8. Alunos durante a atividade prática na Oficina de Robótica.

Os dados obtidos na medição prática P2 para a concentração de $\mathrm{CO}_{2}, \mathrm{PM}_{10}, \mathrm{PM}_{2,5}$ e TBS e UR podem ser observados nas figuras 4.9, 4.10, 4.11 e 4.12, respectivamente.

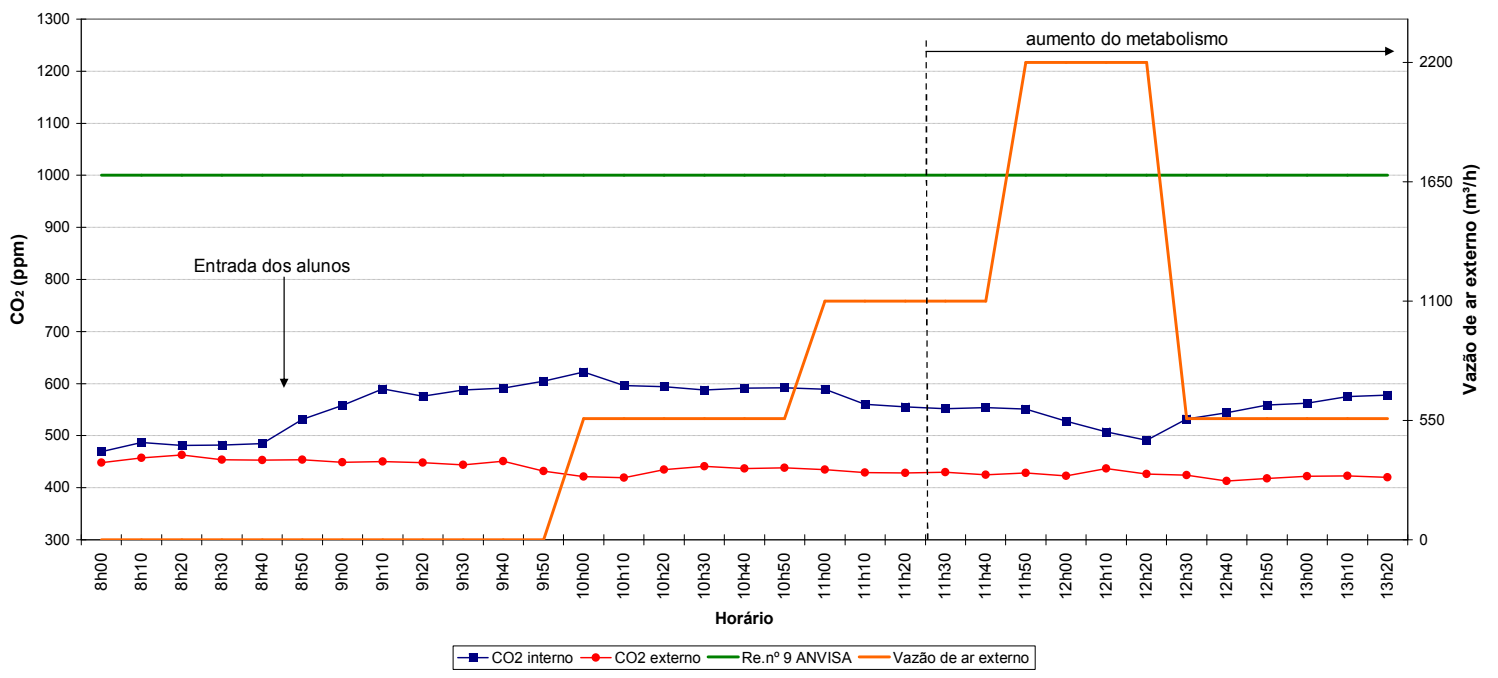

Figura 4.9. Concentração de $\mathrm{CO}_{2}$ - Oficina de Robótica (11/05/2016). 
Da mesma forma que a primeira medição, a concentração de $\mathrm{CO}_{2}$ no interior do ambiente, em nenhum momento ultrapassou os 1000 ppm sugeridos pela resolução da ANVISA. Percebe-se o aumento da concentração de $\mathrm{CO}_{2}$ a partir do momento em que a sala torna-se ocupada, indicando a presença de uma fonte geradora de $\mathrm{CO}_{2}$.

Como visto anteriormente, quanto maior o metabolismo do indivíduo, maior a quantidade de $\mathrm{CO}_{2}$ que ele exala (figura 3.7). Na segunda medição fica evidente este fato, sendo que a partir do momento em que a vazão é diminuída para aproximadamente $550 \mathrm{~m} / \mathrm{h}$, após passar um período em $2200 \mathrm{~m}^{3} / \mathrm{h}$, a concentração de $\mathrm{CO}_{2}$ aumenta para níveis que encontrava-se no ínicio do experimento (vazão de ar externo inexistente), porém com os ocupantes já no interior da sala. Da mesma forma que na primeira medição, verifica-se que o aumento da vazão de ar externo foi suficiente para diminuir em aproximadamente 100 ppm a concentração de $\mathrm{CO}_{2}$ no interior da sala, mesmo com o aumento do metabolismo dos ocupantes.

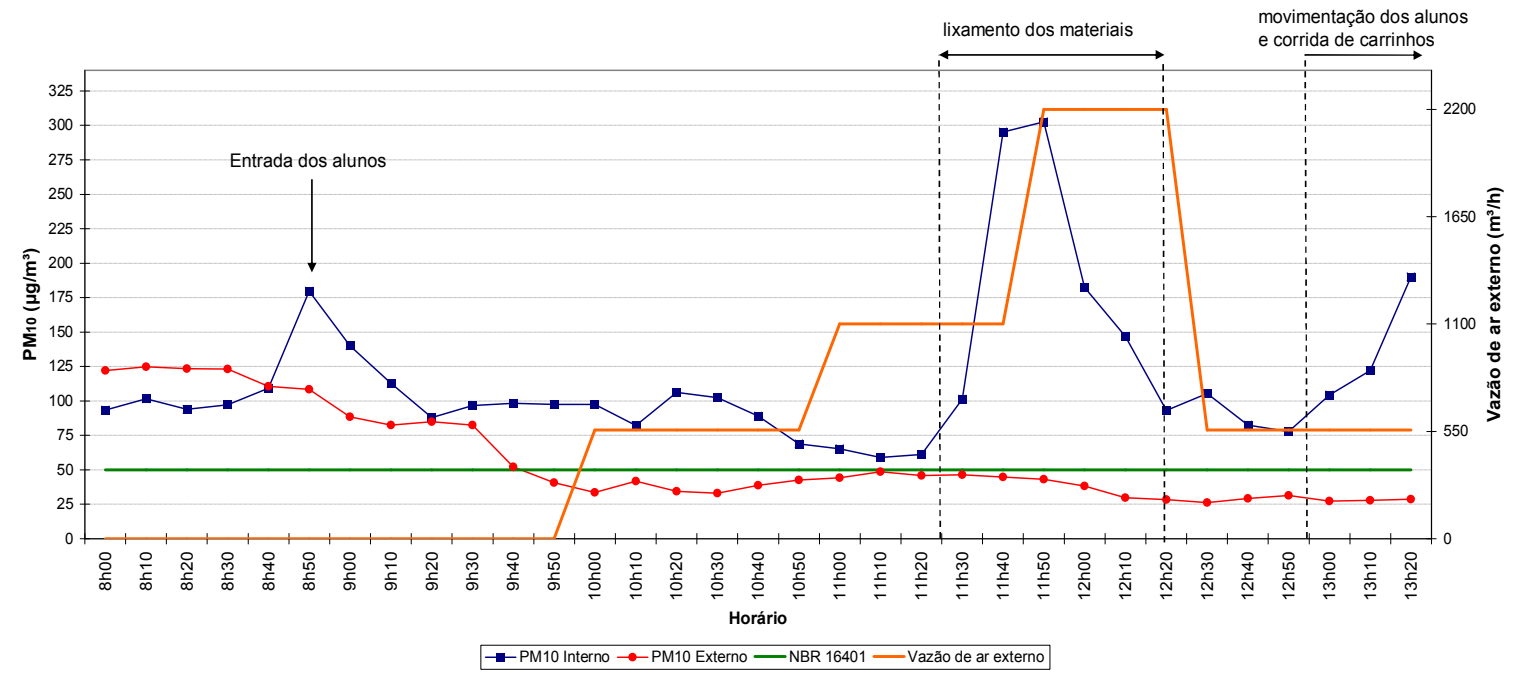

Figura 4.10. Concentração de $P M_{10}$ - Oficina de Robótica (11/06/2016).

Para a concentração de particulado $\mathrm{PM}_{10}$ (figura 4.10) foram verificadas concentrações bem acima do limite aceitável de $50 \mu \mathrm{g} / \mathrm{m}^{3}$ pela NBR 16401 (ABNT, 2008) desde o início do experimento. Nota-se que a concentração de $\mathrm{PM}_{10}$ no ar externo já estava elevada, fazendo com que as taxas internas se mantivessem altas, quando a vazão de ar externo era inexistente. Antes do início das atividades de usinagem, quando a vazão foi elevada para $1100 \mathrm{~m}^{3} / \mathrm{h}$, verificou-se que a concentração de $\mathrm{PM}_{10}$ se aproximou do limite aceitável, mostrando que, 
provavelmente, o limite de $50 \mu \mathrm{g} / \mathrm{m}^{3}$ seria atingido mesmo se a atividade de usinagem não ocorresse naquele momento. Quando foram iniciadas as atividades de usinagem, as concentrações de $\mathrm{PM}_{10}$ chegaram em seis vezes o limite aceitável. Constatou-se que o aumento da vazão de ar externo para $2200 \mathrm{~m}^{3} / \mathrm{h}$ foi suficiente para diminuir em aproximadamente $69 \%$, após 30 minutos do aumento da vazão, a concentração de $\mathrm{PM}_{10}$ no interior da sala de aula mesmo com as atividades de usinagem sendo mantidas. Nota-se que com a diminuição da vazão no final da aula e com a movimentação dos alunos, a concentração de $\mathrm{PM}_{10}$ aumenta em aproximadamente 2,5 vezes em 30 minutos.

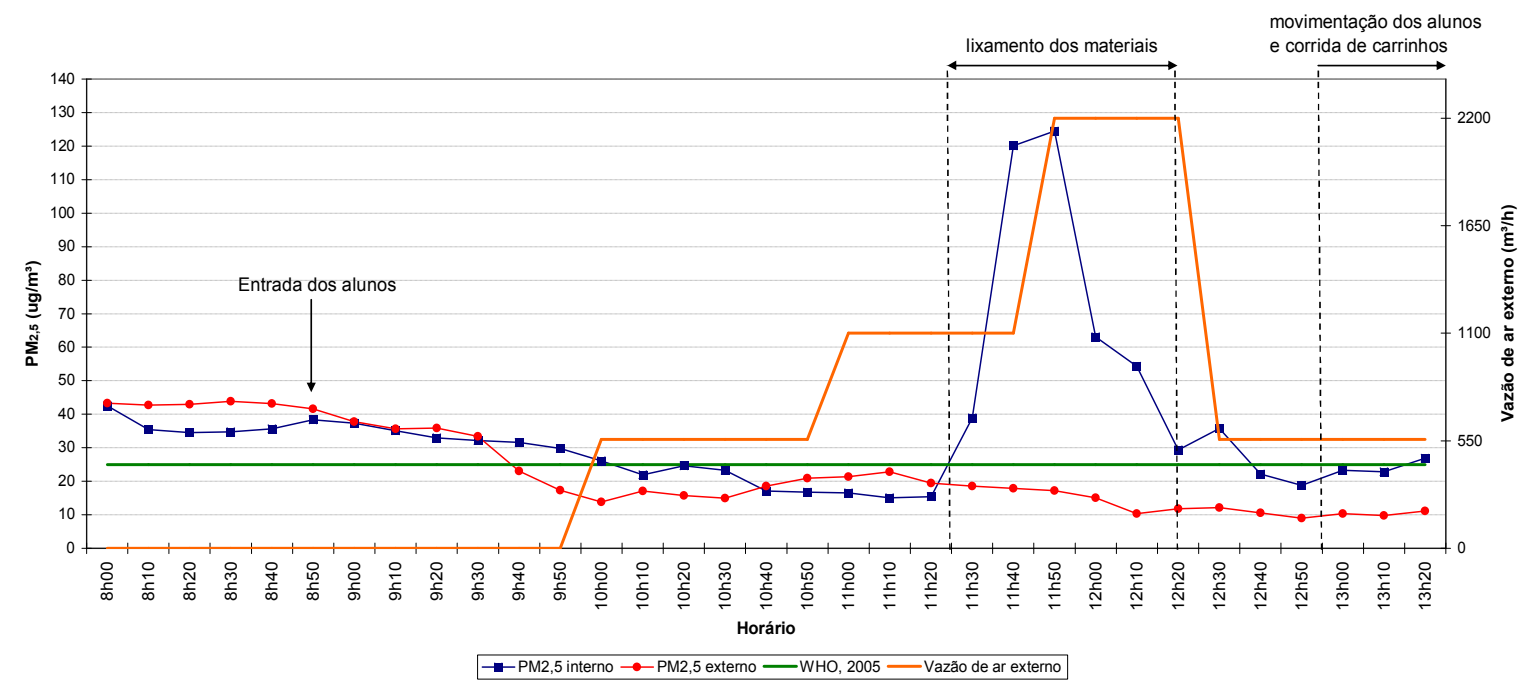

Figura 4.11. Concentração de $\mathrm{PM}_{2,5}$ - Oficina de Robótica (11/06/2016)

Da mesma forma que a concentração de $\mathrm{PM}_{10}$, a concentração de particulado $\mathrm{PM}_{2,5}$ (figura 4.11) apresentou-se acima do limite aceitável de $25 \mu \mathrm{g} / \mathrm{m}^{3}$ pela Organização Mundial da Saúde (World Health Organization, 2005) no início do experimento. Porém, com o insuflamento de ar externo com tratamento no interior do ambiente, a concentração de $\mathrm{PM}_{2,5}$ se manteve dentro do limite aceitável. Quando a vazão foi aumentada para $1100 \mathrm{~m}^{3} / \mathrm{h}$ antes do início das atividades de usinagem, constata-se que a concentração de $\mathrm{PM}_{2,5}$ atinge valores, inclusive, abaixo da concentração do ar externo, ficando evidente a influência dos filtros na tomada do ar externo. Verificou-se também que, com o aumento da vazão de ar externo para $2200 \mathrm{~m}^{3} / \mathrm{h}$, as concentrações de $\mathrm{PM}_{2,5}$ diminuiram em aproximadamente $76 \%$ após 30 minutos do aumento da vazão mesmo com as atividades de usinagem mantidas, aproximando-se do 
limite aceitável. Provavelmente, a concentração do particulado em questão atingiria valores abaixo do limite de $25\left[\mu \mathrm{g} / \mathrm{m}^{3}\right]$, caso a vazão de ar externo de $2200 \mathrm{~m} / \mathrm{h}$ fosse mantida.

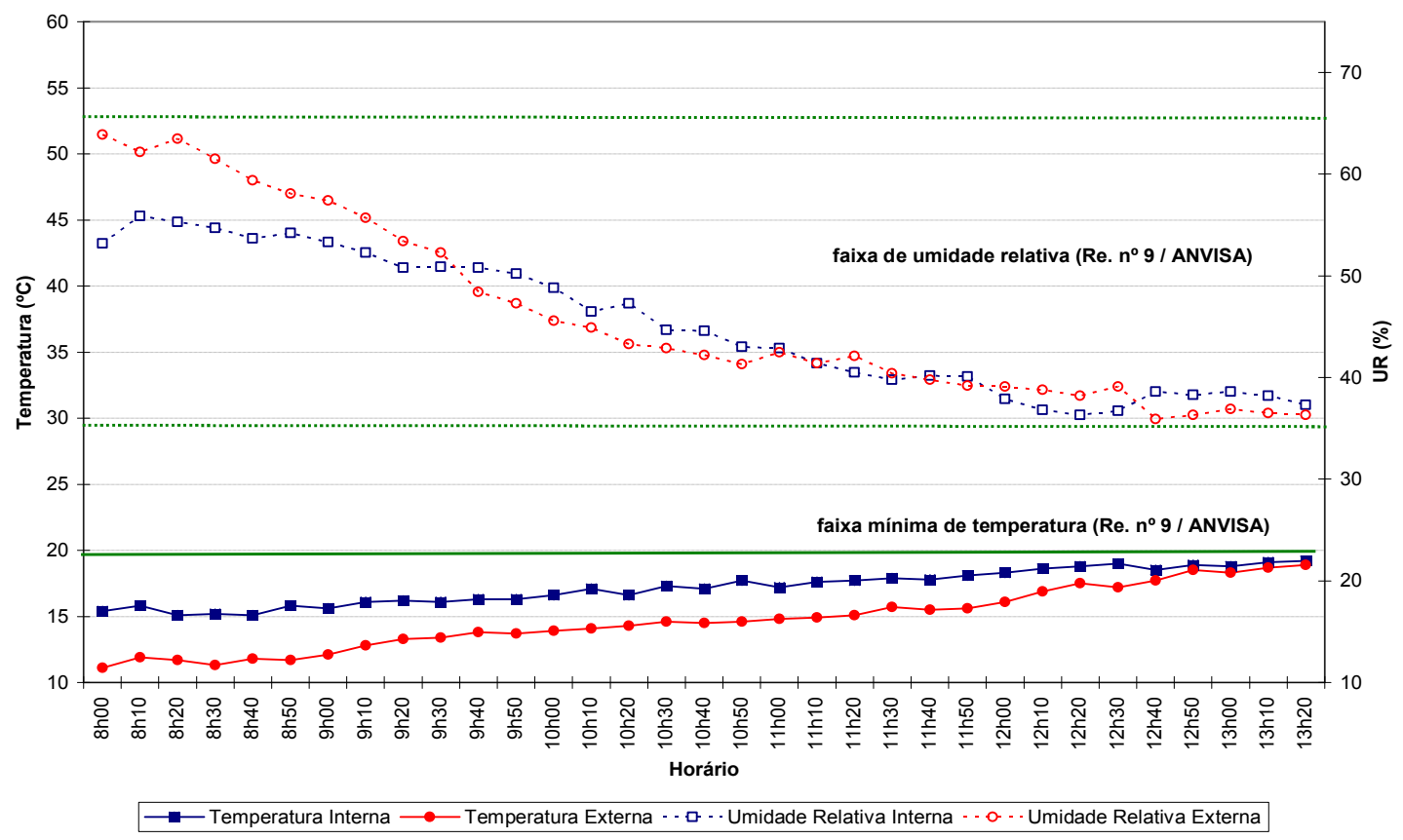

Figura 4.12. Temperatura e umidade relativa - Oficina de Robótica (11/06/2016).

Verifica-se na figura 4.12 que a temperatura no interior da sala de aula se manteve abaixo da faixa mínima de temperatura prevista na resolução $\mathrm{n}^{\circ} 9$ da ANVISA. O fato pode ser explicado por um provável mal funcionamento do sistema de aquecimento das unidades de condicionamento de ar durante a realização das medições. A umidade relativa, por sua vez, ficou dentro da faixa prevista na resolução ${ }^{\circ} 9$ da ANVISA.

\subsubsection{Medição P3 - Sexta-feira (21/10/16) - Aula de Eletrônica e arrumação da sala para a Oficina de Carrinhos de Rolimã}

A terceira medição com atividade prática na sala de aula A2 ocorreu no dia 21/10/2016 (sexta-feira) durante a aula de Eletrônica. Após a aula houve a arrumação da sala para a Oficina de Carrinhos de Rolimã que iria ocorrer nos próximos dois dias. Durante a aula de Eletrônica, além da parte teórica, uma atividade de avaliação, prova, ocorreu na segunda metade da aula, fazendo com que os ocupantes diminuíssem o nível de movimentação. As 
medições, durante a aula, foram realizadas no período das 8 horas às 11:30 horas, e logo em seguida iniciou-se a fase de arrumação da sala, com as medições ocorrendo das 11:40 horas às 13:05 horas.

Para esta medição, as janelas e a porta da sala de aula foram mantidas fechadas durante todo a aula. Apenas no período da arrumação, a porta foi mantida aberta para passagem dos tampos de madeira das mesas. As medidas dos parâmetros internos foram tomadas a cada 10 minutos durante a aula de Eletrônica, com apenas 4 medições de ar externo para verificação do comportamento, já que uma prova seria aplicada evitando a saída da sala. Já, durante a arrumação da sala, as medidas eram feitas a cada 5 minutos, apenas internamente. A vazão de ar externo foi variada de acordo com a tabela a seguir.

Tabela 4.3. Variação da vazão de ar externo para a medição P3.

\begin{tabular}{|c|c|}
\hline Intervalo & Vazão $\left(\mathbf{m}^{\mathbf{3}} / \mathbf{h}\right)$ \\
\hline $08 \mathrm{~h} 00$ às $08 \mathrm{~h} 50$ & 0 \\
\hline $09 \mathrm{~h} 00$ às $10 \mathrm{~h} 20$ & 1100 \\
\hline $10 \mathrm{~h} 30$ às $11 \mathrm{~h} 30$ & 2200 \\
\hline $11 \mathrm{~h} 40$ às $12 \mathrm{~h} 05$ & 558 \\
\hline $12 \mathrm{~h} 10$ às $12 \mathrm{~h} 35$ & 1100 \\
\hline $12 \mathrm{~h} 40$ às $13 \mathrm{~h} 05$ & 2200 \\
\hline
\end{tabular}

Durante a aula de Eletrônica, a sala chegou a possuir 138 ocupantes. Já, no período de arrumação, uma pequena parcela de ocupantes estava presente, aproximadamente 19 pessoas. As imagens a seguir mostram os ocupantes durante a arrumação da sala de aula para a Oficina de Carrinhos de Rolimã. 


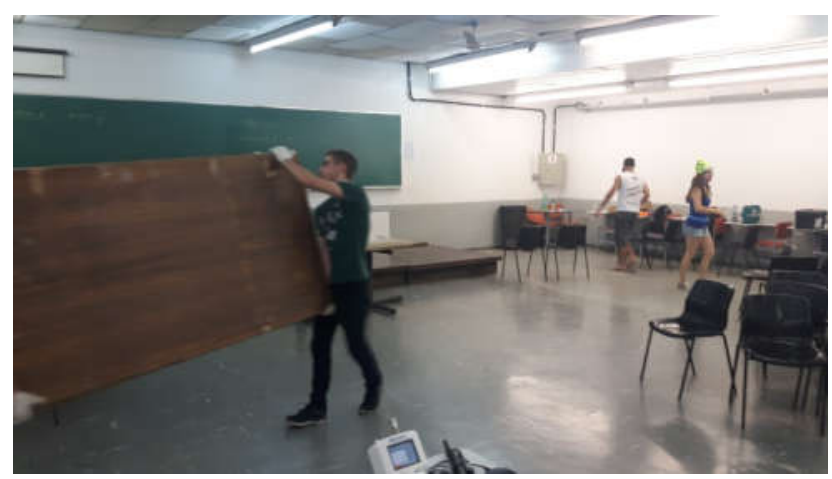

Figura 4.13. Arrumação da sala de aula A2 para a Oficina de Carrinhos de Rolimã.

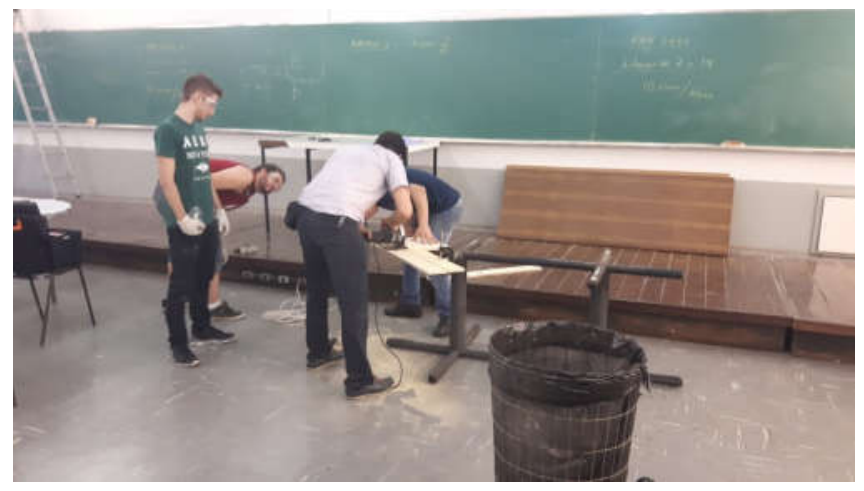

Figura 4.14. Utilização da serra elétrica para confecção dos tampos das mesas.

Os dados obtidos na medição prática $\mathrm{P} 3$ para a concentração de $\mathrm{CO}_{2}, \mathrm{PM}_{10}, \mathrm{PM}_{2,5}$ e TBS e UR podem ser observados nas figuras 4.15, 4.16, 4.17 e 4.18 , respectivamente. 


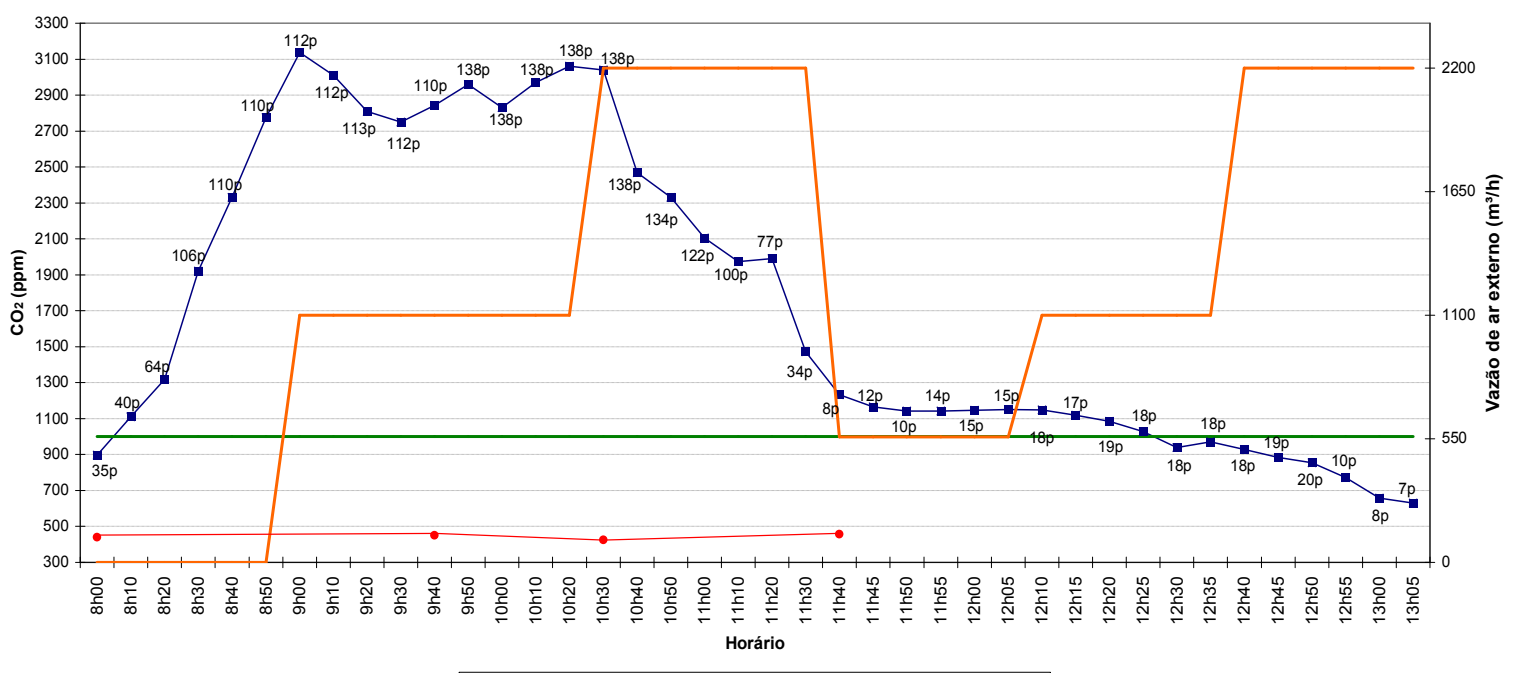

- - CO2 interno $\rightarrow-\mathrm{CO} 2$ externo — Re.n 9 ANVISA — Vazäo de ar externo

Figura 4.15. Concentração de $\mathrm{CO}_{2}$ - Aula de Eletrônica e arrumação da sala (21/10/2016).

O número de pessoas no interior do ambiente é apresentado na figura próxima a cada ponto de medição com a letra "p". Nota-se que a concentração de $\mathrm{CO}_{2}$ no interior do ambiente atingiu valores da ordem de $3100 \mathrm{ppm}$, ultrapassando os $1000 \mathrm{ppm}$ sugeridos pela resolução da ANVISA. Porém, para esse caso, nenhuma unidade de renovação estava em funcionamento, reproduzindo a situação original da sala de aula $\mathrm{A} 2$, sem as unidades de renovação de ar. Percebe-se que, apenas com o acionamento das 4 unidades de ar externo, a concentração de $\mathrm{CO}_{2}$ começa a diminuir. Como a quantidade de ocupantes durante o período da prova é alta (138 pessoas), as 4 unidades de renovação insuflam no ambiente aproximadamente $16 \mathrm{~m}^{3} / \mathrm{h}$ de ar externo por pessoa, como pode ser observado na tabela das medições no Anexo G. 


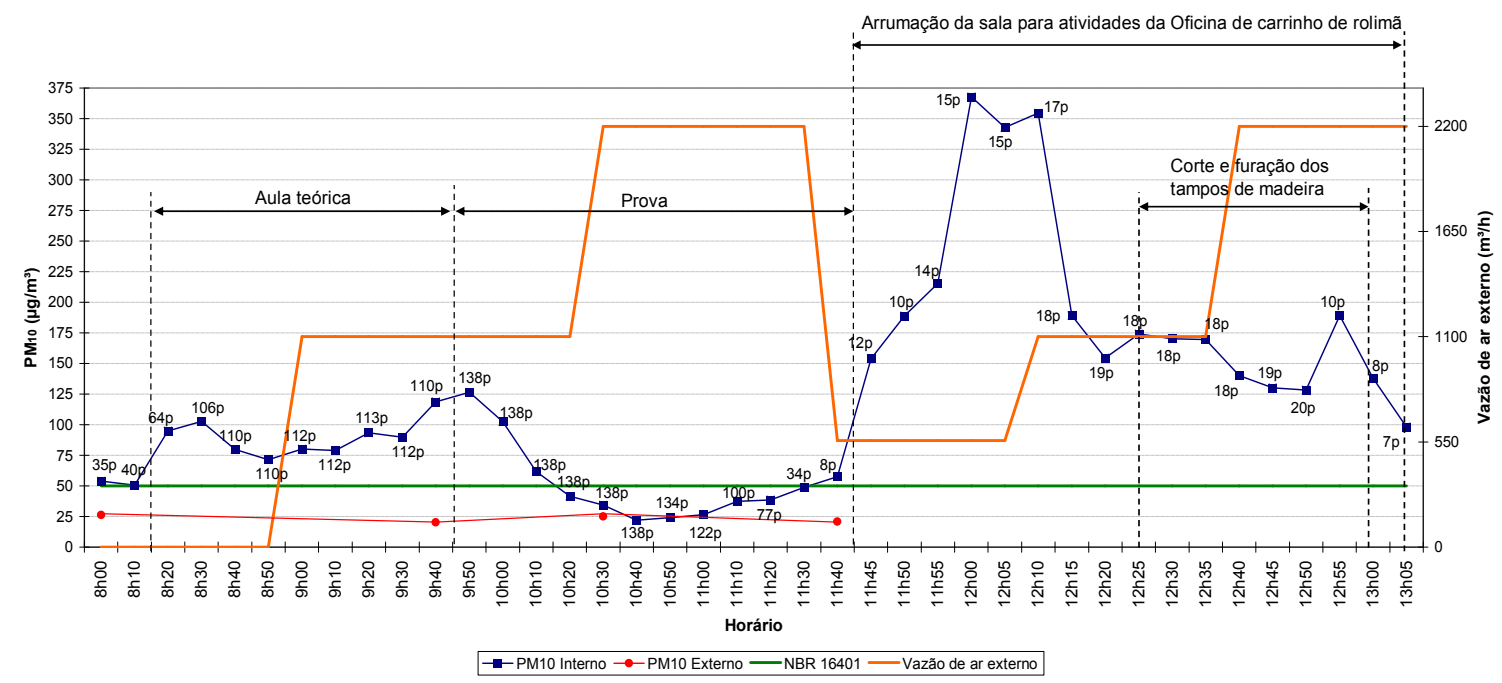

Figura 4.16. Concentração de $\mathrm{PM}_{10}$ - Aula de Eletrônica e arrumação da sala (21/10/2016).

Para a concentração de particulado $\mathrm{PM}_{10}$ (figura 4.16) nota-se que as concentrações estiveram, quase em todo o período, acima do limite aceitável de $50 \mu \mathrm{g} / \mathrm{m}^{3}$ pela NBR 16401 (ABNT, 2008), principalmente durante a arrumação da sala de aula. Apenas durante o período de prova, e com o aumento da vazão de ar externo, verificou-se que a concentração do material particulado $\mathrm{PM}_{10}$ atingiu valores abaixo de $50 \mu \mathrm{g} / \mathrm{m}^{3}$. Quando do início das atividades de usinagem, as concentrações de $\mathrm{PM}_{10}$ atingiram valores de até oito vezes o limite aceitável. No entanto, com o aumento da vazão de ar externo, a concentração de $\mathrm{PM}_{10}$ no interior da sala de aula A2 diminui em aproximadamente 52\% após 30 minutos do aumento da vazão de $558 \mathrm{~m}^{3} / \mathrm{h}$ para $1100 \mathrm{~m}^{3} / \mathrm{h}$, e em aproximadamente $40 \%$ após 30 minutos do aumento da vazão de $1100 \mathrm{~m}^{3} / \mathrm{h}$ para $2200 \mathrm{~m}^{3} / \mathrm{h}$, mesmo com as atividades de usinagem mantidas. 


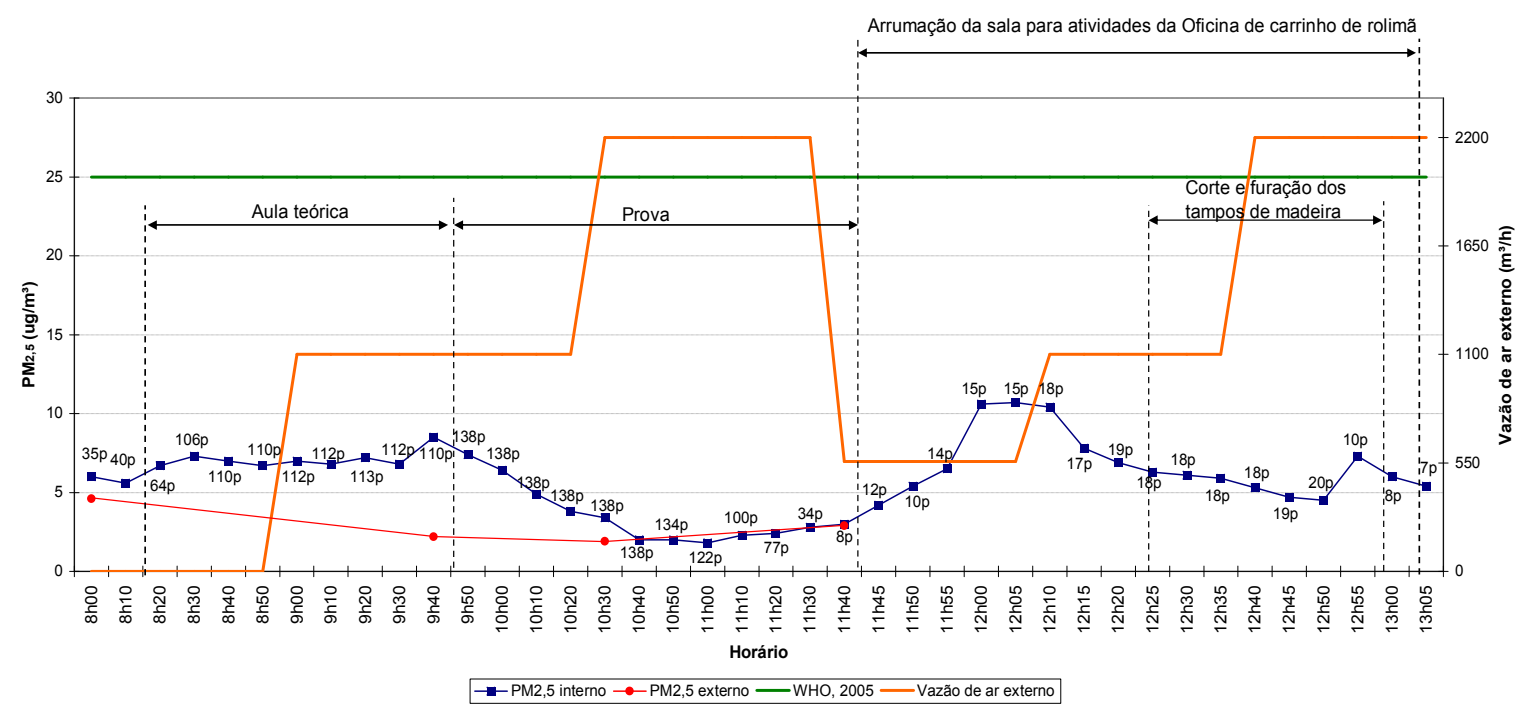

Figura 4.17. Concentração de $\mathrm{PM}_{2,5}$ - Aula de Eletrônica e arrumação da sala (21/10/2016).

Para a concentração de particulado $\mathrm{PM}_{2,5}$ (figura 4.17), os dados se apresentaram bem abaixo do limite aceitável de $25 \mu \mathrm{g} / \mathrm{m}^{3}$ pela Organização Mundial da Saúde (World Health Organization, 2005), mesmo com as atividades de usinagem durante o período de arrumação da sala de aula. É possível verificar a diminuição, em aproximadamente 33\% após 30 minutos do aumento da vazão de $558 \mathrm{~m}^{3} / \mathrm{h}$ para $1100 \mathrm{~m}^{3} / \mathrm{h}$, e em aproximadamente $26 \%$ após 30 minutos do aumento da vazão de $1100 \mathrm{~m}^{3} / \mathrm{h}$ para $2200 \mathrm{~m}^{3} / \mathrm{h}$, da concentração de particulado $\mathrm{PM}_{2,5}$ com o aumento da vazão de ar externo. 


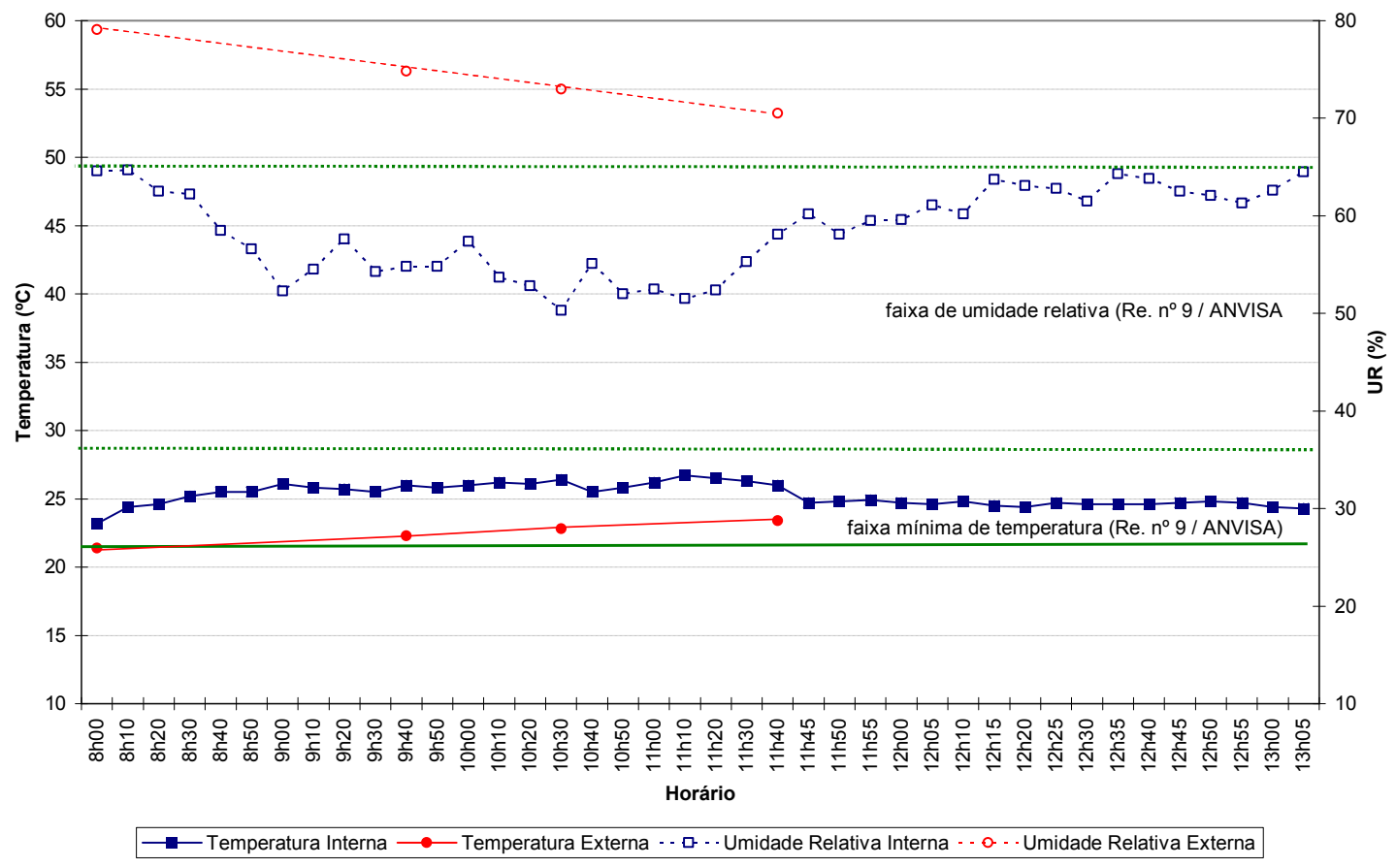

Figura 4.18. Temperatura e umidade relativa - Aula de Eletrônica e arrumação da sala (21/10/2016).

Verifica-se na figura 4.18 que, tanto a temperatura de bulbo seco, como a umidade relativa no interior da sala, mantiveram-se adequadas durante todo o experimento.

\subsubsection{Medição P4 - Sábado (22/10/16) - Oficina de Carrinhos de Rolimã (1º} dia)

A quarta medição com atividade prática na sala de aula A2 ocorreu no dia 22/10/2016 (sábado) durante a Oficina de Carrinhos de Rolimã realizada pelo Programa Poli Cidadã em parceria com o CAM (Centro Acadêmico da Mecânica e Mecatrônica). A atividade empregava alunos voluntários da Escola Politécnica da Universidade de São Paulo (EPUSP) para orientar crianças na manufatura de carrinhos de rolimã durante dois dias. As medições, durante a atividade do sábado, foram realizadas no período das 9:20 horas às 16:50 horas.

Para esta medição, as janelas da sala de aula foram mantidas fechadas e a porta aberta durante todo o experimento. As medidas dos parâmetros internos e externos foram tomadas a cada 10 minutos. A vazão de ar externo foi variada de acordo com a tabela a seguir. 
Tabela 4.4. Variação da vazão de ar externo para a medição P4.

\begin{tabular}{|c|c|}
\hline Intervalo & Vazão $\left(\mathbf{m}^{\mathbf{3}} / \mathbf{h}\right)$ \\
\hline $09 \mathrm{~h} 10$ às $09 \mathrm{~h} 20$ & 2200 \\
\hline $09 \mathrm{~h} 30$ às $14 \mathrm{~h} 00$ & 0 \\
\hline $14 \mathrm{~h} 10$ às $15 \mathrm{~h} 30$ & 1100 \\
\hline $15 \mathrm{~h} 40$ às $16 \mathrm{~h} 50$ & 2200 \\
\hline
\end{tabular}

Durante a atividade, alguns instrutores (alunos da EPUSP) entravam e saíam da sala, mantendo uma média aproximada de 40 pessoas no interior. Atividades de usinagem foram realizadas pelos alunos durante a oficina.

As imagens a seguir mostram os alunos e os instrutores durante a Oficina de Carrinhos de Rolimã.

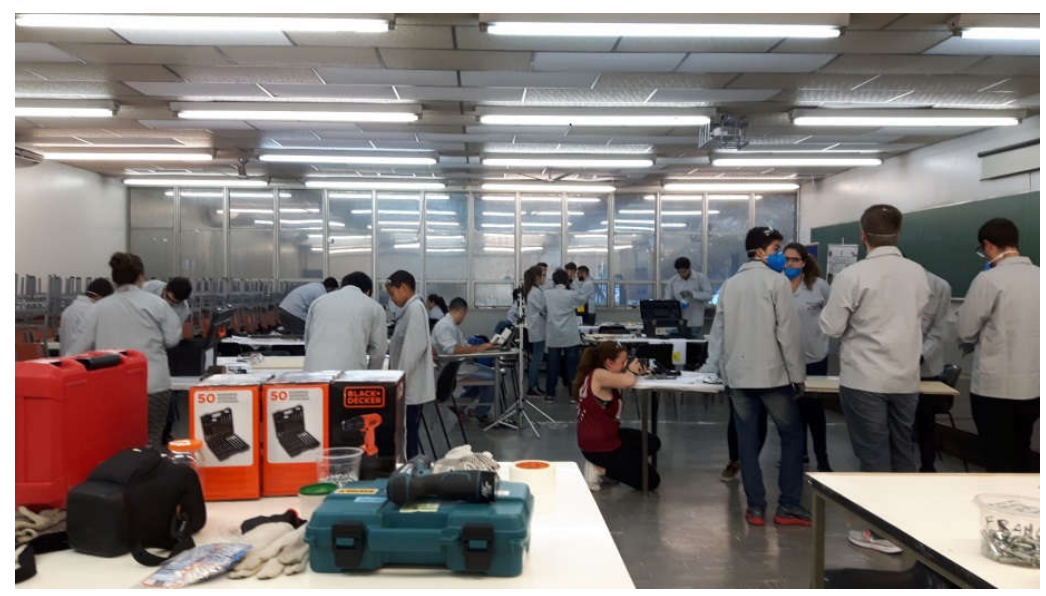

Figura 4.19. Alunos e instrutores durante a atividade na Oficina de Carrinhos de Rolimã. 


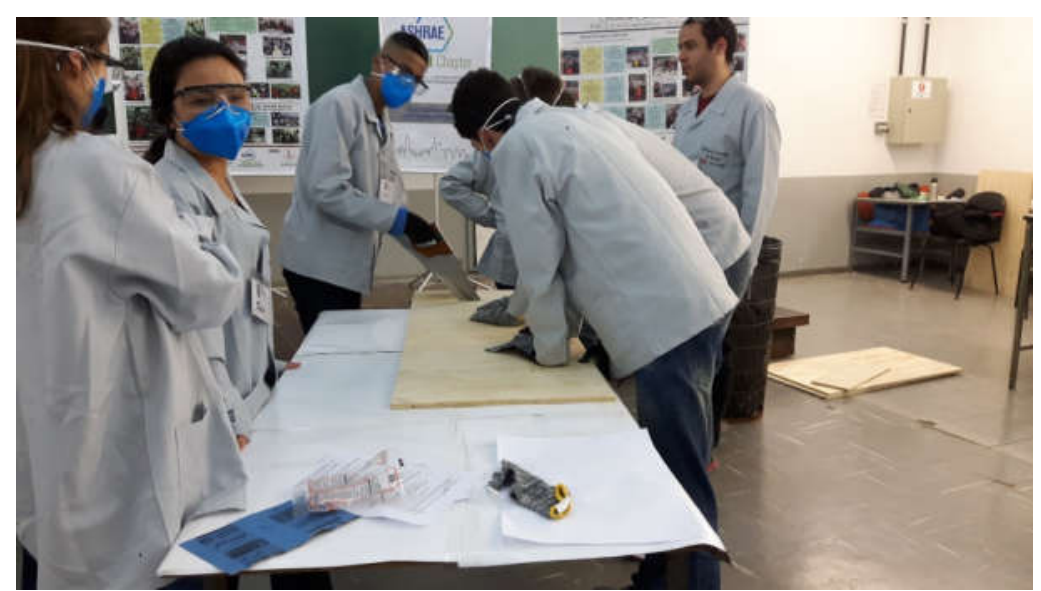

Figura 4.20. Alunos e instrutores realizando atividade de usinagem na Oficina de Carrinhos de Rolimã.

Os dados obtidos na medição prática $\mathrm{P} 4$ para a concentração de $\mathrm{CO}_{2}, \mathrm{PM}_{10}, \mathrm{PM}_{2,5}$ e TBS e UR podem ser observados nas figuras 4.21, 4.22, 4.23 e 4.24, respectivamente.

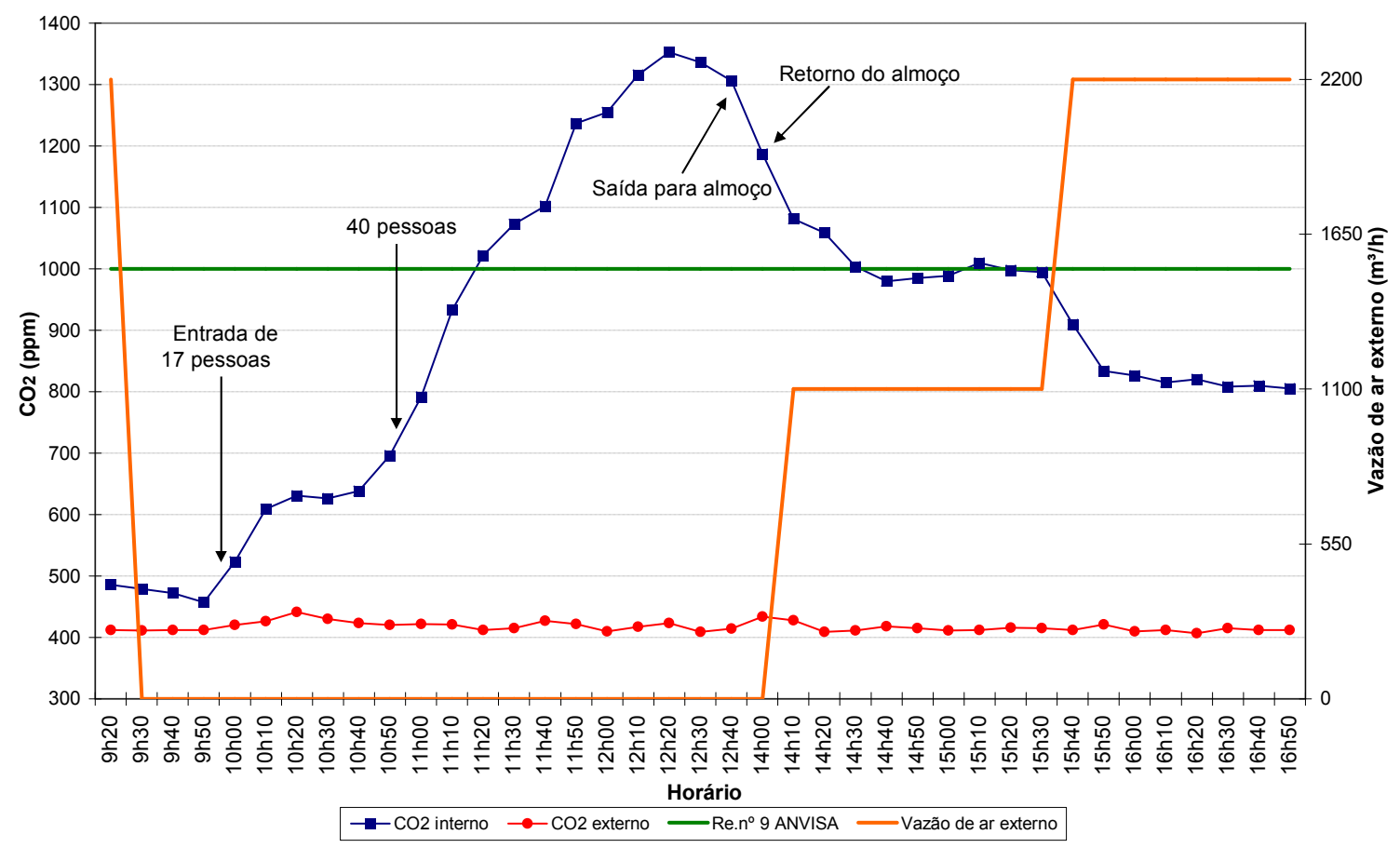

Figura 4.21. Concentração de $\mathrm{CO}_{2}$ - Oficina de Carrinhos de Rolimã (22/10/2016).

Nota-se que a concentração de $\mathrm{CO}_{2}$ no interior do ambiente ultrapassou os 1000 ppm sugeridos pela resolução da ANVISA no período da manhã. No período em questão, a sala 
apresentava ocupação máxima e nenhuma das unidades de renovação encontravam-se ligadas. É possível observar o aumento da concentração de $\mathrm{CO}_{2}$ a partir do momento em que a sala torna-se ocupada, indicando a presença de uma fonte geradora de $\mathrm{CO}_{2}$. Após o retorno do almoço, nota-se que, apesar da sala ter ficado vazia por um período de uma hora e 20 minutos, a concentração de $\mathrm{CO}_{2}$ praticamente não variou, pois não havia troca de ar no ambiente. Logo em seguida, duas unidades de renovação são acionadas, insuflando aproximadamente $28 \mathrm{~m}^{3} / \mathrm{h}$ de ar externo por pessoa, e a concentração de $\mathrm{CO}_{2}$ estabiliza-se em valores próximos aos 1000 ppm.

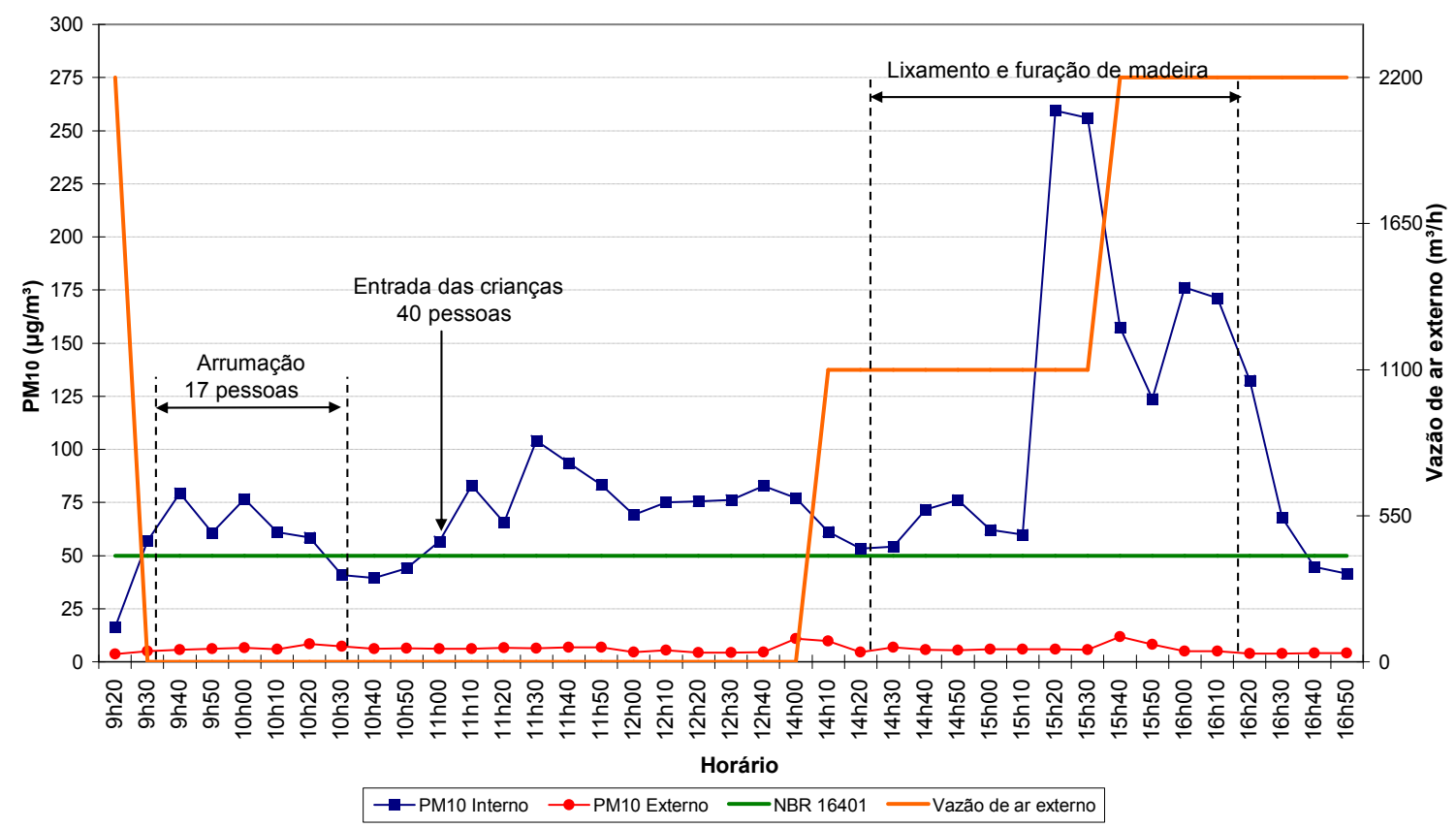

Figura 4.22. Concentração de $\mathrm{PM}_{10}$ - Oficina de Carrinhos de Rolimã (22/10/2016).

Para a concentração de particulado $\mathrm{PM}_{10}$ (figura 4.22), verifica-se que as concentrações estiveram praticamente sempre acima do limite aceitável de $50 \mu \mathrm{g} / \mathrm{m}^{3}$ pela NBR 16401 (ABNT, 2008). Antes do início da ocupação da sala, todas as unidades estavam ligadas, fazendo com que a concentração inicial de $\mathrm{PM}_{10}$ fosse baixa. Este fato pode ser observado na primeira medida do particulado em questão. Observa-se que ocorre um aumento da concentração do material particulado após 40 minutos do início das atividades de usinagem, quando as concentrações de $\mathrm{PM}_{10}$ chegaram em aproximadamente seis vezes o limite aceitável, mesmo com duas unidades de renovação em funcionamento. Este fato justifica-se 
pela início do lixamento de madeira. Verifica-se, no entanto, que o aumento da vazão de ar externo, com o acionamento das outras duas unidades, (de $1100 \mathrm{~m}^{3} / \mathrm{h}$ para $2200 \mathrm{~m}^{3} / \mathrm{h}$ aproximadamente) foi suficiente para diminuir a concentração de $\mathrm{PM}_{10}$ no interior da sala de aula A2 em aproximadamente 51\%, após 20 minutos do aumento da vazão de ar externo, mesmo com as atividades de lixamento sendo mantidas. Com o término das atividades de usinagem e com a vazão de ar externo em 2200 m³/h, a concentração de $\mathrm{PM}_{10}$ diminui em aproximadamente $75 \%$ após 40 minutos do término das atividades.

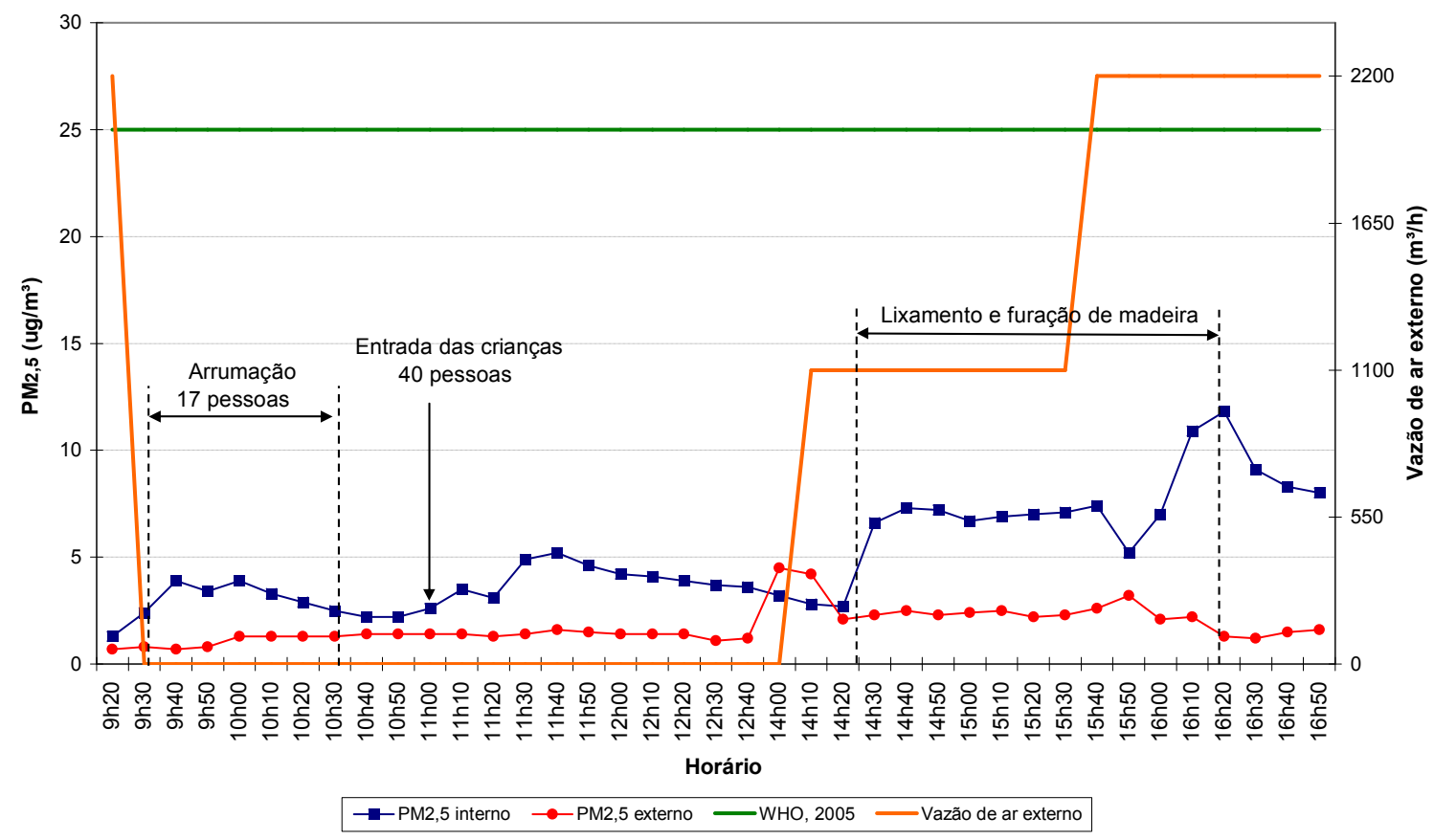

Figura 4.23. Concentração de $\mathrm{PM}_{2,5}$ - Oficina de Carrinhos de Rolimã (22/10/2016).

Para a concentração de particulado $\mathrm{PM}_{2,5}$ (figura 4.23), os dados se apresentaram sempre abaixo do limite aceitável de $25 \mu \mathrm{g} / \mathrm{m}^{3}$ pela Organização Mundial da Saúde (World Health Organization, 2005) durante toda medição. Observa-se que com o início das atividades de usinagem, a concentração de $\mathrm{PM}_{2,5}$ aumenta, mas não ultrapassa o limite aceitável. Verificouse que, com o aumento da vazão de ar externo a partir do acionamento das caixas de renovação, as concentrações de $\mathrm{PM}_{2,5}$ no interior da sala de aula $\mathrm{A} 2$ mantiveram-se abaixo do limite aceitável, mesmo com o início das atividades de usinagem. 


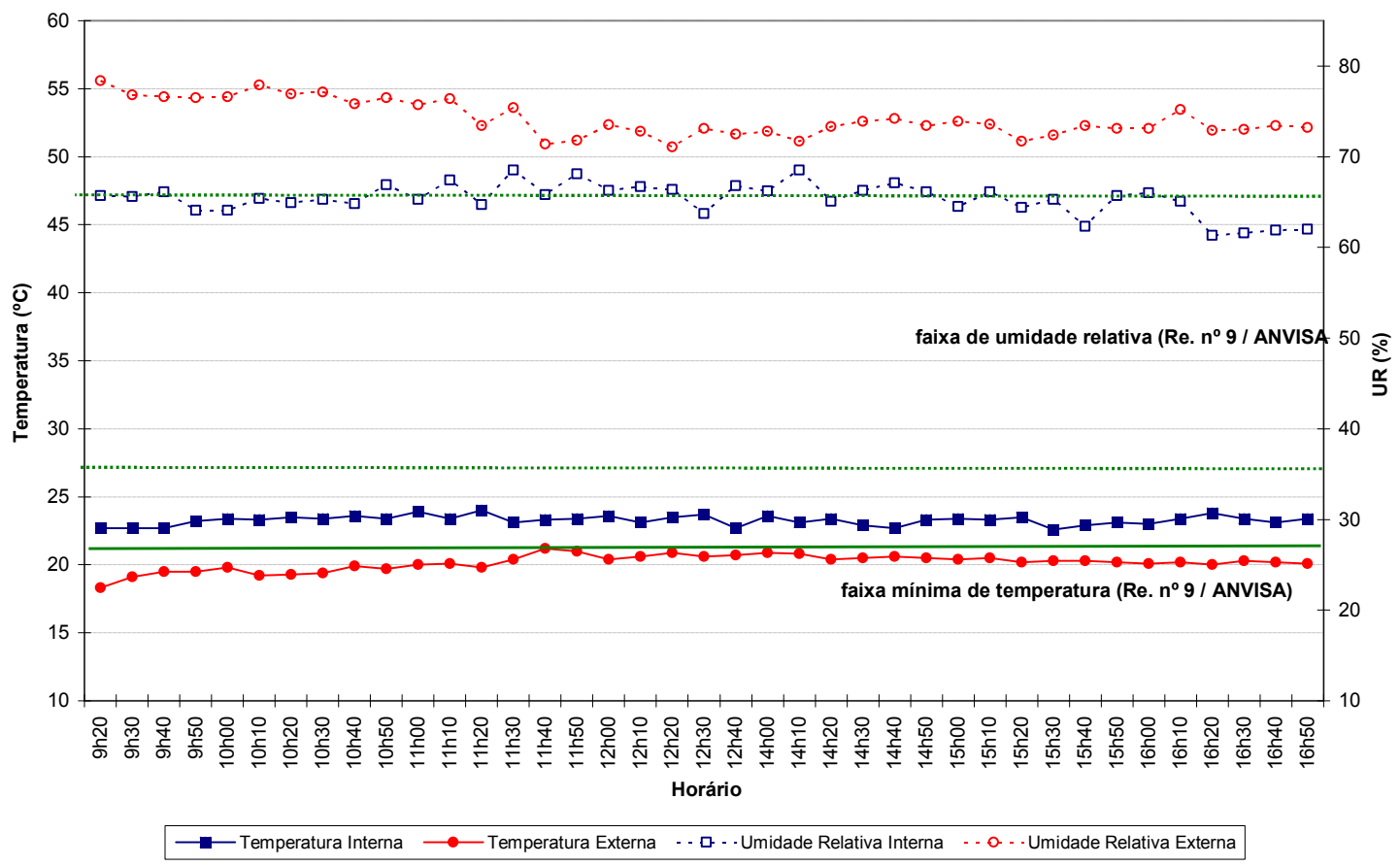

Figura 4.24. Temperatura e umidade relativa - Oficina de Carrinhos de Rolimã (22/10/2016).

Verifica-se na figura 4.24 que, tanto a temperatura de bulbo seco, como a umidade relativa no interior da sala de aula, mantiveram-se adequadas durante todo o experimento.

\subsubsection{Medição P5 - Domingo (23/10/16) - Oficina de Carrinhos de Rolimã (2} dia)

A quinta medição com atividade prática na sala de aula A2 ocorreu no dia 23/10/2016 (domingo) durante o segundo dia de atividades da Oficina de Carrinhos de Rolimã. As medições deste dia, foram realizadas no período das 9:00 horas às 15:00 horas.

Da mesma forma que na medição do primeiro dia da Oficina de Carrinhos de Rolimã, as janelas da sala de aula foram mantidas fechadas e a porta aberta durante todo o experimento. As medidas dos parâmetros internos e externos foram tomadas a cada 10 minutos. A vazão de ar externo foi variada de acordo com a tabela a seguir. 
Tabela 4.5. Variação da vazão de ar externo para a medição P5.

\begin{tabular}{|c|c|}
\hline Intervalo & Vazão $\left(\mathbf{m}^{\mathbf{3}} / \mathbf{h}\right)$ \\
\hline $09 \mathrm{~h} 00$ às $10 \mathrm{~h} 00$ & 0 \\
\hline $10 \mathrm{~h} 10$ às $11 \mathrm{~h} 00$ & 1100 \\
\hline $11 \mathrm{~h} 10$ às $13 \mathrm{~h} 40$ & 2200 \\
\hline $13 \mathrm{~h} 50$ às $15 \mathrm{~h} 00$ & 558 \\
\hline
\end{tabular}

Durante a atividade, alguns ocupantes entravam e saíam da sala mantendo uma média aproximada de 38 pessoas no interior da sala de aula.

As imagens a seguir mostram os alunos e os instrutores durante o segundo dia de atividades da Oficina de Carrinhos de Rolimã.

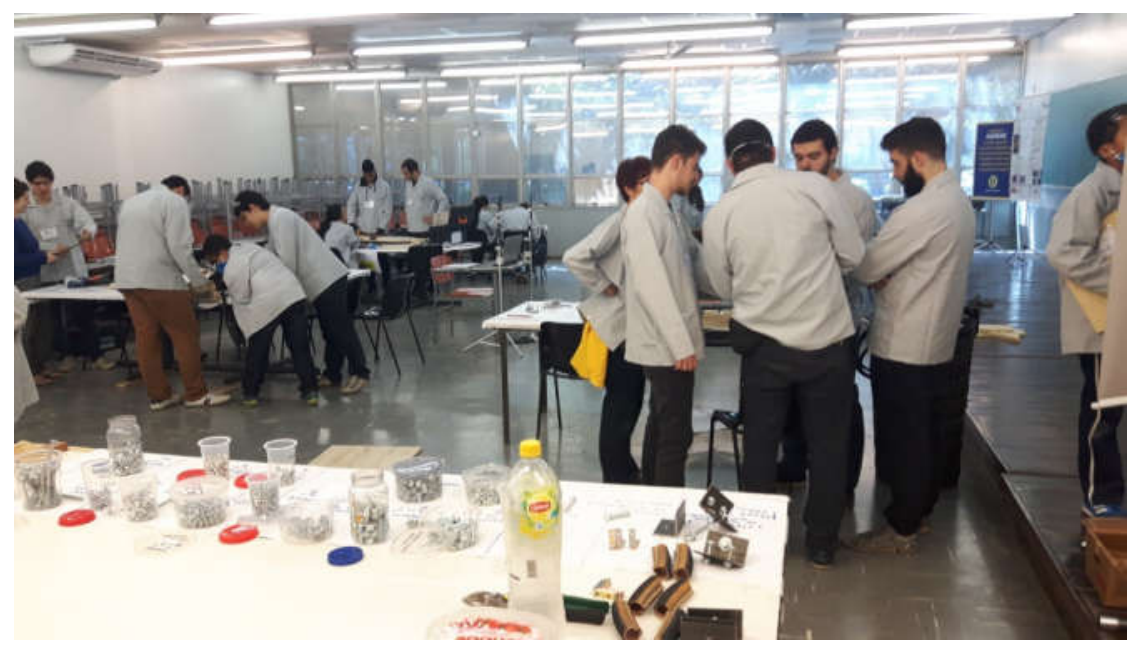

Figura 4.25. Segundo dia de atividades da Oficina de Carrinhos de Rolimã. 


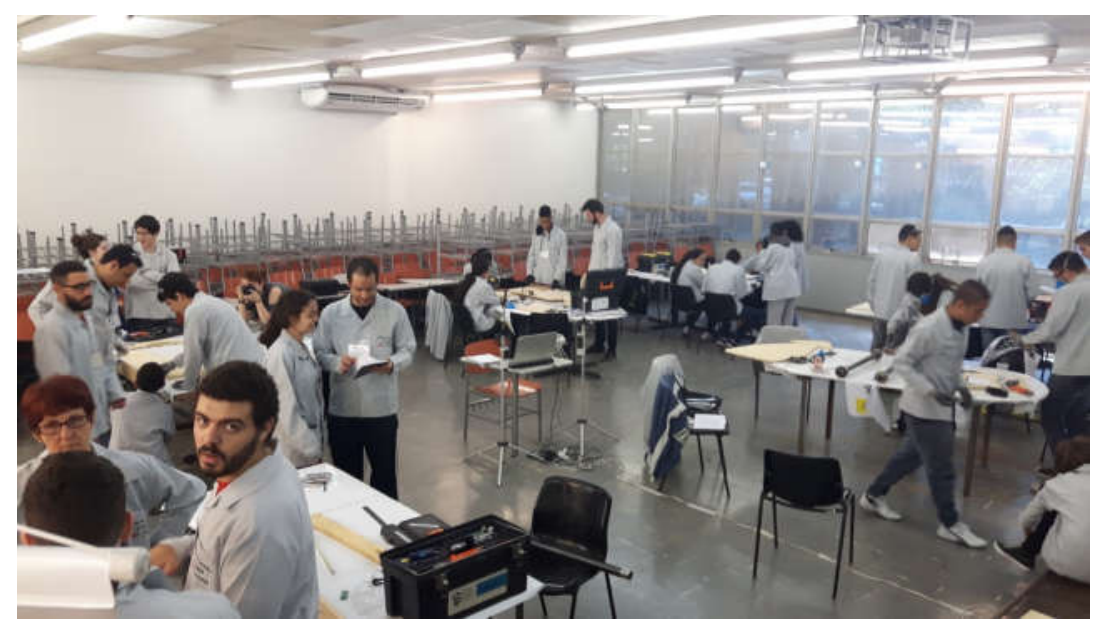

Figura 4.26. Alunos e instrutores durante as atividades do segundo dia da Oficina de Carrinhos de Rolimã.

Os dados obtidos na medição prática P5 para a concentração de $\mathrm{CO}_{2}, \mathrm{PM}_{10}, \mathrm{PM}_{2,5}$ e TBS e UR podem ser observados nas figuras $4.27,4.28,4.29$ e 4.30 , respectivamente.

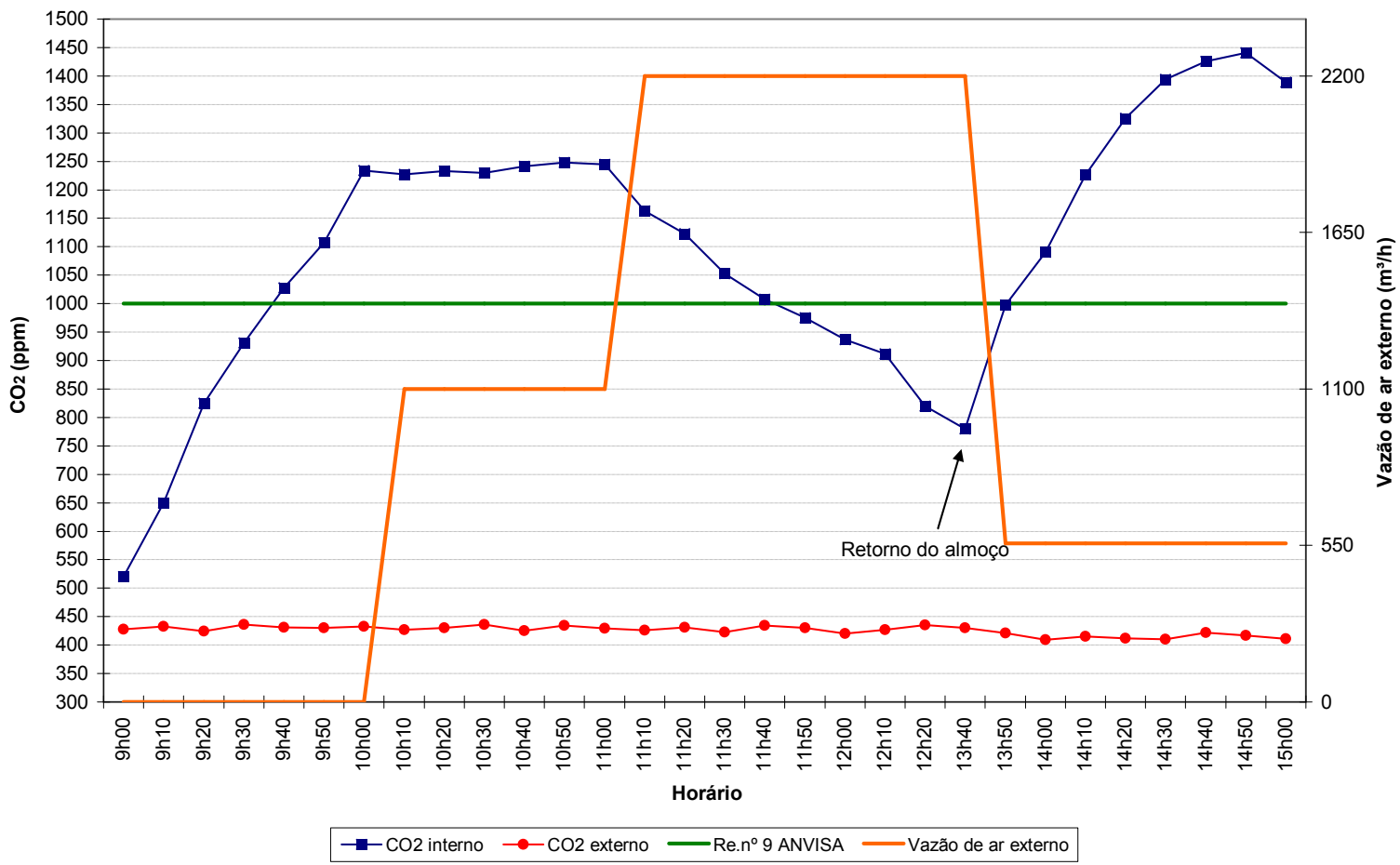

Figura 4.27. Concentração de $\mathrm{CO}_{2}$ - Oficina de Carrinhos de Rolimã (23/10/2016). 
A figura 4.27 apresenta os dados obtidos para a concentração de $\mathrm{CO}_{2}$. Nota-se que a concentração de $\mathrm{CO}_{2}$ no interior do ambiente ultrapassou os 1000 ppm sugeridos pela resolução da ANVISA no período da manhã e da tarde, quando a sala apresentava ocupação máxima e a vazão de ar externo era menor que $30 \mathrm{~m}^{3} / \mathrm{h}$ por pessoa. Diferentemente da primeira medição, após o retorno do almoço, nota-se que a concentração de $\mathrm{CO}_{2}$ estava bem abaixo dos 1000 ppm sugeridos pela resolução ${ }^{\circ} 9$ da ANVISA, haja vista que as 4 unidades de renovação ficaram ligadas durante o horário de almoço. Com o desligamento das unidades de renovação às 13 horas e 45 minutos, evidencia-se que a concentração de $\mathrm{CO}_{2}$ aumenta, retornando a patamares acima da faixa aceitável em $45 \%$.

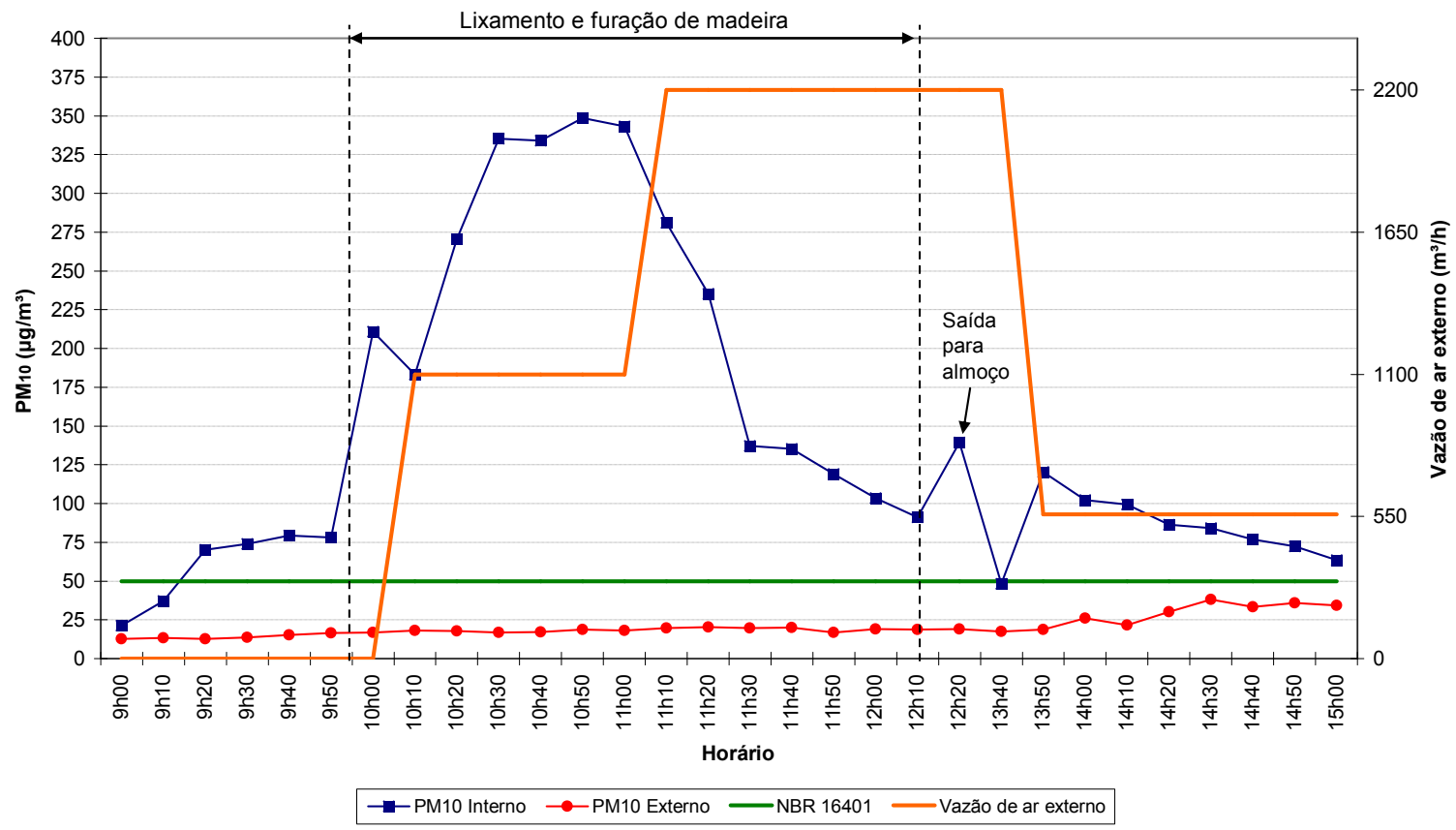

Figura 4.28. Concentração de $\mathrm{PM}_{10}$ - Oficina de Carrinhos de Rolimã (23/10/2016).

Para a concentração de particulado $\mathrm{PM}_{10}$ (figura 4.28), nota-se que as concentrações estiveram sempre acima do limite aceitável de $50 \mu \mathrm{g} / \mathrm{m}^{3}$ pela NBR 16401 (ABNT, 2008), com exceção da primeira medida, na qual não existiam ocupantes no ambiente. Quando do início das atividades de usinagem, as concentrações de $\mathrm{PM}_{10}$ chegaram em oito vezes o limite aceitável. Verifica-se que o aumento da vazão de ar externo (de $1100 \mathrm{~m}^{3} / \mathrm{h}$ para $2200 \mathrm{~m}^{3} / \mathrm{h}$ aproximadamente) foi suficiente para diminuir em aproximadamente $65 \%$, após 50 minutos 
do aumento da vazão de ar externo, a concentração de $\mathrm{PM}_{10}$ no interior da sala de aula $\mathrm{A} 2$ mesmo com as atividades de usinagem mantidas.

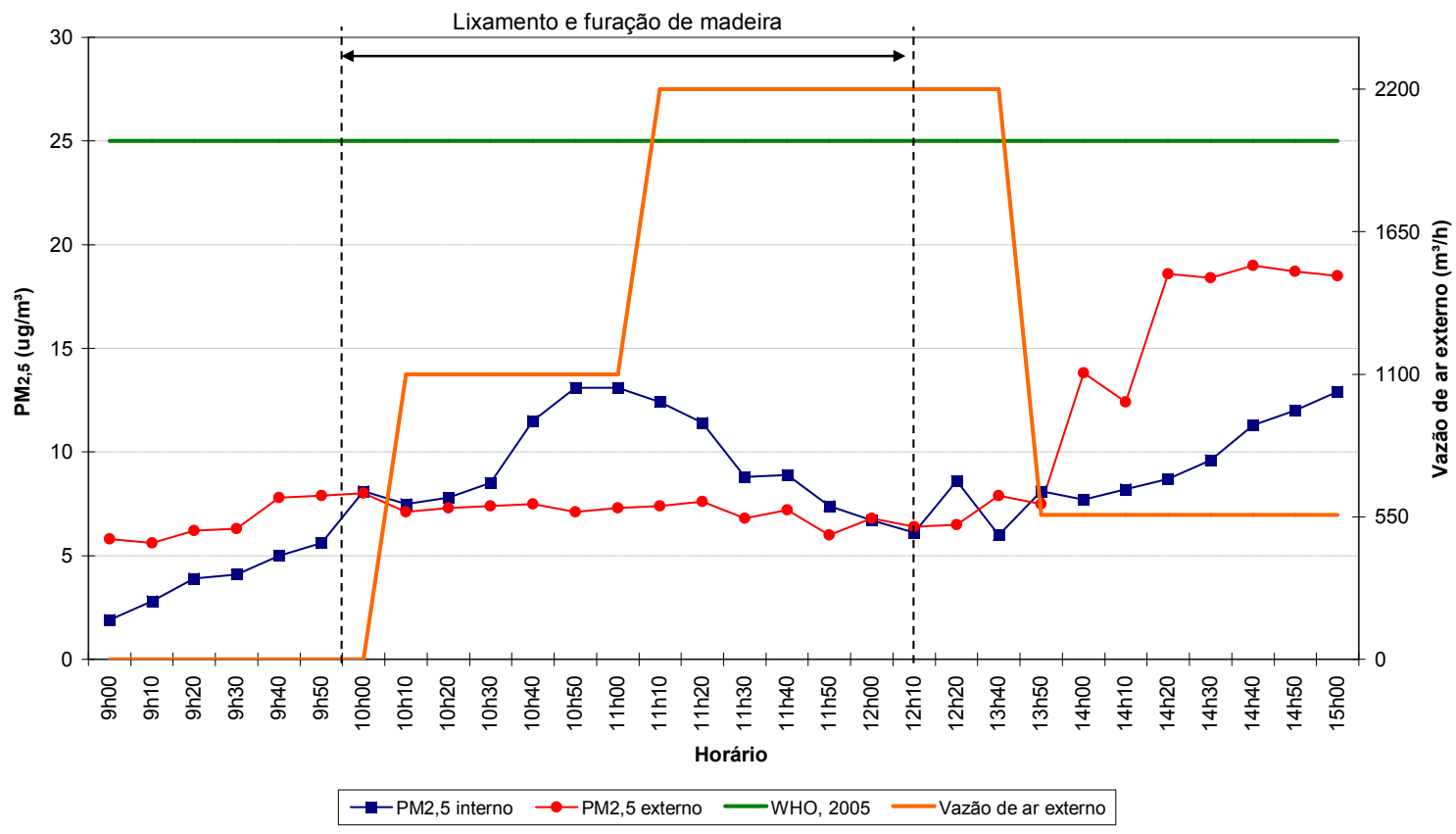

Figura 4.29. Concentração de PM2,5 - Oficina de Carrinhos de Rolimã (23/10/2016).

Para a concentração de particulado $\mathrm{PM}_{2,5}$ (figura 4.29), os dados se apresentaram abaixo do limite aceitável de $25 \mu \mathrm{g} / \mathrm{m}^{3}$ pela Organização Mundial da Saúde (World Health Organization, 2005) durante toda a atividade. Observa-se, no entanto, que com o início das atividades de usinagem, a concentração de $\mathrm{PM}_{2,5}$ aumenta, mas não ultrapassa o limite aceitável. Assim como foi constatado com o $\mathrm{PM}_{10}$, verificou-se que com o aumento da vazão de ar externo (de $1100 \mathrm{~m}^{3} / \mathrm{h}$ para $2200 \mathrm{~m}^{3} / \mathrm{h}$ aproximadamente), as concentrações de $\mathrm{PM}_{2,5}$ no interior da sala de aula A2 diminuiram mesmo com as atividades de usinagem mantidas. Por meio da análise da figura 4.29 é possível observar a influência da concentração de $\mathrm{PM}_{2,5}$ do ar externo no ar interno. Essa influência pode ser verificada principalmente no período da tarde quando ocorreu o aumento crescente do particulado externo e interno, quase que simultaneamente. 


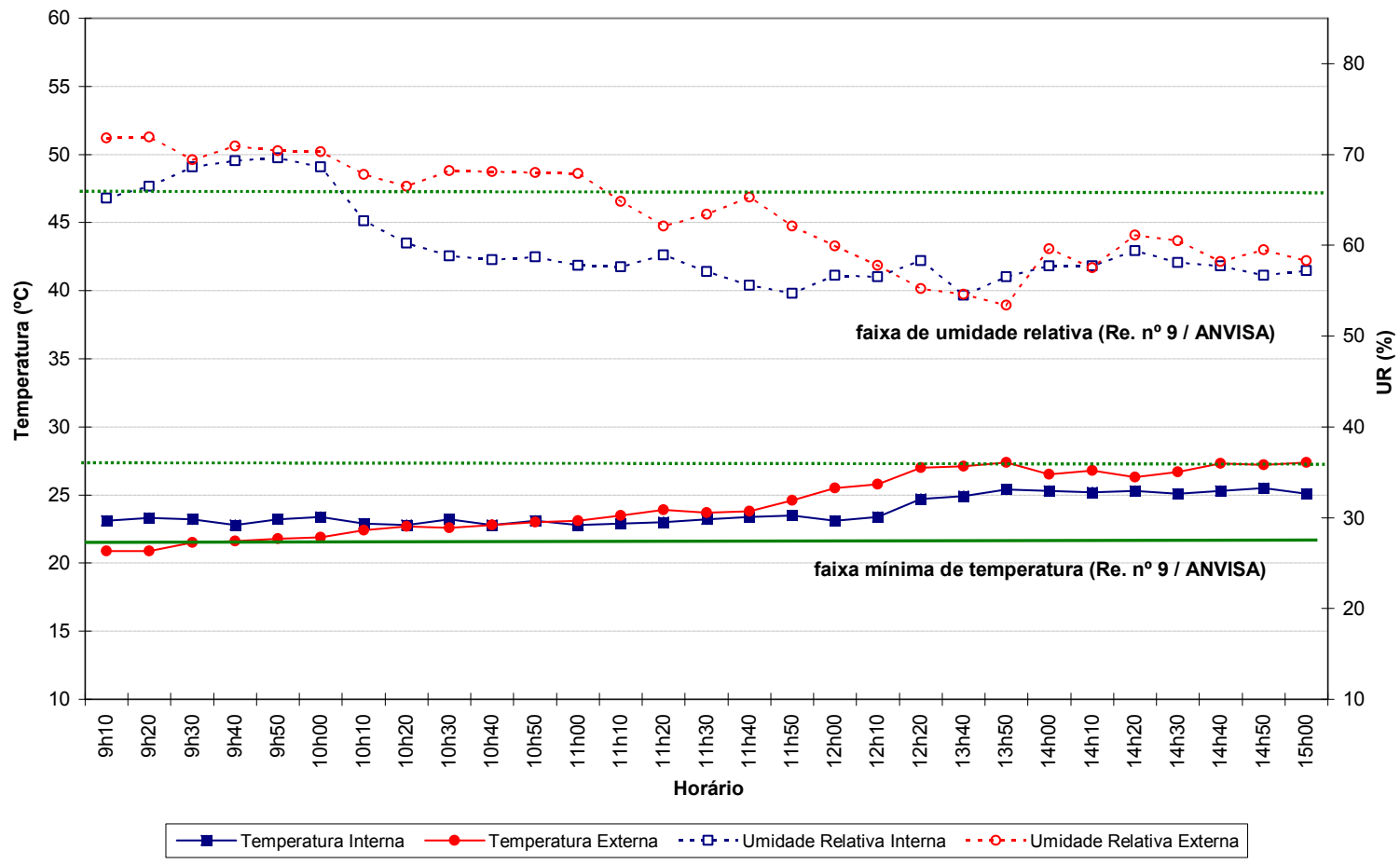

Figura 4.30. Temperatura e umidade relativa - Oficina de Carrinhos de Rolimã (23/10/2016).

Verifica-se na figura 4.30 que, tanto a temperatura de bulbo seco, como a umidade relativa no interior da sala de aula, mantiveram-se adequadas durante todo o experimento. 


\subsection{Medições na sala de aula A2 durante aulas teóricas}

Nos itens a seguir são apresentados os dados obtidos nas medições realizadas durante aulas exclusivamente teóricas desempenhadas na sala de aula A2, assim como a análise dos mesmos. As tabelas com os valores obtidos para cada parâmetro podem ser visualizados no Anexo G. As medições ocorreram em seis dias distintos.

Para todas as medições as janelas e a porta foram mantidas fechadas, e as medidas dos parâmetros internos e externos foram tomadas a cada 10 minutos. A vazão de ar externo foi variada de acordo com a tabela a seguir.

Tabela 4.6. Variação da vazão de ar externo para a medição T1.

\begin{tabular}{|c|c|}
\hline Intervalo & Vazão $\left(\mathbf{m}^{\mathbf{3}} / \mathbf{h}\right)$ \\
\hline $09 \mathrm{~h} 00$ às $09 \mathrm{~h} 30$ & 0 \\
\hline $09 \mathrm{~h} 40$ às $10 \mathrm{~h} 10$ & 1100 \\
\hline $10 \mathrm{~h} 20$ às $11 \mathrm{~h} 10$ & 2200 \\
\hline
\end{tabular}

A figura 4.31 mostra uma das aulas onde ocorreu a medição.

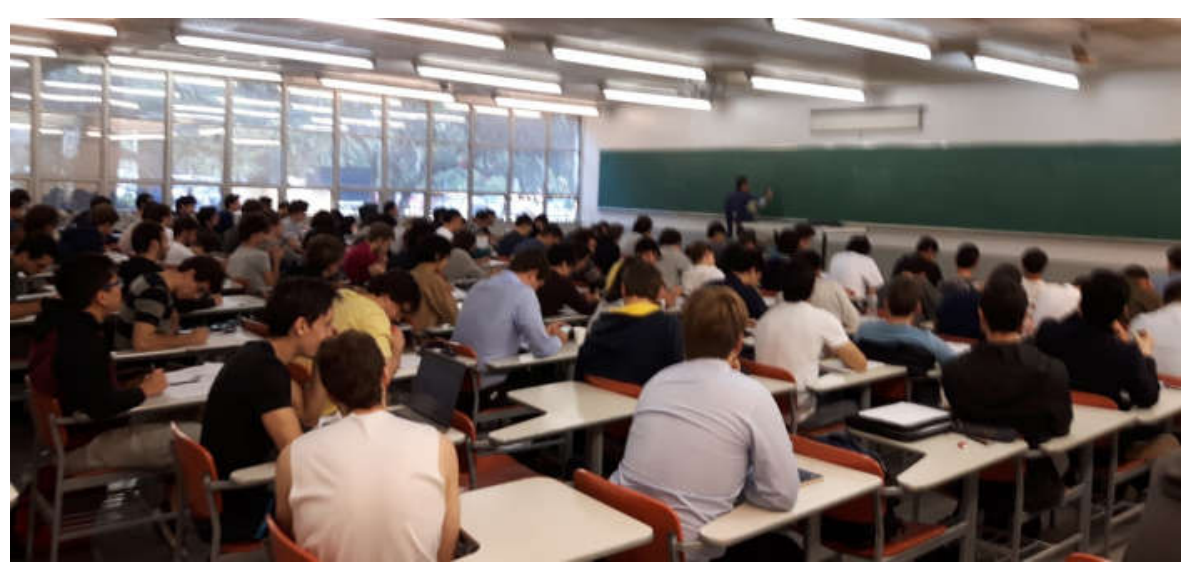

Figura 4.31. Medição da aula teórica de Eletrônica. 


\subsubsection{Primeira medição (T1) - quarta-feira (17/08/16)}

A primeira medição das aulas teóricas na sala de aula A2 ocorreu no dia 17/08/2016 (quartafeira) durante a aula de Mecânica dos Fluidos. O número de ocupantes durante a aula chegou em 60 pessoas. As medições, durante a aula, foram realizadas no período das 09 horas às $10 \mathrm{~h} 10$.

Como as aulas teóricas possuem um período de duração menor do que as aulas práticas, neste primeiro dia, apenas as concentrações de $\mathrm{CO}_{2}$ foram medidas a fim de verificar o comportamento do ambiente, dependendo da vazão adotada, e o tempo de estabilização dos parâmetros.

Os dados obtidos na medição teórica $\mathrm{T} 1$ para a concentração de $\mathrm{CO}_{2}$, e TBS e UR podem ser observados nas figuras 4.32 e 4.33 , respectivamente. O número de ocupantes em cada ponto de medição está indicado nas figuras pela letra " $p$ ".

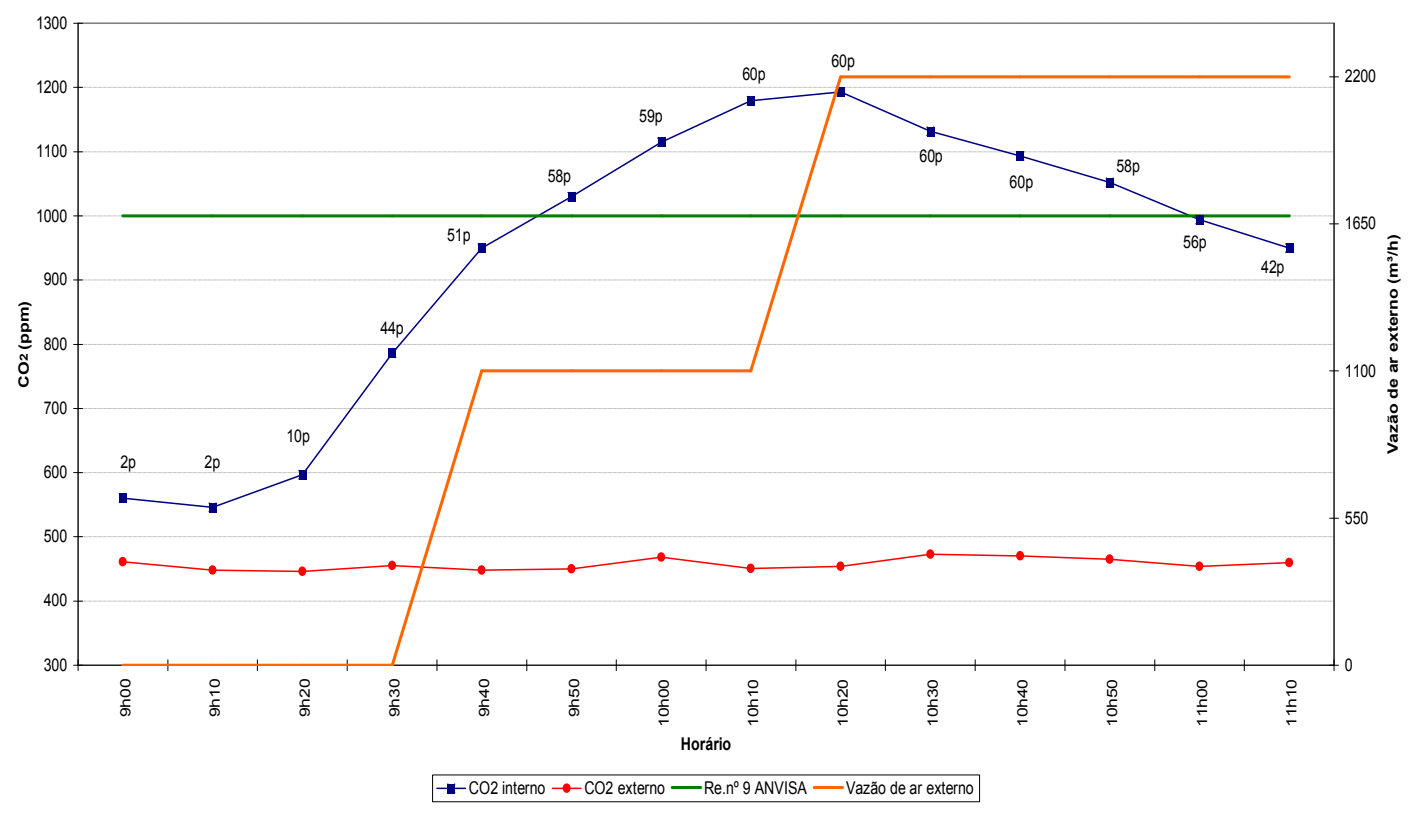

Figura 4.32. Concentração de $\mathrm{CO}_{2}$ na sala de aula $\mathrm{A} 2$ do dia 17/08/2016.

Percebe-se o aumento da concentração de $\mathrm{CO}_{2}$ a partir do momento em que a sala torna-se ocupada, indicando a presença de uma fonte geradora de $\mathrm{CO}_{2}$. Nota-se que a concentração de 
$\mathrm{CO}_{2}$ no interior do ambiente ultrapassou os 1000 ppm sugeridos pela resolução da ANVISA enquanto a vazão de ar externo se manteve na faixa dos $1100 \mathrm{~m}^{3} / \mathrm{h}$, ou seja, com duas unidade de renovação em funcionamento. Porém, com o aumento da vazão de ar externo, verifica-se uma queda de aproximadamente $250 \mathrm{ppm}$, após 50 minutos do aumento da vazão, na concentração de $\mathrm{CO}_{2}$, quando do início do funcionamento das quatro unidades de renovação. Devido ao número excessivo de ocupantes, apenas duas unidades de renovação em funcionamento não eram suficientes para garantir a vazão de $27 \mathrm{~m}^{3} / \mathrm{h}$ por pessoa, recomendada pela resolução $\mathrm{n}^{\circ} 9$ da ANVISA como taxa de renovação de ar.

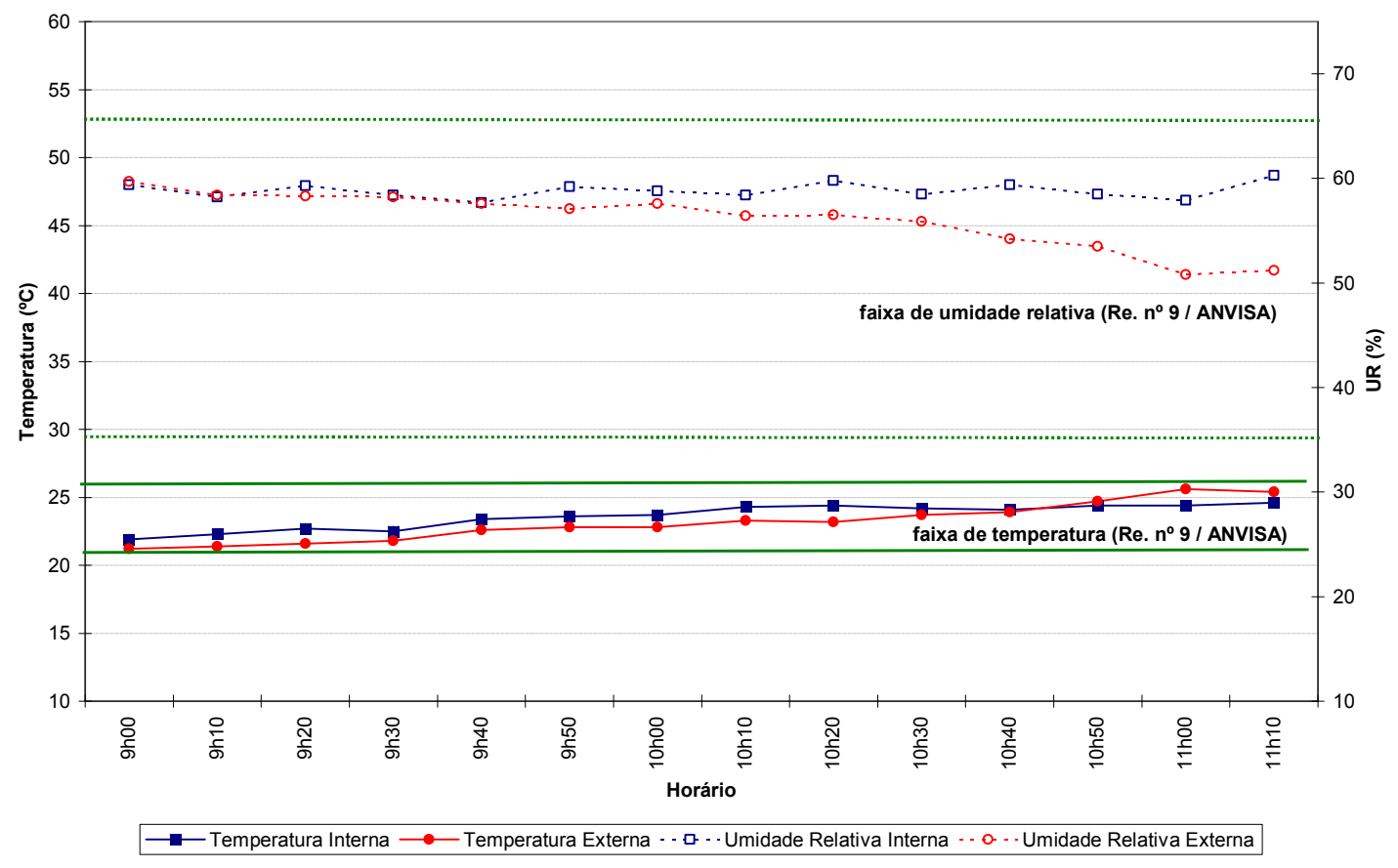

Figura 4.33. Temperatura e umidade relativa na sala de aula A2 do dia 17/08/2016.

Verifica-se na figura 4.33 que, tanto a temperatura, como a umidade relativa no interior da sala de aula, mativeram-se adequadas durante todo o experimento. 


\subsubsection{Segunda medição (T2) - sexta-feira (19/08/16)}

A segunda medição das aulas teóricas na sala de aula A2 ocorreu no dia 19/08/2016 (sextafeira) durante uma aula de Eletrônica. O número de ocupantes chegou em 100 pessoas. As medições, durante a aula, foram realizadas no período das 08 horas às $11 \mathrm{~h} 10$.

Diferentemente da primeira medição das aulas teóricas, na segunda medição foram medidas as concentrações de $\mathrm{PM}_{2,5}$ e $\mathrm{PM}_{10}$, além da concentração de $\mathrm{CO}_{2}$. A vazão de ar externo foi variada de acordo com a tabela a seguir.

Tabela 4.7. Variação da vazão de ar externo para a medição T2.

\begin{tabular}{|c|c|}
\hline Intervalo & Vazão $\left(\mathbf{m}^{\mathbf{3}} / \mathbf{h}\right)$ \\
\hline $08 \mathrm{~h} 00$ às $08 \mathrm{~h} 50$ & 0 \\
\hline $09 \mathrm{~h} 00$ às $09 \mathrm{~h} 50$ & 1100 \\
\hline $10 \mathrm{~h} 00$ às $11 \mathrm{~h} 10$ & 2200 \\
\hline
\end{tabular}

Os dados obtidos na medição teórica T2 para a concentração de $\mathrm{CO}_{2}, \mathrm{PM}_{10}, \mathrm{PM}_{2,5}$ e TBS e UR podem ser observados nas figuras 4.34, 4.35, 4,36 e 4,37, respectivamente. O número de ocupantes em cada ponto de medição está indicado nas figuras pela letra "p". 


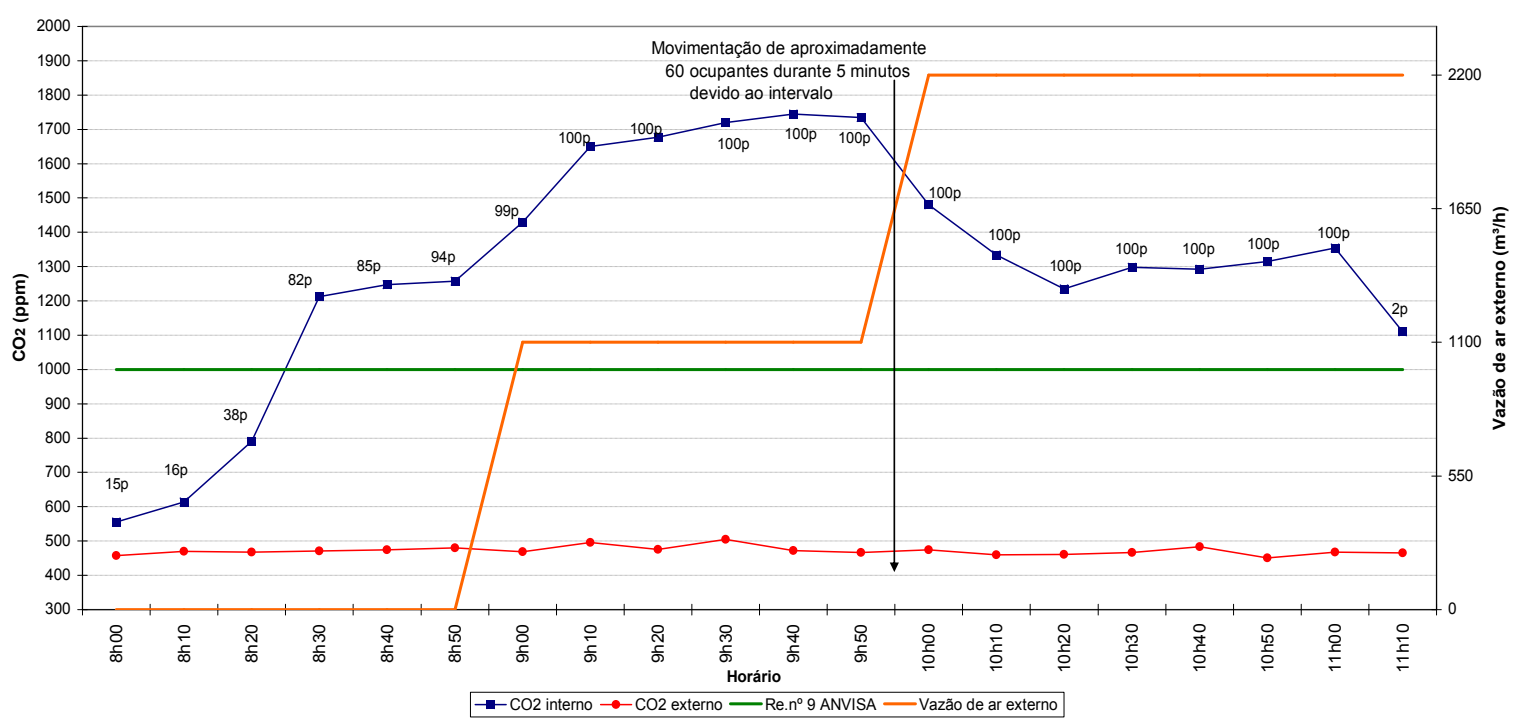

Figura 4.34. Concentração de $\mathrm{CO}_{2}$ na sala de aula $\mathrm{A} 2$ do dia 19/08/2016.

Conforme visto anteriormente, percebe-se o aumento da concentração de $\mathrm{CO}_{2}$ a partir do momento em que a sala torna-se ocupada. Verifica-se que a concentração de $\mathrm{CO}_{2}$ no interior do ambiente ultrapassou os 1000 ppm sugeridos pela resolução da ANVISA, mesmo com o aumento da vazão de ar externo, utilizando as 4 unidades de renovação. Devido ao número excessivo de ocupantes, as quatro unidades de renovação em funcionamento não são suficientes para garantir a vazão de $27 \mathrm{~m}^{3} / \mathrm{h}$ por pessoa, definida pela resolução $\mathrm{n}^{\mathrm{o}} 9$ da ANVISA como taxa de renovação de ar. 


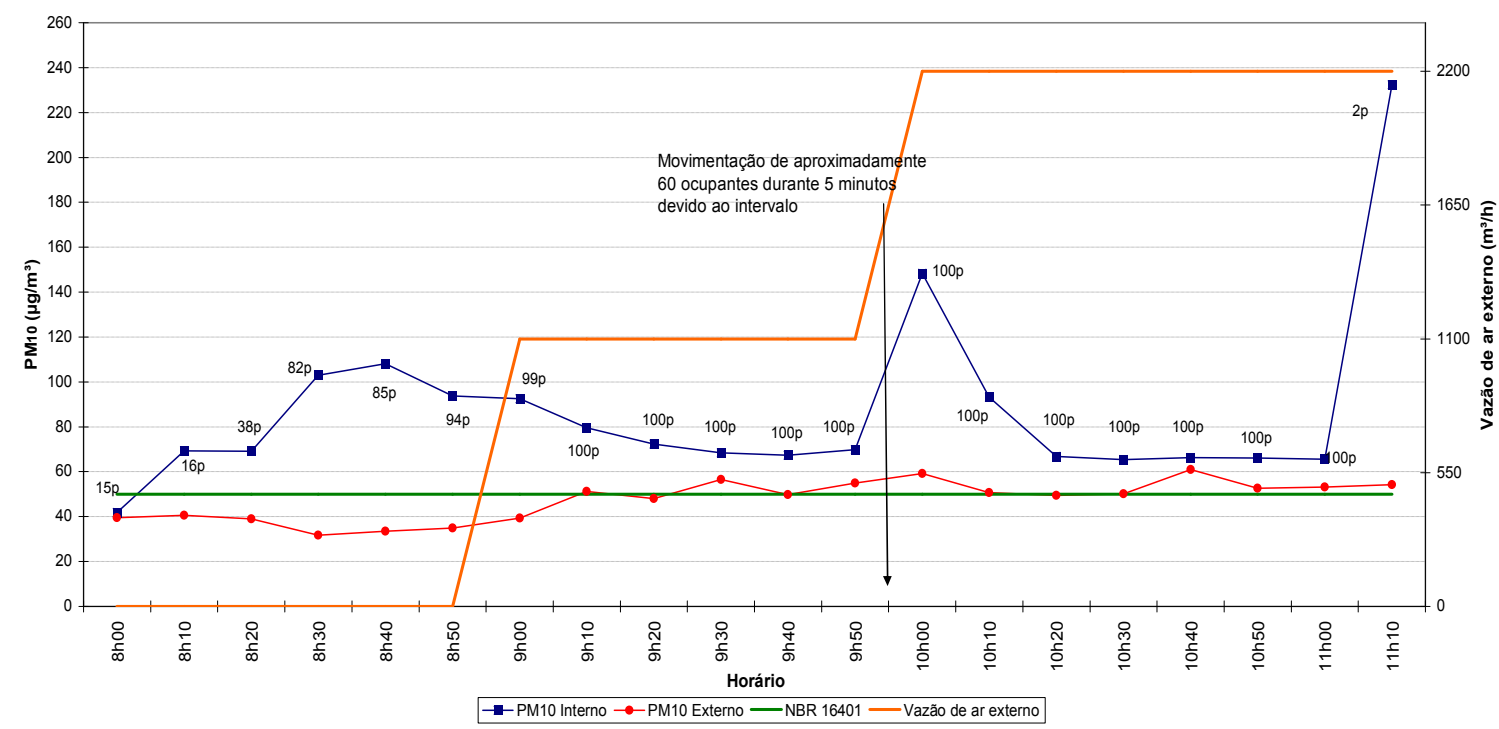

Figura 4.35. Concentração de $\mathrm{PM}_{10}$ na sala de aula A2 do dia 19/08/2016.

Para a concentração de particulado $\mathrm{PM}_{10}$ (figura 4.35), verifica-se também que as concentrações estiveram sempre acima do limite aceitável de $50 \mu \mathrm{g} / \mathrm{m}^{3}$ pela NBR 16401 (ABNT, 2008). Apesar da diminuição de aproximadamente $55 \%$ da concentração de $\mathrm{PM}_{10}$ com as quatro unidades de renovação em funcionamento, esta não foi suficiente para chegar ao limite aceitável. Notaram-se dois picos de concentração de $\mathrm{PM}_{10}$, sendo o primeiro na movimentação dos ocupantes para o intervalo, e o segundo na movimentação para a saída da aula. O aumento da concentração deste particulado possivelmente justifica-se pela suspensão do material particulado que estava depositado nas superfícies internas de móveis e no chão. 


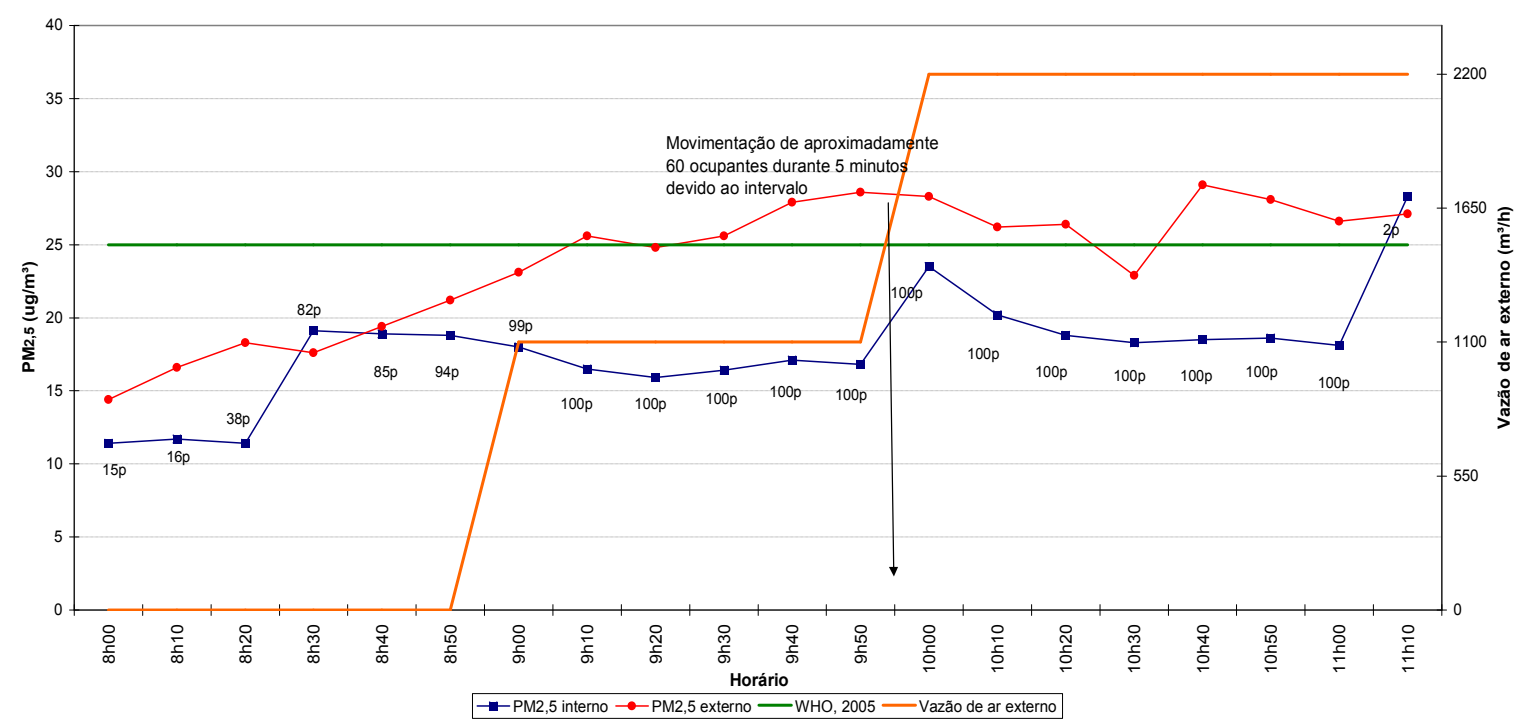

Figura 4.36. Concentração de $\mathrm{PM}_{2,5}$ na sala de aula $A 2$ do dia 19/08/2016.

Para a concentração de particulado $\mathrm{PM}_{2,5}$ (figura 4.36), os dados se apresentaram abaixo do limite aceitável de $25 \mu \mathrm{g} / \mathrm{m}^{3}$ pela Organização Mundial da Saúde (World Health Organization, 2005) praticamente durante toda o período. Apenas no final da aula, quando da saída de todos os ocupantes, a concentração ultrapassou o limite aceitável. Nota-se, novamente, a influência dos filtros na tomada de ar externo, visto que é possível observar que a concentração de material particulado $\mathrm{PM}_{2,5}$ no interior do ambiente era menor que a do ar externo, mesmo com geração interna de particulados. 


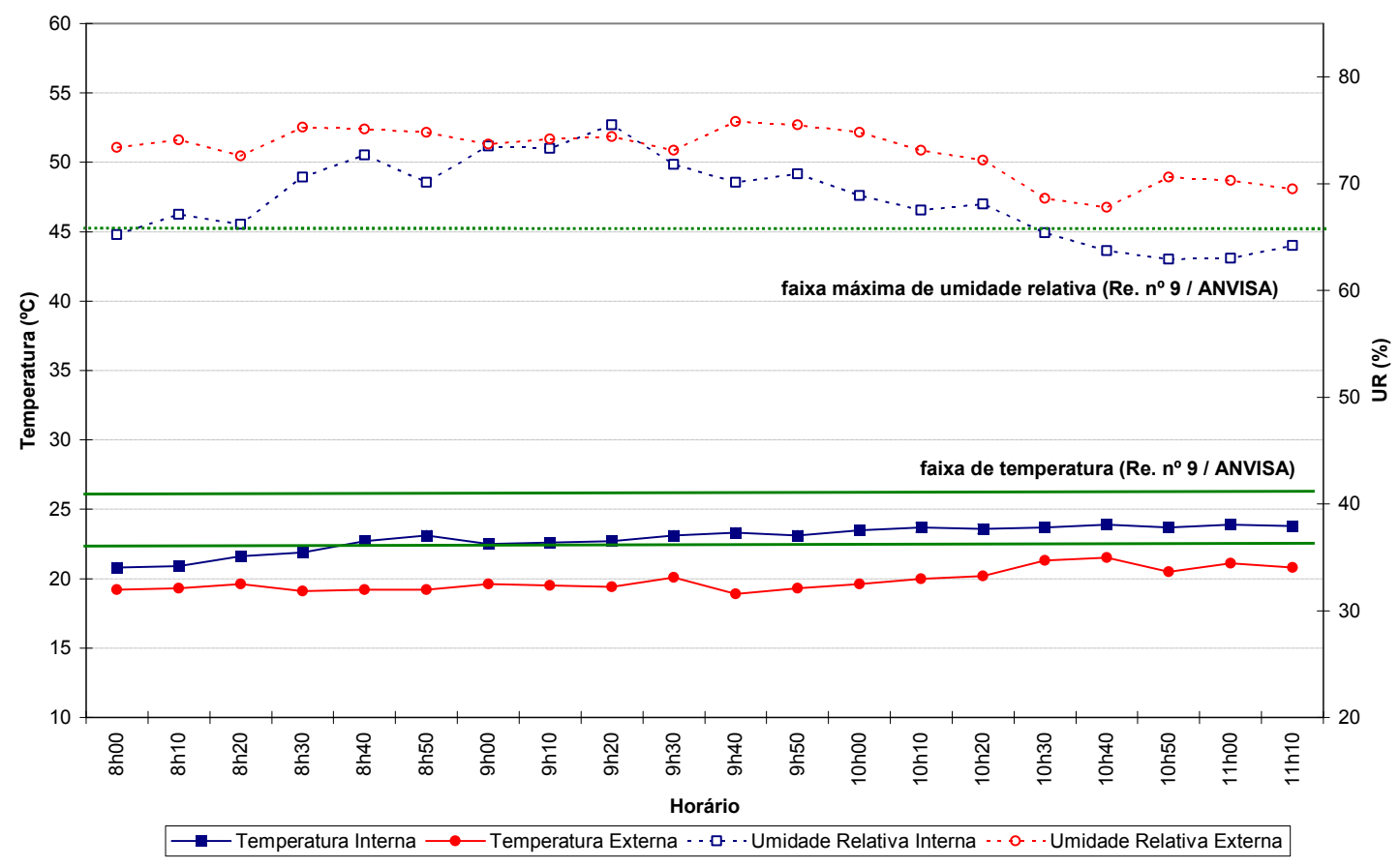

Figura 4.37. Temperatura e umidade relativa na sala de aula A2 do dia 19/08/2016.

Verifica-se na figura 4.37 que a temperatura no interior da sala de aula se manteve adequada durante todo o experimento. A umidade relativa, por sua vez, ficou acima do imposto na resolução número 9 da ANVISA, haja vista que a umidade relativa externa estava alta e o sistema de tratamento de ar, no interior do ambiente, não entrou em operação de refrigeração devido a temperatura que encontrava-se a sala.

\subsubsection{Terceira medição (T3) - segunda-feira (22/08/16)}

A terceira medição das aulas teóricas na sala de aula A2 ocorreu no dia 22/08/2016 (segundafeira) durante uma aula de Mecânica dos Fluidos. O número de ocupantes chegou em 68 pessoas. As medições foram realizadas no período das 9 às 11 horas.

Nesta medição foram verificadas as concentrações de $\mathrm{PM}_{2,5}$ e $\mathrm{PM}_{10}$, além da concentração de $\mathrm{CO}_{2}$. A vazão de ar externo foi variada de acordo com a tabela a seguir. 
Tabela 4.8. Variação da vazão de ar externo para a medição T3.

\begin{tabular}{|c|c|}
\hline Intervalo & Vazão $\left(\mathbf{m}^{\mathbf{3}} / \mathbf{h}\right)$ \\
\hline $09 \mathrm{~h} 00$ às $09 \mathrm{~h} 50$ & 0 \\
\hline $10 \mathrm{~h} 00$ às $11 \mathrm{~h} 00$ & 2200 \\
\hline
\end{tabular}

Os dados obtidos na medição teórica T3 para a concentração de $\mathrm{CO}_{2}, \mathrm{PM}_{10}, \mathrm{PM}_{2,5}$ e TBS e UR podem ser observados nas figuras 4.38, 4.39, 4,40 e 4,41, respectivamente. O número de ocupantes em cada ponto de medição está indicado nas figuras pela letra "p".

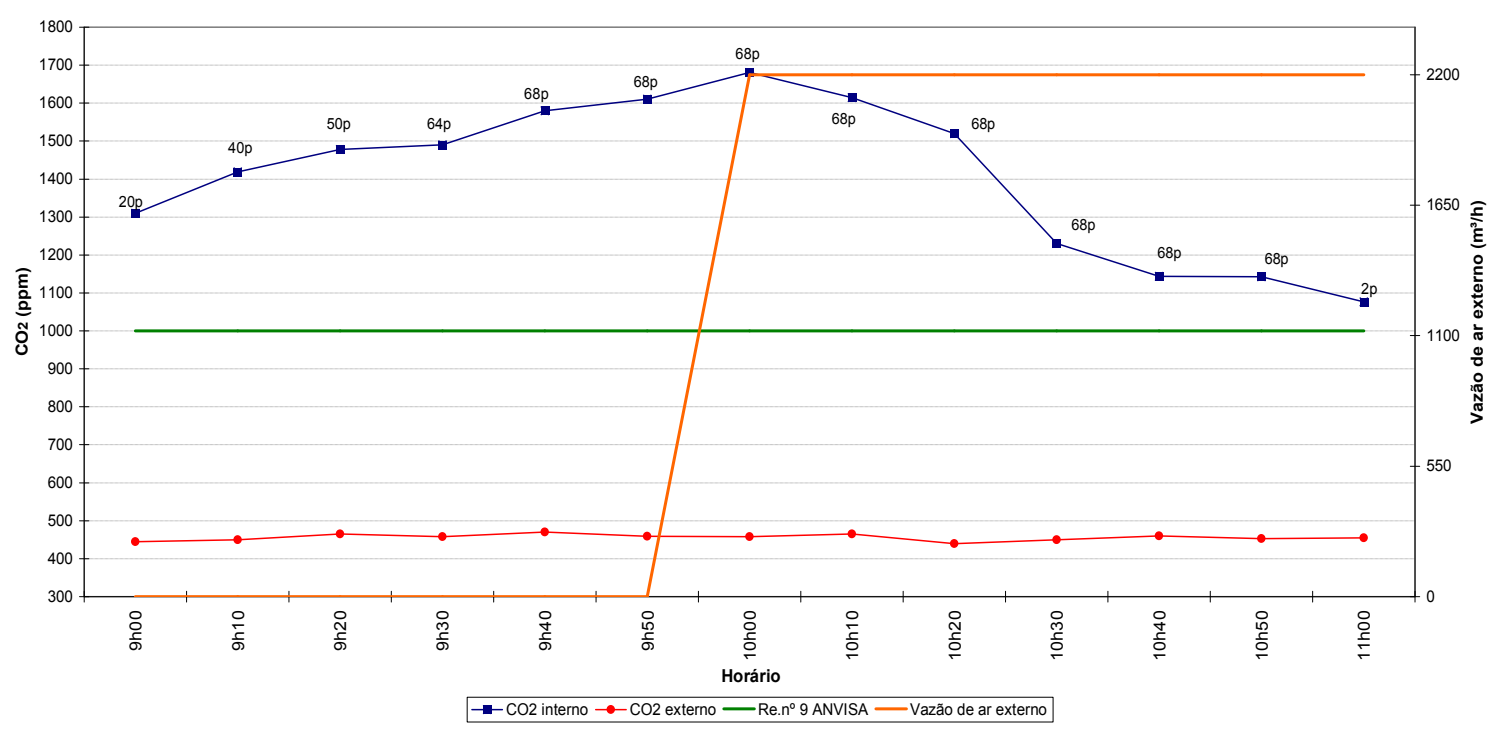

Figura 4.38. Concentração de $\mathrm{CO}_{2}$ na sala de aula $\mathrm{A} 2$ do dia 22/08/2016.

Conforme visto anteriormente, percebe-se o aumento da concentração de $\mathrm{CO}_{2}$ a partir do momento em que a sala torna-se ocupada.

Nota-se que a concentração de $\mathrm{CO}_{2}$ no interior do ambiente, antes do ínicio das medições, já se encontrava acima dos 1000 ppm sugeridos pela resolução da ANVISA. As altas taxas de $\mathrm{CO}_{2}$ verificadas devem-se ao fato de que a sala estava ocupada anteriormente por alunos de outra disciplina. Observa-se que com o aumento da vazão de ar externo, com 4 unidades de renovação em funcionamento, ocorre uma queda de aproximadamente 600 ppm, após 50 minutos do aumento da vazão de ar externo, na concentração de $\mathrm{CO}_{2}$. Esta queda, apesar de significativa, não atingiu o limite máximo de 1000 ppm. 


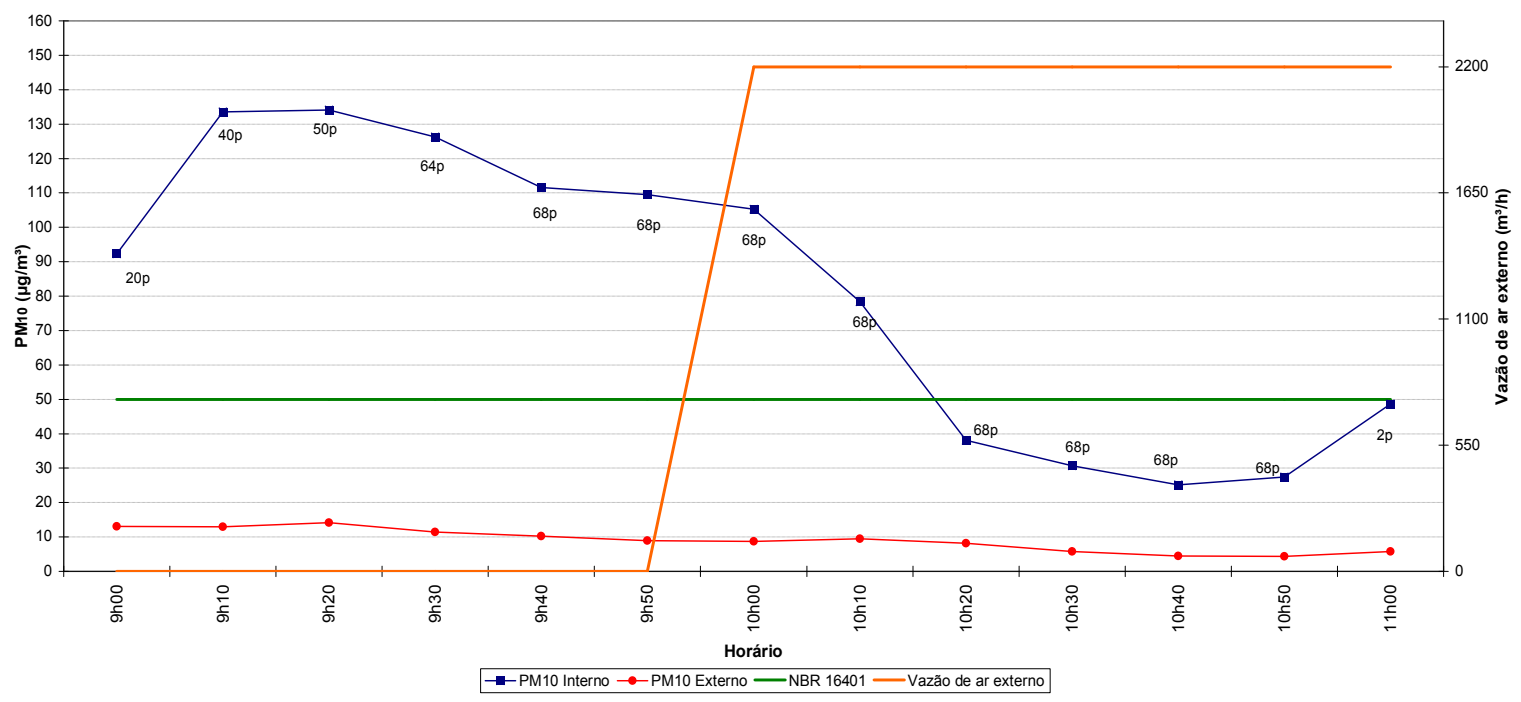

Figura 4.39. Concentração de $\mathrm{PM}_{10}$ na sala de aula $\mathrm{A} 2$ do dia 22/08/2016.

Devido à ocupação prévia da sala, nota-se que a concentração de particulado $\mathrm{PM}_{10}$ (figura 4.39) já se encontrava acima do limite aceitável de $50 \mu \mathrm{g} / \mathrm{m}^{3}$ pela NBR 16401 (ABNT, 2008). Com a entrada dos ocupantes, ocorreu um aumento da concentração. Já, com o funcionamento das 4 unidades de renovação, a concentração de $\mathrm{PM}_{10}$ diminui significativamente, aproximadamente $76 \%$ após 40 minutos do aumento da vazão de ar externo, atingindo valores abaixo do limite aceitável de $50 \mu \mathrm{g} / \mathrm{m}^{3}$. 


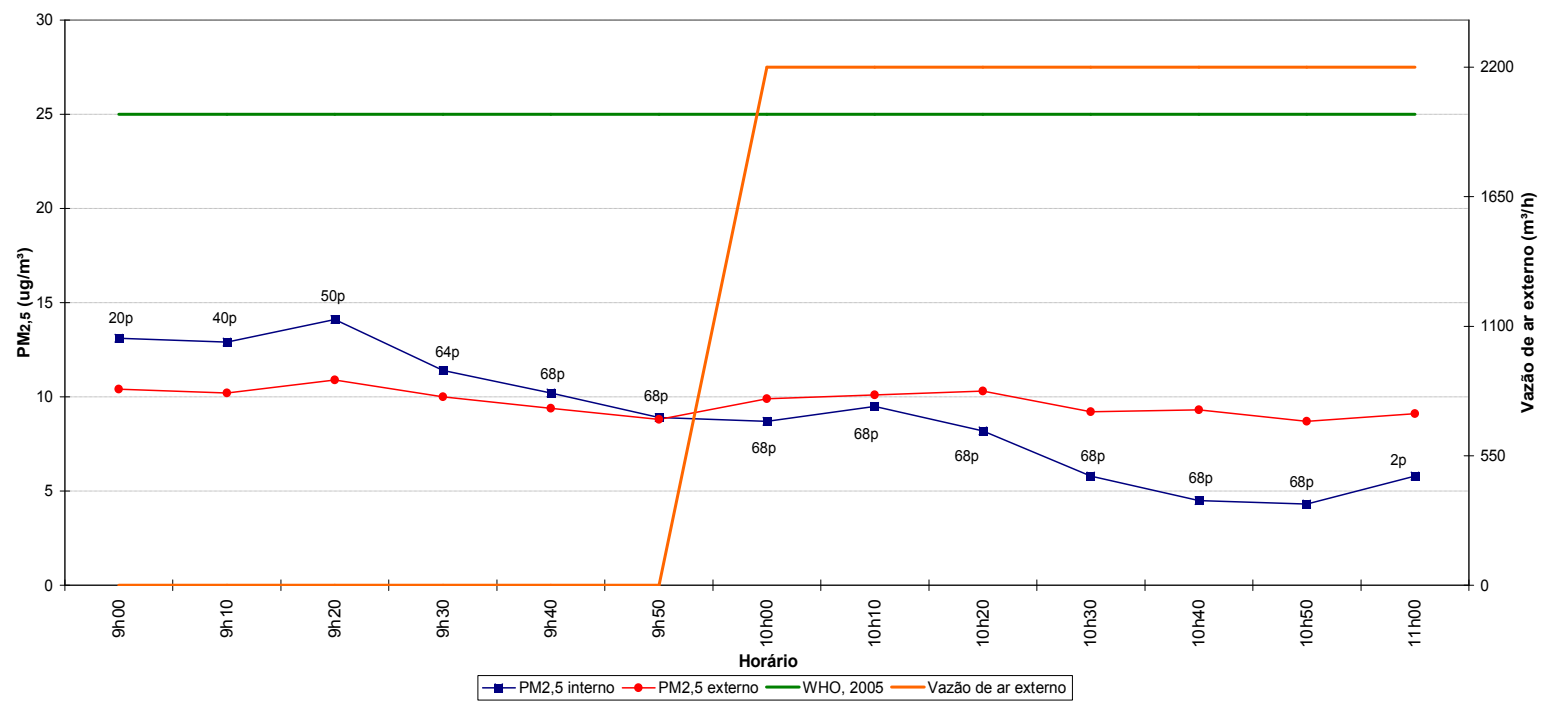

Figura 4.40. Concentração de $\mathrm{PM}_{2,5}$ na sala de aula $\mathrm{A} 2$ do dia 22/08/2016.

Para a concentração de particulado $\mathrm{PM}_{2,5}$ (figura 4.40), os dados se apresentaram abaixo do limite aceitável de $25 \mu \mathrm{g} / \mathrm{m}^{3}$ pela Organização Mundial da Saúde (World Health Organization, 2005) durante toda a aula. Nota-se novamente a influência dos filtros na tomada de ar externo, visto que é possível observar que a concentração de material particulado $\mathrm{PM}_{2,5}$ no interior do ambiente torna-se menor que a do ar externo com 4 unidades em funcionamento, mesmo com geração interna de particulados. 


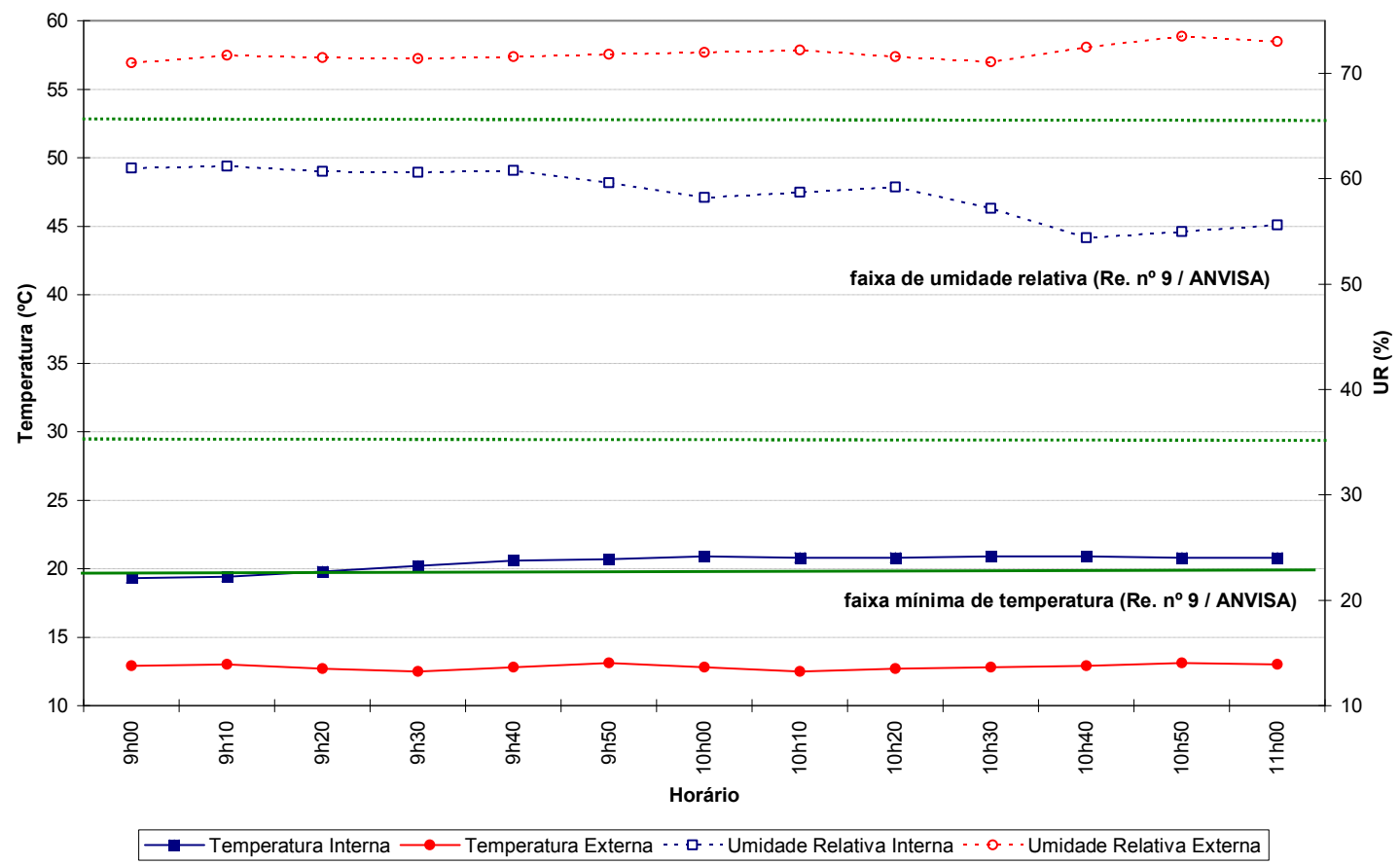

Figura 4.41. Temperatura e umidade relativa na sala de aula A2 do dia 22/08/2016.

Verifica-se na figura 4.41 que a temperatura no interior da sala de aula se manteve adequada durante todo o experimento, bem como a umidade relativa, de acordo com a resolução número 9 da ANVISA.

\subsubsection{Quarta medição (T4) - quarta-feira (24/08/16)}

A quarta medição das aulas teóricas na sala de aula A2 ocorreu no dia 24/08/2016 (quartafeira) durante a aula de Mecânica dos Fluidos. Nesta medição foram verificadas as concentrações de $\mathrm{CO}_{2}, \mathrm{PM}_{2,5}$ e $\mathrm{PM}_{10}$. O número de ocupantes chegou em 63 pessoas. As medições foram realizadas no período das 8 horas às 11 horas e 35 minutos.

A vazão de ar externo foi variada depois de transcorridas duas horas de aula. As medições ocorreram a cada 10 minutos durante o período da aula. Após o término da mesma (11 horas da manhã), as medidas foram tomadas a cada 5 minutos apenas internamente. Dessa forma, busca-se observar o comportamento dos parâmetros medidos com a saída dos ocupantes devido ao término da aula. A vazão de ar externo foi variada de acordo com a tabela a seguir. 
Tabela 4.9. Variação da vazão de ar externo para a medição T4.

\begin{tabular}{|c|c|}
\hline Intervalo & Vazão $\left(\mathbf{m}^{\mathbf{3}} / \mathbf{h}\right)$ \\
\hline $08 \mathrm{~h} 10$ às $09 \mathrm{~h} 50$ & 0 \\
\hline $10 \mathrm{~h} 00$ às $11 \mathrm{~h} 35$ & 2200 \\
\hline
\end{tabular}

Os dados obtidos na medição teórica T4 para a concentração de $\mathrm{CO}_{2}, \mathrm{PM}_{10}, \mathrm{PM}_{2,5}$ e TBS e UR podem ser observados nas figuras 4.42, 4.43, 4,44 e 4,45, respectivamente. O número de ocupantes em cada ponto de medição está indicado nas figuras pela letra "p".

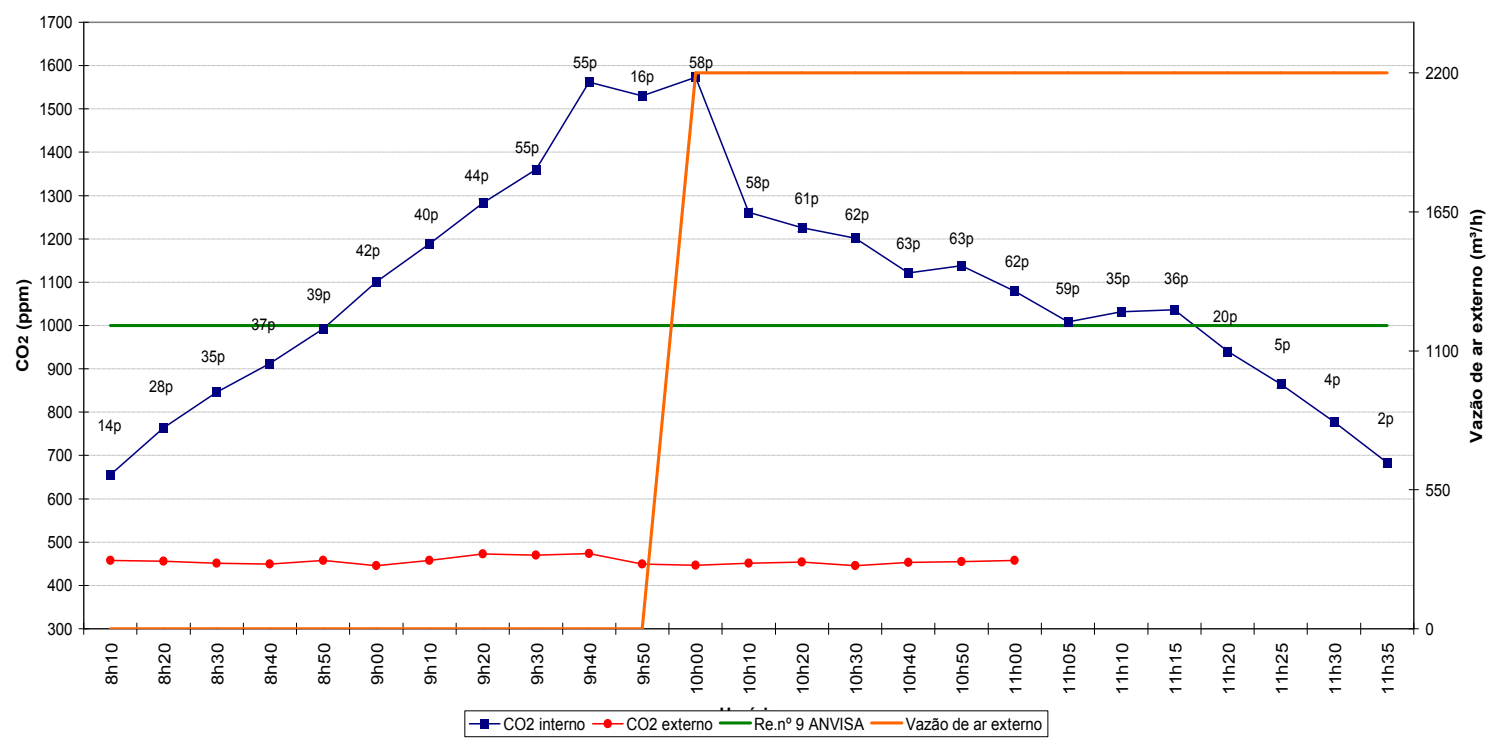

Figura 4.42. Concentração de $\mathrm{CO}_{2}$ na sala de aula A2 do dia 24/08/2016.

Porém, com o início da operação das 4 unidades de renovação, a concentração de $\mathrm{CO}_{2}$ começa a diminuir até um patamar próximo aos 1000 ppm sugeridos pela resolução $\mathrm{n}^{\circ} 9$ da ANVISA. A concentração fica abaixo do limite dos 1000 ppm apenas após a saída dos ocupantes. 


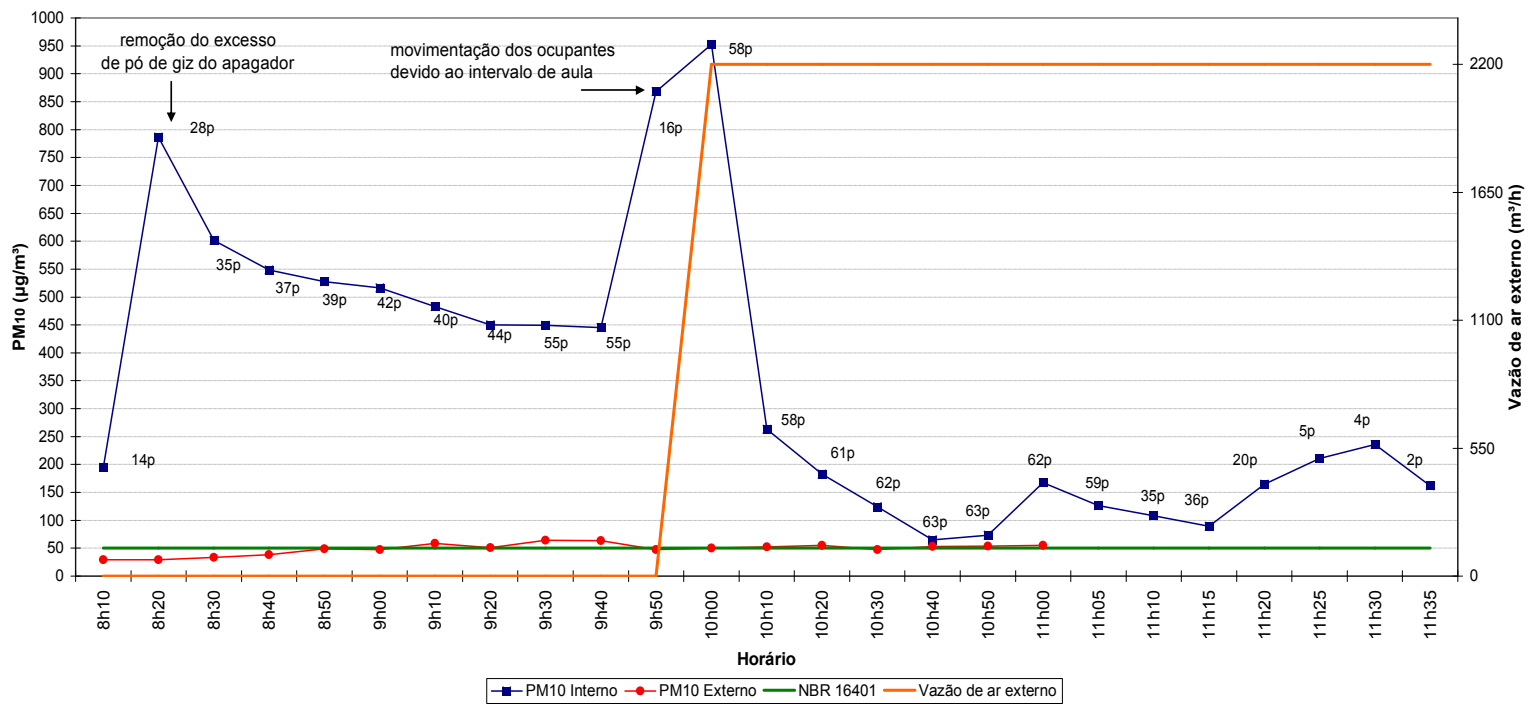

Figura 4.43. Concentração de $\mathrm{PM}_{10}$ na sala de aula $\mathrm{A} 2$ do dia 24/08/2016.

Mesmo a sala se encontrando vazia no período anterior às medições, nota-se que a concentração de particulado $\mathrm{PM}_{10}$ (figura 4.43) já se encontrava acima do limite aceitável de $50 \mu \mathrm{g} / \mathrm{m}^{3}$ pela NBR 16401 (ABNT, 2008). Com a entrada dos ocupantes e uma pequena remoção do excesso de giz do apagador pelo professor, ocorre um aumento da concentração do particulado. Já, com o funcionamento das 4 unidades de renovação, a concentração de $\mathrm{PM}_{10}$ diminui significativamente, aproximadamente 94\% após 40 minutos do aumento da vazão de ar externo, atingindo valores próximos ao limite aceitável de $50 \mu \mathrm{g} / \mathrm{m}^{3}$, porém sempre acima. Verifica-se também uma alta concentração de $\mathrm{PM}_{10}$ no ar externo, muitas vezes com valores superiores aos $50 \mu \mathrm{g} / \mathrm{m}^{3}$. 


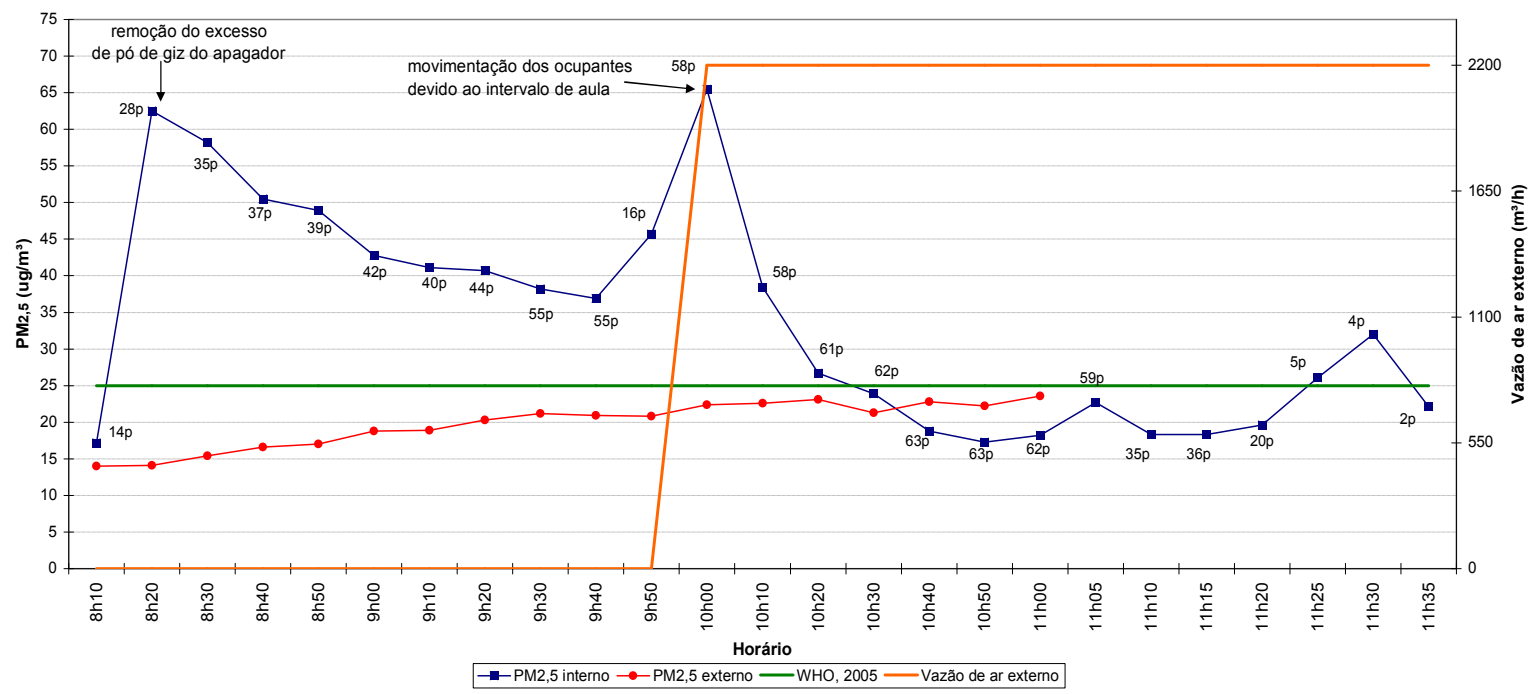

Figura 4.44. Concentração de $\mathrm{PM}_{2,5}$ na sala de aula $\mathrm{A} 2$ do dia 24/08/2016.

Para a concentração de particulado $\mathrm{PM}_{2,5}$ (figura 4.44), os dados se apresentaram acima do limite aceitável de $25 \mu \mathrm{g} / \mathrm{m}^{3}$ pela Organização Mundial da Saúde (World Health Organization, 2005) enquanto as unidades de renovação não estavam em funcionamento. Após o início de operação das 4 unidades de renovação, a concentração de $\mathrm{PM}_{2,5}$ chegou ficar abaixo dos 25 $\mu \mathrm{g} / \mathrm{m}^{3}$. Outrossim, durante este período, a concentração desse particulado esteve menor que a do ar externo, verificando novamente a influência dos filtros na tomada de ar externo. 


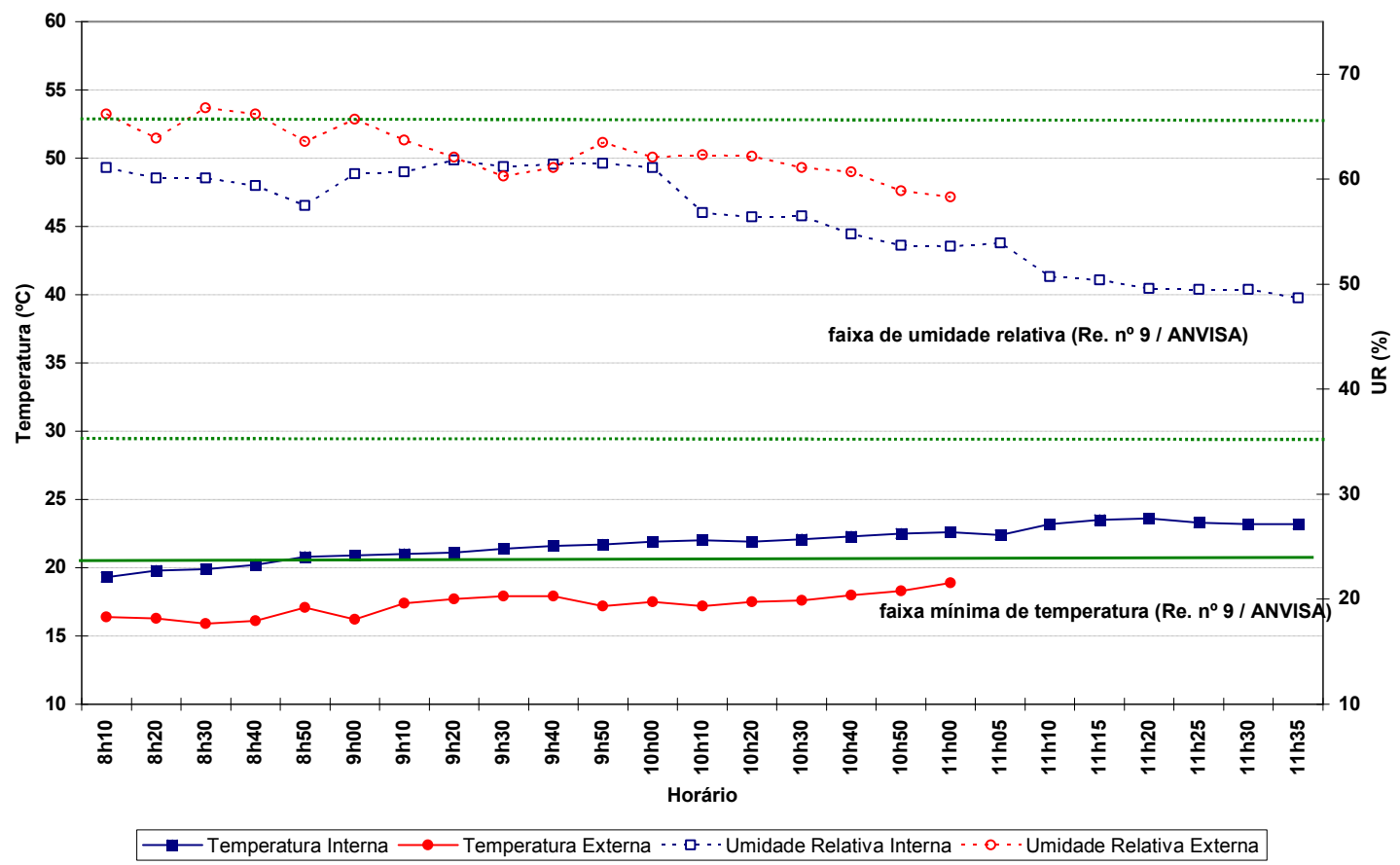

Figura 4.45. Temperatura e umidade relativa na sala de aula A2 do dia 24/08/2016.

Verifica-se na figura 4.45 que a temperatura no interior da sala de aula se manteve adequada durante todo o experimento, bem como a umidade relativa, de acordo com a resolução número 9 da ANVISA.

\subsubsection{Quinta medição (T5) - sexta-feira (26/08/16)}

A quinta medição das aulas teóricas na sala de aula A2 ocorreu no dia 26/08/2016 (sextafeira) durante a aula de Eletrônica. O número de ocupantes chegou em 114 pessoas. As medições foram realizadas no período das 8 horas e 10 minutos às 11 horas e 40 minutos.

Nesta medição foram aferidas as concentrações de $\mathrm{CO}_{2}, \mathrm{PM}_{2,5}$ e $\mathrm{PM}_{10}$. A vazão de ar externo foi variada três vezes: primeiro acionou-se duas unidades de renovação (aos 50 minutos de aula); após mais 1 hora e 30 minutos foram ligadas as quatro unidades de renovação; e por fim, foram desligadas todas as unidades (após mais 1 hora de aula). Da mesma forma que a medição anterior (24/08/16), após as 11 horas e 10 minutos da manhã, apenas as medidas do ambiente interno foram tomadas a cada 5 minutos. Dessa forma, buscou-se observar o 
comportamento dos parâmetros medidos com a saída dos ocupantes, devido ao término da aula. A vazão de ar externo foi variada de acordo com a tabela a seguir.

Tabela 4.10. Variação da vazão de ar externo para a medição T5.

\begin{tabular}{|c|c|}
\hline Intervalo & Vazão $\left(\mathbf{m}^{\mathbf{3}} / \mathbf{h}\right)$ \\
\hline $08 \mathrm{~h} 10$ às $08 \mathrm{~h} 50$ & 0 \\
\hline $09 \mathrm{~h} 00$ às $10 \mathrm{~h} 20$ & 1100 \\
\hline $10 \mathrm{~h} 30$ às $11 \mathrm{~h} 20$ & 2200 \\
\hline $11 \mathrm{~h} 25$ às $11 \mathrm{~h} 40$ & 0 \\
\hline
\end{tabular}

Os dados obtidos na medição teórica T5 para a concentração de $\mathrm{CO}_{2}, \mathrm{PM}_{10}, \mathrm{PM}_{2,5}$ e TBS e UR podem ser observados nas figuras 4.46, 4.47, 4,48 e 4,49, respectivamente. O número de ocupantes em cada ponto de medição está indicado nas figuras pela letra "p".

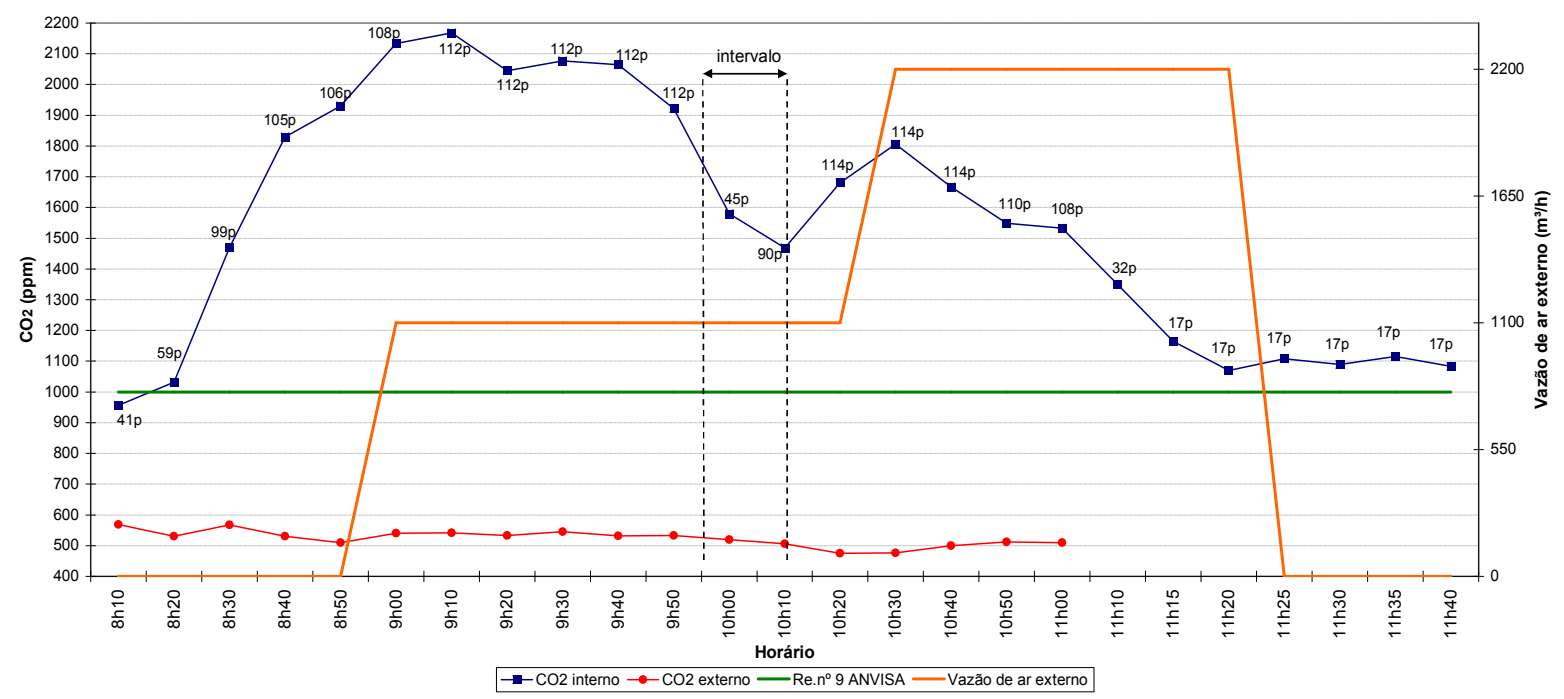

Figura 4.46. Concentração de $\mathrm{CO}_{2}$ na sala de aula $\mathrm{A} 2$ do dia 26/08/2016.

Como indicativo da presença de uma fonte geradora de $\mathrm{CO}_{2}$, a concentração do parâmetro começa a aumentar conforme a ocupação da sala.Com o início da operação de duas unidades 
de renovação, a concentração de $\mathrm{CO}_{2}$ começa a estabilizar e diminuir lentamente até o intervalo de aula, que diminui rapidamente com a saída dos ocupantes. Porém, após o intervalo, a concentração de $\mathrm{CO}_{2}$ volta a aumentar até a entrada das 4 unidades de renovação, fazendo com que a concentração diminua até valores próximos aos 1000 ppm sugeridos pela resolução no 9 da ANVISA.

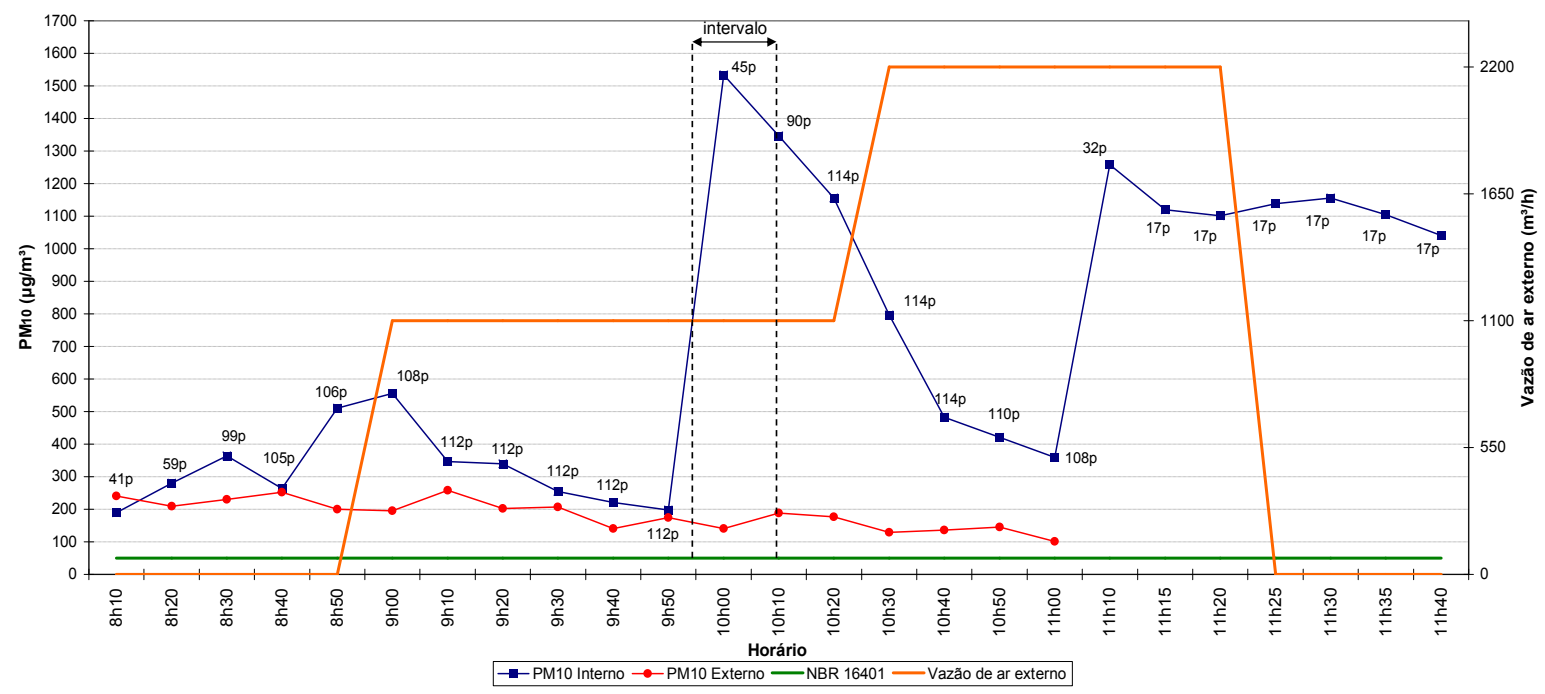

Figura 4.47. Concentração de $\mathrm{PM}_{10}$ na sala de aula A2 do dia 26/08/2016.

Apesar da não ocupação prévia da sala, nota-se que a concentração de particulado $\mathrm{PM}_{10}$ (figura 4.47) já se encontrava acima do limite aceitável de $50 \mu \mathrm{g} / \mathrm{m}^{3}$ pela NBR 16401 (ABNT, 2008). Esse fato deve-se a uma obra que estava sendo realizada no ambiente externo, ao lado da sala de aula A2. Com a entrada dos ocupantes, ocorre, além do aumento natural dos parâmetros (verificados nas outras medições), um transporte de particulado através das correntes de ar para o interior da sala, contribuindo ainda mais com a elevação da concentração de particulados. Com o acionamento de duas unidades de renovação, a concentração diminui lentamente. Em virtude do intervalo de aula, o qual gera a abertura da porta da sala, ocorre uma grande movimentação dos ocupantes acarretando em um aumento rápido da concentração de $\mathrm{PM}_{10}$. Porém, com o funcionamento das 4 unidades de renovação, a concentração de $\mathrm{PM}_{10}$ diminui significativamente até uma nova movimentação dos ocupantes em virtude do término da aula. 


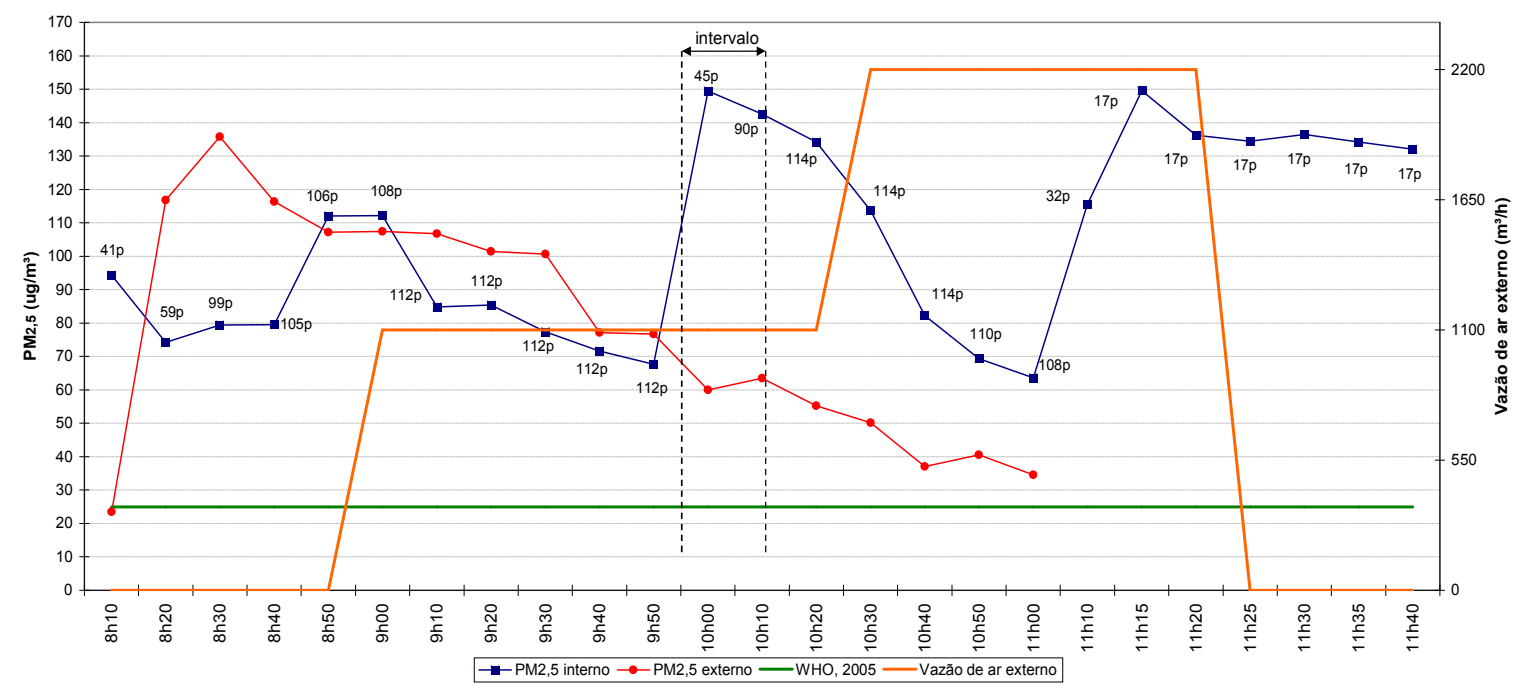

Figura 4.48. Concentração de $\mathrm{PM}_{2,5}$ na sala de aula $\mathrm{A} 2$ do dia 26/08/2016.

Para a concentração de particulado $\mathrm{PM}_{2,5}$ (figura 4.48), os dados se apresentaram acima do limite aceitável de $25 \mu \mathrm{g} / \mathrm{m}^{3}$ pela Organização Mundial da Saúde (World Health Organization, 2005) durante toda a aula. A concentração de $\mathrm{PM}_{2,5}$ comportou-se de maneira similar ao $\mathrm{PM}_{10}$ com o acionamento das unidades de renovação e movimentação dos ocupantes. 


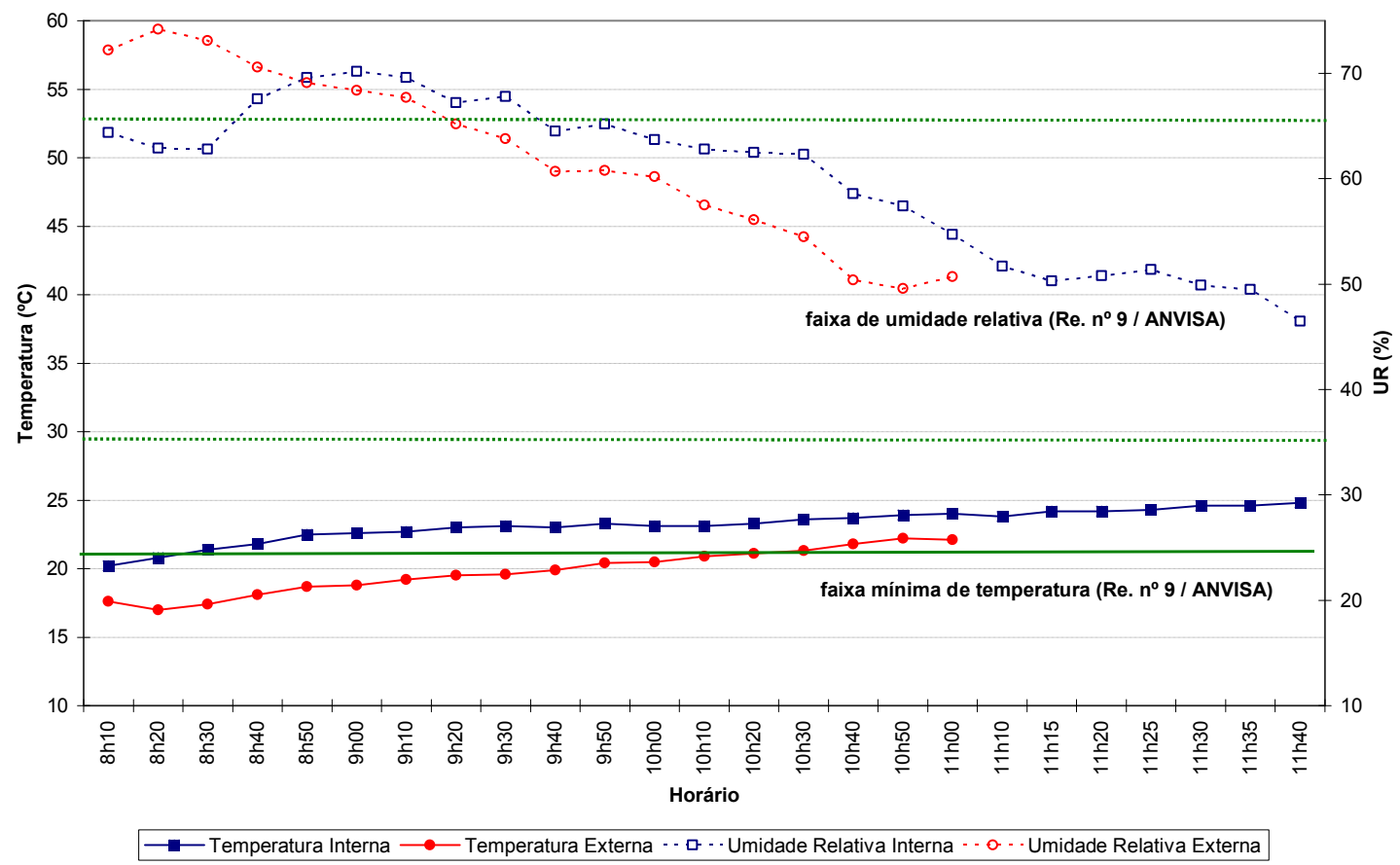

Figura 4.49. Temperatura e umidade relativa na sala de aula A2 do dia 26/08/2016.

Verifica-se na figura 4.49 que a temperatura no interior da sala de aula se manteve adequada durante todo o experimento, bem como a umidade relativa, de acordo com a resolução número 9 da ANVISA.

\subsubsection{Sexta medição (T6) - segunda-feira (24/10/16)}

A sexta medição das aulas teóricas na sala de aula A2 ocorreu no dia 24/10/2016 (segundafeira) durante outra aula de Mecânica dos Fluidos, no dia seguinte à Oficina de Carrinhos de Rolimã. O número de ocupantes chegou em 40 pessoas. As medições foram realizadas no período das 8:50 horas às 11:25 horas.

Para esta medição foram verificadas as concentrações de $\mathrm{CO}_{2}, \mathrm{PM}_{2,5}$ e $\mathrm{PM}_{10}$. A medição teve o objetivo básico de confirmar algumas hipóteses observadas nas medições das aulas teóricas anteriores. Sendo assim, a vazão de ar externo era variada de acordo com a quantidade de ocupantes no interior da sala, ou seja, duas unidades de renovação ficaram em funcionamento com os 40 ocupantes, insuflando aproximadamente $28 \mathrm{~m}^{3} / \mathrm{h}$ por pessoa de ar externo. A ideia foi manter a vazão aproximada de $27 \mathrm{~m}^{3} / \mathrm{h}$ por pessoa de ar externo para garantir a 
concentração de $\mathrm{CO}_{2}$ dentro dos 1000 ppm, e assim verificar se a mesma vazão era suficiente para manter as concentrações de material particulado dentro dos limites estabelecidos. A vazão de ar externo foi variada de acordo com a tabela a seguir.

Tabela 4.11. Variação da vazão de ar externo para a medição T6.

\begin{tabular}{|c|c|}
\hline Intervalo & Vazão $\left(\mathbf{m}^{\mathbf{3}} / \mathbf{h}\right)$ \\
\hline $08 \mathrm{~h} 40$ às $08 \mathrm{~h} 50$ & 0 \\
\hline $09 \mathrm{~h} 00$ às $09 \mathrm{~h} 20$ & 558 \\
\hline $09 \mathrm{~h} 30$ às $11 \mathrm{~h} 25$ & 1100 \\
\hline
\end{tabular}

Cabe observar que a primeira metade da aula foi ministrada utilizando projetor, e a segunda metade da aula utilizando a lousa. A alteração da forma de ministrar a aula gerou uma variação de particulado no ar, a qual pode ser verificada nas figuras 4.51 e 4.52 .

Após as 11 horas da manhã, com o término da aula, as medidas do ambiente interno foram tomadas a cada 5 minutos. Dessa forma, buscou-se observar o comportamento dos parâmetros medidos com a saída dos ocupantes.

Os dados obtidos na medição teórica T6 para a concentração de $\mathrm{CO}_{2}, \mathrm{PM}_{10}, \mathrm{PM}_{2,5}$ e TBS e UR podem ser observados nas figuras 4.50, 4.51, 4,52 e 4,53, respectivamente. O número de ocupantes em cada ponto de medição está indicado nas figuras pela letra "p". 


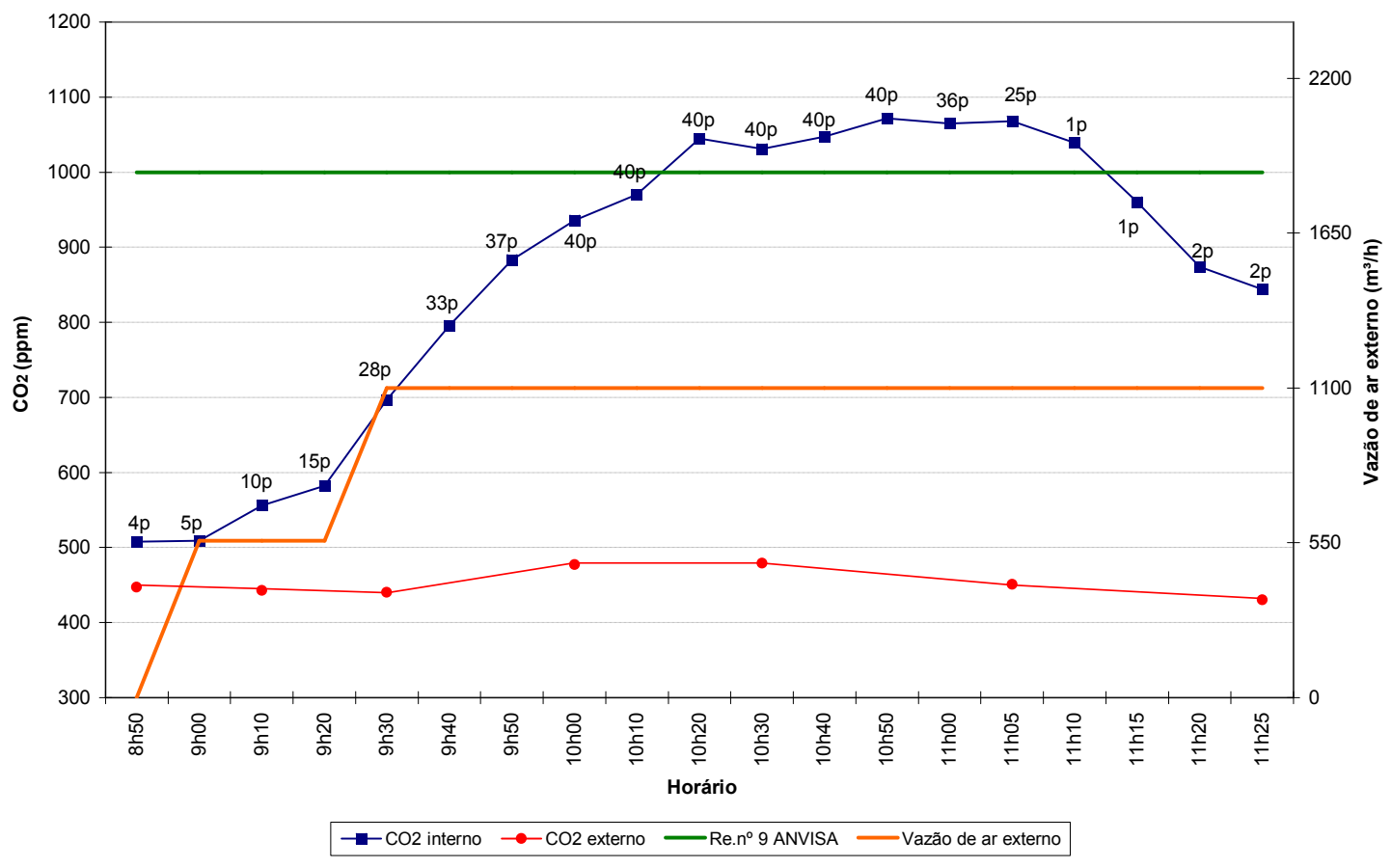

Figura 4.50. Concentração de $\mathrm{CO}_{2}$ na sala de aula $\mathrm{A} 2$ do dia 24/10/2016.

A figura 4.50 apresenta os dados obtidos para a concentração de $\mathrm{CO}_{2}$, e o número de ocupantes em cada ponto de medição indicados pela letra "p". Da mesma forma que as outras medições, ocorre um aumento da concentração de $\mathrm{CO}_{2}$ a partir do momento em que a sala torna-se ocupada, indicando a presença de uma fonte geradora de $\mathrm{CO}_{2}$. Porém, com o início da operação das 2 unidades de renovação para manter aproximadamente os $27 \mathrm{~m}^{3} / \mathrm{h}$ por pessoa de ar externo, a concentração de $\mathrm{CO}_{2}$ estabiliza-se em um patamar próximo aos 1000 ppm sugeridos pela resolução $\mathrm{n}^{\circ} 9$ da ANVISA. Após a saída dos ocupantes, a concentração de $\mathrm{CO}_{2}$ diminui rapidamente, ficando abaixo do limite dos $1000 \mathrm{ppm}$. 


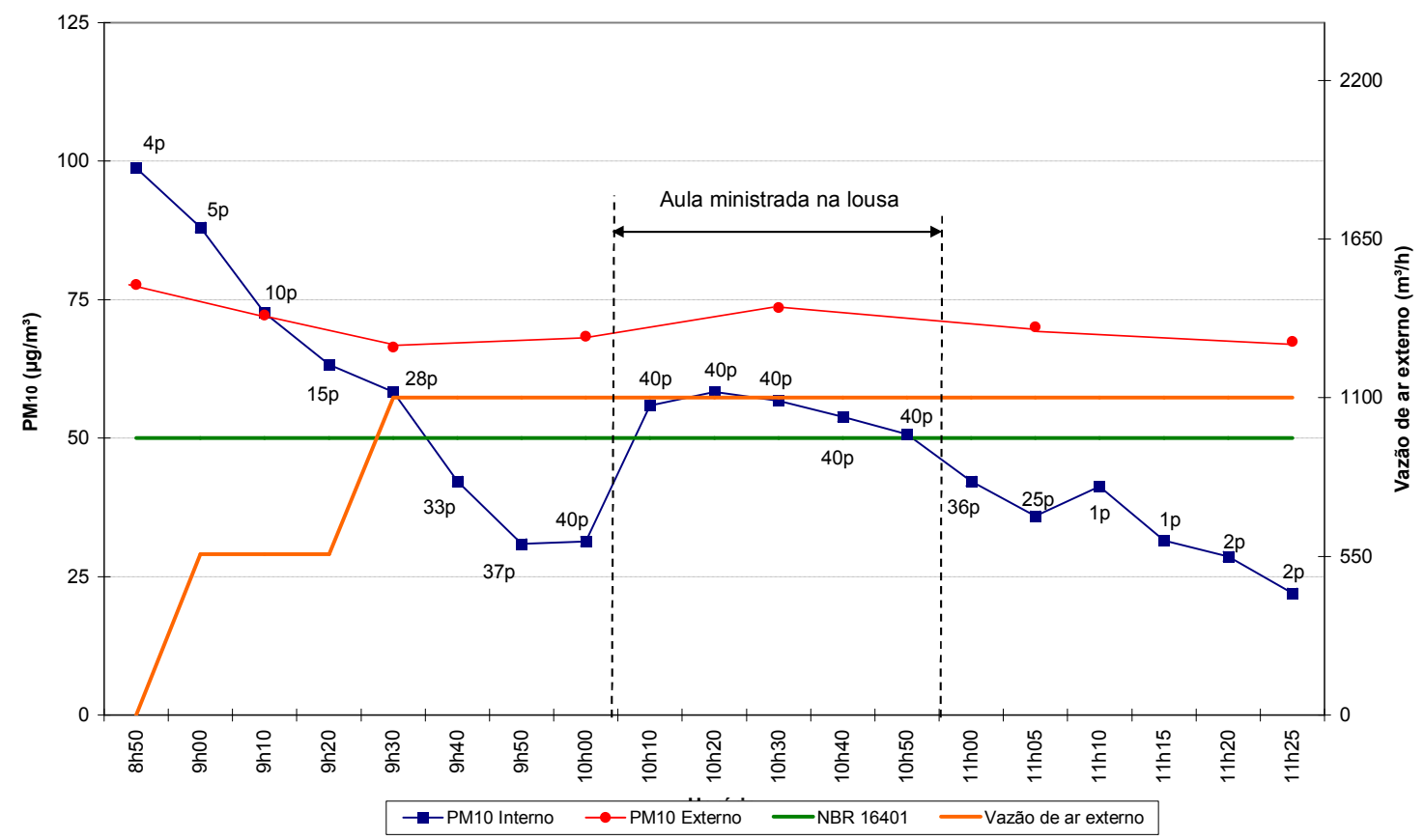

Figura 4.51. Concentração de $\mathrm{PM}_{10}$ na sala de aula $\mathrm{A} 2$ do dia 24/10/2016.

Apesar da não ocupação prévia da sala, nota-se que a concentração de particulado $\mathrm{PM}_{10}$ (figura 4.51) já se encontrava acima do limite aceitável de $50 \mu \mathrm{g} / \mathrm{m}^{3}$ pela NBR 16401 (ABNT, 2008). É possível observar que a concentração de particulado no ambiente externo nesse dia encontrava-se elevada, influenciando na concentração inicial da sala.

Com o início da operação das 2 unidades de renovação de ar, a concentração de $\mathrm{PM}_{10}$ diminui atingindo valores abaixo do limite aceitável de $50 \mu \mathrm{g} / \mathrm{m}^{3}$. Observa-se que, com o início da utilização da lousa, a concentração do particulado supracitado aumenta em aproximadamente $50 \%$, mesmo com as unidades de renovação em funcionamento, atingindo valores superiores aos $50 \mu \mathrm{g} / \mathrm{m}^{3}$. 


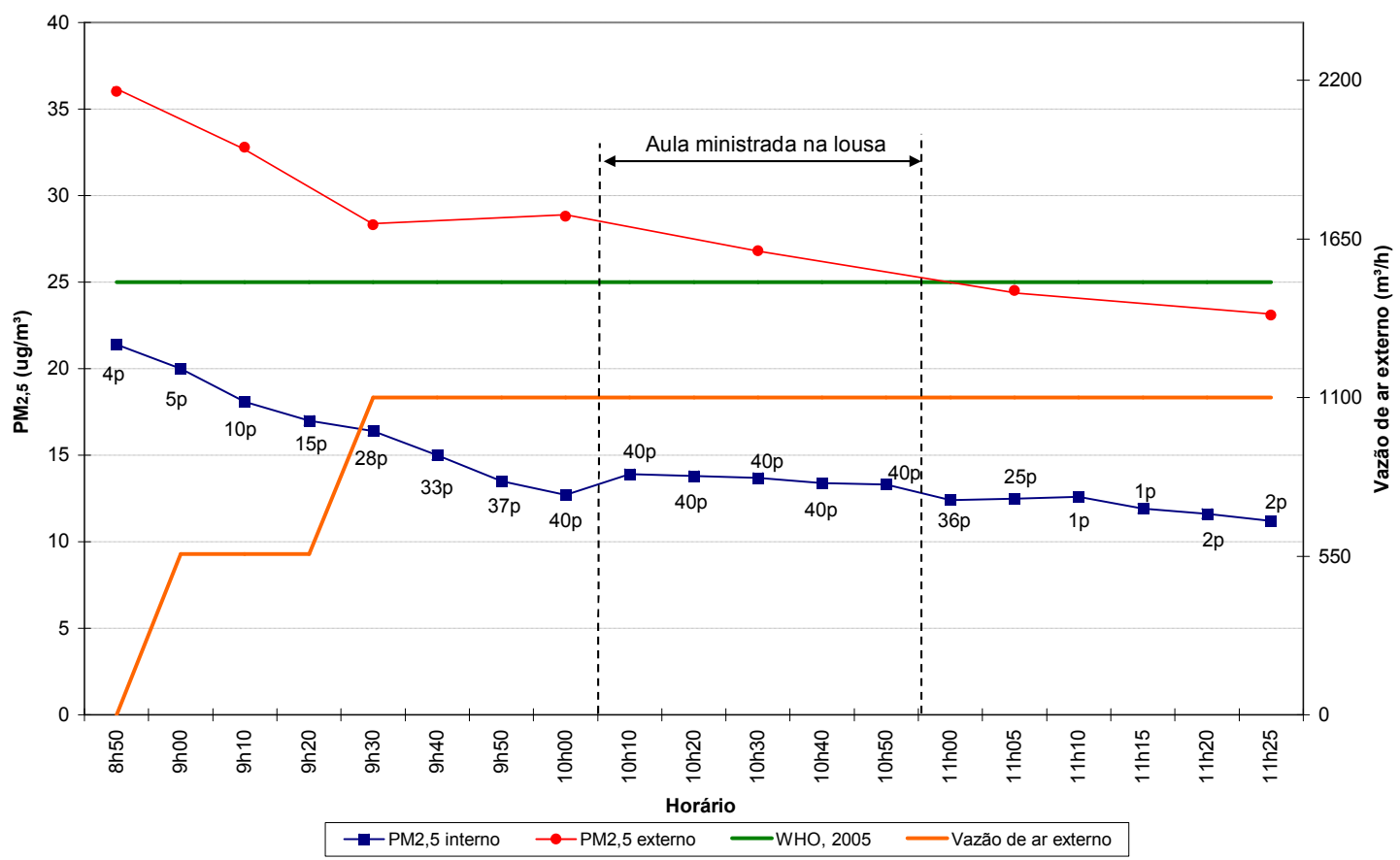

Figura 4.52. Concentração de $P M_{2,5}$ na sala de aula $A 2$ do dia 24/10/2016.

Para a concentração de particulado $\mathrm{PM}_{2,5}$ (figura 4.52), os dados se apresentaram abaixo do limite aceitável de $25 \mu \mathrm{g} / \mathrm{m}^{3}$ pela Organização Mundial da Saúde (World Health Organization, 2005) durante toda a aula. É possível observar que o comportamento da concentração de $\mathrm{PM}_{2,5}$ no interior da sala é semelhante ao do ar externo. A concentração de $\mathrm{PM}_{2,5}$ apresenta um pequeno aumento, e diverge suavemente do comportamento da concentração do particulado no ar externo, apenas quando inicia-se a aula na lousa. 


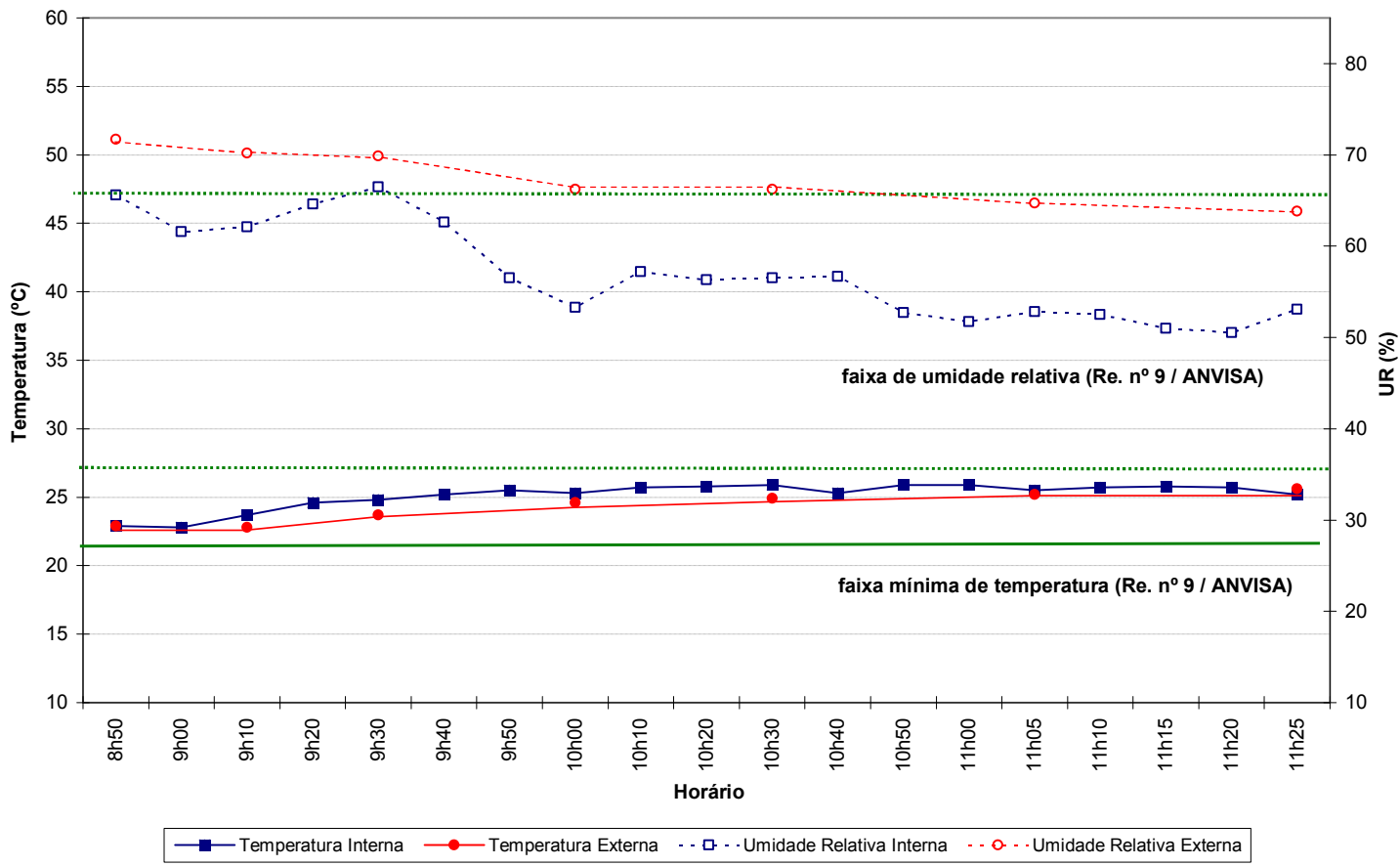

Figura 4.53. Temperatura e umidade relativa na sala de aula A2 do dia 24/10/2016.

Verifica-se na figura 4.53 que a temperatura no interior da sala de aula se manteve adequada durante todo o experimento, bem como a umidade relativa, de acordo com a resolução número 9 da ANVISA. 


\section{ANÁLISE GERAL DOS RESULTADOS}

As variações nas concentrações internas dos parâmetros monitorados estão relacionadas com aspectos relativos à interface com o ambiente externo, com o sistema de tratamento de ar, com as condições requeridas pelos usuários, bem como com as atividades desempenhadas no interior do ambiente.

Os valores de temperatura e umidade foram controlados com as duas unidades de condicionamento de ar instaladas. Apesar de não haver nenhum controle de umidade das salas, apenas nas medições (P1 e T2) dos dias 21/05/2016 e 19/08/2016 (figuras 4.6 e 4.37) os valores obtidos estiveram acima do limite recomendo de $65 \%$ para o verão conforme a resolução $n^{\circ} 9$ da ANVISA e a parte 2 da NBR 16401 (ABNT, 2008).

Para a concentração de $\mathrm{CO}_{2}$, observa-se que a renovação de ar é importante para a manutenção das suas concentrações limites, haja vista que as concentrações de $\mathrm{CO}_{2}$ nas medições realizadas sem as unidades de renovação sempre ultrapassavam o limite aceitável de 1000 ppm recomendado pela ANVISA, ou até mesmo os 700 ppm a mais que o ar externo, conforme a parte 3 da NBR 16401 (ABNT, 2008). Valores superiores a três vezes o limite foram observados na medição P3 do dia 21/10/16 (figura 4.15), sendo que patamares maiores não foram atingidos pois as unidades de renovação foram ligadas.

Conforme visto na revisão da literatura, altas concentrações de $\mathrm{CO}_{2}$ são prejudiciais para o aprendizado de estudantes. O período em que as unidades de renovação estavam desligadas evidenciam o comportamento da sala de aula antes da instalação das mesmas. Apesar da utilização das 4 unidades, elas não foram suficientes para suprimento de $27 \mathrm{~m}^{3} / \mathrm{h}$ de ar externo nos casos em que a ocupação da sala de aula é máxima (figura 4.15), medição P3. As quatro unidades de renovação instaladas possuem capacidade de atendimento de aproximadamente 80 ocupantes para disponibilizar uma taxa de renovação de $27 \mathrm{~m}^{3} / \mathrm{h}$ por pessoa, conforme recomendação da resolução $\mathrm{n}^{\mathrm{o}} 9$ da ANVISA. Dessa forma, observou-se em algumas medições (P3, T2 e T5) que, quando a sala possuía mais do que 80 ocupantes, as 4 unidades de renovação não conseguiram suprir os $27 \mathrm{~m}^{3} / \mathrm{h}$ de ar externo por pessoa propostos, fazendo com que o limite aceitável não fosse atingido (figuras 4.15, 4.34 e 4.46).

Nas medições realizadas por Bordini (2015) na sala de aula A2, apenas com ventilação natural através da porta e janelas, a concentração máxima de $\mathrm{CO}_{2}$ registrada foi de aproximadamente 
500 ppm para a Oficina de Carrinhos de Rolimã. Comparando com as medições atuais da aula prática P4 e P5 da mesma oficina (figuras 4.21 e 4.27), verifica-se que a concentração de $\mathrm{CO}_{2}$ atingiu valores mínimos de $800 \mathrm{ppm}$ e $850 \mathrm{ppm}$, respectivamente, mesmo com as quatro unidade de renovação em funcionamento e a mesma quantidade de ocupantes do experimento de Bordini. Para as medições de aula teórica, a figura 4.50 (medição T6) apresenta uma estabilização em aproximadamente 1050 ppm de $\mathrm{CO}_{2}$ com duas unidades de renovação em funcionamento e 40 ocupantes. Em Bordini (2015), a concentração máxima de $\mathrm{CO}_{2}$ foi de 800 ppm para a aula teórica com 56 ocupantes. Observa-se que nas duas medições, a concentração de $\mathrm{CO}_{2}$ externa era de aproximadamente $450 \mathrm{ppm}$. Os gráficos obtidos por Bordini são apresentados no Anexo H.

No estudo de Bordini (2015) para a concentração de $\mathrm{PM}_{10}$ é possível observar que na aula teórica, a concentração de $\mathrm{PM}_{10}$ no interior da sala $\mathrm{A} 2$ acompanhou basicamente a concentração do ar externo. Já para a medição atual da Oficina de Carrinhos de Rolimã (medição P4 e P5), a concentração máxima atingida foi de $250 \mu \mathrm{g} / \mathrm{m}^{3}$. Comparando com as medições atuais, conclui-se que a filtragem do ar externo evita que a concentração de particulado no interior da sala se comporte semelhante ao apresentado por Bordini (2015) na aula teórica. Porém, para a Oficina de Carrinhos de Rolimã, a concentração máxima por ele apresentada foi inferior à das medições atuais.

O comportamento da concentração de $\mathrm{CO}_{2}$ e do $\mathrm{PM}_{10}$ nos estudos de Bordini (2015), utilizando apenas de ventilação natural, em alguns momentos, foi melhor do que obtido neste estudo com as unidades de renovação. É importante destacar, no entanto, que no estudo de Bordini (2015), a sala de aula não possuía controle de temperatura e umidade e, nos casos em que o ar externo apresentava concentrações elevadas de particulado, o mesmo não era filtrado para o suprimento do ambiente.

Para a concentração de material particulado, $\mathrm{PM}_{2,5}$ e $\mathrm{PM}_{10}$, verifica-se que, independentemente das atividades de usinagem existirem no interior da sala de aula ou não (aulas práticas e aula teóricas), a concentração de material particulado atinge valores acima dos limites impostos. Tais fatos devem-se principalmente à ação de escrever na lousa com giz pelo professor, sendo evidenciada principalmente na medição T6 (figuras 4.51 e 4.52), onde não ocorreu tal atividade no início da aula e logo em seguida o professor começou a escrever na lousa, e na medição P3 (figuras 4.16 e 4.17) onde tal atividade aconteceu durante a primeira parte da aula e deixou de existir para aplicação da prova. A tabela a seguir apresenta 
a variação das concentrações de $\mathrm{PM}_{2,5}$ e $\mathrm{PM}_{10}$ devido ao início ou término da ação de escrever na lousa pelo professor.

Tabela 5.1. Variação da concentração de particulado devido à ação de escrever com giz na lousa.

\begin{tabular}{|c|c|c|c|c|c|c|c|}
\hline Medição & $\begin{array}{c}\text { Vazão de } \\
\text { ar } \\
\text { externo }\end{array}$ & $\begin{array}{c}\mathbf{P M}_{\mathbf{2 , 5}} \\
\text { inicial }\end{array}$ & $\begin{array}{c}\mathbf{P M}_{\mathbf{2}, \mathbf{5}} \\
\text { final }\end{array}$ & $\begin{array}{c}\text { Variação } \\
\text { de } \mathbf{P M}_{\mathbf{2 , 5}}\end{array}$ & $\begin{array}{c}\mathbf{P M}_{\mathbf{1 0}} \\
\text { inicial }\end{array}$ & $\begin{array}{c}\mathbf{P M}_{\mathbf{1 0}} \\
\text { final }\end{array}$ & $\begin{array}{c}\text { Variação } \\
\text { de } \mathbf{P M}_{\mathbf{1 0}}\end{array}$ \\
\hline $\mathrm{m} \mathrm{m}^{3} / \mathrm{h}$ & $\mu \mathrm{g} / \mathrm{m}^{3}$ & $\mu \mathrm{g} / \mathrm{m}^{3}$ & $\%$ & $\mu \mathrm{g} / \mathrm{m}^{3}$ & $\mu \mathrm{g} / \mathrm{m}^{3}$ & $\%$ \\
\hline T6 & 1100 & 6,8 & 4,9 & $-28 \%$ & 118,7 & 61,8 & $-48 \%$ \\
\hline
\end{tabular}

Também é possível constatar que, quando as unidades de renovação não estão em funcionamento, a simples retirada do pó de giz do apagador, na medição T4, (figuras 4.43 e 4.44) é suficiente para deixar o ar interior com altos níveis de concentração de particulado por um longo período de tempo.

A influência do ar exterior também é evidênciada nas figuras 4.47 e 4.48, medição T5. Neste caso, as obras existentes no ambiente externo contribuíram significativamente com o rápido aumento da concentração de particulado no momento em que a porta era aberta, gerando correntes de ar para o interior da sala sem uma filtragem prévia. Para essa medição em particular, os valores das concentrações de $\mathrm{PM}_{2,5}$ e $\mathrm{PM}_{10}$, no interior da sala de aula, atingiram patamares superiores a aproximadamente 6 e 30 vezes, respectivamente, os valores dos limites aceitáveis. Neste caso, a influência da filtragem na tomada de ar externo pode ser observada quando as correntes de ar atingiam o ambiente interno sem a devida filtragem trazendo consigo os contaminantes do ambiente externo.

Para a redução do material particulado, as unidades de renovação constituem um papel importante. Verifica-se em todas as medições que, ao acionarmos as 4 unidades de renovação, ou seja, aproximadamente $2200 \mathrm{~m}^{3} / \mathrm{h}$ de ar externo, a concentração de material particulado $\mathrm{PM}_{10}$ diminuiu em mais de $50 \%$ nos primeiros 20 minutos, com exceção da medição P3 em que a redução foi de aproximadamente $25 \%$. Este fato pode ser explicado pois já havia ocorrido um aumento prévio da vazão, onde observa-se uma redução de aproximadamente $52 \%$ na concentração de $\mathrm{PM}_{10}$. Já para o $\mathrm{PM}_{2,5}$ observa-se uma redução acima de $20 \%$ nos primeiros 20 minutos. Apesar da diminuição ser menor, as concentrações de $\mathrm{PM}_{2,5}$ na maioria das medições já não eram significativas, já estando abaixo do limite de $25 \mu \mathrm{g} / \mathrm{m}^{3}$. Nas 
medições em que a concentração estava acima do limite (P1, P2, T4 e T5), antes do aumento da vazão, a redução foi maior. Os valores da redução do material particulado após 20 minutos do aumento da vazão podem ser observados na tabela a seguir.

Tabela 5.2. Variação da concentração de material particulado no interior da sala devido ao aumento da vazão de ar externo.

\begin{tabular}{|c|c|c|c|c|c|c|c|c|}
\hline & \multicolumn{3}{|c|}{$\begin{array}{c}\text { Antes do aumento da } \\
\text { vazão }\end{array}$} & \multicolumn{3}{c|}{ Após 20 minutos } & Diminuição \\
Medição & $\begin{array}{c}\text { Vazão } \\
\text { inicial }\end{array}$ & $\mathbf{P M}_{\mathbf{2 , 5}}$ & $\mathbf{P M}_{\mathbf{1 0}}$ & $\begin{array}{c}\text { Vazão } \\
\text { final }\end{array}$ & $\mathbf{P M}_{\mathbf{2 , 5}}$ & $\mathbf{P M}_{\mathbf{1 0}}$ & & ${\text { de } \mathbf{P M}_{\mathbf{1 0}}}^{\mathbf{n}}$ \\
\cline { 2 - 10 } & $\mathrm{m}^{3} / \mathrm{h}$ & $\mu \mathrm{g} / \mathrm{m}^{3}$ & $\mu \mathrm{g} / \mathrm{m}^{3}$ & $\mathrm{~m}^{3} / \mathrm{h}$ & $\mu \mathrm{g} / \mathrm{m}^{3}$ & $\mu \mathrm{g} / \mathrm{m}^{3}$ & $\%$ & $\%$ \\
\hline $\mathbf{P 1}$ & 1100 & 29,3 & 715,5 & 1658 & 11,9 & 165,7 & 59,4 & 76,8 \\
\hline $\mathbf{P 2}$ & 1100 & 124,5 & 302,6 & 2200 & 54,3 & 146,9 & 56,4 & 51,5 \\
\hline \multirow{2}{*}{$\mathbf{P 3}$} & 558 & 10,4 & 354,4 & 1100 & 6,9 & 170,3 & 33,7 & 51,9 \\
\hline $\mathbf{P 4}$ & 1100 & 6,1 & 170,3 & 2200 & 4,5 & 128,4 & 26,2 & 24,6 \\
\hline $\mathbf{P 5}$ & 1100 & 7,1 & 256 & 2200 & 5,2 & 123,8 & 26,8 & 51,6 \\
\hline T2 & 1100 & 13,1 & 343,2 & 2200 & 8,8 & 137,2 & 32,8 & 60,0 \\
\hline T3 & 0 & 9,5 & 105,3 & 2200 & 5,8 & 38,1 & 38,9 & 63,8 \\
\hline T4 & 0 & 65,5 & 952,5 & 2200 & 26,7 & 182,6 & 59,2 & 80,8 \\
\hline T5 & 1100 & 134,2 & 1155,9 & 2200 & 82,2 & 482,7 & 38,7 & 58,2 \\
\hline
\end{tabular}

Constatou-se, no entanto, que em algumas medições (P2, P3, P4, P5 e T4), como exemplo as figuras 4.9, 4.10 e 4.11, que apesar das unidades de renovação suprirem os $27 \mathrm{~m}^{3} / \mathrm{h}$ por pessoas conforme recomendação da resolução $n^{\circ} 9$ da ANVISA para atingir o limite aceitável de $1000 \mathrm{ppm}$ recomendado, ou os $700 \mathrm{ppm}$ a mais que o ar externo, conforme a parte $3 \mathrm{da}$ NBR 16401 (ABNT, 2008), a mesma vazão não era suficiente para diminuir a concentração de material particulado $\mathrm{PM}_{10}$ a níveis abaixo do limite recomendado.

Percebe-se também que, em algumas medições (P3, P4, P5, T2, T3 e T6), a concentração de $\mathrm{PM}_{2,5}$ não ultrapassou o limite aceitável, enquanto o $\mathrm{PM}_{10}$ possuía valores superiores ao limite aceitável de $50 \mu \mathrm{g} / \mathrm{m}^{3}$ pela NBR 16401 (ABNT, 2008). Em nenhum momento o inverso foi observado. Dessa forma, o $\mathrm{PM}_{10}$ mostrou-se um parâmetro importante para verificação da concentração de material particulado no interior dos ambientes. 


\section{CONCLUSÕeS}

Em resumo, os dados obtidos experimentalmente dos parâmetros de QAI estabelecidos (TBS, $\mathrm{UR}, \mathrm{CO}_{2}, \mathrm{PM}_{2,5}$ e $\mathrm{PM}_{10}$ ) para monitoramento na sala de aula $\mathrm{A} 2$ se mostraram fundamentais e suficientes para análise da influência da variação da vazão de ar exterior.

Os dados indicaram a possibilidade da utilização do aumento da vazão de ar externo, devidamente filtrado, na redução de contaminantes internos ao ambiente, sendo possível observar reduções de $50 \%$ e $20 \%$ para o $\mathrm{PM}_{10}$ e $\mathrm{PM}_{2,5}$, respectivamente, nos primeiros 20 minutos para vazões de renovação da ordem de $2200 \mathrm{~m}^{3} / \mathrm{h}$. Da mesma forma, a importância dos filtros no ar externo é salientada nos momentos em que atividades externas ao ambiente educacional são realizadas, podendo contribuir com o aumento da concentração de poluentes no interior do ambiente quando o ar não é filtrado.

Vazões de ar externo da ordem de $27 \mathrm{~m} / \mathrm{h}$ por pessoa recomendada pela ANVISA não foram suficientes para atingir os limites aceitáveis para o material particulado $\mathrm{PM}_{10}$, mesmo essa sendo suficiente para a concentração de $\mathrm{CO}_{2}$. A concentração de $\mathrm{PM}_{10}$ atingia valores acima do limite mesmo nos momentos em que apenas atividade teórica era ministrada.

$\mathrm{O} \mathrm{PM}_{10}$ mostrou-se um parâmetro importante e suficiente para avaliação da concentração de material particulado no ambiente, uma vez que em várias medições o limite aceitável de $50 \mu \mathrm{g} / \mathrm{m}^{3}$ pela NBR 16401 (ABNT, 2008) era excedido enquanto o mesmo não se verificava para a concentração limite do $\mathrm{PM}_{2,5}$. Salienta-se que em nenhum momento o inverso foi observado.

Dessa forma, sugere-se novas avaliações das vazões recomendadas de ar externo para ambientes interiores, principalmente em ambientes educacionais, haja vista que para a sala de aula A2, vazões de ar externo acima das recomendadas eram necessárias para atingir o limite aceitável de $\mathrm{PM}_{10}$ no interior do ambiente. 


\section{REFERÊNCIAS BIBLIOGRÁFICAS}

ABNT - Associação Brasileira de Normas Técnicas. NBR 9547: Material particulado em suspensão no ambiente. Determinação da concentração total pelo método do amostrador de grandes volumes. Brasil, 2007.

ABNT - Associação Brasileira de Normas Técnicas. NBR 16401: Instalações de arcondicionado. Sistemas centrais e unitários. Brasil, 2008.

ABNT - Associação Brasileira de Normas Técnicas. NBR 16101: Filtros para partículas em suspensão no ar. Determinação da eficiência para filtros grossos, médios e finos. Brasil, 2012.

ANVISA - Agência Nacional de Vigilância Sanitária. Guia da Qualidade para Sistemas de Tratamento de Ar e Monitoramento Ambiental. Brasília, 2013.

APAMBIENTE - Agência Portuguesa do Ambiente. Qualidade do ar em espaços interiores - Um guia técnico. 2009.

ARRUDA, R. J. Análise da associação entre poluição atmosférica e internações hospitalares por doenças respiratórias em crianças, adolescentes e idosos na cidade de Cubatão entre 1997 e 2004. Dissertação (Mestrado). Universidade Católica de Santos. Departamento de Meio Ambiente e Saúde, Santos, 2008.

ASHRAE - American Society of Heating, Refrigerating, and Air Conditioning Engineers. Standard 62.1-2004. Ventilation for acceptable indoor air quality, Inc.: Atlanta, 2004.

ASSUNÇÃO, J. V. Importância da ventilação no controle da Síndrome dos Edifícios Doentes. Encontro Brasileiro de Higienistas Ocupacionais, São Paulo, p. 19-22, 1997.

BASTO, J. E. Qualidade do Ar. Engenharia de Segurança do Trabalho, Itajaí, Brasil, 2007.

BRASIL. Portaria $\mathrm{n}^{\mathrm{o}} 3.523$ de 28 de Agosto de 1998. Dispõe sobre como minimizar o risco potencial à saúde dos usuários, em face da permanência prolongada em ambientes dotados de sistemas de ar condicionado, e dá outras providências. Ministério da Saúde MS. 
BRASIL. Resolução - $\mathrm{n}^{\circ} 9$ de 16 de janeiro de 2003. Dispõe sobre os Padrões Referenciais de Qualidade do Ar Interior em Ambientes Climatizados Artificialmente de Uso Público e Coletivo, e dá outras providências. Agência Nacional de Vigilância Sanitária - ANVISA.

BRASIL. Resolução CONAMA n. ${ }^{\circ 003 / 1990 . ~ E s t a b e l e c e ~ P a d r o ̃ e s ~ d e ~ Q u a l i d a d e ~ d o ~ A r ~ e ~}$ Amplia o Número de Poluentes Atmosféricos Passíveis de Monitoramento e Controle. Coletânea de Legislação Ambiental, 1990.

BOLliger JR, R.; MARIANI, A. L. C. Sistemas de Ar Condicionado e Ventilação. Apostila do curso “Ar Condicionado e Ventilação”. EPUSP, São Paulo, 2006.

BOLligeR JR, R.; MARIANI, A. L. C. Módulo II: Psicrometria. Apostila do curso “Programa Smacna de Educação Continuada em Tratamento de Ar”. São Paulo, 2012.

BORDINI, M. D.; Qualidade do Ar no Interior de Ambientes Climatizados - Medição de Parâmetros. Trabalho de formatura - Escola Politécnica da Universidade de São Paulo, São Paulo, Brasil, 2015.

CETESB - Companhia de Tecnologia de Saneamento Ambiental. Padrões de Qualidade do Ar. São Paulo, 2015. Disponível em: http://www.cetesb.sp.gov.br/ar/Informa??es-B?sicas/22Padr?es-e-?ndices

COUTO, J. M. Entre Estatais e transnacionais: o Pólo Industrial de Cubatão. Tese (Doutorado), UNICAMP, Campinas, Brasil, 2003.

DAISEY, J. M.; ANGELL, W. J.; APTE, M. G. Indoor Air Quality, Ventilation and Health Symptoms in Schools: an analysis of existing information. Indoor Air, Denmark, 13, p. 53-64, 2003.

EPA (Environmental Protection Agency). Energy Savings Plus Health: Indoor Air Quality Guidelines for School Building Upgrades. Indoor Air Quality. United States, October, 2014.

EPA (Environmental Protection Agency). Particulate Matter (PM) Pollution: What is PM, and how does it get into the air? 2016. Disponível em: https://www.epa.gov/pmpollution/particulate-matter-pm-basics\#PM Acesso em Junho de 2016.

FAUSTMAN, E. M.; SILBERNAGEL, S. M.; FENSKE, R. A.; BURBACHER, T. M.; PONCE, R. A. Mechanisms underlying children's susceptibility to environmental toxicants. Environmental Health Perspectives, 108 Suppl. 1, p. 13-21, 2000. 
FISK, W. J. Health and Productivity Gains from Better Indoor Environments. The Role of Emerging Energy-Efficient Technology in Promoting Workplace Productivity and Health. Report by Lawrence Berkeley National Laboratory, February, 2002a.

FISK, W. J. How IEQ Affects Health, Productivity. ASHRAE Journal, May, 2002b.

FREITAS, C. U.; PEREIRA, L. A. A.; SALDIVA, P. H. N. Vigilância dos Efeitos na Saúde Decorrentes da Poluição Atmosférica: Estudo de Factibilidade. 1996. Disponível em: http://www.cve.saude.sp.gov.br/htm/doma/doma vig.htm

FREITAS, C. U.; BREMNER, S. A.; GOUVEIA, N.; PEREIRA, L. A. A.; SALDIVA, P. H. N. Internações e Óbitos e sua Relação com a Poluição Atmosférica em São Paulo, 1993 a 1997. Centro de Vigilância Epidemiológica, São Paulo, SP, FMUSP, 2004.

FREITAS, C. U.; MARTINS, L. C.; MARCILIO, I. O.; GOUVEIA, N. Poluição do ar e efeitos na saúde nas populações de duas grandes metrópoles brasileiras. Epidemiol. e Serv. de Saúde, v12, n. 1, São Paulo, 2003.

FUJII, R. K. Avaliação da Qualidade do Ar em Duas Estações do Metrô de São Paulo. Tese (Mestrado) - Faculdade de Saúde Pública da Universidade de São Paulo, São Paulo, Brasil, 2006.

HAQUE, R.; SHAKIL, A.; AKHTER, S. Monitoring of particulate matter in different locations and improvement of indoor air quality in Rajshahi City of Bangladesh. Global Journal of Researches in Engineering. Bangladesh, v.13, 2013.

HAVERINEN-SHAUGHNESSY, U.; MOSCHANDREAS, D. J.; SHAUGHNESSY, R.J. Association between substandard classroom ventilation rates and students' academic achievement. Indoor Air, 21(2), p. 121-31, 2011.

HEDGE, A. Linking Environmental Conditions to Productivity. Eastern Ergonomics Conference \& Exposition. New York, June, 2004.

HEINZERLING, D.; SCHIAVON, S.; WEBSTER, T.; ARENS, E. Indoor Environmental Quality Assessment Models: A Literature Review and a Proposed Weighting and Classification Scheme. Building and Environment, 70, p. 210-222, 2013.

INMETRO. Avaliação de dados de medição: Guia para a expressão de incerteza de medição - GUM 2008. Duque de Caxias, Rio de Janeiro, Brasil, 141 p., 2012. 
ITO, K.; MURAKAMI, S.; KANEKO, T.; FUKAO, H. Study on the productivity in the classroom (part 2): realistic simulation experiment on effects of air quality /thermal environment on learning performance. Healthy Buildings, Lisboa, Portugal. p. 207-212, $2006 b$.

ITO, K.; MURAKAMI, S.; KANEKO, T.; FUKAO, H. Study on the productivity in the classroom (part 1) field survey of the effects of air quality /thermal environment on learning performance. Healthy Buildings. Lisboa, Portugal. p. 271-276, 2006a.

JENKLINS, P. L.; PHILliPS, T. J.; MULBERG, J. M.; HUI, S. P. Activity patterns of Californians: use of proximity to indoor pollutant sources. Atmospheric Environ., 26A, p. 291-297, 1992.

JOVANOVIC, M.; VUCICEVIC, B.; TURANJANIN, V.; ZIVKOVIC, M. Investigation of indoor and outdoor air quality of the classrooms at a school in Serbia. Energy, 77, p. 4248, 2014.

KOSONEN, R.; TAN, F. The effect of perceived indoor air quality on productivity loss. Energy and Buildings, Finland, v. 36, f. 10, p. 981-986, 2004.

LANDRIGAN, P. J. Environmental hazards for children in USA. Int. J. Occup. Med. Environ. Health, 11, p. 189-94, 1998.

LEE, S. C.; CHANG, M. Indoor and outdoor air quality investigation at schools in Hong Kong. Chemosphere, 41, p. 109-113, 2000.

MENDELL, M. J.; HEATH, G. A. Do indoor pollutants and thermal conditions in schools influence student performance? A critical review of the literature. Indoor Air. 15, p. 27-52, 2005.

MORAES, A. P. Qualidade do Ar Interno com ênfase na Concentração de Aerodispersóides nos Edifícios. Dissertação (Mestrado). Escola Politécnica da Universidade de São Paulo, São Paulo, Brasil, 2006.

MYHRVOLD, A.; OLESEN, E. Pupil's health and performance due to renovation of schools. Healthy Buildings/IAQ 1997, p. 81-86, 1997. 
NEDERMAN. Catálogo de Braço extractor Original. 2015. Disponível em: http://www.nederman.com.br/products/extraction-arms/welding-fume-extractionarms/original-welding-fume-and-dust-extraction-arm Acesso em Janeiro de 2015.

OLESEN, B. W. Indoor Environment - Health, Comfort and Productivity. Clima. Lausanne, 8th REHVA World Congress, Switzerland, Oct. 9-12, 2005.

OMS (ORGANIZAÇÃO MUNDIAL DA SAÚDE). Critérios de Qualide do Ar. Genebra, Suíça, 1999.

OTAM. Catálogo de Gabinetes de Ventilação Tipo Limit Load GVL. Pás inclinadas para trás. 2015a.

OTAM. Catálogo de Ventiladores Centrífugos Tipo Sirocco RSS e RSD. Pás curvadas para frente. $2015 b$.

PARKER, J. The toxic zone. Buildings Services the CIBSE Journal,v.15, n.03, p. 24-26, 1993.

PEGAS, P. N., EVTYUGINA, M. G., ALVES, C. A., NUNES, T., CERQUEIRA, M., FRANCHI, M.; PIO, C. Outdoor/Indoor air quality in primary schools in Lisbon: A preliminary study. Quim, Nova, 33, p. 1145-1149, 2010.

PRADO, R. T. A. Contribuição ao estudo do papel da engenharia nas interações entre o homem, o edifício e o ambiente. Tese de Livre Docência - Escola Politécnica da Universidade de São Paulo, São Paulo, Brasil, p. 197, 2003.

REHVA. Ambiente Interior e Eficiência Energética nas Escolas $-1^{\mathrm{a}}$ parte - Princípios. Manual $n^{\circ} 13$. Lisboa, 2010.

REHVA. Filtragem de Ar nos Sistemas de AVAC. Manual nº 11. Lisboa, 2011.

REPUBLIC OF SERBIA, Statistical Office. Statistical yearbook of the Republic of Serbia. Demography and Social Statistics, Belgrade, 2012.

RICHARDS, W. Allergy, asthma, and school problems. J. Sch. Health, 56, p. 151-2, 1986.

ROLlo, A. F. Estudo de Sistema de Ar Condicionado e Ventilação para Laboratórios. Trabalho de Conclusão de Curso - Escola Politécnica da Universidade de São Paulo, São Paulo, Brasil, 2013. 
SAlDiVA, P. H. N., PEREIRA, L. A. A.; BRAGA A. Poluição Atmosférica e seus Efeitos na Saúde Humana. Faculdade de Medicina da Universidade de São Paulo. Trabalho apresentado em Sustentabilidade na Geração e uso de Energia, UNICAMP, 2002.

SEPPÄNEN, O.; FISK, W. J. A Method to Estimate The Cost Effectiveness of Indoor Environments in Office Work. Clima, Lausanne, 8th REHVA World Congress, Switzerland, Oct. 9-12, 2005.

SEPPÄNEN, O.; FISK, W.J. Some quantitative relations between indoor environmental quality and work performance or health. International Journal of HVAC\&R Research, 12(4): p. 957-973, 2006.

SEPPÄNEN, O.; FISK, W.J.; LEI, Q.H. Ventilation and performance in office work. Indoor Air, 16(1), p. 28-36, 2006.

SHAUGHNESSY，R. J.; HAVERINEN-SHAUGHNESSY，U.; NEVALAINEN，A. A. Preliminary study on the association between ventilation rates in classrooms and student performance. Indoor Air. 16, p. 465-468, 2006.

SMITH, K. R.; CORVALÁN, C. F.; KJELLSTRÖM, T. How much global ill health is attributable to environmental factors? Journal of Epidemiology, 10 (5), p. 573-584, 1999.

STERN, A.C. Air pollution: The effects of Air Pollution. United Kingdom: Academic Press, Vol. 2, $3^{\text {rd }}$ edition, 1977.

TANABE, S. I. Productivity and Future HVAC. Clima, Lausanne, 8th REHVA World Congress, Switzerland, Oct. 9-12, 2005.

TROX. Ceiling Diffusers Type DLQ-Varyset - ADLQ-Varyset. Recommended for room heights from $2.60 \mathrm{~m}$ to $4.00 \mathrm{~m} .2015$.

TROX. Catálogo Técnico de Intercambiador de Calor Séries ICH-DX, ICV-DX. Disponível em: http://www.troxbrasil.com.br/br/products/fan_coils/ich_dcv_dx/index.html Acesso em Janeiro de 2015.

TROX. Catálogo Técnico de Filtros de Bolsas para Montagem em Dutos. Disponível em: http://www.troxbrasil.com.br/br/products/filters and filter_units/fine filters/f3 fbdu/index.ht $\underline{\mathrm{ml}}$ Acesso em Janeiro de 2015. 
TURUNEN, M.; TOYINBO, O.; PUTUS, T.; NEVALAINEN, A.; SHAUGHNESSY, R.; HAVERINEN-SHAUGHNESSY, U. Indoor environmental quality in school buildings, and the health and wellbeing of students. International Journal of Hygiene and Environmental Health. 217, p. 733-739, 2014.

U.S. General Accounting Office. School facilities: condition of America's schools. U.S. GAO, Washington, D.C, 1995.

VALENTE, J., BORREGO, C., LOPES, M., MIRANDA, A. I., NUNES, T., FERREIRA, J., CASCÃO, P., AMORIM. J. H.; COSTA, A. M. Contribution of school indoor concentrations to total PM exposure in Children. Particulate matter: Research and management. ISBN, 2010.

VERANI, L. H. W. Contaminantes Químicos. Apostila do CEST. Florianópolis, 2003.

WAllaCE, L.; QUAKENBOSS, J.;RHODES, C. AWMA/EPA. Symposium on the Mesurement of Toxic and Related Air Pollutants, Research Triangle Park, NC, p. 860-871, 1997.

WARGOCKI, P. Making the Case for IAQ. ASHRAE IAQ Applications, Fall, 2002.

WARGOCKI, P.; WYON, D. P. Research report on effects of HVAC on student performance. ASHRAE Journal, 48, p. 22-28, 2006.

WARGOCKI, P.; WYON, D. P. The effect of moderately raised classroom temperatures and classroom ventilation rate on the performance of schoolwork by children. HVAC\&R Research, 13(2), p. 193-220, 2007a.

WARGOCKI, P.; WYON, D. P. The effects of outdoor air supply rate and supply air filter condition in classrooms on the performance of schoolwork by children. HVAC\&R Research, 13(2), p. 165-191, 2007b.

WARGOCKI, P.; WYON, D. P.; BAIK, Y. K.; CLAUSEN, G.; FANGER, P. O. Perceived air quality, sick building syndrome (SBS) symptoms and productivity in an office with two different pollution loads. Indoor Air, 9(3): p. 165-179, 1999.

WARGOCKI, P.; WYON, D. P.; SUNDELL, J.; CLAUSEN, G.; FANGER, P. O. The effects of outdoor air supply rate in an office on perceived air quality, sick building syndrome (SBS) symptoms and productivity. Indoor Air, 10(4): p. 222-36, 2000. 
WARGOCKI, P.; WYON, D. P.; SUNDELL, J.; LAGERCRANTZ, L.; WITTERSEH, T.; FANGER, P. O. Subjective perceptions, symptom intensity, and performance: a comparison of two independent studies, both changing similarly the pollution load in an office. Indoor Air, 12(2), p. 74-80, 2002.

WORLD HEALTH ORGANIZATION. Health aspects related to indoor air quality. EURO Reports and Studies, 21, 1979.

WORLD HEALTH ORGANIZATION. Air quality guidelines: Global update 2005: Particulate matter, ozone, nitrogen dioxide and sulfur dioxide. 2005.

YASSI, A.; KJEllstrom, T.; GUIDOTTI, K. T. Salud Ambiental Básica. México DF, PNUMA, 2002. 


\section{Anexo A - Descrição dos poluentes}

Este anexo apresenta uma breve descrição oferecida pela CETESB (CETESB, 2015) do grupo de poluentes que servem como indicadores de qualidade do ar, sendo esses adotados universalmente e que foram escolhidos em razão da frequência de ocorrência e de seus efeitos adversos. O objetivo deste é familiarizar o leitor com o vocabulário utilizado no presente trabalho e não de introduzir um conceito detalhado de cada um.

\section{A.1 Material particulado (MP)}

Sob a denominação geral de Material Particulado se encontra um conjunto de poluentes constituídos de poeiras, fumaças e todo tipo de material sólido e líquido que se mantém suspenso na atmosfera por causa de seu pequeno tamanho. As principais fontes de emissão de particulado para a atmosfera são: veículos automotores, processos industriais, queima de biomassa, ressuspensão de poeira do solo, entre outros. O material particulado pode também se formar na atmosfera a partir de gases como dióxido de enxofre $\left(\mathrm{SO}_{2}\right)$, óxidos de nitrogênio $\left(\mathrm{NO}_{\mathrm{x}}\right)$ e compostos orgânicos voláteis (COVs), que são emitidos principalmente em atividades de combustão, transformando-se em partículas como resultado de reações químicas no ar.

O tamanho das partículas está diretamente associado ao seu potencial para causar problemas à saúde, sendo que quanto menores maiores os efeitos provocados. O particulado pode também reduzir a visibilidade na atmosfera. O material particulado pode ser classificado como:

- $\quad$ Partículas Totais em Suspensão(PTS):

Podem ser definidas de maneira simplificada como aquelas cujo diâmetro aerodinâmico é menor que $50 \mu \mathrm{m}$. Uma parte destas partículas é inalável e pode causar problemas à saúde, outra parte pode afetar desfavoravelmente a qualidade de vida da população, interferindo nas condições estéticas do ambiente e prejudicando as atividades normais da comunidade. 
- $\quad \underline{\text { Partículas Inaláveis }\left(\mathrm{PM}_{10}\right) \text { : }}$

Podem ser definidas de maneira simplificada como aquelas cujo diâmetro aerodinâmico é menor que $10 \mu \mathrm{m}$. Dependendo da distribuição de tamanho na faixa de 0 a $10 \mu \mathrm{m}$, podem ficar retidas na parte superior do sistema respiratório ou penetrar mais profundamente, alcançando os alvéolos pulmonares.

\section{- $\quad$ Partículas Inaláveis Finas $\left(\mathrm{PM}_{2,5}\right)$ :}

Podem ser definidas de maneira simplificada como aquelas cujo diâmetro aerodinâmico é menor que 2,5 $\mu \mathrm{m}$. Devido ao seu tamanho diminuto, penetram profundamente no sistema respiratório, podendo atingir os alvéolos pulmonares.

- Fumaça (FMC):

Está associada ao material particulado suspenso na atmosfera proveniente dos processos de combustão. O método de determinação da fumaça é baseado na medida de refletância da luz que incide na poeira (coletada em um filtro), o que confere a este parâmetro a característica de estar diretamente relacionado ao teor de fuligem na atmosfera.

\section{A.2 Dióxido de Enxofre $\left(\mathrm{SO}_{2}\right)$}

Resulta principalmente da queima de combustíveis que contém enxofre, como óleo diesel, óleo combustível industrial e gasolina. É um dos principais formadores da chuva ácida. O dióxido de enxofre pode reagir com outras substâncias presentes no ar formando partículas de sulfato que são responsáveis pela redução da visibilidade na atmosfera.

\section{A.3 Monóxido de Carbono (CO)}

É um gás incolor e inodoro que resulta da queima incompleta de combustíveis de origem orgânica (combustíveis fósseis, biomassa, etc.). Em geral é encontrado em maiores concentrações nas cidades, emitido principalmente por veículos automotores. Altas concentrações de $\mathrm{CO}$ são encontradas em áreas de intensa circulação de veículos. 


\section{A.4 Ozônio $\left(\mathrm{O}_{3}\right)$ e oxidantes fotoquímicos}

Oxidantes fotoquímicos é a denominação que se dá à mistura de poluentes secundários formados pelas reações entre os óxidos de nitrogênio e compostos orgânicos voláteis, na presença de luz solar, sendo estes últimos liberados na queima incompleta e evaporação de combustíveis e solventes. O principal produto desta reação é o ozônio, por isso mesmo utilizado como parâmetro indicador da presença de oxidantes fotoquímicos na atmosfera. Tais poluentes formam a chamada névoa fotoquímica ou smog fotoquímico, que possui este nome porque causa na atmosfera diminuição da visibilidade.

Além de prejuízos à saúde, o ozônio pode causar danos à vegetação. É sempre bom ressaltar que o ozônio encontrado na faixa de ar próxima do solo, onde respiramos, chamado de "mau ozônio", é tóxico. Entretanto, na estratosfera (a cerca de $25 \mathrm{~km}$ de altitude) o ozônio tem a importante função de proteger a Terra, como um filtro, dos raios ultravioletas emitidos pelo Sol.

\section{A.5 Hidrocarbonetos (HC)}

São gases e vapores resultantes da queima incompleta e evaporação de combustíveis e de outros produtos orgânicos voláteis. Diversos hidrocarbonetos como o benzeno são cancerígenos e mutagênicos, não havendo uma concentração ambiente totalmente segura. Participam ativamente das reações de formação da névoa fotoquímica.

\section{A.6 Óxido de Nitrogênio (NO) e Dióxido de Nitrogênio $\left(\mathrm{NO}_{2}\right)$}

São formados durante processos de combustão. Em grandes cidades, os veículos geralmente são os principais responsáveis pela emissão dos óxidos de nitrogênio. $\mathrm{O}$ NO, sob a ação de luz solar se transforma em $\mathrm{NO}_{2}$ e tem papel importante na formação de oxidantes fotoquímicos como o ozônio. Dependendo das concentrações, o $\mathrm{NO}_{2}$ causa prejuízos à saúde. 


\section{Anexo B - Tabelas da CETESB}

Este anexo apresenta duas tabelas provindas da CETESB (CETESB, 2015). A primeira delas relaciona os efeitos sobre a saúde da população, para faixas de concentração distintas para cada poluente, identificados por estudos epidemiológicos desenvolvidos dentro e fora do país. A segunda, apresenta as medidas de prevenção a serem adotadas pela população afetada devido aos efeitos sobre a saúde. 
B.1 Qualidade do Ar e Efeitos sobre a Saúde (CETESB, 2015)

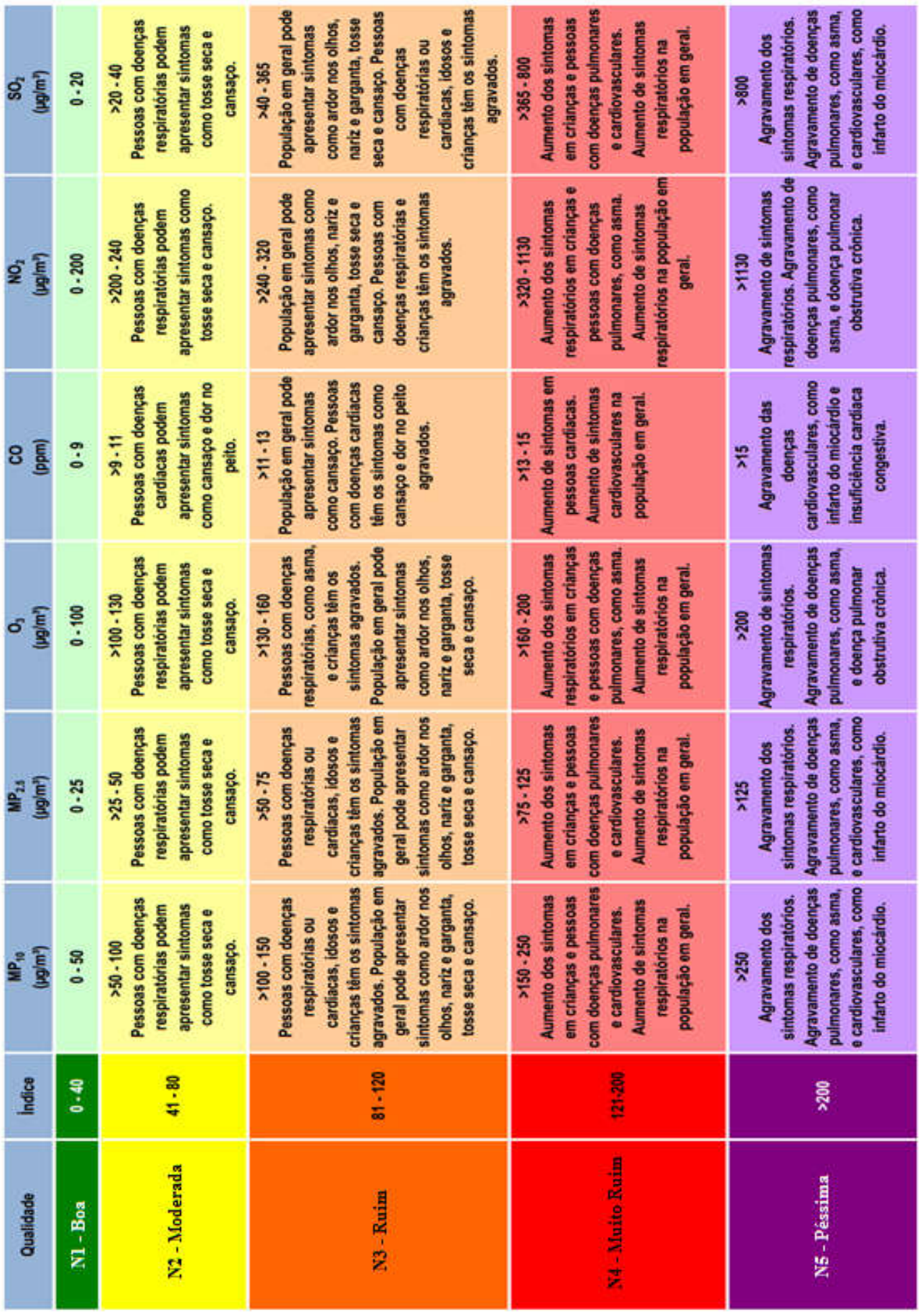




\section{B.2 Qualidade do Ar e Prevenção de Riscos à Saúde}

\section{(CETESB, 2015)}

\begin{tabular}{|c|c|c|c|c|c|}
\hline 品 & ๙ి & 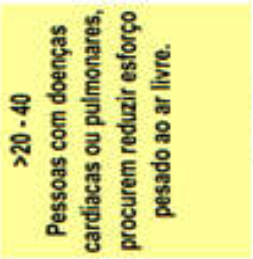 & 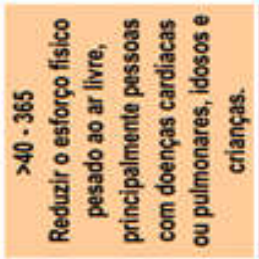 & 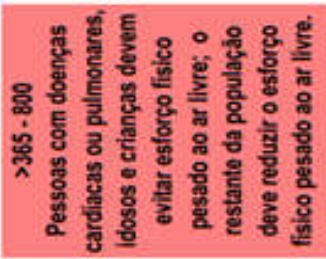 & 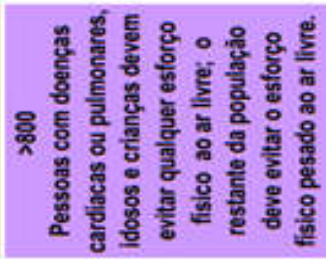 \\
\hline$\frac{\delta}{2}$ & ণ্̊ি & 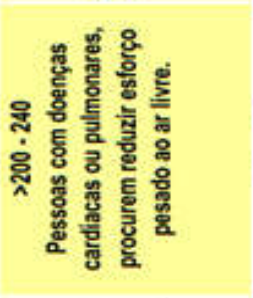 & 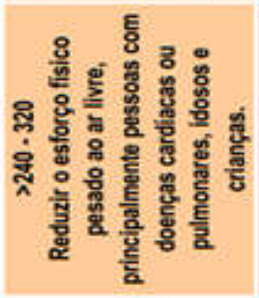 & 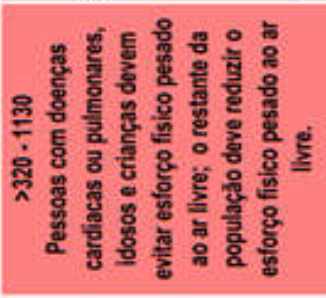 & 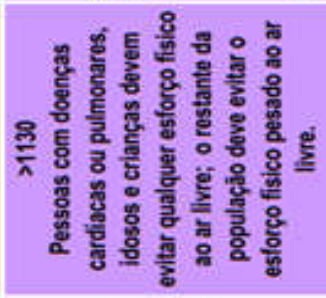 \\
\hline 8 & $\stackrel{\leftrightarrow}{\dot{0}}$ & 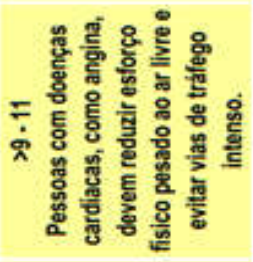 & 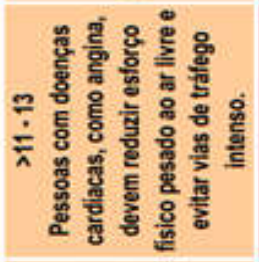 & 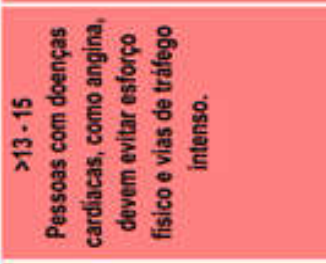 & 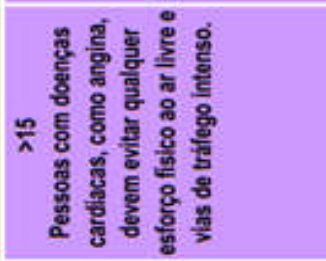 \\
\hline$\sigma^{\circ}$ & $\frac{8}{\circ}$ & 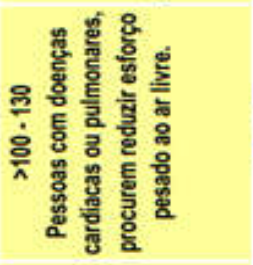 & 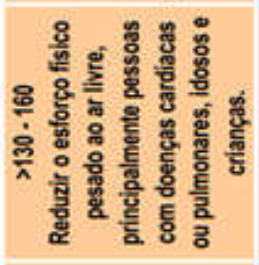 & 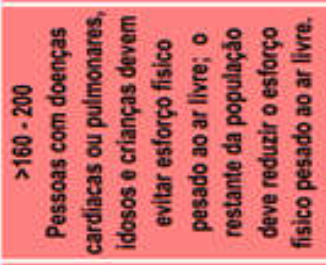 & 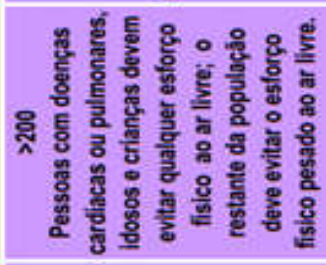 \\
\hline$\frac{a}{2}$ & ฆั & 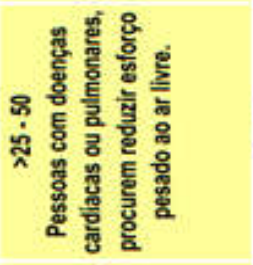 & 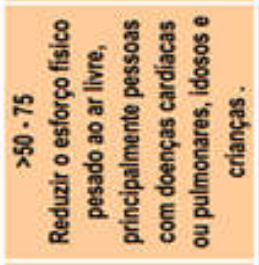 & 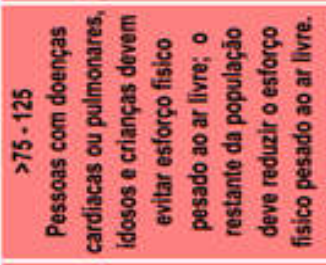 & 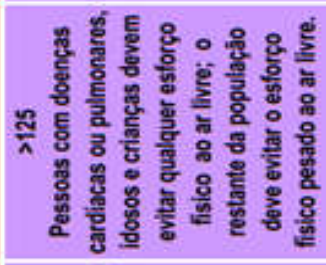 \\
\hline$\frac{2}{2} \frac{\bar{E}}{\mathrm{~g}}$ & ధి & 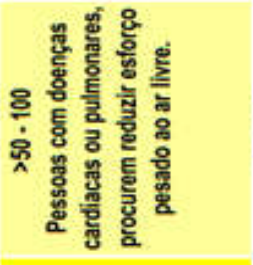 & 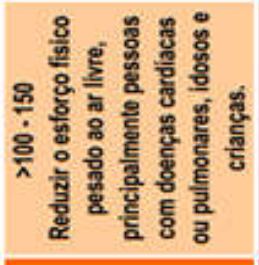 & 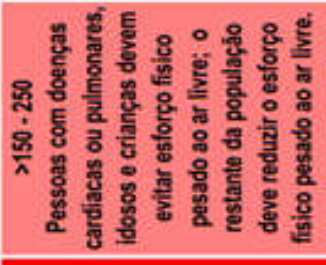 & 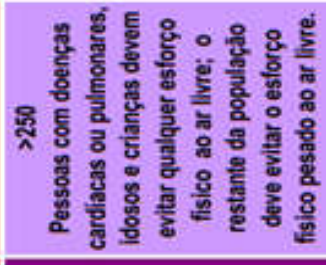 \\
\hline 횸 & 융 & 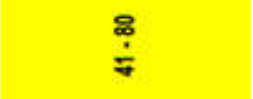 & $\frac{\text { ఇิ }}{\frac{\infty}{6}}$ & 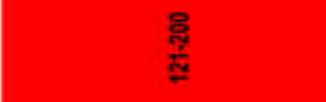 & ఫ్రి \\
\hline & 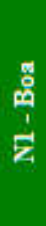 & 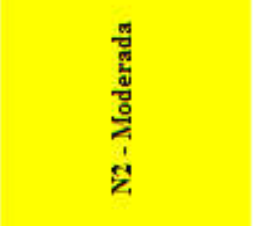 & z & 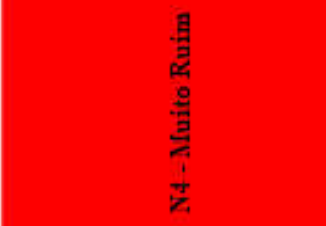 & 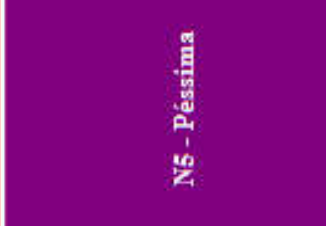 \\
\hline
\end{tabular}




\section{Anexo C - Tabela da NBR 16401-3 (ABNT, 2008)}

Este anexo apresenta uma tabela proveniente da NBR16401-3 (ABNT, 2008) a qual lista alguns poluentes químicos comuns e indica as concentrações consideradas aceitáveis por diversas entidades internacionais.

\section{C.1 Concentração máxima de alguns poluentes do ambiente interior}

\begin{tabular}{|c|c|c|c|}
\hline Poluente & Limite & Fontes & Comentários \\
\hline $\begin{array}{l}\text { Monóxido de carbono } \\
\qquad(\mathrm{CO})^{\mathrm{a}}\end{array}$ & $9 \mathrm{ppm}(8 \mathrm{~h})$ & $\begin{array}{l}\text { Queima de combustiveis, e gás, } \\
\text { gasolina, óleo diesel, carvão etc. } \\
\text { Captação de ar de garagens e } \\
\text { estacionamentos ou de ruas muito } \\
\text { movimentadas } \\
\text { Vazamentos de aquecedores ou } \\
\text { caldeiras a gás }\end{array}$ & $\begin{array}{l}\text { Ambientes com elevadas concentrações de CO } \\
\text { devem ser investigados, para localização da fonte } \\
\text { O cO é um gás asfixiante que reduz a oxigenação do } \\
\text { sangue } \\
\text { Limite estipulado com base na sensibilidade de } \\
\text { pessoas com enfermidades coronárias }\end{array}$ \\
\hline $\begin{array}{l}\text { Formaldeido } \\
\qquad(\mathrm{HCHO})^{b}\end{array}$ & $27 \mathrm{ppb}(8 \mathrm{~h})$ & $\begin{array}{l}\text { Colas, verniz, retardantes de } \\
\text { chamas, aglomerados de madeira }\end{array}$ & $\begin{array}{l}\text { Inalação de elevadas concentrações de formaldeido } \\
\text { pode causar sintomas respiratórios, irritação nos } \\
\text { olhos, nariz e garganta } \\
\text { Estudos relacionam o formaldeido a câncer de } \\
\text { pulmão e câncer das células naso-faringeas } \\
\text { A EPA classificou o formaldeido no Grupo B1 - } \\
\text { provável carcinogênico humano com risco de nivel } \\
\text { médio }\end{array}$ \\
\hline Dióxido de nitrogênio ${ }^{a}$ & $100 \mu \mathrm{g} / \mathrm{m}^{3}$ & $\begin{array}{l}\text { Vazamento de equipamentos com } \\
\text { queima incompleta de combustivel } \\
\text { (caldeiras, fogões, aquecedores) } \\
\text { Cigarro } \\
\text { Queima de gás, gasolina, diesel, gás } \\
\text { natural, carvão, óleo }\end{array}$ & $\begin{array}{l}\text { É um irritante de mucosas dos olhos, nariz e } \\
\text { garganta, sendo ainda um indutor de crise de asma } \\
\text { O dióxido de nitrogênio ambiental é um componente } \\
\text { da chuva ácida (os aerossóis ácidos) }\end{array}$ \\
\hline Material particulado $\left(\mathrm{PM}_{10}\right)^{\mathrm{a}}$ & $50 \mu \mathrm{g} / \mathrm{m}^{3}$ & $\begin{array}{l}\text { Degradação do material sólido } \\
\text { Poeira proveniente de limpeza, } \\
\text { processos industriais, trânsito, } \\
\text { queima de combustivel, } \\
\text { fragmentação de papel etc. }\end{array}$ & $\begin{array}{l}\text { Baseado em proteger a população em geral de } \\
\text { doenças respiratórias e evitar a indução de crise de } \\
\text { asma. Exposição média de um ano, se não possuir } \\
\text { material carcinogênico } \\
\text { Irritação de olhos, nariz e garganta } \\
\text { Co-fator de bronquites e crises de asma }\end{array}$ \\
\hline
\end{tabular}


(Continuação)

\begin{tabular}{|c|c|c|c|}
\hline Poluente & Limite & Fontes & Comentários \\
\hline Dióxido de enxofre $\left(\mathrm{SO}_{2}\right)^{a}$ & $50 \mu \mathrm{g} / \mathrm{m}^{3}$ & $\begin{array}{l}\text { Queima de carvão e óleo que } \\
\text { contenham elevadas concentrações } \\
\text { de enxofre } \\
\text { Normalmente deve ser pesquisado } \\
\text { em usinas siderúrgicas e papel }\end{array}$ & $\begin{array}{l}\text { Problemas respiratórios e danos irreversiveis ao } \\
\text { pulmão }\end{array}$ \\
\hline $\begin{array}{l}\text { Ozônio } \\
\qquad\left(\mathrm{O}_{3}\right)^{\mathrm{c}}\end{array}$ & $100 \mu \mathrm{g} / \mathrm{m}^{3}(8)$ & $\begin{array}{l}\text { Campos eletromagnéticos } \\
\text { Equipamentos de escritório } \\
\text { Geradores de ozônio } \\
\text { Ar exterior }\end{array}$ & $\begin{array}{l}\text { Causador de problemas respiratórios, redução da } \\
\text { função de pulmão, asma, irritante dos olhos, nariz, } \\
\text { reduz a resistência orgânica aos resfriados e outras } \\
\text { infecções } \\
\text { O ozônio em baixos niveis de concentração pode } \\
\text { contribuir à degradação da qualidade do ar de } \\
\text { interiores, pela formação de substâncias indesejadas } \\
\text { pela oxidação }\end{array}$ \\
\hline Dióxido de carbono $\left(\mathrm{CO}_{2}\right)^{d}$ & 3500 ppm & $\begin{array}{l}\text { Combustão completa de produtos } \\
\text { orgânicos } \\
\text { Respiração humana }\end{array}$ & $\begin{array}{l}\text { O } \mathrm{CO}_{2} \text { não é tóxico, irritante e de nenhuma maneira } \\
\text { nocivo à saúde ou ao bem-estar, exceto em } \\
\text { concentraçōes altas, quando desloca o oxigênio do ar } \\
\text { em proporção tal que dificulta a respiração, podendo } \\
\text { se tornar fator asfixiante } \\
\text { Ver Anexo C }\end{array}$ \\
\hline \multicolumn{4}{|c|}{$\begin{array}{l}\text { a US EPA - Environmental Protection Agency - } 2000 \text { - National ambiental air quality standards } \\
\text { b California Environmental Protection Agency - Office of Environmental Health Hazard Assessment - } 1999 \\
\text { c US FDA - Food and Drug Administration - } 1986 \text { - Code of federal regulations - Title } 21 \text { - Maximum acceptable levels of ozone } \\
\text { d Health Canada - } 1995 \text { - Exposure guidelines for residential indoor air quality }\end{array}$} \\
\hline
\end{tabular}




\section{Anexo D - Proposta de projeto de sistemas de tratamento de ar para futuros estudos de QAI}

Neste anexo propõe-se um projeto detalhado de dois sistemas de tratamento de ar para laboratórios didáticos e de pesquisa, Laboratório de Instrumentação -Sala MT16, e Laboratório de Túneis de Vento - Sala MT06 do Departamento de Engenharia Mecânica da EPUSP, para que esses possam ter equipamentos e instalações que visem estudos futuros de monitoração de parâmetros que definim a QAI. Propõe-se que nestes ambientes haja também a implantação de um sistema com Ciclo Economizador, para que em estudos futuros possam ser avaliados a operação de instalações energeticamente eficiente com monitoramento da QAI.

\section{D.1 Laboratórios didáticos para estudo de QAI}

Os laboratórios de Instrumentação MT16 e Túneis de Vento MT06, propostos para apresentação de um projeto detalhado para estudos futuros da qualidade do ar no ambiente interior, estão localizados no Departamento de Engenharia Mecânica da Escola Politécnica da Universidade de São Paulo. A figura D.1 adaptada de Rollo (2013) representa a planta dos laboratórios.

Para a proposta de projeto detalhado, serão utilizados os valores de carga térmica obtidos previamente por Rollo (2013) em seu estudo. Dessa forma, a carga térmica utilizada para o projeto pode ser observada na tabela D.1. 


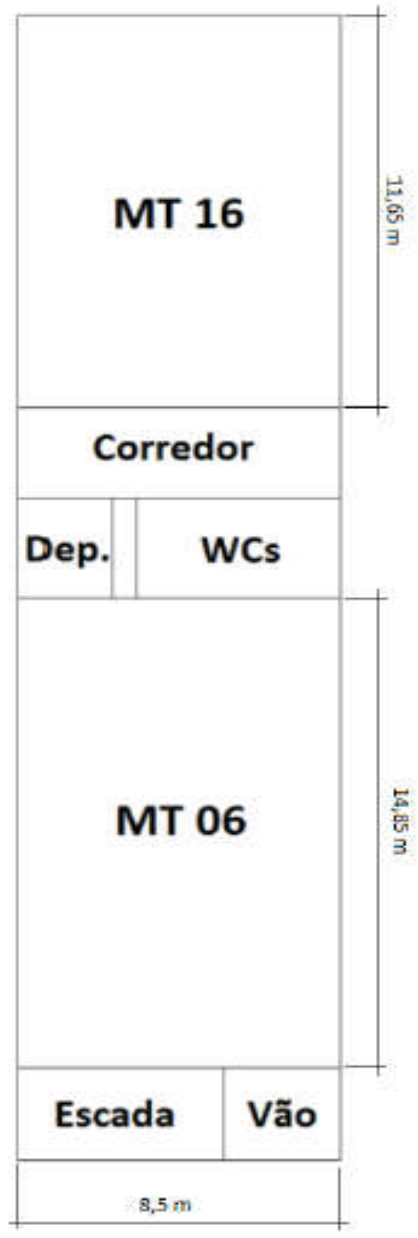

Figura D.1. Layout dos laboratórios de Instrumentação (MT16) e Túneis de Vento (MT06) e ambientes contíguos.

Tabela D.1. Carga térmica dos laboratórios de estudo de acordo com Rollo (2013).

\begin{tabular}{|c|c|c|}
\hline \multicolumn{3}{|c|}{ Carga Térmica dos Laboratórios (W) } \\
\hline Componentes & Instrumentação (MT16) & Túneis de Vento (MT06) \\
\hline Paredes & 1.202 & 1.117 \\
\hline Teto & 1.283 & 1.636 \\
\hline Vidros & 4.035 & 96 \\
\hline Pessoas & 931 & 5.587 \\
\hline Iluminação & 1.980 & 1.760 \\
\hline Equipamentos & 1.079 & 5.664 \\
\hline TOTAL & $\mathbf{1 0 . 5 1 0}$ & $\mathbf{1 5 . 8 6 0}$ \\
\hline
\end{tabular}


Segundo Rollo (2013), a melhor configuração para o sistema de AVAC, visando a eficiência energética é aquela na qual o ar externo é misturado com o ar de recirculação na caixa de mistura do equipamento, conforme figura D.2.

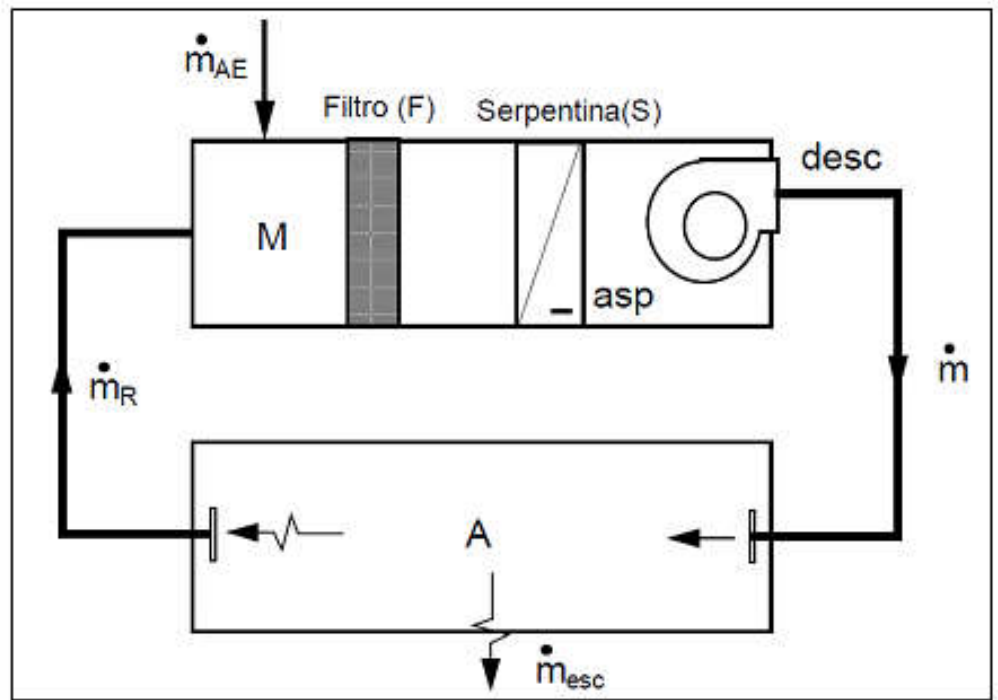

Figura D.2. Configuração na qual o ar externo é misturado com o ar de recirculação na caixa de mistura (BOLLIGER JR, MARIANI, 2006).

Além dessa configuração, ele concluiu que a utilização de máquinas para refrigeração do tipo expansão direta, ou seja, sem a utilização de Chillers para refrigeração de água, se apresentaram mais eficientes energeticamente para os laboratórios em estudo. Sendo assim, para a climatização dos ambientes serão utilizadas máquinas de expansão direta.

Para seleção final da máquina, Rollo (2013) também calculou a carga térmica proveniente do ar externo necessária para a renovação do ambiente. Os valores de carga térmica final obtidos estão representados na tabela D.2. 
Tabela D.2. Carga térmica total dos laboratórios (ROLLO, 2013).

\begin{tabular}{|c|c|c|}
\hline \multicolumn{3}{|c|}{ Carga Térmica dos Laboratórios (W) } \\
\hline Componente & Instrumentação (MT16) & Túneis de Vento (MT06) \\
\hline Ambiente & 10.510 & 15.860 \\
\hline Ar Externo & 2.500 & 5.300 \\
\hline TOTAL & $\mathbf{1 2 . 5 1 0}$ & $\mathbf{2 1 . 1 6 0}$ \\
\hline
\end{tabular}

Com a configuração definida e o tipo de sistema que será utilizado para a climatização dos laboratórios, Rollo (2013) definiu as vazões nas quais os sistemas irão operar. As vazões que serão utilizadas para os cálculos e projeto estão definidas na tabela D.3.

Tabela D.3. Vazões de ar para os laboratórios de estudo (ROLLO, 2013).

\begin{tabular}{|c|c|c|c|}
\hline \multicolumn{4}{|c|}{ Vazões dos Laboratórios $\mathbf{~ m}^{\mathbf{3}} / \mathbf{h}$} \\
\hline Vazões (Q) & Instrumentação (MT16) & Túneis de Vento (MT06) & Densidade $\mathbf{\rho}\left(\mathbf{k g} / \mathbf{m}^{\mathbf{3}}\right.$ ) \\
\hline Insuflamento & 3.465 & 4.156 & 1,104 \\
\hline Retorno & 2.796 & 2.827 & 1,067 \\
\hline Renovação & 810 & 1.525 & 1,039 \\
\hline
\end{tabular}

\section{D.2 Projeto dos sistemas de tratamento de ar para os laboratórios}

\subsection{Seleção dos equipamentos e acessórios}

\subsubsection{Equipamentos condicionadores de ar}

Tendo em vista os valores de capacidade de carga térmica requisitados para os equipamentos de acordo com a configuração escolhida, onde o ar externo e o ar de retorno serão unidos na caixa de mistura da máquina, verificou-se dentro dos modelos disponíveis no mercado e de acordo com a forma de distribuição de ar planejada, o modelo que mais se adequava à necessidade. 
Para esta configuração serão utilizadas duas máquinas, uma para cada laboratório, as quais deverão ser dotadas de uma caixa de mistura na qual serão unidas as parcelas provenientes do ar de recirculação e do ar de renovação. As características principais dos equipamentos selecionados, ambos da marca Trox, com condensador a ar remoto centrífugo, estão disponíveis na tabela D.4.

Tabela D.1. Equipamentos selecionados para os laboratórios (TROX, 2015).

\begin{tabular}{|l|c|c|}
\hline $\begin{array}{l}\text { Características do } \\
\text { Equipamento }\end{array}$ & $\begin{array}{c}\text { Lab. de Instrumentação } \\
\text { (MT 16) }\end{array}$ & $\begin{array}{c}\text { Lab. de Túneis de } \\
\text { Vento (MT 06) }\end{array}$ \\
\hline Nome & ICH-DX 5 & ICH-DX 7,5 \\
\hline $\begin{array}{l}\text { Capacidade } \\
\text { Nominal }\end{array}$ & $5 \mathrm{TR}$ & $7,5 \mathrm{TR}$ \\
\hline Fluido Refrigerante & $\mathrm{R} 22$ & $\mathrm{R} 22$ \\
\hline Tensão Nominal & $220 / 380 \mathrm{~V}$ & $220 / 380 \mathrm{~V}$ \\
\hline $\begin{array}{l}\text { Frequência } \\
\text { Nominal }\end{array}$ & $60 \mathrm{~Hz}$ & $60 \mathrm{~Hz}$ \\
\hline Potência Motor & $2 \mathrm{cv}$ & $3 \mathrm{cV}$ \\
\hline Capacidade Total & $5,3 \mathrm{TR}$ & $8,6 \mathrm{TR}$ \\
\hline $\begin{array}{l}\text { Capacidade } \\
\text { Sensível }\end{array}$ & $3,5 \mathrm{TR}$ & $5,8 \mathrm{TR}$ \\
\hline $\begin{array}{l}\text { Capacidade } \\
\text { Latente }\end{array}$ & $1,8 \mathrm{TR}$ & $2,8 \mathrm{TR}$ \\
\hline Condensador & $\mathrm{A}$ ar remoto & A ar remoto \\
\hline
\end{tabular}

Esta é a linha leve de Intercambiadores de Calor de expansão direta que são utilizados para conforto e com desempenho similar às unidades de tratamento de ar especiais. Possui filtro grosso classe G4, conforme norma NBR 16101 (ABNT, 2012), fabricado em fibra sintética encartonada, que é substituído frontalmente à máquina. A figura D.3 mostra o intercambiador de calor selecionado. 


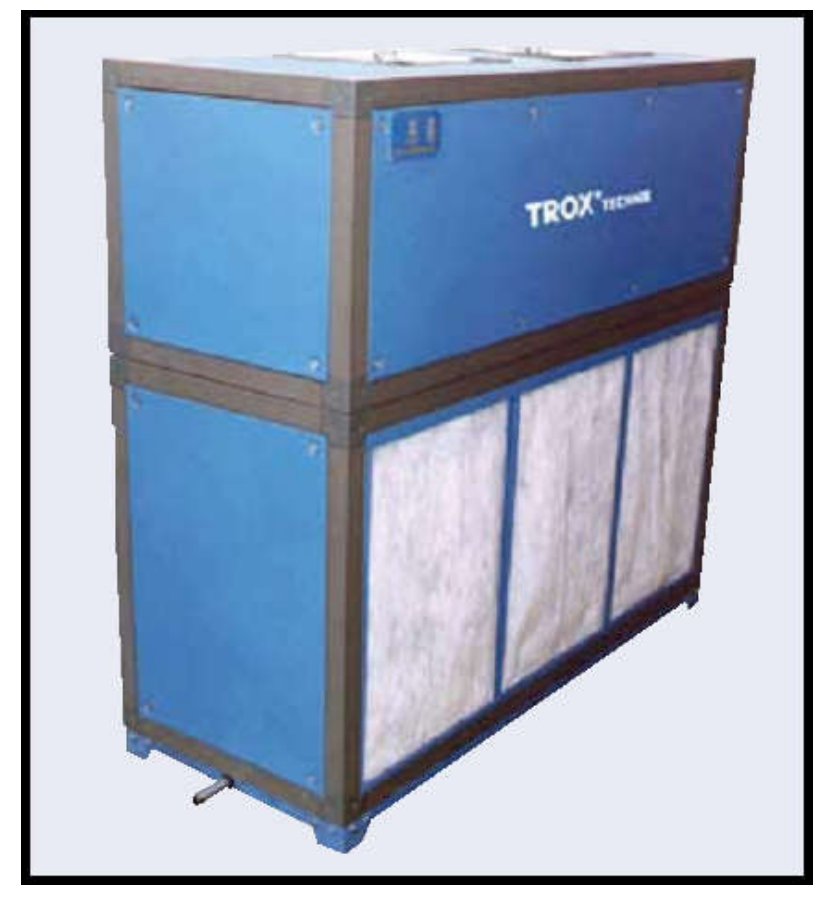

Figura D.1. Intercambiador de calor série ICV-DX (TROX, 2015).

\subsubsection{Filtragem}

Para se ter uma boa Qualidade do Ar Interior, o sistema tratamento de ar deve filtrar continuamente o material particulado trazido pelo ar exterior, e também os gerados internamente, que são transportados pelo ar de retorno. Dessa maneira, a filtragem contribui para a redução da concentração dos poluentes no recinto a níveis aceitáveis e, consequentemente, reduz o acúmulo de poluentes nos equipamentos e dutos do sistema.

De acordo com a NBR 16401-3 (ABNT, 2008), a classe mínima de filtragem que deve ser adotada para sala de aula é a classe F5. Outrossim, a norma estipula um pré-filtro adicional para o ar exterior, no mínimo de classe G4.

Desde 2012, entrou em vigor a NBR 16101 (ABNT, 2012) que trata de filtros para partículas em suspensão no ar, trazendo dentre outras novidades, uma nova classificação, sendo que o filtro de classe F5, se tornou hoje M5. Sendo assim, para esse projeto se faz necessário a utilização de um filtro com grau de filtragem de no mínimo M5 para as salas de aula, com uma pré-filtragem de classe G4. 
Apesar da classe de filtragem M5 adotada pela norma para ambientes escolares, o projeto proposto contará com caixas de filtragem tanto no ar externo como na recirculação, a fim de comparar diferentes classes de filtragem e vazões para o controle de particulado no interior do ambiente. Dessa forma, todas as caixas de filtragem foram selecionadas para as vazões propostas e para 2 estágios de filtragem até filtros absolutos. Assim, nos trabalhos futuros utilizando o sistema proposto, poderá ser utilizado qualquer filtro com classes de filtragem superiores ao M5 proposto em norma.

As caixas de filtragem e seus respectivos filtros foram dimensionados partindo dos catálogos da TROX (TROX, 2015c), sendo estes próprios para montagem em dutos de ar condicionado ou ventilação. São fabricados em chapa de aço galvanizado, tendo lateralmente uma porta de inspeção para a troca dos filtros. A fixação dos elementos filtrantes dentro das carcaças é executada mediante as molduras com juntas e presilhas de fixação. Este sistema da TROX garante uma estaqueidade, e devido às presilhas, a troca pode ser executada facilmente e de maneira rápida.

Estes filtros sintéticos são fabricados com $100 \%$ de material que não libera partículas. No processo de fabricação dos filtros, o meio filtrante é submetido a um agente antimicrobiano que inibe o crescimento e elimina agentes microbianos tais como esporos, bactérias, fungos e algas, gerando assim uma boa qualidade do ar que irá para o ambiente interno aos laboratórios. A figura D.4 apresenta um filtro tipo bolsa que poderá ser utilizado nos laboratórios.

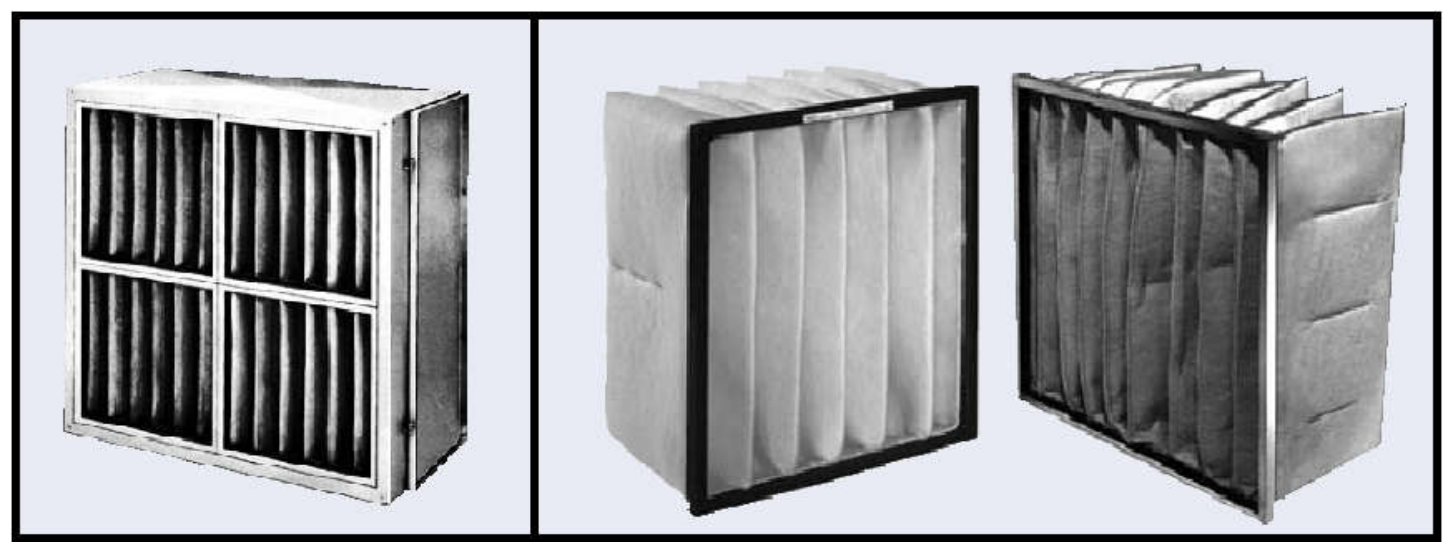

Figura D.2. Filtro bolsa para dutos para os laboratórios (TROX, 2015c). 


\subsubsection{Ventiladores}

Para o projeto dos laboratórios, quando da utilização do ciclo economizador proposto por Rollo (2013), quatro ventiladores se fazem necessários. Dois para realizar o insuflamento de ar, e os outros dois para a exaustão. Além disso, outro exaustor deverá ser utilizado no laboratório de instrumentação (MT16) onde existe um equipamento de solda elétrica, o que exige o dimensionamento de um sistema de exaustão local para retirada adequada dos fumos gerados pela soldagem, evitando a dissipação dos mesmos para o ambiente.

Com o sistema ciclo economizador, proposto por Rollo (2013), em funcionamento, os circuitos de refrigeração dos equipamentos de condicionamento de ar estarão desligados, viabilizando uma economia no consumo de energia elétrica.

Em seu estudo, Rollo (2013) propôs uma vazão de insuflação de $8.640 \mathrm{~m}^{3} / \mathrm{h}$ para o Laboratório de Instrumentação (MT 16), e de $10.800 \mathrm{~m}^{3} / \mathrm{h}$ para o Laboratório de Túneis de Vento (MT 06), as quais representariam aproximadamente 700 horas para a sala MT $16 \mathrm{e}$ 1.300 horas para a sala MT 06 somente com a utilização do ciclo economizador.

No projeto detalhado proposto, apenas o laboratório MT06 contará com o ciclo economizador. O laboratório MT16 contará com um projeto diferente, tendo em vista a bancada de soldagem.

Para o insuflamento de ar do laboratório MT06, será utilizada uma caixa de ventilação composta por um ventilador e um filtro G4, o qual servirá de pré-filtro para não ocorrer a saturação rápida dos filtros na caixa de filtragem propostos futuramente. A caixa de ventilação selecionada é da marca Otam, a qual pode ser observada na tabela D.5 e figura D.5.

Tabela D.2. Tabela de seleção das caixas de ventilação para os laboratórios (OTAM, 2015a).

\begin{tabular}{|c|c|c|c|c|c|c|c|c|c|c|c|c|c|c|c|}
\hline \multirow{2}{*}{ TAMANHO } & \multirow{2}{*}{$\begin{array}{l}\text { VAZĀOO } \\
\left(\mathrm{m}^{2} / \mathrm{h}\right)\end{array}$} & \multirow{2}{*}{$\begin{array}{l}\text { VELOCIDADE DE } \\
\text { DESCARGA (m/s) }\end{array}$} & \multirow{2}{*}{\begin{tabular}{c|} 
(Ipm) \\
(cv/n $/ n^{\circ}$ pólos)
\end{tabular}} & \multicolumn{12}{|c|}{ PRESSĀO ESTÁTICA (mmca) } \\
\hline & & & & 50 & 60 & 70 & 80 & 90 & 100 & 110 & 120 & 140 & 160 & 180 & 200 \\
\hline \multirow{6}{*}{$\begin{array}{l}8 \\
\text { ㅇ } \\
\stackrel{3}{0}\end{array}$} & \multirow{2}{*}{10800} & \multirow{2}{*}{8.0} & ROTAÇĀO & 1193 & 1274 & 1351 & 1426 & 1498 & 1567 & 1634 & 1699 & 1823 & 1942 & 2055 & 2165 \\
\hline & & & MOTOR / PÓL & $4 / \mathrm{N}$ & $4 / \mathrm{IN}$ & $5 / \mathrm{NV}$ & $6 / \mathrm{IV}$ & $6 / \mathrm{IV}$ & $7,5 / \mathrm{N}$ & $7,5 / \mathrm{N}$ & $10 / \mathrm{IV}$ & $10 / \mathrm{IV}$ & $12,5 / \mathrm{IN}$ & $12,5 / \mathrm{IV}$ & $15 / \mathrm{N}$ \\
\hline & \multirow{2}{*}{13500} & \multirow{2}{*}{10.0} & ROTAÇĀO & 1295 & 1367 & 1436 & 1503 & 1568 & 1632 & 1693 & 1753 & 1869 & 1979 & 2085 & 2187 \\
\hline & & & MOTOR / PÓL & $5 / \mathrm{N}$ & $5 / \mathrm{IV}$ & $6 / \mathrm{IV}$ & $7,5 / \mathrm{IV}$ & $7.5 / \mathrm{IV}$ & $10 / \mathrm{IV}$ & $10 / \mathrm{IV}$ & $10 / \mathrm{IV}$ & $12,5 / \mathrm{IV}$ & $15 / \mathrm{IV}$ & $15 / I V$ & $20 / \mathrm{N}$ \\
\hline & \multirow{2}{*}{16200} & \multirow{2}{*}{12.0} & ROTAÇÁAO & 1415 & 1480 & 1542 & 1603 & 1662 & 1719 & 1775 & 1830 & 1937 & 2040 & 2139 & 2235 \\
\hline & & & MOTOR / PÓL. & $6 / N$ & $7,5 / \mathrm{IV}$ & $7,5 / \mathrm{IV}$ & $10 / \mathrm{N}$ & $10 / \mathrm{N}$ & $10 / \mathrm{IV}$ & $12,5 / \mathrm{IV}$ & $12,5 / \mathrm{NV}$ & $15 / \mathrm{IV}$ & $20 / \mathrm{NV}$ & $20 / \mathrm{N}$ & $20 / N$ \\
\hline
\end{tabular}


O gabinete de ventilação selecionado foi o GVL 500 para a sala MT06. Foram consideradas as perdas de carga calculadas no estudo de Rollo (2013) para os dutos de insuflamento, acrescidas da perda de carga dos possíveis filtros a serem empregados para o laboratório. A pressão estática disponível no selecionamento foi de $100 \mathrm{mmca}$ para a caixas de ventilação.

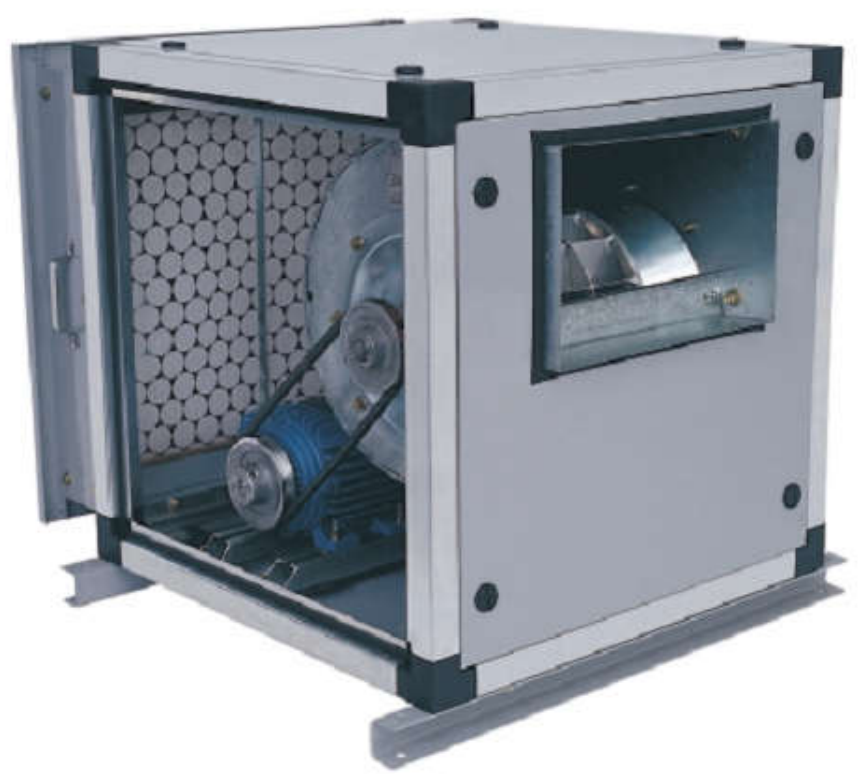

Figura D.3. Caixa de ventilação a ser utilizada nos laboratórios com gaveta para filtro (OTAM, 2015a).

Os gabinetes de ventilação da linha GVL selecionado da OTAM são equipados com ventiladores de pás inclinadas para trás (tipo "limit load”), de dupla aspiração. Segundo a OTAM (2015a), a concepção dos gabinetes GVL foi feita para permitir uma instalação fácil com baixa manutenção. Os gabinetes possuem uma gaveta para filtro, o que possibilita a utilização de um pré-filtro do tipo G4 para o laboratório.

Para a exaustão de ar do laboratório MT06 e da mesa de soldagem, os ventiladores selecionados podem ser observados na tabela D.6 e figuras D.6 e D.7. 
Tabela D.3. Ventiladores de exaustão selecionados para os laboratórios (OTAM, 2015b).

\begin{tabular}{|c|c|c|}
\hline Sistema & $\begin{array}{l}\text { Exaustão } \\
\text { MT06 }\end{array}$ & $\begin{array}{c}\text { Exaustão localizada } \\
\text { MT16 }\end{array}$ \\
\hline Modelo & RSS 710 & RLS 200 \\
\hline Vazão ( Q em m m $\left.^{3} / \mathrm{h}\right)$ & 10.800 & 790 \\
\hline Pressão Estática (P em mmca) & 25 & 55 \\
\hline Rotação (rpm) & 387 & 3091 \\
\hline Rendimento ( $\eta)$ & $67 \%$ & $70,6 \%$ \\
\hline Potência Absorvida (cv) & 1,7 & 0,21 \\
\hline
\end{tabular}

As vazões utilizadas para a seleção correspondem às vazões do ciclo economizador para as redes de exaustão do laboratório MT 06. Para a exaustão localizada, será utilizado a vazão de $790 \mathrm{~m}^{3} / \mathrm{h}$ correspondente à vazão necessária para um braço tipo similar ao fabricado por Nederman.

Para a definição da pressão estática, foram consideradas as perdas de carga calculadas por Rollo (2013) para as redes de exaustão das salas, e as perdas do braço Nederman para a exaustão localizada da MT16 .

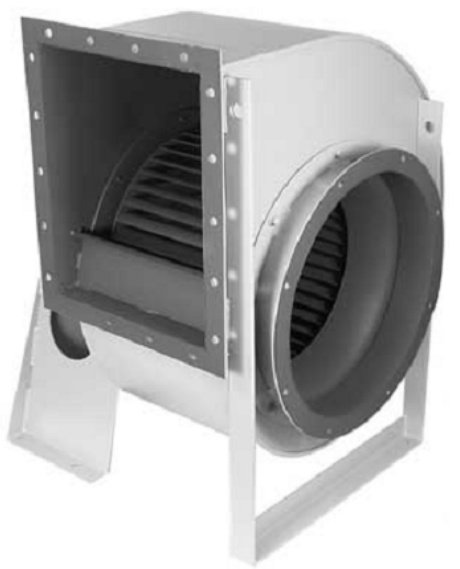

Figura D.4. Ventilador de exaustão selecionado para operação no laboratório MT06 (OTAM, 2015b).

Os ventiladores da linha RS possuem rotores de pás curvadas para frente para operação silenciosa em instalações de ventilação e exaustão. 


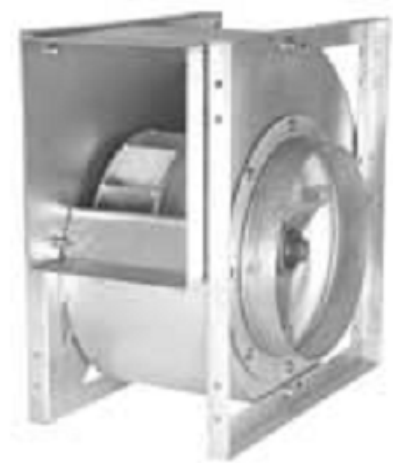

Figura D.5. Ventilador para exaustão localizada (OTAM, 2015b).

Os ventiladores da linha RS possuem rotores de pás voltadas para trás, proporcionando altos valores de pressão estática disponível.

O braço extrator utilizado será do modelo tipo "Nederman Original", que é utilizado em aplicações com solda, rebarbagem ou outros processos industriais para ambientes de trabalho com fumos, vapores ou poeiras não explosivas. O braço extrator a ser utilizado pode ser visualizado na figura D.8.

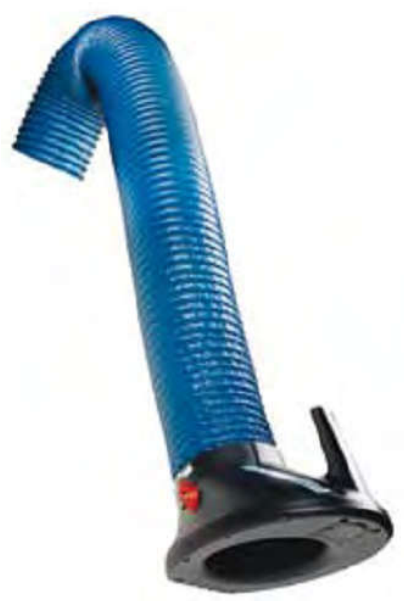

Figura D.6. Braço extrator modelo “Nederman Original” (NEDERMAN, 2015). 


\subsubsection{Difusores e grelhas}

Para fazer o insuflamento e a exaustão do ar dos ambientes dos laboratórios, a seleção dos difusores e grelhas é muito importante, tendo em vista que o sistema poderá trabalhar com o ciclo economizador, este com vazão bem maior quando comparada com o sistema de condicionamento de ar projetado.

Assim, da mesma forma que no dimensionamento dos filtros, as grelhas foram calculadas para a vazão máxima de exaustão, ou seja, a do ciclo economizador para o laboratório MT 06, sendo de $10.800 \mathrm{~m}^{3} / \mathrm{h}$.

As grelhas selecionadas são da marca TROX, sendo 8 grelhas para a sala MT 06 e 6 grelhas para a sala MT 16. As grelhas selecionadas serão de 625 x $425 \mathrm{~mm}$ para o MT 06 e de $325 \mathrm{x}$ $225 \mathrm{~mm}$ para a MT 16, modelo AR da TROX, sendo que a grelha selecionada pode ser vista na figura D.9.

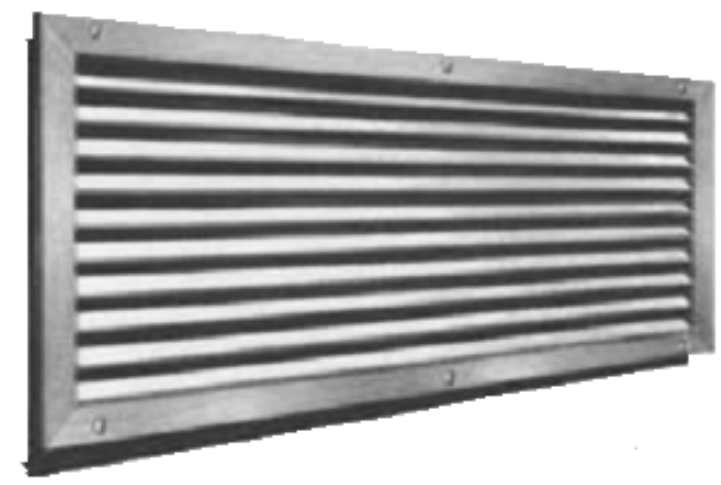

Figura D.7. Grelha de retorno modelo AR da TROX.

Nesta medição foram verificadas as concentrações de $\mathrm{CO}_{2}, \mathrm{PM}_{2,5}$ e $\mathrm{PM}_{10}$. Para o insuflamento, os difusores selecionados devem permitir o trabalho em diferentes faixas de vazões para a MT 06, tendo em vista que o sistema ora operará com o sistema de condicionamento de ar, e ora trabalhará com o ciclo economizador. Sendo assim, foram selecionados 15 difusores de ar para a sala MT 06, e 12 difusores para a sala MT 16. Os difusores irão trabalhar conforme a tabela D.7. 
Tabela D.4. Faixas de vazões de trabalho para os difusores dos Laboratórios.

\begin{tabular}{|l|c|c|}
\hline Ambiente & Sala MT 16 & Sala MT 06 \\
\hline $\begin{array}{l}\text { Vazão total Ciclo } \\
\text { economizador }\left(\mathbf{m}^{\mathbf{3}} / \mathbf{h}\right)\end{array}$ & - & 10.800 \\
\hline $\begin{array}{l}\text { Vazão total } \\
\text { Condicionamento }\left(\mathbf{m}^{\mathbf{3}} / \mathbf{h}\right)\end{array}$ & 3.465 & 4.156 \\
\hline $\mathbf{n}^{\mathbf{0}}$ de difusores & 12 & 15 \\
\hline Vazão de Trabalho $\left(\mathbf{m}^{\mathbf{3}} / \mathbf{h}\right)$ & 290 & $280-720$ \\
\hline
\end{tabular}

Os difusores selecionados para o MT 06, por se tratar de vazões que podem variar, foram os da marca TROX, tamanho 500 do modelo ADLQ com o sistema Varyset. A tabela utilizada no selecionamento pode ser observado na tabela D.8, juntamente com a figura D.10 do difusor.

Tabela D.5. Tabela de seleção do difusor Tipo ADLQ com Varyset (TROX, 2015a).

\begin{tabular}{|c|c|c|c|c|c|c|c|c|c|c|c|c|}
\hline \multirow{2}{*}{ Tamanho } & \multicolumn{2}{|c|}{ v } & \multicolumn{8}{|c|}{ FREQUÉNCIA } & \multirow{2}{*}{$\begin{array}{c}\text { Lwa } \\
d B(A)\end{array}$} & \multirow{2}{*}{$\begin{array}{l}\text { Lwuc } \\
\text { NC }\end{array}$} \\
\hline & $\mathrm{U} / \mathrm{s}$ & $m^{3} / \mathrm{h}$ & 63 & 125 & 250 & 500 & 1000 & 2000 & 4000 & 8000 & & \\
\hline \multirow{5}{*}{400} & 30 & 110 & 27 & 18 & 26 & 22 & $<15$ & $<15$ & $<15$ & $<15$ & 21 & 15 \\
\hline & 55 & 200 & 39 & 33 & 29 & 27 & 17 & $<15$ & $<15$ & $<15$ & 27 & 21 \\
\hline & 80 & 290 & 37 & 33 & 30 & 28 & 19 & $<15$ & $<15$ & $<15$ & 28 & 22 \\
\hline & 110 & 395 & 43 & 36 & 33 & 32 & 28 & 18 & $<15$ & $<15$ & 33 & 26 \\
\hline & 140 & 505 & 47 & 41 & 37 & 36 & 34 & 26 & $<15$ & $<15$ & 38 & 32 \\
\hline \multirow{5}{*}{500} & 55 & 200 & 38 & 39 & 35 & 28 & 17 & $<15$ & $<15$ & $<15$ & 30 & 22 \\
\hline & 80 & 290 & 40 & 38 & 33 & 30 & 26 & 17 & $<15$ & $<15$ & 32 & 25 \\
\hline & 110 & 395 & 45 & 40 & 35 & 32 & 29 & 18 & $<15$ & $<15$ & 34 & 27 \\
\hline & 170 & 610 & 46 & 42 & 37 & 34 & 30 & 21 & $<15$ & $<15$ & 35 & 29 \\
\hline & 220 & 790 & 51 & 46 & 42 & 39 & 36 & 29 & $<15$ & $<15$ & 41 & 35 \\
\hline \multirow{6}{*}{600} & 70 & 250 & 34 & 27 & 24 & 15 & $<15$ & $<15$ & $<15$ & $<15$ & 18 & 9 \\
\hline & 100 & 360 & 36 & 29 & 29 & 23 & $<15$ & $<15$ & $<15$ & $<15$ & 24 & 17 \\
\hline & 150 & 540 & 40 & 34 & 33 & 28 & 24 & $<15$ & $<15$ & $<15$ & 29 & 22 \\
\hline & 190 & 685 & 41 & 34 & 33 & 29 & 26 & 15 & $<15$ & $<15$ & 31 & 25 \\
\hline & 250 & 900 & 46 & 37 & 36 & 32 & 31 & 22 & $<15$ & $<15$ & 35 & 30 \\
\hline & 300 & 1080 & 51 & 40 & 38 & 35 & 34 & 27 & 16 & 15 & 38 & 33 \\
\hline
\end{tabular}

Os difusores ADLQ da TROX são ideais para uso em sistemas de volume de ar variável por possuírem o sistema Varyset. Eles proporcionam uma diferença de vazão de $100 \%$ até $25 \%$ e são recomendados para ambientes com pé direito entre 2,60 m e $4 \mathrm{~m}$. 


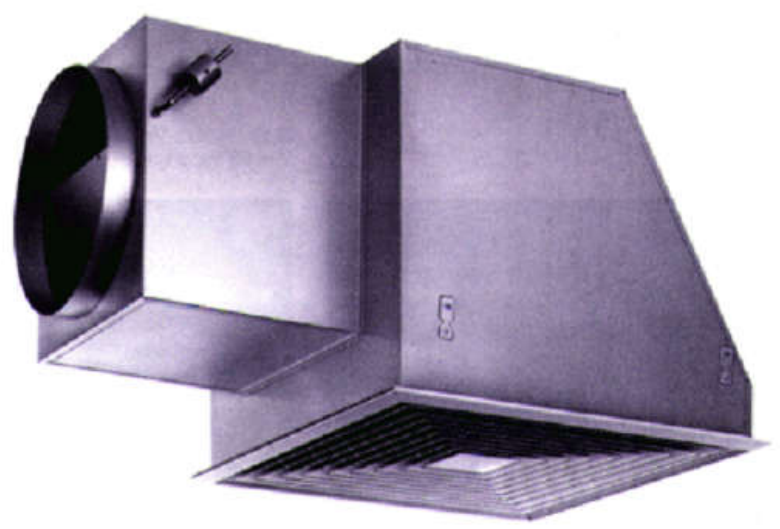

Figura D.8. Difusor selecionado para insuflamento de ar no laboratório MT06 (TROX, 2015a).

Com o sistema Varyset, a vazão de ar pode ser reduzida até $25 \%$ da vazão total, mantendo um fluxo de ar aceitável, sendo que a figura D.11 apresenta o princípio de funcionamento do sistema Varyset.

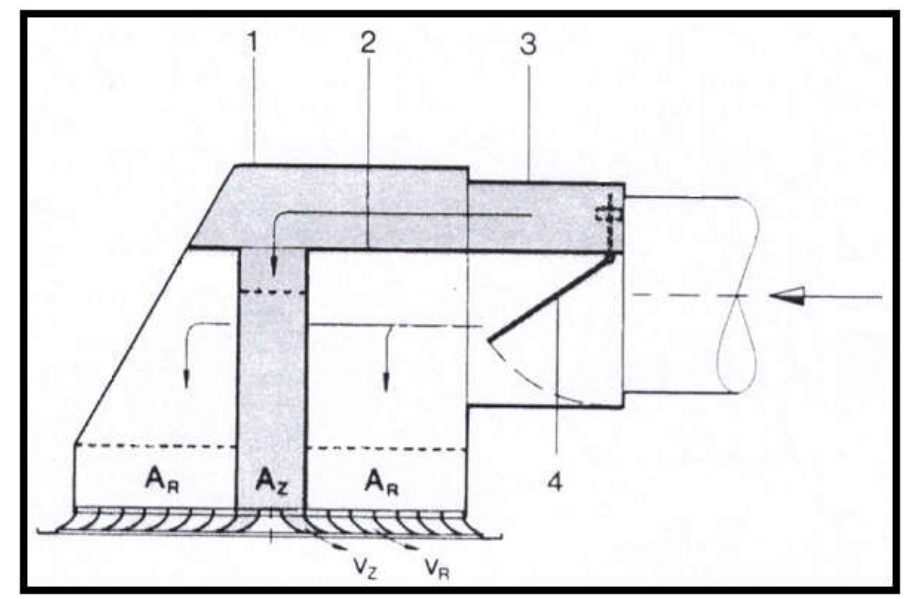

Figura D.9. Princípio de funcionamento do sistema Varyset.

Na caixa plenum (1) é prevista uma chapa de separação (2) de tal forma que a superfície de insuflamento é dividida na área periférica $\left(\mathrm{A}_{\mathrm{R}}\right)$ e na área central $\left(\mathrm{A}_{\mathrm{Z}}\right)$. No colarinho da entrada do plenum, a seção é dividida em duas superfícies, sendo que na superfície de baixo está colocada uma comporta de sobrepressão (4), que se abre mais ou menos em função da pressão do fluxo de ar, sem necessidade de energia externa. 


\section{D.3 Funcionamento do sistema}

Este item visa ajudar no entendimento dos fluxogramas de engenharia (Anexo E) para esclarecer o funcionamento do sistema de tratamento de ar proposto para os laboratórios.

Os sistemas de tratamento de ar propostos para os laboratórios, além de melhorar a qualidade de ar interna do ambiente, possuem o objetivo de proporcionar futuros estudos sobre a Qualidade do Ar Interior, possibilitando a variação das vazões de recirculação e de ar externo, e a mudança da classe dos estágios de filtragem, tanto para a recirculação, como para o ar externo. Esse objetivo é comum aos dois sistemas propostos para os laboratórios, porém os mesmos possuem características específicas, as quais podem ser observadas nos próximos parágrafos.

Para o o Laboratório de Instrumentação (MT 16), o sistema de tratamento de ar proposto possui uma exaustão localizada para a bancada de soldagem. Neste caso, um exaustor será utilizado para captação dos gases gerados no processo. Para este laboratório, o sistema funcionará normalmente, e existirá a possibilidade da variação da vazão de ar externo e da recirculação através de dampers com acionamento manual. Os filtros poderão ser trocados para diferentes experimentos.

O sistema de tratamento de ar proposto para o Laboratório de Tunéis de Vento (MT 06), além do sistema principal, contará com um subsistema tipo ciclo economizador. O sistema irá operar apenas com um subsistema, dependendo da entalpia do ar externo. Para isso, o laboratório contará com modos de operação diferentes. Quando da operação do ciclo economizador, o intercambiador estará desligado, funcionando apenas a caixa de ventilação de ar externo e o exaustor. Já, para o sistema principal, o intercambiador entrará em funcionamento e a vazão de ar externo poderá ser variada através dos dampers de acionamento manual localizados nas linhas. Da mesma forma que o sistema para o outro laboratório, este também contará com duas caixas de filtragem, sendo uma para o ar externo e a outra para a recirculação, com a possibilidade de mudança dos filtros com diferentes classes de filtragem. O isolamento dos sistemas, quando da operação do outro, poderá ser realizado através dos dampers motorizados localizados nas linhas.

Para os dois sistemas, a vazão de exaustão sairá por frestas, com a finalidade da obtenção de uma leve pressurização do ambiente dos laboratórios, evitando-se assim a entrada de ar externo sem tratamento prévio nos laboratórios. 


\section{Anexo E - Projeto dos sistemas de VAC para os laboratórios}

Este anexo apresenta os fluxogramas de engenharia do projeto básico proposto dos sistemas de ventilação e ar condicionado para tratamento do ar dos laboratórios de estudo, e as plantas com o arranjo de dutos e equipamentos. Outrossim, os cortes das plantas, bem como a lista de componentes também serão apresentados para um melhor entendimento do projeto. As dimensões dos dutos e dos acessórios estão em milímetros, e as vazões indicadas $\mathrm{em}^{3} / \mathrm{h}$. 
E.1 Fluxograma da casa de máquinas do Laboratório de Instrumentação (MT 16)

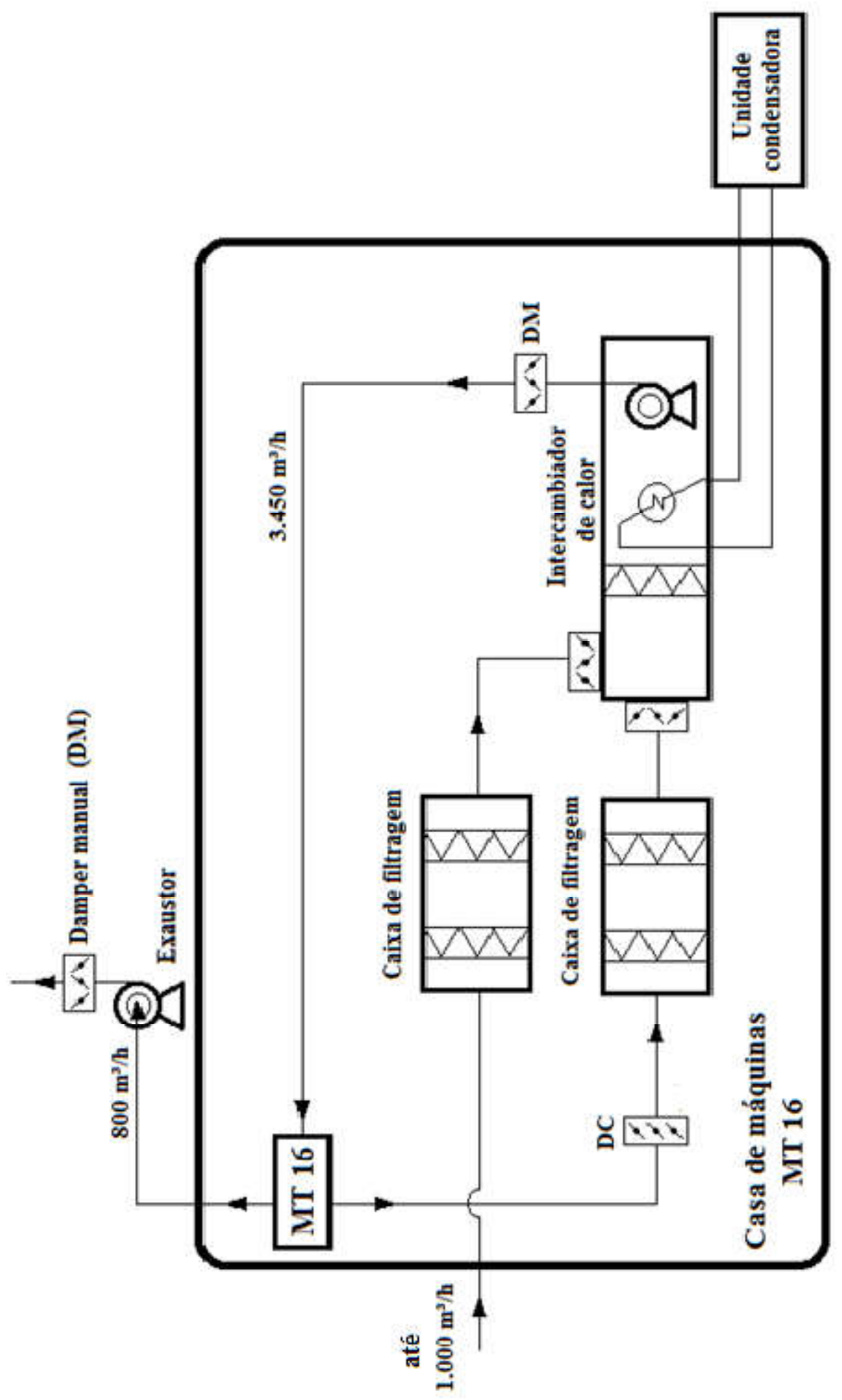


E.2 Fluxograma da casa de máquinas do Laboratório de Túneis de Vento (MT 06)

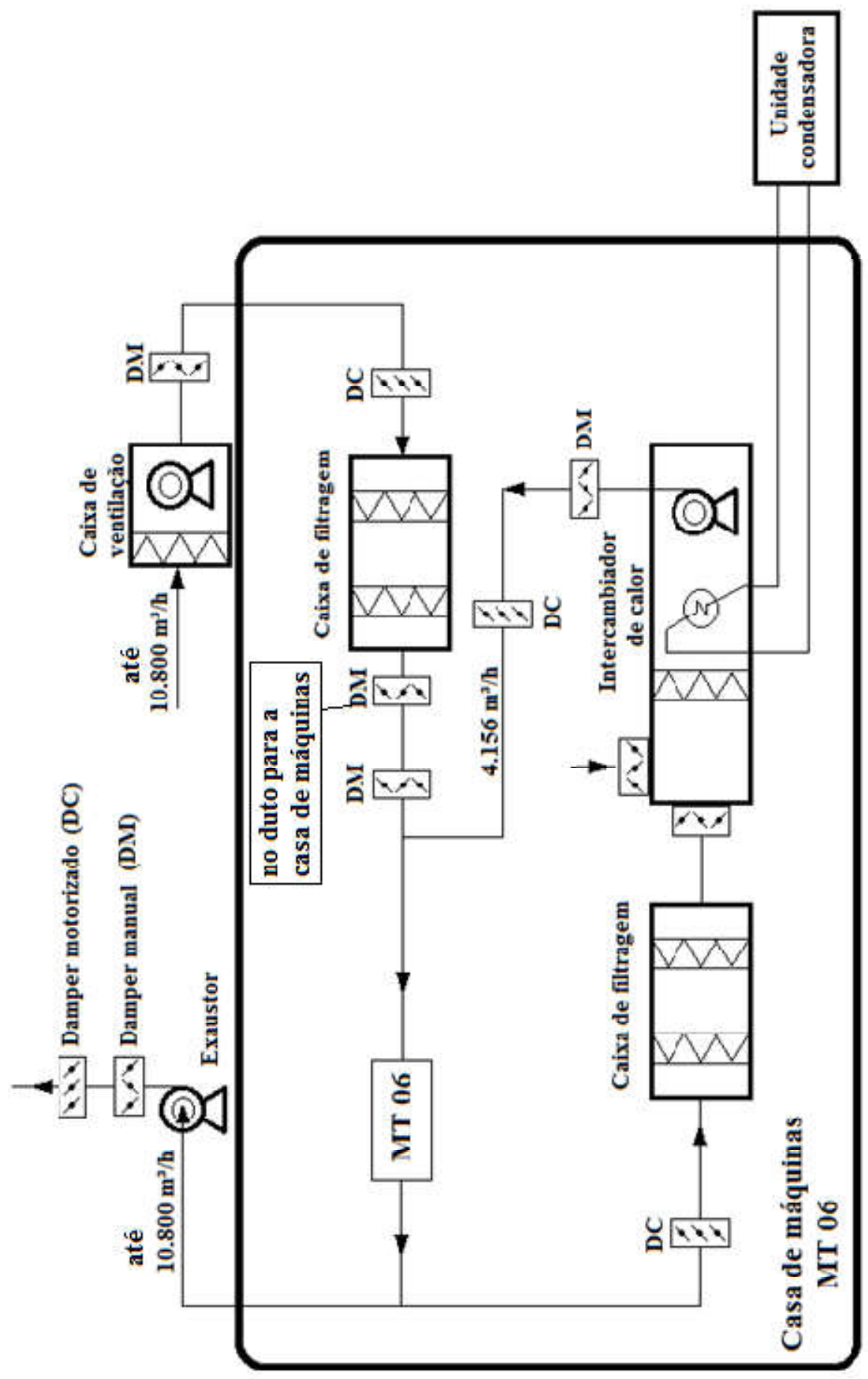


E.3 Arranjo de dutos e equipamentos do Laboratório de Instrumentação (MT 16)

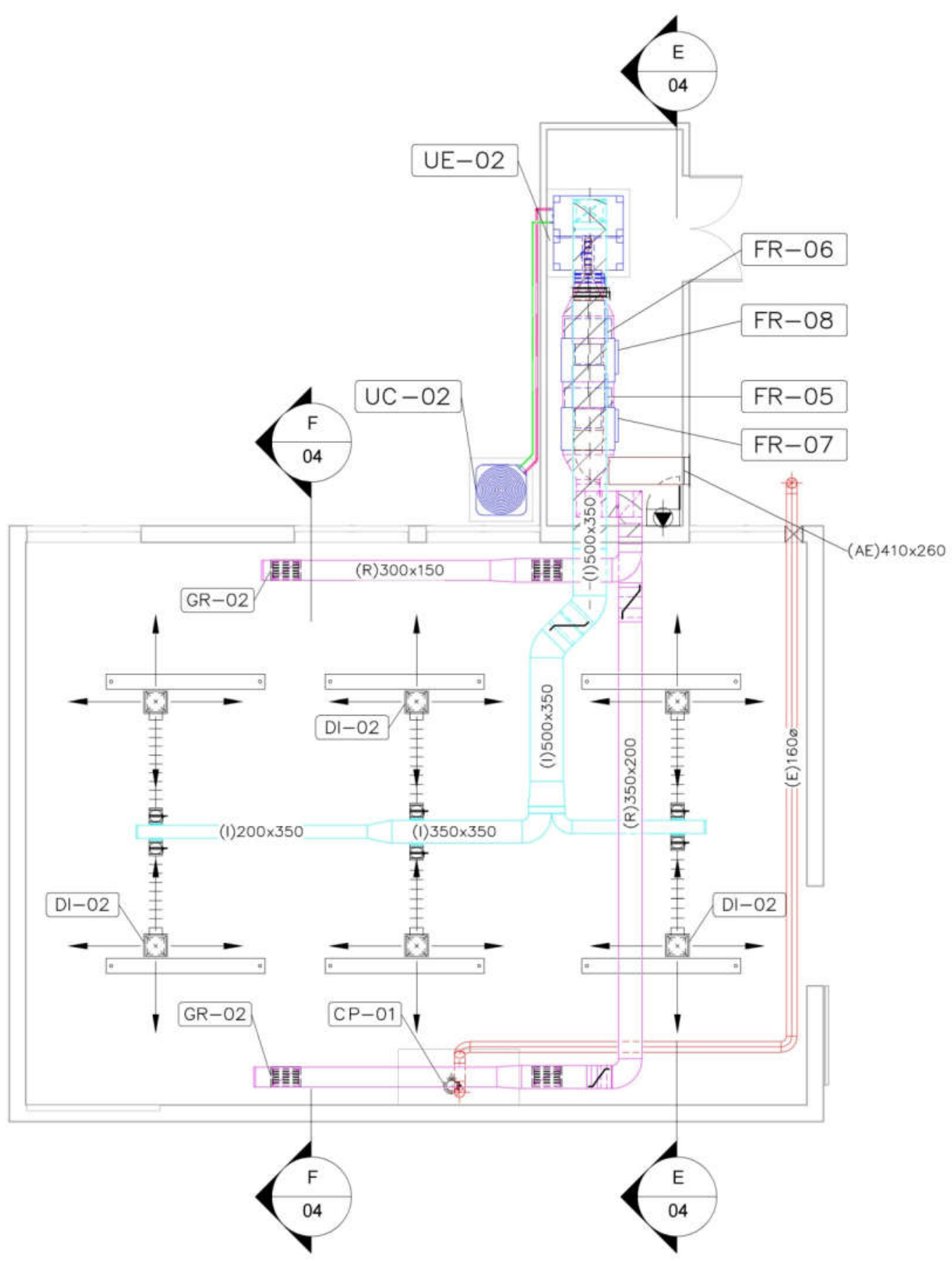


E.4 Arranjo de dutos e equipamentos do Laboratório de Túneis de Vento (MT 06)

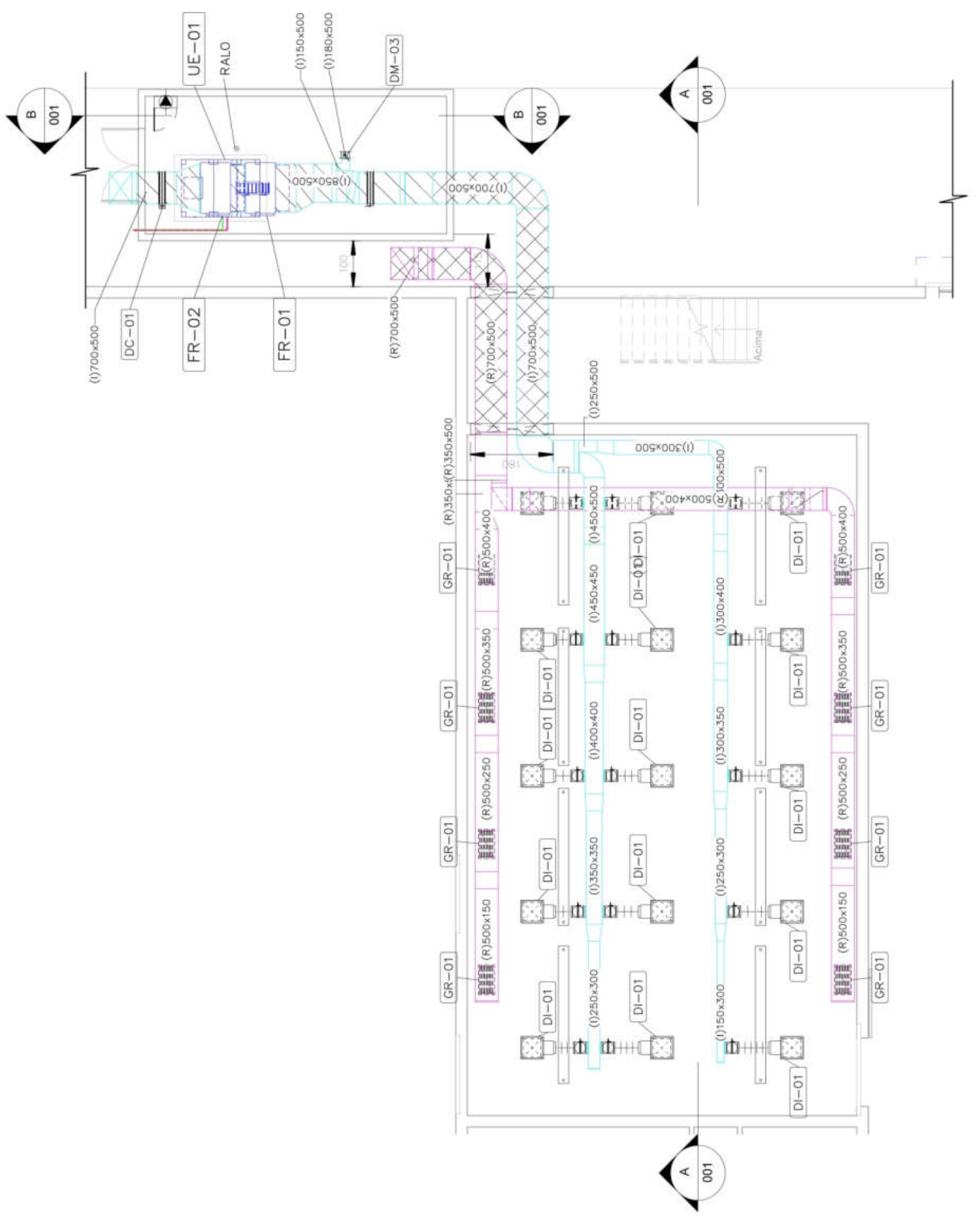




\section{E.5 Arranjo de dutos e equipamentos Cobertura}
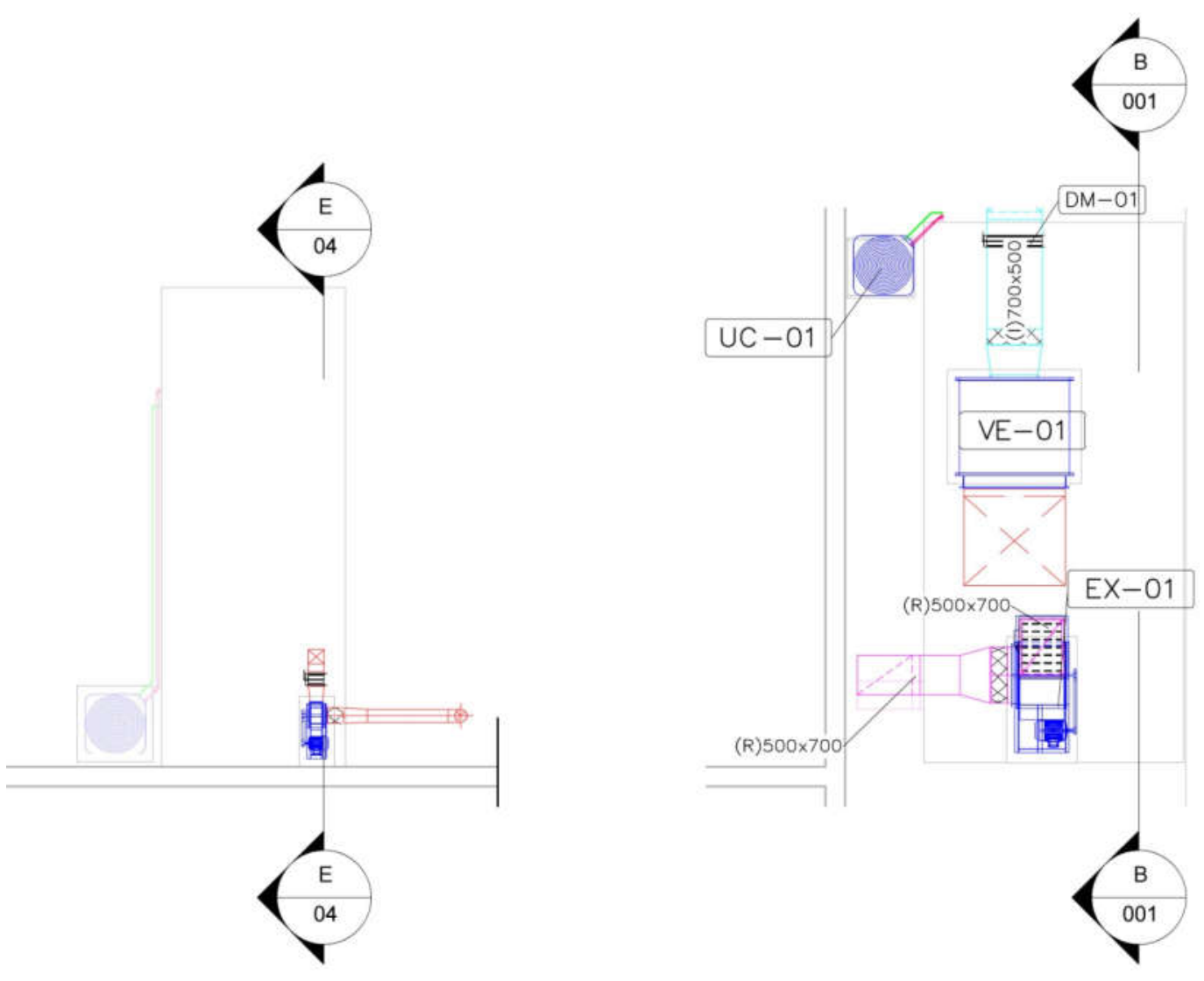


\section{E.6 Corte A-A}

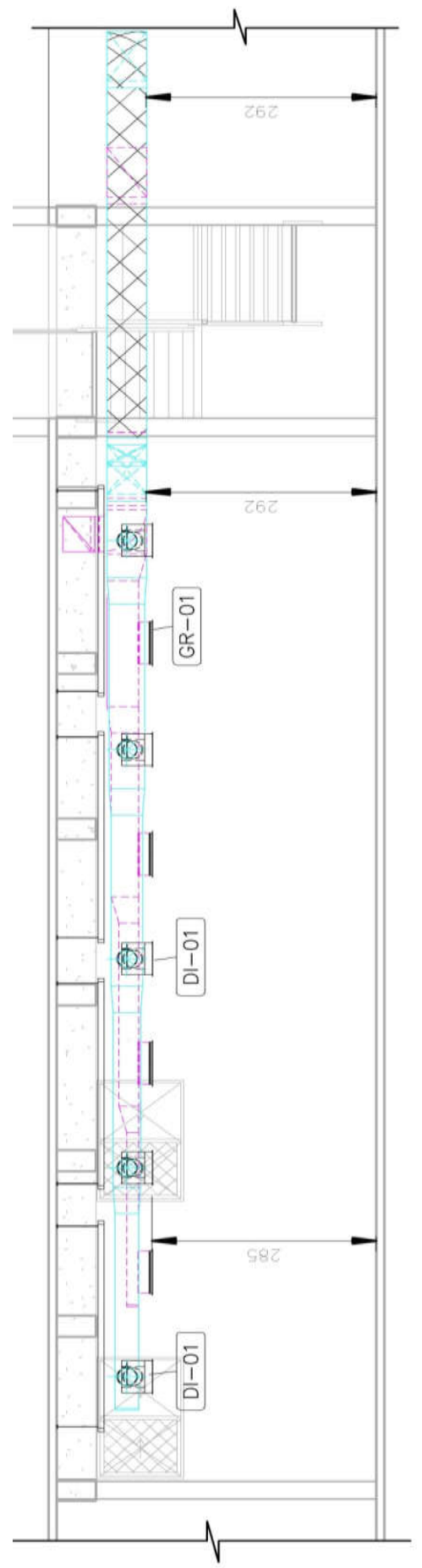




\section{E.7 Corte B-B}

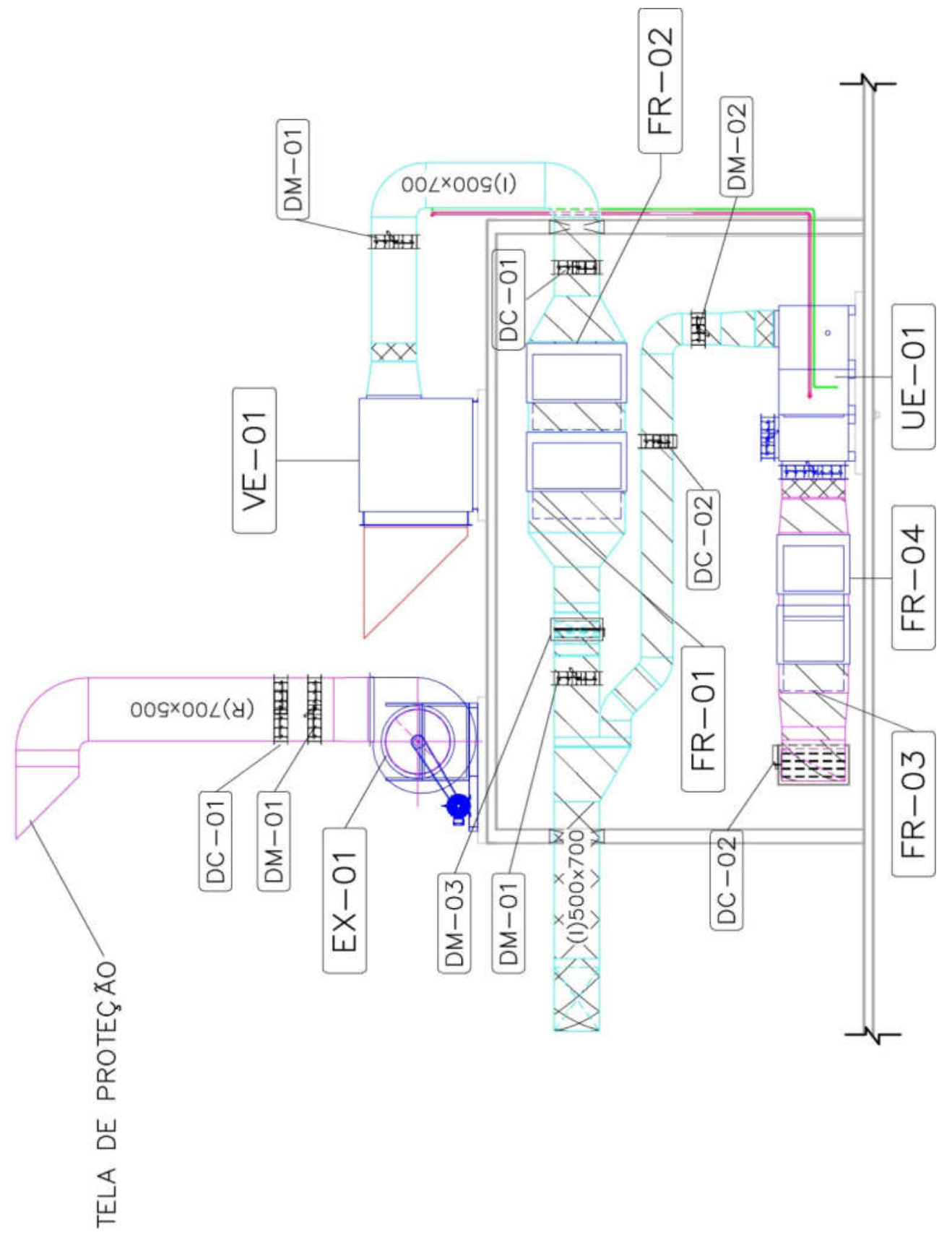




\section{E.8 Corte C-C}

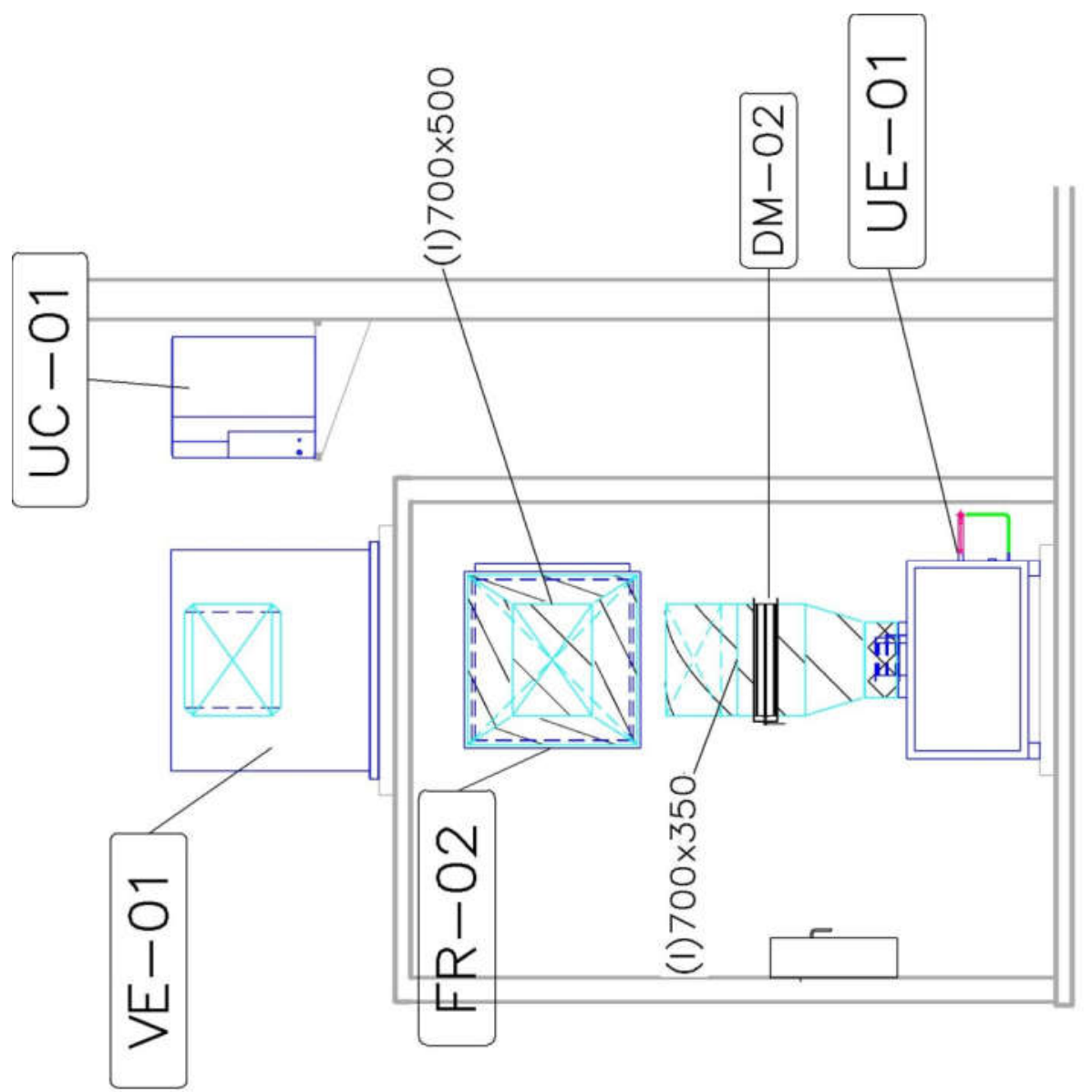




\section{E.9 Corte D-D}

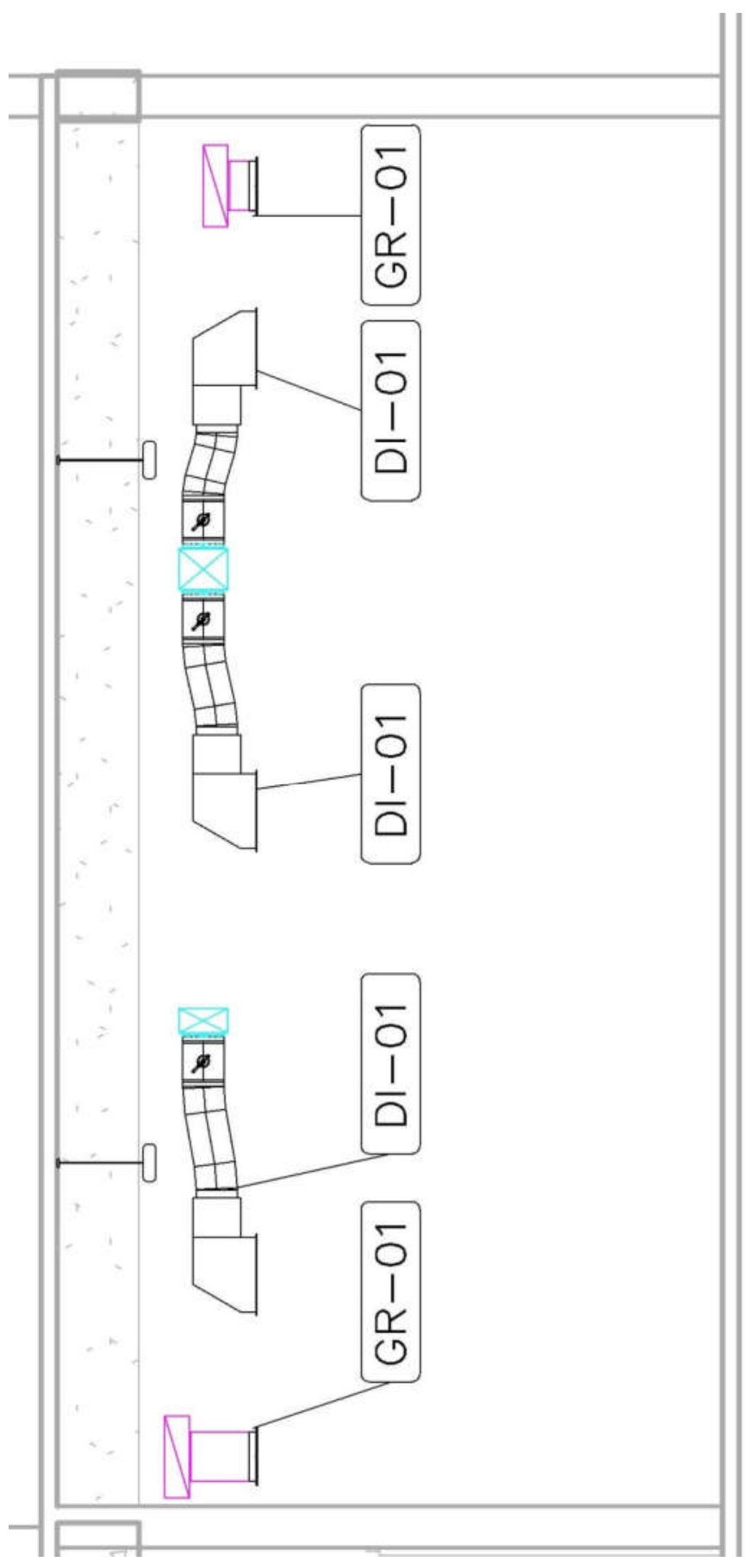




\section{E.10 Corte E-E}

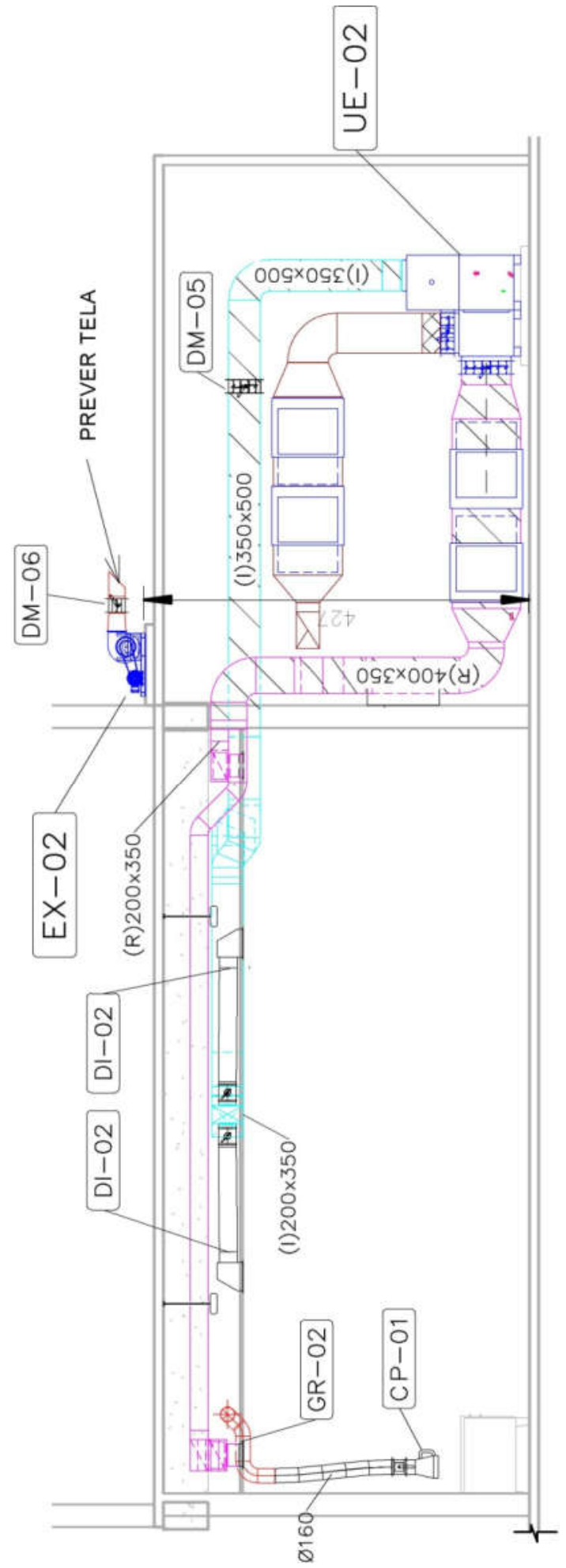




\section{E.11 Corte F-F}

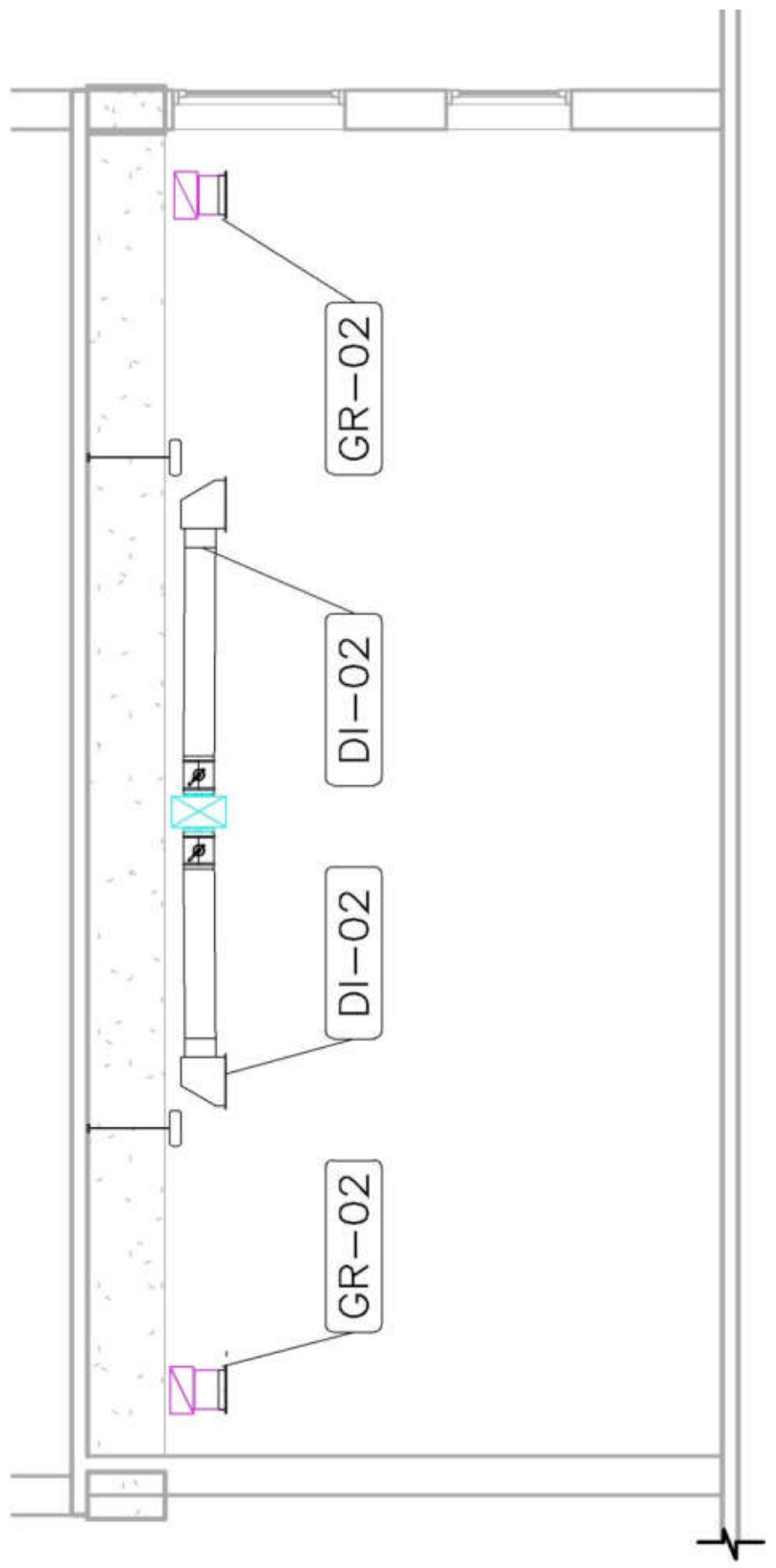


E.12 Vista da casa de máquinas do laboratório de Instrumentação (MT 16)

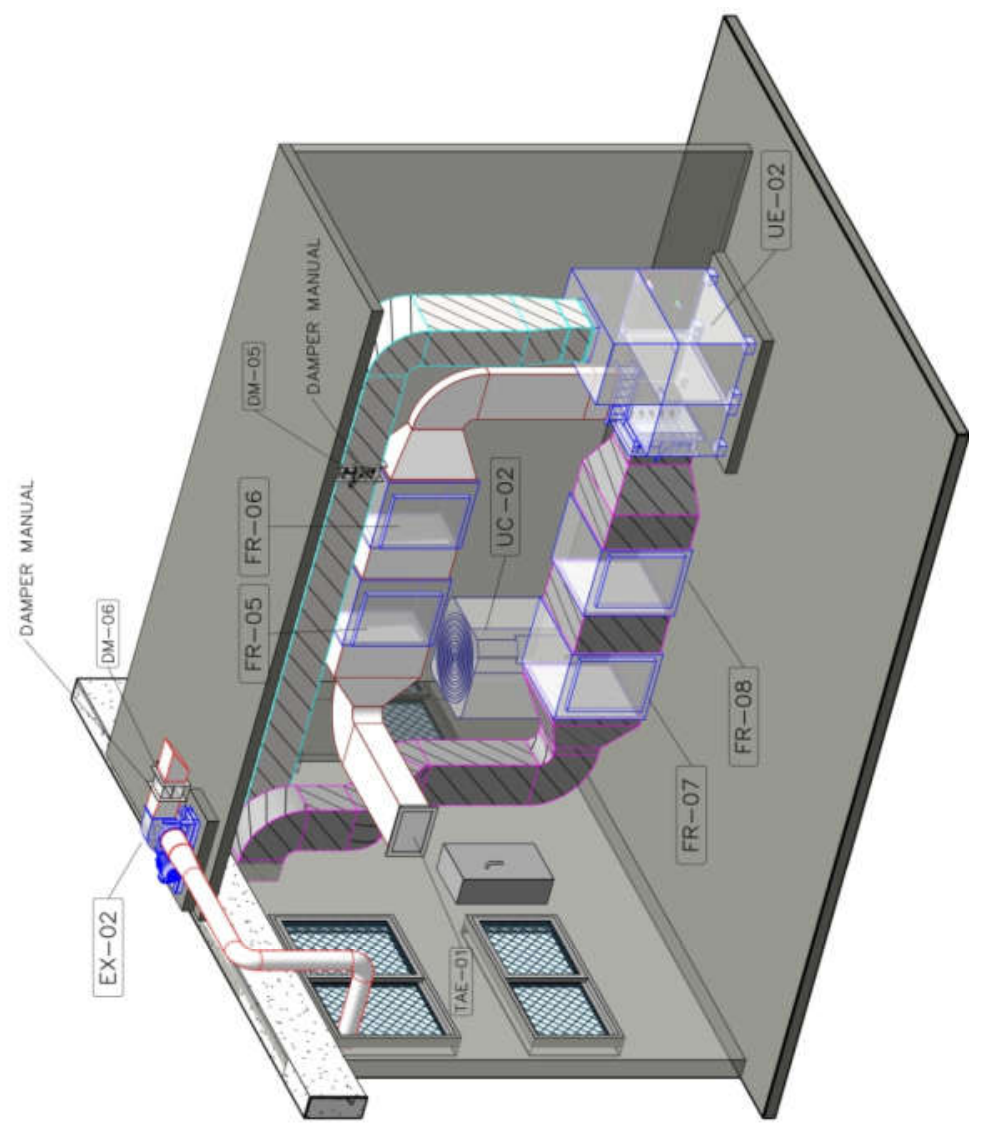


E.13 Vista da casa de máquinas do laboratório de Túneis de Vento (MT 06)

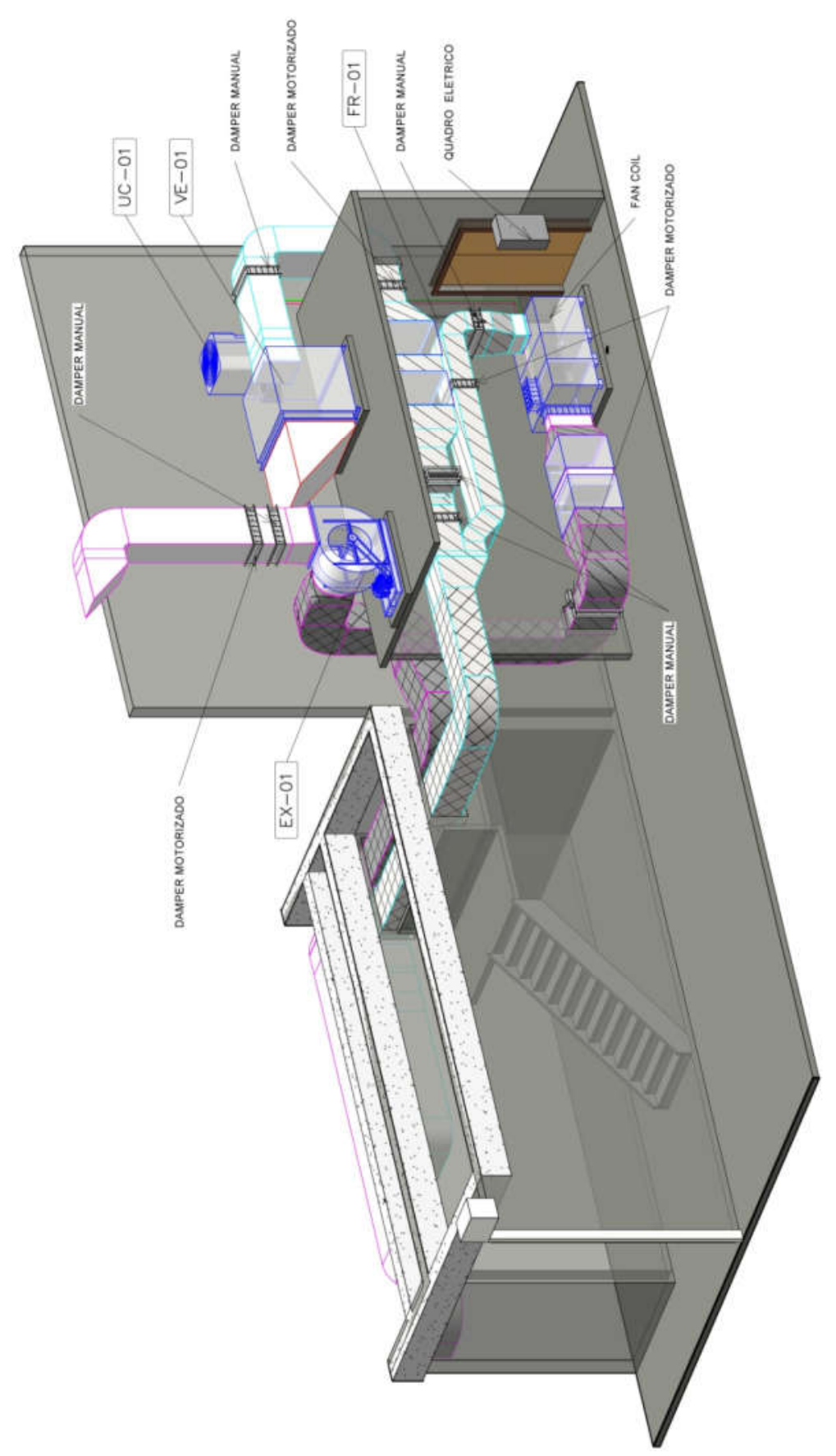




\section{E.14 Vista geral dos laboratórios}

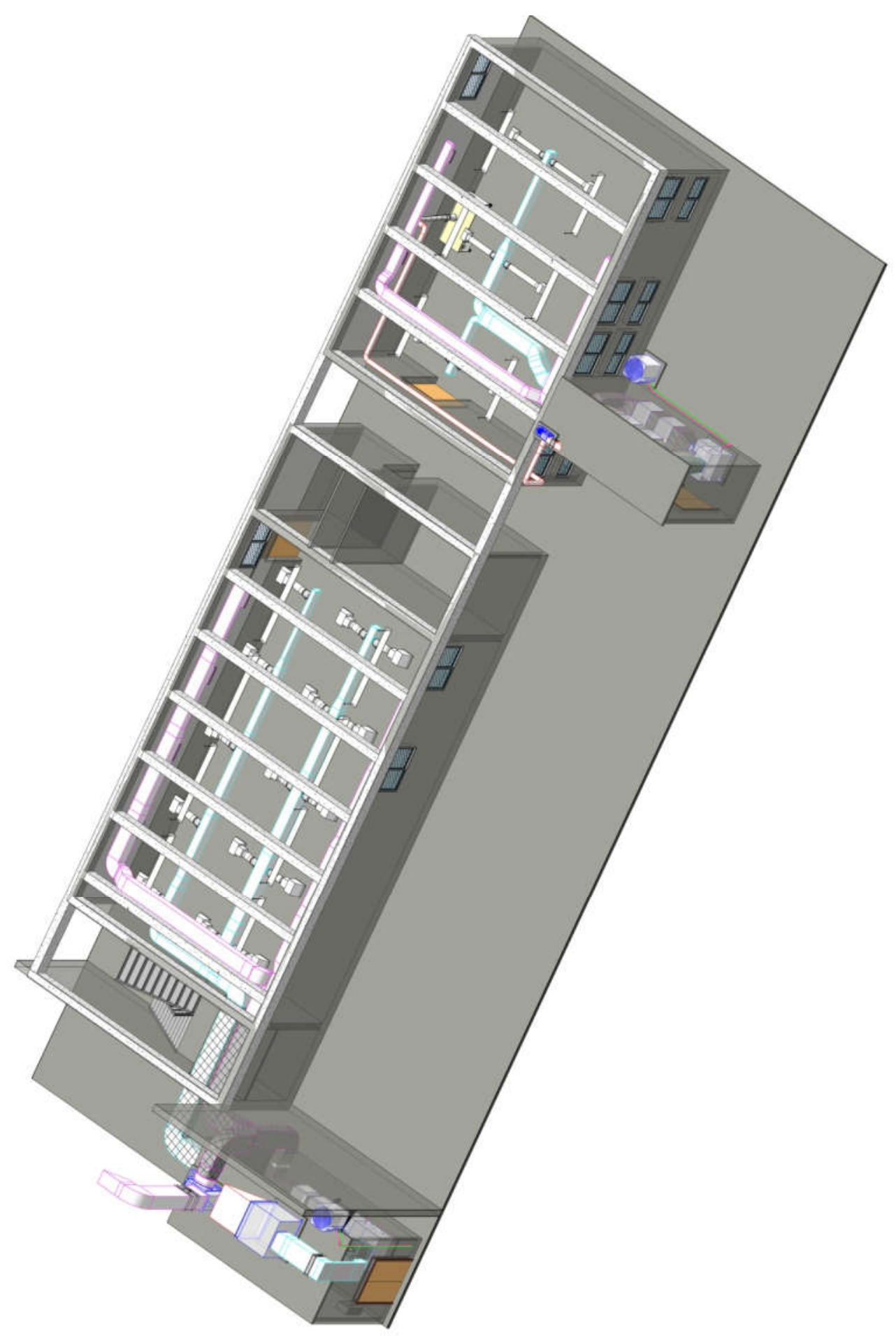




\section{E.15 Tabela de componentes do sistema do laboratório}

\section{(MT 16)}

\begin{tabular}{|c|c|c|c|}
\hline \multicolumn{4}{|c|}{ Laboratório MT16 } \\
\hline \multirow{2}{*}{ Intercambiador de Calor } & $\begin{array}{l}\text { MODELO } \\
\text { (TROX) }\end{array}$ & & \\
\hline & ICH-DX 5 & $3450 \mathrm{~m}^{3} / \mathrm{h}$ & $130 \mathrm{mmca}$ \\
\hline \multirow{2}{*}{ Ventilador de Exaustão } & Vazão & $\Delta \mathrm{P}$ disponível & \\
\hline & $800 \mathrm{~m}^{3} / \mathrm{h}$ & $90 \mathrm{mmca}$ & \\
\hline \multirow{2}{*}{$\begin{array}{l}\text { CAIXA DE FILTRAGEM } \\
\text { (1Filtro Médio + } 1 \text { Filtro } \\
\text { absoluto) }\end{array}$} & Vazão & & \\
\hline & $1000 \mathrm{~m}^{3} / \mathrm{h}$ & & \\
\hline \multirow{2}{*}{$\begin{array}{l}\text { CAIXA DE FILTRAGEM } \\
\text { (1Filtro Médio + } 1 \text { Filtro } \\
\text { absoluto) }\end{array}$} & Vazão & & \\
\hline & $3450 \mathrm{~m}^{3} / \mathrm{h}$ & & \\
\hline Difusores & \multirow{2}{*}{\multicolumn{2}{|c|}{$\begin{array}{l}\text { Multivias quadrado com registro AG, } \\
\text { com caixa plenum AK6, Tam. T3 }\end{array}$}} & Quantidade \\
\hline & & & 12 \\
\hline Grelhas & \multirow{2}{*}{\multicolumn{2}{|c|}{$\begin{array}{l}\text { Grelhas de Retorno de aletas fixas } \\
\qquad \mathrm{B}(\mathrm{mm}) 325 ; \mathrm{H}(\mathrm{mm}) 225\end{array}$}} & Quantidade \\
\hline Greinas & & & 6 \\
\hline \multirow{2}{*}{ Veneziana de Ar Externo } & Quantidade & $\begin{array}{l}\text { Tamanho } \\
\text { BxH(mm) }\end{array}$ & \\
\hline & 1 & $397 \times 297$ & \\
\hline \multirow{2}{*}{$\begin{array}{l}\text { Dampers de Regulagem } \\
\text { com Aletas Convergentes }\end{array}$} & Quantidade & $\begin{array}{l}\text { Tamanho } \\
\text { BxH(mm) }\end{array}$ & Acionamento \\
\hline & 1 & $500 \times 345$ & Manual \\
\hline \multirow{2}{*}{$\begin{array}{l}\text { Dampers de Regulagem } \\
\text { Circulares }\end{array}$} & Quantidade & Diâmetro $(\mathrm{mm})$ & Acionamento \\
\hline & 12 & 150 & Manual \\
\hline \multirow{2}{*}{$\begin{array}{l}\text { Braço Articulado para } \\
\text { exaustão localizada de } \\
\text { fumos de solda }\end{array}$} & Quantidade & Vazão $\left(m^{3} / h\right)$ & Comprimento (m) \\
\hline & 1 & 800 & 2 \\
\hline
\end{tabular}




\section{E.16 Tabela de componentes do sistema do laboratório}

\section{(MT 06)}

\begin{tabular}{|c|c|c|c|}
\hline \multicolumn{4}{|c|}{ Laboratório MT06 } \\
\hline Intercambiador de Calor & $\begin{array}{c}\text { MODELO } \\
\text { (TROX) } \\
\text { ICH-DX 7,5 }\end{array}$ & $\begin{array}{c}\text { Vazão } \\
4156 \mathrm{~m}^{3} / \mathrm{h}\end{array}$ & $\begin{array}{c}\mathbf{\Delta P} \\
\text { disponível } \\
130 \mathrm{mmca}\end{array}$ \\
\hline $\begin{array}{l}\text { Caixa de Ventilação } \\
\text { (Filtro G4) }\end{array}$ & $\begin{array}{c}\text { Vazão } \\
0 \sim 10800 \mathrm{~m}^{3} / \mathrm{h} \\
\end{array}$ & $\begin{array}{c}\Delta \mathbf{P} \text { disponível } \\
100 \text { mmca }\end{array}$ & \\
\hline Ventilador de Exaustão & $\begin{array}{c}\text { Vazão } \\
10800 \mathrm{~m}^{3} / \mathrm{h}\end{array}$ & $\begin{array}{c}\Delta \mathrm{P} \text { disponível } \\
40 \text { mmca }\end{array}$ & \\
\hline $\begin{array}{l}\text { CAIXA DE FILTRAGEM } \\
\text { (1Filtro Médio + } 1 \text { Filtro } \\
\text { absoluto) }\end{array}$ & $\begin{array}{c}\text { Vazão } \\
10800 \text { m³/h }\end{array}$ & & \\
\hline $\begin{array}{l}\text { CAIXA DE FILTRAGEM } \\
\text { (1Filtro Médio + 1 Filtro } \\
\text { absoluto) }\end{array}$ & $\begin{array}{c}\text { Vazão } \\
4156 \mathrm{~m}^{3 / h}\end{array}$ & & \\
\hline Difusores & \multicolumn{2}{|c|}{$\begin{array}{l}\text { Multivias quadrado com caixa plenum + } \\
\text { varyset, Tam. T5 }\end{array}$} & $\begin{array}{c}\text { Quantidade } \\
15\end{array}$ \\
\hline Grelhas & \multicolumn{2}{|c|}{$\begin{array}{l}\text { Grelhas de Retorno de aletas fixas } \\
\qquad \mathrm{B}(\mathrm{mm}) 625 ; \mathrm{H}(\mathrm{mm}) 325\end{array}$} & $\begin{array}{c}\text { Quantidade } \\
8\end{array}$ \\
\hline $\begin{array}{l}\text { Dampers de Regulagem } \\
\text { com Aletas Convergentes }\end{array}$ & $\begin{array}{c}\text { Quantidade } \\
\qquad \begin{array}{c}3 \\
1\end{array} \\
\end{array}$ & $\begin{array}{l}\text { Tamanho } \\
\text { BxH(mm) } \\
700 \times 510 \\
700 \times 345 \\
\end{array}$ & $\begin{array}{c}\text { Acionamento } \\
\text { Manual } \\
\text { Manual }\end{array}$ \\
\hline $\begin{array}{l}\text { Dampers de Bloqueio com } \\
\text { Aletas Convergentes }\end{array}$ & $\begin{array}{c}\text { Quantidade } \\
\qquad \begin{array}{c}2 \\
2\end{array}\end{array}$ & $\begin{array}{l}\text { Tamanho } \\
\text { BxH(mm) } \\
700 \times 510 \\
700 \times 345\end{array}$ & $\begin{array}{c}\text { Acionamento } \\
\text { Motorizado } \\
\text { Motorizado }\end{array}$ \\
\hline $\begin{array}{l}\text { Dampers de Regulagem } \\
\text { Circulares }\end{array}$ & $\begin{array}{c}\text { Quantidade } \\
15\end{array}$ & $\begin{array}{l}\text { Diâmetro }(\mathrm{mm}) \\
250\end{array}$ & $\begin{array}{c}\text { Acionamento } \\
\text { Manual }\end{array}$ \\
\hline
\end{tabular}




\section{Anexo F - Tabelas de medições das aulas práticas}

Este anexo apresenta as tabelas das medições realizadas nas aulas com atividade prática. 


\section{F.1 Tabela da medição do dia 21/05/2016}

\begin{tabular}{|c|c|c|c|c|c|c|c|c|c|c|c|c|c|c|}
\hline \multirow{2}{*}{ Hora } & \multicolumn{2}{|c|}{ TBS $\left({ }^{\circ} \mathrm{C}\right)$} & \multicolumn{2}{|c|}{ UR (\%) } & \multicolumn{2}{|c|}{$\mathrm{CO}_{2}(\mathrm{ppm})$} & \multicolumn{2}{|c|}{ PM10 (ug/m³) } & \multicolumn{2}{|c|}{$\mathbf{P} \mathbf{M}_{2,5}\left(\mathbf{u g} / \mathbf{m}^{3}\right)$} & \multicolumn{4}{|c|}{ Observações } \\
\hline & Interno & Externo & Interno & Externo & Interno & Externo & Interno & Externo & \begin{tabular}{|l|} 
Interno \\
\end{tabular} & Externo & Ocupantes & Geral & $\begin{array}{l}\text { Vazão de ar externo } \\
\text { aproximada }\left(\mathbf{m}^{3} / \mathbf{h}\right)\end{array}$ & $\begin{array}{l}\text { Vazão aproximada } \\
\text { por pessoa }\left(\mathrm{m}^{3} / \mathrm{h}\right)\end{array}$ \\
\hline 10h00 & 22,1 & 22,2 & 75,6 & 76,2 & 509 & 409 & 24,6 & 12,3 & 4,8 & 3,9 & 3 & unidades 1 e 3 em operação & 1100 & 367 \\
\hline $10 \mathrm{~h} 10$ & 22,2 & 22,4 & 76,3 & 71,6 & 494 & 447 & 26,1 & 14,6 & 4,2 & 3,8 & 3 & & 1100 & 367 \\
\hline $10 \mathrm{~h} 20$ & 22,1 & 21,6 & 71,9 & 71,6 & 474 & 410 & 22,9 & 12,3 & 3,6 & 3,3 & 4 & & 1100 & 275 \\
\hline $10 \mathrm{~h} 30$ & 21,9 & 20,5 & 72,7 & 76,7 & 466 & 407 & 22,1 & 14,4 & 3,4 & 4,1 & 3 & & 1100 & 367 \\
\hline $10 \mathrm{~h} 40$ & 21,8 & 23,1 & 73,1 & 78,4 & 467 & 454 & 19,9 & 14,2 & 3,2 & 4 & 1 & & 1100 & 1100 \\
\hline $10 \mathrm{h50}$ & 22,1 & 20,6 & 73 & 76,5 & 470 & 409 & 10,9 & 16,4 & 2,8 & 4,5 & 1 & & 1100 & 1100 \\
\hline $11 \mathrm{~h} 00$ & 21,8 & 20,6 & 73,9 & 76,5 & 457 & 403 & 11,9 & 12,9 & 2,8 & 3,8 & 2 & & 1100 & 550 \\
\hline $11 \mathrm{~h} 10$ & 22,3 & 20,7 & 72,9 & 76,8 & 562 & 397 & 70,9 & 14,3 & 4,9 & 3,9 & 42 & $11 \mathrm{~h} 05$ entrada dos alunos & 1100 & 26 \\
\hline $11 \mathrm{~h} 20$ & 22,9 & 19,6 & 72,4 & 80,2 & 680 & 415 & 48 & 15,1 & 5,5 & 4 & 43 & & 1100 & 26 \\
\hline $11 \mathrm{~h} 30$ & 22,5 & 21,2 & 75 & 77,2 & 812 & 418 & 47,9 & 14,5 & 5,3 & 3,8 & 43 & $11 \mathrm{~h} 35$ início chuva forte & 1100 & 26 \\
\hline $11 \mathrm{~h} 40$ & 22,8 & 20,2 & 75,9 & 76,4 & 853 & 418 & 58,9 & 33,2 & 8,4 & 13,1 & 44 & & 1100 & 25 \\
\hline $11 \mathrm{h50}$ & 23 & 21,5 & 75,7 & 77,8 & 880 & 403 & 54,6 & 34,2 & 8,3 & 12,1 & 42 & & 1100 & 26 \\
\hline $12 \mathrm{~h} 00$ & 23,3 & 21,4 & 73,5 & 77,1 & 820 & 409 & 55,9 & 32,3 & 8,3 & 10,3 & 41 & & 1100 & 27 \\
\hline $12 \mathrm{~h} 10$ & 22,9 & 21,5 & 78,3 & 76,8 & 798 & 413 & 54,2 & 29,8 & 8,7 & 11,4 & 43 & & 1100 & 26 \\
\hline $12 \mathrm{~h} 20$ & 22,8 & 19,7 & 74,8 & 81,4 & 647 & 418 & 47,6 & 30,4 & 8,6 & 13,4 & 2 & $12 \mathrm{~h} 15$ saída para almoço & 1100 & 550 \\
\hline \multicolumn{15}{|c|}{ INTERVALO DO ALMOÇO } \\
\hline $13 \mathrm{~h} 20$ & 23,7 & 20,2 & 76,1 & 79,9 & 778 & 423 & 54,3 & 27,1 & 8,5 & 12,5 & 42 & & 1100 & 26 \\
\hline $13 \mathrm{~h} 30$ & 23,1 & 21,5 & 75,4 & 78,7 & 789 & 432 & 66,6 & 25,2 & 9,3 & 10,4 & 43 & & 1100 & 26 \\
\hline $13 \mathrm{~h} 40$ & 22,9 & 20,5 & 75,5 & 79,8 & 812 & 424 & 63,8 & 19,3 & 8,6 & 8,3 & 42 & $11 \mathrm{~h} 35$ término chuva & 1100 & 26 \\
\hline $13 \mathrm{~h} 50$ & 23,2 & 20,5 & 75,3 & 78,5 & 845 & 427 & 60,7 & 16,3 & 7,9 & 6,11 & 44 & & 1100 & 25 \\
\hline $14 \mathrm{~h} 00$ & 22,8 & 19,9 & 76,6 & 79,9 & 904 & 417 & 137,4 & 18,5 & 9,9 & 8,1 & 44 & 14h00 início da lixação & 1100 & 25 \\
\hline $14 \mathrm{~h} 05$ & - & - & - & - & - & - & 522,3 & 18,4 & 23,1 & 7,5 & 44 & & 1100 & 25 \\
\hline $14 \mathrm{~h} 10$ & 23,2 & 20,1 & 75,9 & 79,8 & 875 & 434 & 588,9 & 18,4 & 25,7 & 6,9 & 44 & & 1100 & 25 \\
\hline $14 \mathrm{~h} 15$ & - & - & - & - & - & - & 710,3 & 18 & 28,9 & 7 & 45 & & 1100 & 24 \\
\hline $14 \mathrm{~h} 20$ & 22,4 & 20,8 & 77,5 & 78,1 & 887 & 424 & 715,5 & 17,6 & 29,3 & 7,2 & 45 & & 1658 & 37 \\
\hline $14 \mathrm{~h} 30$ & 23,6 & 21,8 & 74,3 & 75,3 & 886 & 425 & 352,4 & 14,3 & 19,9 & 5,9 & 45 & 14h25 unidades 1,2 e 3 & 1658 & 37 \\
\hline $14 \mathrm{~h} 40$ & 23,9 & 22,7 & 72,1 & 71,6 & 819 & 421 & 165,7 & 13,3 & 11,9 & 5,6 & 44 & & 1658 & 38 \\
\hline $14 \mathrm{~h} 50$ & 23,8 & 21,2 & 74,2 & 76,4 & 807 & 444 & 144,3 & 16,6 & 9,9 & 5,9 & 44 & & 1658 & 38 \\
\hline $15 \mathrm{~h} 00$ & 23,6 & 21,4 & 73,4 & 75,8 & 795 & 439 & 98,4 & 12,9 & 7,7 & 5,7 & 44 & 15h05 término lixação e & 1658 & 38 \\
\hline $15 \mathrm{~h} 10$ & 23,7 & 21,8 & 74,4 & 74,3 & 788 & 449 & 85,7 & 14,5 & 6,8 & 6,4 & 46 & início furação & 1100 & 24 \\
\hline $15 \mathrm{~h} 20$ & 23,5 & 21,7 & 75,1 & 74,3 & 795 & 452 & 83,1 & 13,4 & 6,6 & 5,6 & 45 & $15 \mathrm{~h} 15$ unidades 1 e 3 & 1100 & 24 \\
\hline $15 \mathrm{~h} 30$ & 23,5 & 21,9 & 73,9 & 74,9 & 830 & 432 & 87,1 & 14,4 & 6,9 & 6,5 & 44 & & 1100 & 25 \\
\hline $15 \mathrm{~h} 40$ & 23,1 & 21,6 & 76,3 & 74,4 & 873 & 445 & 103,3 & 14,8 & 7,4 & 6,7 & 44 & & 1100 & 25 \\
\hline 15h50 & 23,9 & 21,9 & 73,7 & 75,3 & 877 & 438 & 149,8 & 14,7 & 8,8 & 6,4 & 46 & & 1100 & 24 \\
\hline $16 \mathrm{~h} 00$ & 21,5 & 21,7 & 75,7 & 74,9 & 871 & 441 & 159,8 & 14,3 & 9,1 & 6,5 & 46 & & 1100 & 24 \\
\hline
\end{tabular}




\section{F.2 Tabela da medição do dia 11/06/2016}

\begin{tabular}{|c|c|c|c|c|c|c|c|c|c|c|c|c|c|c|}
\hline \multirow{2}{*}{ HORA } & \multicolumn{2}{|c|}{ TBS $\left({ }^{\circ} \mathrm{C}\right)$} & \multicolumn{2}{|c|}{ UR (\%) } & \multicolumn{2}{|c|}{$\mathbf{P M}_{10}\left(\mathrm{ug} / \mathrm{m}^{3}\right)$} & \multirow{2}{*}{\multicolumn{2}{|c|}{$\mathbf{P M}_{2,5}\left(\mathrm{ug} / \mathrm{m}^{3}\right)$}} & \multirow{2}{*}{\multicolumn{2}{|c|}{$\mathrm{CO}_{2}(\mathrm{ppm})$}} & \multicolumn{4}{|c|}{$\begin{array}{l}\text { Observações } \\
\end{array}$} \\
\hline & \begin{tabular}{|l|} 
Interno \\
\end{tabular} & Externo & Interno & Externo & \begin{tabular}{|l|} 
Interno \\
\end{tabular} & Externo & \begin{tabular}{|l} 
Interno \\
\end{tabular} & & & & Ocupantes & Geral & $\begin{array}{l}\text { Vazão de ar externo } \\
\text { aproximada }\left(m^{3} / h\right)\end{array}$ & $\begin{array}{l}\text { Vazão aproximada } \\
\text { por pessoa }\left(\mathrm{m}^{3} / \mathrm{h}\right.\end{array}$ \\
\hline $8 \mathrm{~h} 00$ & 15,4 & 11,1 & 53,2 & 63,9 & 93,4 & 122,2 & 42,5 & 43,3 & 469 & 448 & 1 & & 0 & 0 \\
\hline $8 \mathrm{~h} 10$ & 15,8 & 11,9 & 55,9 & 62,2 & 101,7 & 124,8 & 35,4 & 42,7 & 487 & 457 & 2 & & 0 & 0 \\
\hline $8 \mathrm{~h} 20$ & 15,1 & 11,7 & 55,3 & 63,5 & 93,9 & 123,4 & 34,5 & 42,9 & 481 & 463 & 1 & & 0 & 0 \\
\hline $8 \mathrm{~h} 30$ & 15,2 & 11,3 & 54,7 & 61,5 & 97,3 & 123,1 & 34,8 & 43,8 & 482 & 454 & 2 & & 0 & 0 \\
\hline $8 \mathrm{~h} 40$ & 15,1 & 11,8 & 53,7 & 59,4 & 109,2 & 110,7 & 35,6 & 43,2 & 485 & 453 & 2 & & 0 & 0 \\
\hline $8 \mathrm{h50}$ & 15,8 & 11,7 & 54,2 & 58,1 & 179,8 & 108,3 & 38,4 & 41,6 & 531 & 454 & 10 & & 0 & 0 \\
\hline $9 \mathrm{~h} 00$ & 15,6 & 12,1 & 53,3 & 57,4 & 140,1 & 88,5 & 37,3 & 37,8 & 558 & 449 & 10 & & 0 & 0 \\
\hline $9 \mathrm{~h} 10$ & 16,1 & 12,8 & 52,3 & 55,7 & 112,8 & 82,4 & 35,1 & 35,7 & 590 & 450 & 11 & & 0 & 0 \\
\hline $9 \mathrm{~h} 20$ & 16,2 & 13,3 & 50,8 & 53,4 & 88 & 84,8 & 32,9 & 35,9 & 576 & 448 & 11 & & 0 & 0 \\
\hline $9 \mathrm{~h} 30$ & 16,1 & 13,4 & 50,9 & 52,3 & 96,8 & 82,6 & 32,2 & 33,4 & 588 & 444 & 12 & & 0 & 0 \\
\hline $9 \mathrm{~h} 40$ & 16,3 & 13,8 & 50,8 & 48,4 & 98,2 & 52,2 & 31,6 & 23,1 & 591 & 451 & 12 & & 0 & 0 \\
\hline $9 \mathrm{~h} 50$ & 16,3 & 13,7 & 50,2 & 47,3 & 97,6 & 40,8 & 29,8 & 17,3 & 605 & 432 & 12 & & 0 & 0 \\
\hline $10 \mathrm{~h} 00$ & 16,6 & 13,9 & 48,8 & 45,6 & 97,4 & 33,7 & 26,1 & 13,8 & 622 & 421 & 12 & Iń́cio da operação da unidade 1 de ar externo & 558 & 47 \\
\hline 10h10 & 17,1 & 14,1 & 46,5 & 44,9 & 82,1 & 41,7 & 21,9 & 17,1 & 596 & 419 & 12 & & 558 & 47 \\
\hline $10 \mathrm{~h} 20$ & 16,6 & 14,3 & 47,3 & 43,3 & 106,2 & 34,3 & 24,6 & 15,7 & 594 & 435 & 12 & Movimentação dos alunos & 558 & 47 \\
\hline $10 \mathrm{~h} 30$ & 17,3 & 14,6 & 44,7 & 42,9 & 102,3 & 33,1 & 23,3 & 14,9 & 588 & 441 & 12 & Movimentação dos alunos & 558 & 47 \\
\hline $10 \mathrm{~h} 40$ & 17,1 & 14,5 & 44,6 & 42,2 & 89 & 38,7 & 17,1 & 18,5 & 591 & 437 & 12 & & 558 & 47 \\
\hline $10 \mathrm{~h} 50$ & 17,7 & 14,6 & 43 & 41,3 & 68,9 & 42,7 & 16,7 & 20,9 & 592 & 438 & 12 & & 558 & 47 \\
\hline $11 \mathrm{~h} 00$ & 17,2 & 14,8 & 42,9 & 42,5 & 65,3 & 44,2 & 16,5 & 21,4 & 589 & 435 & 12 & Início da operação da unidade 1 e 3 de ar externo & 1100 & 92 \\
\hline $11 \mathrm{~h} 10$ & 17,6 & 14,9 & 41,4 & 41,4 & 59,1 & 48,6 & 15,1 & 22,8 & 560 & 429 & 12 & & 1100 & 92 \\
\hline $11 \mathrm{~h} 20$ & 17,7 & 15,1 & 40,5 & 42,1 & 61,3 & 45,8 & 15,4 & 19,5 & 555 & 428 & 12 & & 1100 & 92 \\
\hline $11 \mathrm{~h} 30$ & 17,9 & 15,7 & 39,8 & 40,4 & 101,3 & 46,3 & 38,9 & 18,6 & 552 & 430 & 12 & Movimentação dos alunos atividade prática; furação & 1100 & 92 \\
\hline $11 \mathrm{~h} 40$ & 17,8 & 15,5 & 40,2 & 39,8 & 295,2 & 44,7 & 120,1 & 17,9 & 554 & 425 & 12 & Lixamento e furação; & 1100 & 92 \\
\hline $11 \mathrm{~h} 50$ & 18,1 & 15,6 & 40,1 & 39,2 & 302,6 & 43,1 & 124,5 & 17,2 & 551 & 428 & 12 & Lixamento e furação; & 2200 & 183 \\
\hline $12 \mathrm{~h} 00$ & 18,3 & 16,1 & 37,9 & 39,1 & 182,5 & 38,2 & 63,1 & 15,1 & 528 & 423 & 12 & Lixamento e furação; $11 \mathrm{~h} 51$ operação das 4 unidades & 2200 & 183 \\
\hline $12 \mathrm{~h} 10$ & 18,6 & 16,9 & 36,8 & 38,8 & 146,9 & 29,7 & 54,3 & 10,3 & 507 & 437 & 12 & Lixamento e furação; & 2200 & 183 \\
\hline $12 \mathrm{~h} 20$ & 18,8 & 17,5 & 36,3 & 38,2 & 93,1 & 28,4 & 29,3 & 11,8 & 491 & 426 & 12 & Movimentação dos alunos & 2200 & 183 \\
\hline $12 \mathrm{~h} 30$ & 19 & 17,2 & 36,7 & 39,1 & 105,3 & 26,2 & 35,8 & 12,1 & 532 & 424 & 11 & Movimentação dos alunos; $12 \mathrm{~h} 22$ Operação da unidade 1 & 558 & 51 \\
\hline $12 \mathrm{~h} 40$ & 18,5 & 17,7 & 38,6 & 35,9 & 82,5 & 29,2 & 22,2 & 10,6 & 544 & 413 & 11 & & 558 & 51 \\
\hline $12 \mathrm{~h} 50$ & 18,9 & 18,5 & 38,3 & 36,3 & 77,9 & 31,5 & 18,8 & $\frac{9}{9}$ & 559 & 418 & 11 & & 558 & 51 \\
\hline $13 \mathrm{~h} 00$ & 18,8 & 18,3 & 38,6 & 36,9 & 104,3 & 27,4 & 23,3 & 10,3 & 562 & 422 & 10 & Movimentação dos alunos & 558 & 56 \\
\hline 13h10 & 19,1 & 18,7 & 38,2 & 36,5 & 122,1 & 27,9 & 22,8 & 9,8 & 575 & 423 & 10 & Movimentação dos alunos; Corrida de carrinhos & 558 & 56 \\
\hline $13 \mathrm{~h} 20$ & 19,2 & 18,9 & 37,3 & 36,3 & 190,2 & 28,6 & 26,9 & 11,1 & 578 & 420 & 10 & Movimentação dos alunos; Saída dos alunos & 558 & 56 \\
\hline
\end{tabular}




\section{F.3 Tabela da medição do dia 21/10/2016}

\begin{tabular}{|c|c|c|c|c|c|c|c|c|c|c|c|c|c|c|}
\hline \multirow{3}{*}{ Hora } & \multirow{2}{*}{\multicolumn{2}{|c|}{ TBS $\left({ }^{\circ} \mathrm{C}\right)$}} & \multirow{2}{*}{\multicolumn{2}{|c|}{ UR (\%) }} & \multirow{2}{*}{\multicolumn{2}{|c|}{ PM10 $\left(u g / m^{3}\right)$}} & \multirow{2}{*}{\multicolumn{2}{|c|}{$\mathbf{P} \mathbf{M}_{2,5}\left(\mathbf{u g} / \mathbf{m}^{3}\right)$}} & \multirow{2}{*}{\multicolumn{2}{|c|}{$\mathrm{CO}_{2}$ (ppm) }} & \multicolumn{4}{|c|}{ Observações } \\
\hline & & & & & & & & & & & \multirow{2}{*}{ Ocupantes } & \multirow{2}{*}{ Geral } & \multirow{2}{*}{\begin{tabular}{|c|} 
Vazão de ar externo \\
aproximada $\left(\mathrm{m}^{3} / \mathrm{h}\right)$
\end{tabular}} & \multirow{2}{*}{$\begin{array}{l}\text { Vazão aproximada } \\
\text { por pessoa }\left(\mathrm{m}^{3} / \mathrm{h}\right)\end{array}$} \\
\hline & Interno & Externo & Interno & Externo & Interno & Externo & Interno & Externo & Interno & Externo & & & & \\
\hline $8 \mathrm{~h} 00$ & 23,2 & 21,4 & 64,6 & 79,1 & 53,8 & 26,1 & 6 & 4,6 & 897 & 440 & 35 & & 0 & 0 \\
\hline $8 \mathrm{~h} 10$ & 24,4 & & 64,7 & & 50,7 & & 5,6 & & 1110 & & 40 & & 0 & 0 \\
\hline $8 \mathrm{~h} 20$ & 24,6 & & 62,5 & & 94,9 & & 6,7 & & 1318 & & 64 & & 0 & 0 \\
\hline $8 \mathrm{h30}$ & 25,2 & & 62,2 & & 102,7 & & 7,3 & & 1920 & & 106 & & 0 & 0 \\
\hline $8 \mathrm{h40}$ & 25,5 & & 58,5 & & 79,9 & & 7 & & 2330 & & 110 & & 0 & 0 \\
\hline $8 \mathrm{h50}$ & 25,5 & & 56,6 & & 71,4 & & 6,7 & & 2775 & & 110 & & 0 & 0 \\
\hline $9 \mathrm{~h} 00$ & 26,1 & & 52,3 & & 80 & & 7 & & 3138 & & 112 & Início de operação das unidades 1 e 3 & 1100 & 9,8 \\
\hline $9 \mathrm{~h} 10$ & 25,8 & & 54,5 & & 78,9 & & 6,8 & & 3010 & & 112 & & 1100 & 9,8 \\
\hline $9 \mathrm{~h} 20$ & 25,7 & & 57,6 & & 93,3 & & 7,2 & & 2810 & & 113 & & 1100 & 9,7 \\
\hline $9 \mathrm{~h} 30$ & 25,5 & & 54,3 & & 89,8 & & 6,8 & & 2750 & & 112 & Fim da aula 9h35 & 1100 & 9,8 \\
\hline $9 \mathrm{~h} 40$ & 26 & 22,3 & 54,8 & 74,8 & 118,7 & 20,3 & 8,5 & 2,2 & 2844 & 451 & 110 & Início da prova 9h55 & 1100 & 10 \\
\hline $9 \mathrm{h50}$ & 25,8 & & 54,8 & & 126,6 & & 7,4 & & 2960 & & 138 & & 1100 & 8 \\
\hline $10 \mathrm{~h} 00$ & 26 & & 57,4 & & 102,5 & & 6,4 & & 2830 & & 138 & & 1100 & 8 \\
\hline $10 \mathrm{~h} 10$ & 26,2 & & 53,7 & & 61,8 & & 4,9 & & 2970 & & 138 & & 1100 & 8 \\
\hline $10 \mathrm{~h} 20$ & 26,1 & & 52,8 & & 41,6 & & 3,8 & & 3061 & & 138 & & 1100 & 8 \\
\hline $10 \mathrm{~h} 30$ & 26,4 & 22,8 & 50,3 & 73 & 34,2 & 25 & 3,4 & 1,9 & 3040 & 424 & 138 & Operação de todas as unidades & 2200 & 15,9 \\
\hline $10 \mathrm{~h} 40$ & 25,5 & & 55,1 & & 22 & & 2 & & 2468 & & 138 & & 2200 & 15,9 \\
\hline $10 \mathrm{~h} 50$ & 25,8 & & 52 & & 24,1 & & 2 & & 2332 & & 134 & & 2200 & 16,4 \\
\hline $11 \mathrm{~h} 00$ & 26,2 & & 52,5 & & 26,5 & & 1,8 & & 2105 & & 122 & & 2200 & 18 \\
\hline $11 \mathrm{~h} 10$ & 26,7 & & 51,5 & & 37,5 & & 2,3 & & 1973 & & 100 & & 2200 & 22 \\
\hline $11 \mathrm{~h} 20$ & 28,5 & & 52,4 & & 38,7 & & 2,4 & & 1990 & & 77 & & 2200 & 28,6 \\
\hline $11 \mathrm{~h} 30$ & 26,3 & & 55,3 & & 48,9 & & 2,8 & & 1473 & & 34 & Fim da prova & 2200 & 64,7 \\
\hline $11 \mathrm{~h} 40$ & 26 & 23,4 & 58,1 & 70,5 & 57,5 & 20,8 & 3 & 2,9 & 1233 & 456 & 8 & Apenas a unidade $1 \mathrm{em}$ funcionamento & 558 & 69,8 \\
\hline $11 \mathrm{~h} 45$ & 24,7 & & 60,2 & & 153,8 & & 4,2 & & 1165 & & 15 & Arrumação & 558 & 37,2 \\
\hline $11 \mathrm{~h} 50$ & 24,8 & & 58,1 & & 188,9 & & 5,4 & & 1143 & & 12 & & 558 & 46,5 \\
\hline $11 \mathrm{~h} 55$ & 24,9 & & 59,5 & & 215,4 & & 6,5 & & 1141 & & 10 & & 558 & 55,8 \\
\hline $12 \mathrm{~h} 00$ & 24,7 & & 59,6 & & 367,8 & & 10,6 & & 1146 & & 14 & & 558 & 39,9 \\
\hline $12 \mathrm{~h} 05$ & 24,6 & & 61,1 & & 342,8 & & 10,7 & & 1151 & & 15 & & 558 & 37,2 \\
\hline $12 \mathrm{~h} 10$ & 24,8 & & 60,2 & & 354,4 & & 10,4 & & 1148 & & 15 & Operação das unidades 1 e 3 & 1100 & 73,3 \\
\hline $12 \mathrm{~h} 15$ & 24,5 & & 63,7 & & 189,2 & & 7,8 & & 1119 & & 17 & & 1100 & 64,7 \\
\hline $12 \mathrm{~h} 20$ & 24,4 & & 63,1 & & 154,5 & & 6,9 & & 1085 & & 18 & & 1100 & 61,1 \\
\hline $12 \mathrm{~h} 25$ & 24,7 & & 62,8 & & 174,1 & & 6,3 & & 1027 & & 19 & Furação em madeira & 1100 & 57,9 \\
\hline $12 \mathrm{~h} 30$ & 24,6 & & 61,5 & & 170,3 & & 6,1 & & 938 & & 18 & & 1100 & 61,1 \\
\hline $12 \mathrm{~h} 35$ & 24,6 & & 64,3 & & 169,5 & & 5,9 & & 971 & & 18 & & 1100 & 61,1 \\
\hline $12 \mathrm{~h} 40$ & 24,6 & & 63,8 & & 140,1 & & 5,3 & & 929 & & 18 & Todas as unidades em funcionamento & 2200 & 122,2 \\
\hline $12 \mathrm{~h} 45$ & 24,7 & & 62,5 & & 130,2 & & 4,7 & & 883 & & 19 & & 2200 & 115,8 \\
\hline $12 \mathrm{~h} 50$ & 24,8 & & 62,1 & & 128,4 & & 4,5 & & 854 & & 20 & & 2200 & 110 \\
\hline $12 \mathrm{~h} 55$ & 24,7 & & 61,3 & & 189,1 & & 7,3 & & 771 & & 10 & Utilização de serra elétrica & 2200 & 220 \\
\hline $13 \mathrm{~h} 00$ & 24,4 & & 62,6 & & 137,9 & & 6 & & 658 & & 8 & & 2200 & 275 \\
\hline 13h05 & 24,3 & & 64,5 & & 98,2 & & 5,4 & & 630 & & 7 & & 2200 & 314,3 \\
\hline
\end{tabular}




\section{F.4 Tabela da medição do dia 22/10/2016}

\begin{tabular}{|c|c|c|c|c|c|c|c|c|c|c|c|c|c|c|}
\hline \multirow{3}{*}{ HORA } & \multirow{2}{*}{\multicolumn{2}{|c|}{ TBS $\left({ }^{\circ} \mathrm{C}\right)$}} & \multirow{2}{*}{\multicolumn{2}{|c|}{ UR (\%) }} & \multirow{2}{*}{\multicolumn{2}{|c|}{$\mathbf{P M}_{2,5}\left(\mu \mathrm{g} / \mathbf{m}^{3}\right)$}} & \multirow{2}{*}{\multicolumn{2}{|c|}{$\mathbf{P M}_{10}\left(\mu \mathrm{g} / \mathrm{m}^{3}\right)$}} & \multirow{2}{*}{\multicolumn{2}{|c|}{$\mathrm{CO}_{2}(\mathrm{ppm})$}} & \multicolumn{4}{|c|}{ Observações } \\
\hline & & & & & & & & & & & \multirow{2}{*}{ Ocupantes } & \multirow{2}{*}{ Geral } & \multirow{2}{*}{$\begin{array}{l}\text { Vazão de ar externo } \\
\text { aproximada }\left(\mathrm{m}^{3} / \mathrm{h}\right) \\
\end{array}$} & \multirow{2}{*}{\begin{tabular}{|c|}
$\begin{array}{c}\text { Vazão aproximada por } \\
\text { pessoa }\left(\mathbf{m}^{3} / \mathbf{h}\right)\end{array}$ \\
\end{tabular}} \\
\hline & Interno & Externo & Interno & Externo & Interno & & Interno & $\frac{\text { Externo }}{36}$ & $\frac{\text { Interno }}{486}$ & Externo & & & & \\
\hline 91020 & 227 & 18,3 & 656 & 78,4 & $\frac{1,5}{24}$ & 0,7 & 16,4 & $\frac{3,6}{5}$ & $\frac{486}{479}$ & 412 & 2 & Todas as unidades ligadas & 2200 & $\frac{1100}{0}$ \\
\hline $9 \mathrm{~h} 40$ & $\frac{22,1}{22,7}$ & $\frac{19,1}{19,5}$ & $\frac{65,0}{66,1}$ & $\begin{array}{l}76,8 \\
76,6\end{array}$ & $\frac{2,4}{3,9}$ & $\begin{array}{l}0,8 \\
0,7\end{array}$ & $\begin{array}{l}56,9 \\
79,3\end{array}$ & $\begin{array}{c}5 \\
5,6\end{array}$ & $\begin{array}{l}479 \\
472\end{array}$ & $\frac{411}{412}$ & $\frac{2}{2}$ & $\begin{array}{c}\text { Unidades desligadas } \\
-\end{array}$ & $\begin{array}{l}0 \\
0\end{array}$ & $\frac{0}{0}$ \\
\hline $10 \mathrm{~h} 00$ & 23,4 & 19,8 & 64,1 & 76,6 & 3,9 & 1,3 & 76,6 & 6,5 & 523 & 420 & 17 & - & 0 & 0 \\
\hline 10h10 & 23,3 & 19,2 & 65,4 & 77,9 & 3,3 & 1,3 & 60,9 & 6 & 609 & 426 & 18 & - & 0 & 0 \\
\hline $10 \mathrm{~h} 20$ & 23,5 & 19,3 & 64,9 & 76,9 & 2,9 & 1,3 & 58,4 & 8,4 & 631 & 441 & 12 & - & 0 & 0 \\
\hline 10h30 & 23,4 & 19,4 & 65,3 & 77,1 & 2,5 & 1,3 & 40,8 & 7,2 & 626 & 430 & 14 & - & 0 & 0 \\
\hline $10 \mathrm{~h} 40$ & 23,6 & 19,9 & 64,8 & 75,8 & 2,2 & 1,4 & 39,5 & 6,2 & 638 & 423 & 18 & - & 0 & 0 \\
\hline $11 \mathrm{~h} 00$ & 23,9 & 20 & 65,3 & 75,7 & 2,6 & 1,4 & 56,7 & 6,1 & 792 & 422 & 40 & - & 0 & 0 \\
\hline 11h10 & 23,4 & 20,1 & 67,4 & 76,4 & 3,5 & 1,4 & 83 & 6,2 & 933 & 421 & 37 & - & 0 & 0 \\
\hline $11 \mathrm{~h} 20$ & 24 & 19,8 & 64,7 & 73,4 & 3,1 & 1,3 & 65,5 & 6,5 & 1022 & 412 & 37 & - & 0 & 0 \\
\hline $11 \mathrm{~h} 30$ & 23,1 & 20,4 & 68,5 & 75,4 & 4,9 & 1,4 & 104,1 & 6,3 & 1073 & 415 & 37 & - & 0 & 0 \\
\hline $11 \mathrm{~h} 40$ & 23,3 & 21,2 & 65,8 & 71,4 & 5,2 & 1,6 & 93,7 & 6,8 & 1102 & 427 & 37 & - & 0 & 0 \\
\hline $11 \mathrm{~h} 50$ & 23,4 & 21 & 68,1 & 71,8 & 4,6 & 1,5 & 83,2 & 6,9 & 1237 & 422 & 38 & - & 0 & 0 \\
\hline $12 \mathrm{~h} 00$ & 23,6 & 20,4 & 66,3 & 73,5 & 4,2 & 1,4 & 69,1 & 4,6 & 1255 & 410 & 40 & - & 0 & 0 \\
\hline $12 \mathrm{~h} 10$ & 23,1 & 20,6 & 66,7 & 72,8 & 4,1 & 1,4 & 75 & 5,5 & 1316 & 417 & 41 & - & 0 & 0 \\
\hline $12 \mathrm{~h} 20$ & 23,5 & 20,9 & 66,4 & 71,1 & 3,9 & 1,4 & 75,6 & 4,2 & 1353 & 423 & 39 & - & 0 & 0 \\
\hline $12 \mathrm{~h} 30$ & 23,7 & 20,6 & 63,7 & 73,1 & 3,7 & 1,1 & 76,1 & 4,2 & 1336 & 409 & 39 & - & 0 & 0 \\
\hline $12 \mathrm{~h} 40$ & 22,7 & 20,7 & 66,8 & 72,5 & 3,6 & 1,2 & 82,8 & 4,5 & 1306 & 414 & 8 & Saída dos alunos & 0 & 0 \\
\hline $14 \mathrm{~h} 00$ & 23,6 & 20,9 & 66,2 & 72,8 & 3,2 & 4,5 & 77,1 & 10,8 & 1187 & 434 & 39 & - & 0 & 0 \\
\hline $14 \mathrm{~h} 20$ & 23,4 & 20,4 & 65,1 & 73,3 & 2,7 & 2,1 & 53,2 & 4,6 & 1059 & 409 & 39 & - & 1100 & 28,2 \\
\hline $14 \mathrm{~h} 30$ & 22,9 & 20,5 & 66,3 & 73,9 & 6,6 & 2,3 & 54,1 & 6,8 & 1004 & 411 & 39 & Corte e furação de madeira & 1100 & 28,2 \\
\hline $14 \mathrm{~h} 40$ & 22,7 & 20,6 & 67,1 & 74,2 & 7,3 & 2,5 & 71,7 & 5,7 & 980 & 418 & 39 & Corte e furação de madeira & 1100 & 28,2 \\
\hline $14 \mathrm{~h} 50$ & 23,3 & 20,5 & 66,1 & 73,4 & 7,2 & 2,3 & 76,1 & 5,5 & 985 & 415 & 39 & Corte e furação de madeira & 1100 & 28,2 \\
\hline $15 \mathrm{~h} 00$ & 23,4 & 20,4 & 64,5 & 73,9 & 6,7 & 2,4 & 62,2 & 5,8 & 989 & 411 & 39 & Corte e furação de madeira & 1100 & 28,2 \\
\hline $15 \mathrm{~h} 10$ & 23,3 & 20,5 & 66,1 & 73,6 & 6,9 & 2,5 & 59,9 & 5,9 & 1010 & 412 & 39 & Corte e furação de madeira & 1100 & 28,2 \\
\hline $15 \mathrm{~h} 20$ & 23,5 & 20,2 & 64,4 & 71,7 & 7 & 2,2 & 259,3 & 5,9 & 998 & 416 & 39 & Lixamento de madeira & 1100 & 28,2 \\
\hline $15 \mathrm{~h} 30$ & 22,6 & 20,3 & 65,3 & 72,4 & 7,1 & 2,3 & 256 & 5,7 & 995 & 415 & 39 & Lixamento de madeira & 1100 & 28,2 \\
\hline $15 \mathrm{~h} 40$ & 22,9 & 20,3 & 62,3 & 73,4 & 7,4 & 2,6 & 157,4 & 11,7 & 910 & 412 & 39 & Todas as unidades/ lixamento & 2200 & 56,4 \\
\hline $15 \mathrm{~h} 50$ & 23,1 & 20,2 & 65,7 & 73,1 & 5,2 & 3,2 & 123,8 & 8,1 & 834 & 421 & 39 & Lixamento e corte & 2200 & 56,4 \\
\hline $16 \mathrm{~h} 00$ & 23 & 20,1 & 66 & 73,1 & 7 & 2,1 & 176,2 & 4,9 & 826 & 410 & 39 & Lixamento e corte & 2200 & 56,4 \\
\hline $16 \mathrm{~h} 10$ & 23,4 & 20,2 & 65,1 & 75,2 & 10,9 & 2,2 & 171,3 & 5,1 & 815 & 412 & 39 & Lixamento e corte & 2200 & 56,4 \\
\hline $16 \mathrm{~h} 20$ & 23,8 & 20 & 61,3 & 72,9 & 11,8 & 1,3 & 132,5 & 3,8 & 820 & 407 & 39 & arrumação da sala & 2200 & 56,4 \\
\hline $16 \mathrm{~h} 30$ & 23,4 & 20,3 & 61,6 & 73 & 9,1 & 1,2 & 67,8 & 3,9 & 808 & 415 & 39 & arrumação da sala & 2200 & 56,4 \\
\hline $16 \mathrm{~h} 40$ & 23,1 & 20,2 & 61,9 & 73,4 & 8,3 & 1,5 & 44,6 & 4,1 & 810 & 412 & 39 & - & 2200 & 56,4 \\
\hline $16 \mathrm{~h} 50$ & 23,4 & 20,1 & 62 & 73,2 & 8 & 1,6 & 41,6 & 4 & 805 & 412 & 39 & & 2200 & 56,4 \\
\hline
\end{tabular}


F.5 Tabela da medição do dia 23/10/2016

\begin{tabular}{|c|c|c|c|c|c|c|c|c|c|c|c|c|c|c|}
\hline \multirow[b]{2}{*}{ HORA } & \multirow{2}{*}{\multicolumn{2}{|c|}{ TBS $\left({ }^{\circ} \mathrm{C}\right)$}} & \multirow{2}{*}{\multicolumn{2}{|c|}{ UR (\%) }} & \multirow{2}{*}{\multicolumn{2}{|c|}{$\mathbf{P M} \mathbf{M}_{2,5}\left(\mu \mathrm{g} / \mathbf{m}^{3}\right)$}} & \multirow{2}{*}{\multicolumn{2}{|c|}{$P_{10}\left(\mu g / m^{3}\right)$}} & \multirow{2}{*}{\multicolumn{2}{|c|}{$\mathrm{CO}_{2}(\mathrm{ppm})$}} & \multicolumn{4}{|c|}{ Observações } \\
\hline & & & & & & & & & & & Ocupantes & Geral & Vazão de ar & Vazão aproximada por \\
\hline $9 \mathrm{9h00}$ & 23 & 20,8 & 54,9 & 71,5 & 1,9 & 5,8 & 21,2 & 12,8 & 520 & 428 & 8 & Nenhuma unidade em funcionamento & 0 & \begin{tabular}{|c|}
0 \\
\end{tabular} \\
\hline $9 \mathrm{~h} 10$ & 23,1 & 20,9 & 65,2 & 71,8 & 2,8 & 5,6 & 37,2 & 13,3 & 650 & 433 & 32 & Chegada dos alunos & 0 & 0 \\
\hline $9 \mathrm{~h} 20$ & 23,3 & 20,9 & 66,5 & 71,9 & 3,9 & 6,2 & 70,1 & 12,6 & 825 & 424 & 33 & & 0 & 0 \\
\hline $9 \mathrm{~h} 30$ & 23,2 & 21,5 & 68,6 & 69,4 & 4,1 & 6,3 & 74,1 & 13,5 & 931 & 436 & 33 & & 0 & 0 \\
\hline $9 \mathrm{~h} 40$ & 22,8 & 21,6 & 69,3 & 70,9 & 5 & 7,8 & 79,3 & 15,1 & 1028 & 431 & 33 & & 0 & 0 \\
\hline $9 \mathrm{h50}$ & 23,2 & 21,8 & 69,6 & 70,4 & 5,6 & 7,9 & 78,2 & 16,5 & 1107 & 430 & 35 & & 0 & 0 \\
\hline $10 \mathrm{~h} 00$ & 23,4 & 21,9 & 68,6 & 70,3 & 8,1 & 8 & 210,9 & 16,9 & 1234 & 433 & 35 & lixamento de madeira & 0 & 0 \\
\hline $10 \mathrm{~h} 10$ & 22,9 & 22,4 & 62,7 & 67,8 & 7,5 & 7,1 & 183,3 & 18,2 & 1227 & 427 & 36 & Operação da unidade 1 e 3; lixamento & 1100 & 30,6 \\
\hline $10 \mathrm{~h} 20$ & 22,8 & 22,7 & 60,2 & 66,5 & 7,8 & 7,3 & 270,5 & 17,9 & 1233 & 430 & 37 & lixamento de madeira & 1100 & 29,7 \\
\hline $10 \mathrm{~h} 30$ & 23,2 & 22,6 & 58,8 & 68,2 & 8,5 & 7,4 & 335,2 & 16,8 & 1230 & 436 & 37 & lixamento de madeira & 1100 & 29,7 \\
\hline $10 \mathrm{~h} 40$ & 22,8 & 22,8 & 58,4 & 68,1 & 11,5 & 7,5 & 334,1 & 17,1 & 1241 & 425 & 37 & lixamento de madeira & 1100 & 29,7 \\
\hline $10 \mathrm{~h} 50$ & 23,1 & 23 & 58,7 & 68 & 13,1 & 7,1 & 348,6 & 18,7 & 1248 & 434 & 37 & lixamento de madeira & 1100 & 29,7 \\
\hline $11 \mathrm{~h} 00$ & 22,8 & 23,1 & 57,8 & 67,9 & 13,1 & 7,3 & 343,2 & 18,2 & 1245 & 429 & 38 & lixamento de madeira & 1100 & 28,9 \\
\hline $11 \mathrm{~h} 10$ & 22,9 & 23,5 & 57,6 & 64,8 & 12,4 & 7,4 & 281 & 19,7 & 1163 & 426 & 38 & lixamento de madeira & 2200 & 57,9 \\
\hline $11 \mathrm{~h} 20$ & 23 & 23,9 & 58,9 & 62,1 & 11,4 & 7,6 & 235,3 & 20,2 & 1123 & 431 & 38 & lixamento de madeira & 2200 & 57,9 \\
\hline $11 \mathrm{~h} 30$ & 23,2 & 23,7 & 57,1 & 63,4 & 8,8 & 6,8 & 137,2 & 19,8 & 1053 & 423 & 38 & lixamento de madeira & 2200 & 57,9 \\
\hline $11 \mathrm{~h} 40$ & 23,4 & 23,8 & 55,6 & 65,3 & 8,9 & 7,2 & 135,1 & 20,1 & 1008 & 434 & 39 & lixamento de madeira & 2200 & 56,4 \\
\hline $11 \mathrm{~h} 50$ & 23,5 & 24,6 & 54,7 & 62,1 & 7,4 & 6 & 119,1 & 16,9 & 975 & 430 & 39 & lixamento de madeira & 2200 & 56,4 \\
\hline $12 \mathrm{~h} 00$ & 23,1 & 25,5 & 56,7 & 59,9 & 6,7 & 6,8 & 103,6 & 19,1 & 937 & 420 & 38 & lixamento de madeira & 2200 & 57,9 \\
\hline $12 \mathrm{~h} 10$ & 23,4 & 25,8 & 56,5 & 57,8 & 6,1 & 6,4 & 91,2 & 18,8 & 912 & 427 & 38 & lixamento de madeira & 2200 & 57,9 \\
\hline $12 \mathrm{~h} 20$ & 24,7 & 27 & 58,3 & 55,2 & 8,6 & 6,5 & 139,4 & 19,2 & 820 & 435 & 2 & saída para almoço & 2200 & 1100 \\
\hline $13 \mathrm{~h} 40$ & 24,9 & 27,1 & 54,5 & 54,6 & 6 & 7,9 & 48,2 & 17,6 & 780 & 430 & 37 & & 2200 & 59,5 \\
\hline $13 \mathrm{~h} 50$ & 25,4 & 27,4 & 56,5 & 53,4 & 8,1 & 7,5 & 120,2 & 18,7 & 998 & 421 & 37 & Apenas a unidade $1 \mathrm{em}$ funcionamento & 558 & 15,1 \\
\hline $14 \mathrm{~h} 00$ & 25,3 & 26,5 & 57,7 & 59,6 & 7,7 & 13,8 & 102,1 & 25,9 & 1090 & 409 & 37 & & 558 & 15,1 \\
\hline $14 \mathrm{~h} 10$ & 25,2 & 26,8 & 57,7 & 57,5 & 8,2 & 12,4 & 99,3 & 21,7 & 1226 & 415 & 39 & & 558 & 14,3 \\
\hline $14 \mathrm{~h} 20$ & 25,3 & 26,3 & 59,4 & 61,1 & 8,7 & 18,6 & 86,5 & 30,3 & 1326 & 412 & 39 & & 558 & 14,3 \\
\hline $14 \mathrm{h30}$ & 25,1 & 26,7 & 58,1 & 60,5 & 9,6 & 18,4 & 84,1 & 38,2 & 1394 & 410 & 39 & & 558 & 14 \\
\hline $14 \mathrm{~h} 40$ & 25,3 & 27,3 & 57,7 & 58,2 & 11,3 & 19 & 76,8 & 33,3 & 1426 & 422 & 39 & & 558 & 14,3 \\
\hline $14 \mathrm{~h} 50$ & 25,5 & 27,2 & 56,7 & 59,5 & 12 & 18,7 & 72,5 & 35,8 & 1441 & 417 & 30 & & 558 & 18,6 \\
\hline $15 \mathrm{~h} 00$ & 25,1 & 27,4 & 57,2 & 58,3 & 12,9 & 18,5 & 63,6 & 34,2 & 1389 & 411 & 12 & Saída dos ocupantes & 558 & 46,5 \\
\hline
\end{tabular}




\section{Anexo G - Tabelas de medições das aulas teóricas}

Este anexo apresenta as tabelas das medições realizadas nas aulas teóricas, sem atividade prática. 


\section{G.1 Tabela da medição do dia 17/08/2016}

\begin{tabular}{|c|c|c|c|c|c|c|c|c|c|c|c|c|c|c|}
\hline \multirow{3}{*}{ Hora } & \multirow{2}{*}{\multicolumn{2}{|c|}{ TBS $\left({ }^{\circ} \mathrm{C}\right)$}} & \multirow{2}{*}{\multicolumn{2}{|c|}{ UR (\%) }} & \multirow{2}{*}{\multicolumn{2}{|c|}{ PM10 (ug/mª }} & \multirow{2}{*}{\multicolumn{2}{|c|}{$\mathbf{P} \mathbf{M}_{2,5}\left(\mathbf{u g} / \mathrm{m}^{3}\right)$}} & \multirow{2}{*}{\multicolumn{2}{|c|}{$\mathrm{CO}_{2}(\mathrm{ppm})$}} & \multicolumn{4}{|c|}{ Observações } \\
\hline & & & & & & & & & & & \multirow{2}{*}{ Ocupantes } & \multirow{2}{*}{ Geral } & \multirow{2}{*}{$\begin{array}{l}\text { Vazão de ar externo } \\
\text { aproximada }\left(\mathrm{m}^{3} / \mathrm{h}\right)\end{array}$} & \multirow{2}{*}{$\begin{array}{l}\text { Vazão aproximada } \\
\text { por pessoa }\left(m^{3} / \mathbf{h}\right)\end{array}$} \\
\hline & Interno & Externo & Interno & Externo & Interno & Externo & Interno & Externo & Interno & Externo & & & & \\
\hline $9 \mathrm{~h} 00$ & 21,9 & 21,2 & 59,4 & 59,7 & - & - & - & - & 560 & 461 & 2 & & 0 & 0 \\
\hline $9 \mathrm{~h} 10$ & 22,3 & 21,4 & 58,2 & 58,4 & - & - & - & - & 546 & 448 & 2 & & 0 & 0 \\
\hline $9 \mathrm{~h} 20$ & 22,7 & 21,6 & 59,3 & 58,3 & - & - & - & - & 597 & 446 & 10 & & 0 & 0 \\
\hline 9 h30 & 22,5 & 21,8 & 58,4 & 58,2 & - & - & - & - & 786 & 455 & 44 & & 0 & 0 \\
\hline $9 \mathrm{~h} 40$ & 23,4 & 22,6 & 57,7 & 57,6 & - & - & - & - & 950 & 448 & 51 & $9 \mathrm{~h} 41$ - Início da operação das unidades 1 e 3 & 1100 & 21,6 \\
\hline $9 h 50$ & 23,6 & 22,8 & 59,2 & 57,1 & - & - & - & - & 1030 & 450 & 58 & & 1100 & 19,0 \\
\hline $10 \mathrm{~h} 00$ & 23,7 & 22,8 & 58,8 & 57,6 & - & - & - & - & 1115 & 468 & 59 & & 1100 & 18,6 \\
\hline 10h10 & 24,3 & 23,3 & 58,4 & 56,4 & - & - & - & - & 1179 & 451 & 60 & & 1100 & 18,3 \\
\hline $10 \mathrm{~h} 20$ & 24,4 & 23,2 & 59,8 & 56,5 & - & - & - & - & 1193 & 454 & 60 & 10h21 - Início da operação de todas as unidades & 2200 & 36,7 \\
\hline 10h30 & 24,2 & 23,7 & 58,5 & 55,9 & - & - & - & - & 1132 & 473 & 60 & & 2200 & 36,7 \\
\hline $10 \mathrm{~h} 40$ & 24,1 & 23,9 & 59,4 & 54,2 & - & - & - & - & 1093 & 470 & 60 & & 2200 & 36,7 \\
\hline $10 \mathrm{~h} 50$ & 24,4 & 24,7 & 58,5 & 53,5 & - & - & - & - & 1052 & 465 & 58 & & 2200 & $\begin{array}{l}37,9 \\
\end{array}$ \\
\hline $11 \mathrm{~h} 00$ & 24,4 & 25,6 & 57,9 & 50,8 & - & - & - & - & 994 & 454 & 56 & & 2200 & 39,3 \\
\hline $11 \mathrm{~h} 10$ & 24,6 & 25,4 & 60,3 & 51,2 & - & - & - & - & 950 & 460 & 42 & & 2200 & 52,4 \\
\hline
\end{tabular}




\section{G.2 Tabela da medição do dia 19/08/2016}

\begin{tabular}{|c|c|c|c|c|c|c|c|c|c|c|c|c|c|c|}
\hline \multirow[b]{2}{*}{ Hora } & \multicolumn{2}{|c|}{ TBS $\left({ }^{\circ} \mathrm{C}\right)$} & \multicolumn{2}{|c|}{ UR (\%) } & \multicolumn{2}{|c|}{$\mathrm{PM}_{10}\left(\mathrm{ug} / \mathbf{m}^{3}\right)$} & \multicolumn{2}{|c|}{$\mathrm{PM}_{2,5}\left(\mathrm{ug} / \mathrm{m}^{3}\right)$} & \multirow{2}{*}{\multicolumn{2}{|c|}{$\mathrm{CO}_{2}(\mathrm{ppm})$}} & \multicolumn{4}{|c|}{ Observações } \\
\hline & \begin{tabular}{|l|} 
Interno \\
\end{tabular} & Externo & \begin{tabular}{|l|} 
Interno \\
\end{tabular} & Externo & \begin{tabular}{|l|} 
Interno \\
\end{tabular} & Externo & \begin{tabular}{|l|} 
Mini, \\
Interno
\end{tabular} & Externo & & & Ocupantes & Geral & $\begin{array}{l}\text { Vazão de ar externo } \\
\text { aproximada }\left(\mathbf{m}^{3} / \mathbf{h}\right)\end{array}$ & \begin{tabular}{|c|} 
Vazão aproximada por \\
pessoa $\left(\mathrm{m}^{3} / \mathrm{h}\right)$
\end{tabular} \\
\hline $8 \mathrm{~h} 00$ & 20,8 & 19,2 & 65,2 & 73,4 & 41,9 & 39,5 & 11,4 & 14,4 & 555 & 457 & 15 & & 0 & 0 \\
\hline $8 \mathrm{~h} 10$ & 20,9 & 19,3 & 67,1 & 74,1 & 69,3 & 40,5 & 11,7 & 16,6 & 614 & 470 & 16 & & 0 & 0 \\
\hline $8 \mathrm{~h} 20$ & 21,6 & 19,6 & 66,2 & 72,6 & 69,1 & 39 & 11,4 & 18,3 & 790 & 468 & 38 & & 0 & 0 \\
\hline $8 \mathrm{h30}$ & 21,9 & 19,1 & 70,6 & 75,3 & 103 & 31,7 & 19,1 & 17,6 & 1213 & 471 & 82 & & 0 & 0 \\
\hline $8 \mathrm{~h} 40$ & 22,7 & 19,2 & 72,7 & 75,1 & 108,2 & 33,5 & 18,9 & 19,4 & 1247 & 474 & 85 & & 0 & 0 \\
\hline $8 \mathrm{h50}$ & 23,1 & 19,2 & 70,1 & 74,8 & 93,7 & 34,9 & 18,8 & 21,2 & 1258 & 480 & 94 & & 0 & 0 \\
\hline $9 \mathrm{~h} 00$ & 22,5 & 19,6 & 73,5 & 73,7 & 92,6 & 39,3 & 18 & 23,1 & 1430 & 469 & 99 & 9 h01 - Início da operação das unidades 1 e 3 & 1100 & 11,1 \\
\hline $9 \mathrm{~h} 10$ & 22,6 & 19,5 & 73,3 & 74,2 & 79,5 & 51,3 & 16,5 & 25,6 & 1650 & 496 & 100 & & 1100 & 11 \\
\hline $9 \mathrm{~h} 20$ & 22,7 & 19,4 & 75,5 & 74,4 & 72,3 & 48,1 & 15,9 & 24,8 & 1677 & 475 & 100 & & 1100 & 11 \\
\hline $9 \mathrm{h30}$ & 23,1 & 20,1 & 71,8 & 73,1 & 68,5 & 56,5 & 16,4 & 25,6 & 1720 & 505 & 100 & & 1100 & 11 \\
\hline $9 \mathrm{~h} 40$ & 23,3 & 18,9 & 70,1 & 75,8 & 67,4 & 49,8 & 17,1 & 27,9 & 1745 & 472 & 100 & & 1100 & 11 \\
\hline $9 \mathrm{h50}$ & 23,1 & 19,3 & 70,9 & 75,5 & 69,9 & 54,9 & 16,8 & 28,6 & 1734 & 467 & 100 & 9 h55 - saída e entrada dos alunos (aproximadamente 50 alunos) & 1100 & 11 \\
\hline $10 \mathrm{~h} 00$ & 23,5 & 19,6 & 68,9 & 74,8 & 148,3 & 59,2 & 23,5 & 28,3 & 1480 & 474 & 100 & 10h01 - Início da operação de todas as unidades & 2200 & 22 \\
\hline 10h10 & 23,7 & 20 & 67,5 & 73,1 & 93,3 & 50,7 & 20,2 & 26,2 & 1334 & 460 & 100 & & 2200 & 22 \\
\hline $10 \mathrm{~h} 20$ & 23,6 & 20,2 & 68,1 & 72,2 & 66,8 & 49,5 & 18,8 & 26,4 & 1235 & 461 & 100 & & 2200 & 22 \\
\hline $10 \mathrm{~h} 30$ & 23,7 & 21,3 & 65,4 & 68,6 & 65,4 & 50,1 & 18,3 & 22,9 & 1298 & 467 & 100 & & 2200 & 22 \\
\hline $10 \mathrm{~h} 40$ & 23,9 & 21,5 & 63,7 & 67,8 & 66,2 & 60,9 & 18,5 & 29,1 & 1292 & 483 & 100 & & 2200 & 22 \\
\hline $10 \mathrm{~h} 50$ & 23,7 & 20,5 & 62,9 & 70,6 & 66,1 & 52,7 & 18,6 & 28,1 & 1315 & 451 & 100 & & 2200 & 22 \\
\hline $11 \mathrm{~h} 00$ & 23,9 & 21,1 & 63 & 70,3 & 65,6 & 53,2 & 18,1 & 26,6 & 1354 & 468 & 100 & & 2200 & 22 \\
\hline $11 \mathrm{~h} 10$ & 23,8 & 20,8 & 64,2 & 69,5 & 232,4 & 54,3 & 28,3 & 27,1 & 1110 & 465 & 2 & Saída dos alunos & 2200 & 1100 \\
\hline
\end{tabular}




\section{G.3 Tabela da medição do dia 22/08/2016}

\begin{tabular}{|c|c|c|c|c|c|c|c|c|c|c|c|c|c|c|}
\hline \multirow{3}{*}{ HORA } & \multirow{2}{*}{\multicolumn{2}{|c|}{ TBS $\left({ }^{\circ} \mathrm{C}\right)$}} & \multirow{2}{*}{\multicolumn{2}{|c|}{ UR (\%) }} & \multirow{2}{*}{\multicolumn{2}{|c|}{$\mathrm{PM}_{10}\left(\mathrm{ug} / \mathrm{m}^{3}\right)$}} & \multirow{2}{*}{\multicolumn{2}{|c|}{$\mathrm{PM}_{2,5}\left(\mathrm{ug} / \mathrm{m}^{3}\right)$}} & \multirow{2}{*}{\multicolumn{2}{|c|}{$\mathrm{CO}_{2}(\mathrm{ppm})$}} & \multicolumn{4}{|c|}{ Observações } \\
\hline & & & & & & & & & & & \multirow{2}{*}{ Ocupantes } & \multirow{2}{*}{ Geral } & \multirow{2}{*}{$\begin{array}{l}\text { Vazão de ar externo } \\
\text { aproximada }\left(\mathrm{m}^{3} / \mathrm{h}\right)\end{array}$} & \multirow{2}{*}{\begin{tabular}{|c|} 
Vazão aproximada \\
por pessoa $\left(\mathrm{m}^{3} / \mathbf{h}\right)$
\end{tabular}} \\
\hline & Interno & Externo & Interno & Externo & Interno & Externo & Interno & Externo & Interno & \begin{tabular}{|l|} 
Externo \\
\end{tabular} & & & & \\
\hline 9h00 & 19,3 & 12,9 & 61 & 71 & 92,3 & 41,5 & 13,1 & 10,4 & 1310 & 445 & 20 & & 0 & 0 \\
\hline $9 \mathrm{~h} 10$ & 19,4 & 13 & 61,2 & 71,7 & 133,5 & 41,7 & 12,9 & 10,2 & 1419 & 450 & 40 & & 0 & 0 \\
\hline $9 \mathrm{h20}$ & 19,8 & 12,7 & 60,7 & 71,5 & 134,1 & 38,8 & 14,1 & 10,9 & 1478 & 465 & 50 & & 0 & 0 \\
\hline $9 \mathrm{h30}$ & 20,2 & 12,5 & 60,6 & 71,4 & 126,3 & 38,4 & 11,4 & 10 & 1490 & 458 & 64 & & 0 & 0 \\
\hline $9 \mathrm{~h} 40$ & 20,6 & 12,8 & 60,8 & 71,6 & 111,6 & 37,5 & 10,2 & 9,4 & 1580 & 470 & 68 & & 0 & 0 \\
\hline $9 h 50$ & 20,7 & 13,1 & 59,6 & 71,8 & 109,5 & 38,7 & 8,9 & 8,8 & 1610 & 459 & 68 & & 0 & 0 \\
\hline $10 \mathrm{~h} 00$ & 20,9 & 12,8 & 58,2 & 72 & 105,3 & 40,3 & 8,7 & 9,9 & 1681 & 458 & 68 & Início da operação das 4 unidades de ar externo & 2200 & 32,4 \\
\hline $10 \mathrm{~h} 10$ & 20,8 & 12,5 & 58,7 & 72,2 & 78,4 & 35,9 & 9,5 & 10,1 & 1615 & 465 & 68 & & 2200 & 32,4 \\
\hline $10 \mathrm{~h} 20$ & 20,8 & 12,7 & 59,2 & 71,6 & 38,1 & 40,7 & 8,2 & 10,3 & 1520 & 440 & 68 & & 2200 & 32,4 \\
\hline $10 \mathrm{~h} 30$ & 20,9 & 12,8 & 57,2 & 71,1 & 30,7 & 31,7 & 5,8 & 9,2 & 1230 & 450 & 68 & & 2200 & 32,4 \\
\hline $10 \mathrm{~h} 40$ & 20,9 & 12,9 & 54,4 & 72,5 & 25,1 & 37,3 & 4,5 & 9,3 & 1144 & 460 & 68 & & 2200 & 32,4 \\
\hline $10 \mathrm{~h} 50$ & 20,8 & 13,1 & 55 & 73,5 & 27,4 & 37,7 & 4,3 & 8,7 & 1143 & 453 & 68 & & 2200 & 32,4 \\
\hline $11 \mathrm{~h} 00$ & 20,8 & 13 & 55,6 & 73 & 48,6 & 35,2 & 5,8 & 9,1 & 1077 & 455 & 2 & & 2200 & 1100 \\
\hline
\end{tabular}




\section{G.4 Tabela da medição do dia 24/08/2016}

\begin{tabular}{|c|c|c|c|c|c|c|c|c|c|c|c|c|c|c|}
\hline \multirow[b]{2}{*}{ Hora } & \multirow{2}{*}{\multicolumn{2}{|c|}{ TBS $\left({ }^{\circ} \mathrm{C}\right)$}} & \multirow{2}{*}{\multicolumn{2}{|c|}{ UR (\%) }} & \multirow{2}{*}{\multicolumn{2}{|c|}{ PM10 (ug/m³) }} & \multirow{2}{*}{\multicolumn{2}{|c|}{$\mathbf{P M} \mathbf{M}_{2,5}\left(\mathrm{ug} / \mathbf{m}^{3}\right)$}} & \multirow{2}{*}{\multicolumn{2}{|c|}{$\mathrm{CO}_{2}(\mathrm{ppm})$}} & \multicolumn{4}{|c|}{ Observações } \\
\hline & & Externo & & $\begin{array}{l}\text { (\%) } \\
\text { Externo }\end{array}$ & & ug/mº & \begin{tabular}{|r|} 
PM2,5 \\
Interno
\end{tabular} & & & & Ocupantes & Geral & \begin{tabular}{|c|} 
Vazão de ar externo \\
aproximada $\left(\mathrm{m}^{3} / \mathrm{h}\right)$
\end{tabular} & $\begin{array}{l}\text { Vazão aproximada } \\
\text { por pessoa }\left(\mathrm{m}^{3} / \mathrm{h}\right)\end{array}$ \\
\hline $8 \mathrm{~h} 10$ & 19,3 & 16,4 & 61,1 & 66,2 & 194,9 & 29,6 & 17,2 & 14 & 656 & 458 & $\overline{14}$ & & 0 & 0 \\
\hline $8 \mathrm{~h} 20$ & 19,8 & 16,3 & 60,1 & 63,9 & 786,5 & 29,2 & 62,5 & 14,1 & 764 & 456 & 28 & Remoção do excesso de pó de giz do apagador & 0 & 0 \\
\hline $8 \mathrm{~h} 30$ & 19,9 & 15,9 & 60,1 & 66,8 & 601,3 & 33,3 & 58,2 & 15,4 & 846 & 451 & 35 & & 0 & 0 \\
\hline $8 \mathrm{~h} 40$ & 20,2 & 16,1 & 59,4 & 66,2 & 548,2 & 38,6 & 50,5 & 16,6 & 912 & 449 & 37 & & 0 & 0 \\
\hline $8 \mathrm{h50}$ & 20,8 & 17,1 & 57,5 & 63,6 & 527,5 & 48,5 & 48,9 & 17 & 993 & 458 & 39 & & 0 & 0 \\
\hline $9 \mathrm{ho0}$ & 20,9 & 16,2 & 60,5 & 65,7 & 516,3 & 47,2 & 42,8 & 18,8 & 1101 & 446 & 42 & & 0 & 0 \\
\hline $9 \mathrm{~h} 10$ & 21 & 17,4 & 60,7 & 63,7 & 483,1 & 58,4 & 41,1 & 18,9 & 1189 & 458 & 40 & & 0 & 0 \\
\hline $9 \mathrm{~h} 20$ & 21,1 & 17,7 & 61,8 & 62,1 & 450,2 & 51,1 & 40,7 & 20,3 & 1283 & 473 & 44 & & 0 & 0 \\
\hline $9 \mathrm{~h} 30$ & 21,4 & 17,9 & 61,2 & 60,3 & 449,7 & 64,3 & 38,2 & 21,2 & 1360 & 470 & 55 & & 0 & 0 \\
\hline $9 \mathrm{~h} 40$ & 21,6 & 17,9 & 61,4 & 61,1 & 445,3 & 63,7 & 36,9 & 20,9 & 1562 & 474 & 55 & & 0 & 0 \\
\hline 9 9h50 & 21,7 & 17,2 & 61,5 & 63,5 & 868,2 & 47,5 & 45,7 & 20,8 & 1530 & 449 & 16 & & 0 & 0 \\
\hline $10 \mathrm{~h} 00$ & 21,9 & 17,5 & 61,1 & 62,1 & 952,5 & 50,3 & 65,5 & 22,4 & 1573 & 447 & 58 & Início da operação das 4 unidades de ar externo & 2200 & 37,9 \\
\hline 10h10 & 22 & 17,2 & 56,8 & 62,3 & 263,2 & 52,5 & 38,4 & 22,6 & 1261 & 451 & 58 & & 2200 & 37,9 \\
\hline $10 \mathrm{~h} 20$ & 21,9 & 17,5 & 56,4 & 62,2 & 182,6 & 55,2 & 26,7 & 23,1 & 1226 & 454 & 61 & & 2200 & 36,1 \\
\hline $10 \mathrm{~h} 30$ & 22,1 & 17,6 & 56,5 & 61,1 & 124,5 & 47,2 & 23,9 & 21,3 & 1202 & 446 & 62 & & 2200 & 35,5 \\
\hline $10 \mathrm{~h} 40$ & 22,3 & 18 & 54,8 & 60,7 & 65,1 & 52,9 & 18,8 & 22,8 & 1121 & 453 & 63 & & 2200 & 34,9 \\
\hline 10h50 & 22,5 & 18,3 & 53,7 & 58,9 & 73,4 & 53,9 & 17,3 & 22,2 & 1138 & 455 & 63 & & 2200 & 34,9 \\
\hline $11 \mathrm{~h} 00$ & 22,6 & 18,9 & 53,6 & 58,3 & 167,5 & 55,1 & 18,2 & 23,6 & 1079 & 458 & 62 & & 2200 & 35,5 \\
\hline $11 \mathrm{~h} 05$ & 22,4 & - & 53,9 & - & 126,2 & - & 22,7 & - & 1008 & - & 59 & & 2200 & 37,3 \\
\hline $11 \mathrm{~h} 10$ & 23,2 & - & 50,7 & - & 107,9 & - & 18,3 & - & 1032 & - & 35 & & 2200 & 62,9 \\
\hline $11 \mathrm{~h} 15$ & 23,5 & - & 50,4 & - & 89,3 & - & 18,3 & - & 1036 & - & 36 & & 2200 & 61,1 \\
\hline $11 \mathrm{~h} 20$ & 23,6 & - & 49,6 & - & 164,4 & - & 19,6 & - & 940 & - & 20 & & 2200 & 110 \\
\hline $11 \mathrm{~h} 25$ & 23,3 & - & 49,5 & - & 210,5 & - & 26,1 & - & 865 & - & 5 & & 2200 & 440 \\
\hline $11 \mathrm{~h} 30$ & 23,2 & - & 49,5 & - & 236 & - & 32 & - & 778 & - & 4 & & 2200 & 550 \\
\hline $11 \mathrm{~h} 35$ & 23,2 & - & 48,7 & - & 161,8 & - & 22,1 & - & 684 & - & 2 & & 2200 & 1100 \\
\hline
\end{tabular}




\section{G.5 Tabela da medição do dia 26/08/2016}

\begin{tabular}{|c|c|c|c|c|c|c|c|c|c|c|c|c|c|c|}
\hline \multirow[b]{2}{*}{ Hora } & \multicolumn{2}{|c|}{ TBS $\left({ }^{\circ} \mathrm{C}\right)$} & \multirow{2}{*}{\multicolumn{2}{|c|}{ UR (\%) }} & \multirow{2}{*}{\multicolumn{2}{|c|}{ PMio $\left(u g / \mathbf{m}^{3}\right)$}} & \multirow{2}{*}{\multicolumn{2}{|c|}{$\mathbf{P} \mathbf{M}_{2,5}\left(\mathbf{u g} / \mathbf{m}^{3}\right)$}} & \multirow{2}{*}{\multicolumn{2}{|c|}{$\mathrm{CO}_{2}(\mathrm{ppm})$}} & \multicolumn{4}{|c|}{ Observações } \\
\hline & \begin{tabular}{|l|} 
ID \\
Interno \\
\end{tabular} & Externo & & & & & & & & & Ocupantes & Geral & $\begin{array}{c}\text { Vazão de ar externo } \\
\text { aproximada }\left(\mathrm{m}^{3} / \mathrm{h}\right)\end{array}$ & $\begin{array}{l}\text { Vazão aproximada } \\
\text { por } \operatorname{pessoa}\left(\mathbf{m}^{3} / \mathbf{h}\right)\end{array}$ \\
\hline $8 \mathrm{~h} 10$ & 20,2 & 17,6 & 64,4 & 72,2 & 189,7 & 240,2 & 94,3 & 23,5 & 957 & 569 & 41 & & 0 & 0 \\
\hline $8 \mathrm{~h} 20$ & 20,8 & 17 & 62,9 & 74,2 & 279,8 & 208,8 & 74,2 & 116,8 & 1032 & 530 & 59 & & 0 & 0 \\
\hline $8 \mathrm{h30}$ & 21,4 & 17,4 & 62,8 & 73,1 & 364,1 & 230,3 & 79,4 & 135,8 & 1470 & 568 & 99 & & 0 & 0 \\
\hline $8 \mathrm{~h} 40$ & 21,8 & 18,1 & 67,6 & 70,6 & 263,7 & 252,3 & 79,5 & 116,4 & 1830 & 530 & 105 & & 0 & 0 \\
\hline $8 \mathrm{h50}$ & 22,5 & 18,7 & 69,6 & 69,1 & 510,5 & 200,4 & 112 & 107,2 & 1930 & 510 & 106 & & 0 & 0 \\
\hline $9 \mathrm{~h} 00$ & 22,6 & 18,8 & 70,2 & 68,4 & 556,2 & 195 & 112,2 & 107,4 & 2133 & 540 & 108 & Início da operação das unidades 1 e 3 & 1100 & 10,2 \\
\hline $9 \mathrm{~h} 10$ & 22,7 & 19,2 & 69,6 & 67,7 & 346,2 & 258,3 & 84,8 & 106,8 & 2168 & 542 & 112 & & 1100 & 9,8 \\
\hline $9 \mathrm{h20}$ & 23 & 19,5 & 67,2 & 65,2 & 340 & 202 & 85,4 & 101,4 & 2045 & 533 & 112 & & 1100 & 9,8 \\
\hline $9 \mathrm{h30}$ & 23,1 & 19,6 & 67,8 & 63,8 & 254,8 & 207,5 & 77,4 & 100,6 & 2077 & 545 & 112 & & 1100 & 9,8 \\
\hline $9 \mathrm{~h} 40$ & 23 & 19,9 & 64,5 & 60,7 & 221,3 & 140,6 & 71,6 & 77,2 & 2064 & 532 & 112 & & 1100 & 9,8 \\
\hline $9 \mathrm{h50}$ & 23,3 & 20,4 & 65,2 & 60,8 & 198 & 173,9 & 67,7 & 76,7 & 1922 & 533 & 112 & & 1100 & 9,8 \\
\hline $10 \mathrm{~h} 00$ & 23,1 & 20,5 & 63,7 & 60,2 & 1534 & 140,5 & 149,4 & 60 & 1580 & 519 & 45 & Intervalo & 1100 & 24,4 \\
\hline $10 \mathrm{~h} 10$ & 23,1 & 20,9 & 62,8 & 57,5 & 1346,3 & 188,5 & 142,6 & 63,5 & 1469 & 506 & 90 & & 1100 & 12,2 \\
\hline $10 \mathrm{~h} 20$ & 23,3 & 21,1 & 62,5 & 56,1 & 1155,9 & 176,7 & 134,2 & 55,2 & 1681 & 475 & 114 & & 1100 & 9,6 \\
\hline $10 \mathrm{~h} 30$ & 23,6 & 21,3 & 62,3 & 54,5 & 796,3 & 128,6 & 113,6 & 50,2 & 1806 & 476 & 114 & Início da operação de todas as unidades & 2200 & 19,3 \\
\hline $10 \mathrm{~h} 40$ & 23,7 & 21,8 & 58,6 & 50,4 & 482,7 & 135,7 & 82,2 & 37,1 & 1667 & 500 & 114 & & 2200 & 19,3 \\
\hline $10 \mathrm{~h} 50$ & 23,9 & 22,2 & 57,4 & 49,6 & 421,1 & 145,3 & 69,4 & 40,5 & 1549 & 512 & 110 & & 2200 & 20,0 \\
\hline $11 \mathrm{~h} 00$ & 24 & 22,1 & 54,7 & 50,7 & 359 & 101,6 & 63,6 & 34,6 & 1533 & 510 & 108 & & 2200 & 20,4 \\
\hline $11 \mathrm{~h} 10$ & 23,8 & - & 51,7 & - & 1257,6 & - & 115,5 & - & 1349 & - & 32 & Fim da aula & 2200 & 68,75 \\
\hline $11 \mathrm{~h} 15$ & 24,2 & - & 50,3 & - & 1119,2 & - & 149,6 & - & 1164 & - & 17 & & 2200 & 129,4 \\
\hline $11 \mathrm{~h} 20$ & 24,2 & - & 50,8 & - & 1101,4 & - & 136,2 & - & 1070 & - & 17 & & 2200 & 129,4 \\
\hline $11 \mathrm{~h} 25$ & 24,3 & - & 51,4 & - & 1138,3 & - & 134,4 & - & 1108 & - & 17 & Desligou-se todas as unidades de renovação & 0 & 0 \\
\hline $11 \mathrm{~h} 30$ & 24,6 & - & 49,9 & - & 1155,4 & - & 136,4 & - & 1089 & - & 17 & & 0 & 0 \\
\hline $11 \mathrm{~h} 35$ & 24,6 & - & 49,5 & - & 1104,1 & - & 134,2 & - & 1115 & - & 17 & & 0 & 0 \\
\hline $11 \mathrm{~h} 40$ & 24,8 & - & 46,5 & - & 1040,3 & - & 132 & - & 1083 & - & 17 & & 0 & 0 \\
\hline
\end{tabular}




\section{G.6 Tabela da medição do dia 24/10/2016}

\begin{tabular}{|c|c|c|c|c|c|c|c|c|c|c|c|c|c|c|}
\hline \multirow[b]{2}{*}{ HORA } & \multicolumn{2}{|c|}{ TBS $\left({ }^{\circ} \mathrm{C}\right)$} & \multicolumn{2}{|c|}{ UR (\%) } & \multicolumn{2}{|c|}{$\mathbf{P} \mathbf{M}_{2,5}\left(\mu \mathrm{g} / \mathrm{m}^{3}\right)$} & \multicolumn{2}{|c|}{$\mathrm{PM}_{10}\left(\boldsymbol{\mu g} / \mathrm{m}^{3}\right)$} & \multicolumn{2}{|c|}{$\mathrm{CO}_{2}(\mathrm{ppm})$} & \multicolumn{4}{|c|}{ Observações } \\
\hline & \begin{tabular}{|l|} 
Interno \\
\end{tabular} & \begin{tabular}{|l|} 
Externo \\
\end{tabular} & Interno & \begin{tabular}{|l|} 
Externo \\
\end{tabular} & Interno & Externo & \begin{tabular}{|l|} 
Interno \\
\end{tabular} & Externo & Interno & Externo & Ocupantes & Geral & \begin{tabular}{|c|} 
Vazão de ar \\
aproximada $\left(\mathbf{m}^{3} / \mathbf{h}\right)$
\end{tabular} & $\begin{array}{l}\text { Vazão aproximada } \\
\text { por pessoa }\left(\mathrm{m}^{3} / \mathbf{h}\right)\end{array}$ \\
\hline $8 \mathrm{~h} 50$ & 22,9 & 22,9 & 65,6 & 71,7 & 21,4 & 36 & 98,8 & 77,7 & 508 & 447 & 4 & Nenhuma unidade em funcionamento & 0 & 0 \\
\hline $9 \mathrm{~h} 00$ & 22,8 & & 61,6 & & 20 & & 88,1 & & 509 & & 5 & Operação da unidade 1 & 558 & 111,6 \\
\hline 9 9h10 & 23,7 & 22,8 & 62,1 & 70,2 & 18,1 & 32,8 & 72,6 & 72,2 & 556 & 443 & 10 & & 558 & 55,8 \\
\hline $9 \mathrm{~h} 20$ & 24,6 & & 64,6 & & 17 & & 63,3 & & 582 & & 15 & & 558 & 37,2 \\
\hline $9 \mathrm{9h30}$ & 24,8 & 23,7 & 66,5 & 69,9 & 16,4 & 28,3 & 58,3 & 66,4 & 697 & 440 & 28 & Operação da unidade 1 e 3 & 1100 & 39,3 \\
\hline $9 \mathrm{~h} 40$ & 25,2 & & 62,6 & & 15 & & 42,2 & & 796 & & 33 & & 1100 & 33,3 \\
\hline $9 \mathrm{9h50}$ & 25,5 & & 56,5 & & 13,5 & & 30,9 & & 883 & & 37 & & 1100 & 29,7 \\
\hline $10 \mathrm{~h} 00$ & 25,3 & 24,6 & 53,3 & 66,2 & 12,7 & 28,8 & 31,3 & 68,4 & 936 & 477 & 40 & & 1100 & 28 \\
\hline 10h10 & 25,7 & & 57,2 & & 13,9 & & 55,9 & & 970 & & 40 & Professor começou a escrever na lousa & 1100 & 28 \\
\hline $10 \mathrm{~h} 20$ & 25,8 & & 56,3 & & 13,8 & & 58,3 & & 1045 & & 40 & & 1100 & 28 \\
\hline $10 \mathrm{~h} 30$ & 25,9 & 24,9 & 56,5 & 66,2 & 13,7 & 26,8 & 56,7 & 73,5 & 1031 & 479 & 40 & & 1100 & 28 \\
\hline 10h40 & 25,3 & & 56,7 & & 13,4 & & 53,8 & & 1047 & & 40 & & 1100 & 28 \\
\hline $10 \mathrm{h50}$ & 25,9 & & 52,7 & & 13,3 & & 50,7 & & 1072 & & 40 & & 1100 & 28 \\
\hline $11 \mathrm{~h} 00$ & 25,9 & & 51,7 & & 12,4 & & 42,2 & & 1065 & & 36 & Fim da aula & 1100 & 30,6 \\
\hline $11 \mathrm{~h} 05$ & 25,5 & 25,2 & 52,8 & 64,7 & 12,5 & 24,5 & 35,9 & 70,1 & 1068 & 451 & 25 & & 1100 & 44 \\
\hline $11 \mathrm{~h} 10$ & 25,7 & & 52,5 & & 12,6 & & 41,3 & & 1039 & & 1 & & 1100 & 1100 \\
\hline $11 \mathrm{~h} 15$ & 25,8 & & 51 & & 11,9 & & 31,5 & & 960 & & 1 & & 1100 & 1100 \\
\hline $11 \mathrm{~h} 20$ & 25,7 & & 50,5 & & 11,6 & & 28,6 & & 874 & & 2 & & 1100 & 550 \\
\hline $11 \mathrm{~h} 25$ & 25,2 & 25,6 & 53,1 & 63,8 & 11,2 & 23,1 & 22 & 67,4 & 844 & 430 & 2 & & 1100 & 550 \\
\hline
\end{tabular}




\section{Anexo H - Gráficos das medições de Bordini (2015)}

Este anexo apresenta os gráficos das medições realizadas por Bordini (2015) para uma aula teórica e para a Oficina de Carrinhos de Rolimã. Em seu estudo, Bordini (2015) mediu a concentração de $\mathrm{CO}_{2}$ e $\mathrm{PM}_{10}$ na sala de aula $\mathrm{A} 2$.

Nas medições realizadas, as portas e as janelas foram mantidas abertas para a ventilação natural, pois a sala de aula A2 não possuia unidades de renovação de ar externo. A quantidade de ocupantes na aula teórica e na Oficina de Carrinhos de Rolimã era de aproximadamente 56 e 44 pessoas, respectivamente. 
H.1 Concentração de $\mathrm{CO}_{2}$ na sala $\mathrm{A} 2$ durante a aula teórica (BORDINI, 2015)

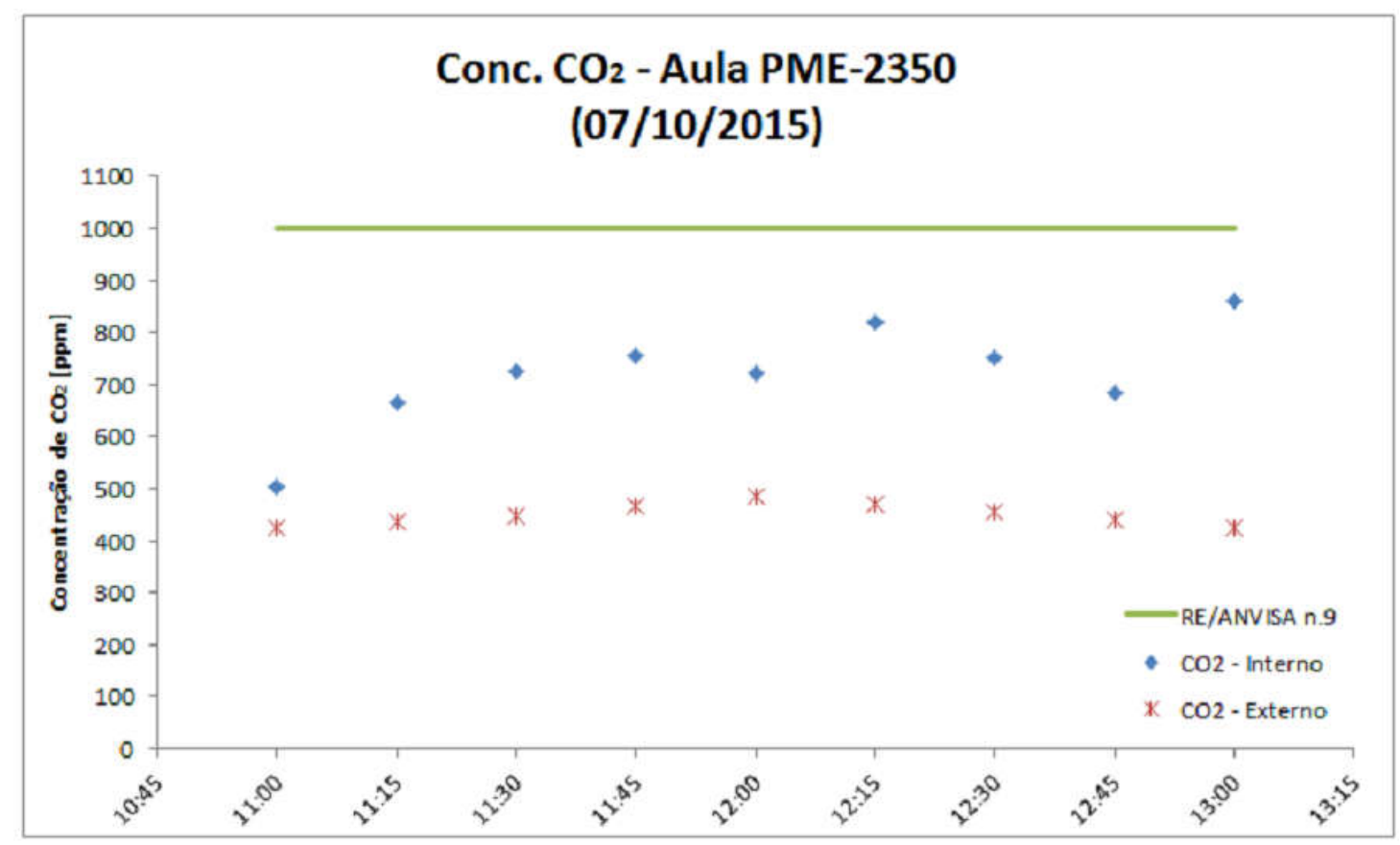


194

H.2 Concentração de $\mathrm{PM}_{10}$ na sala $\mathrm{A} 2$ durante a aula teórica (BORDINI, 2015)

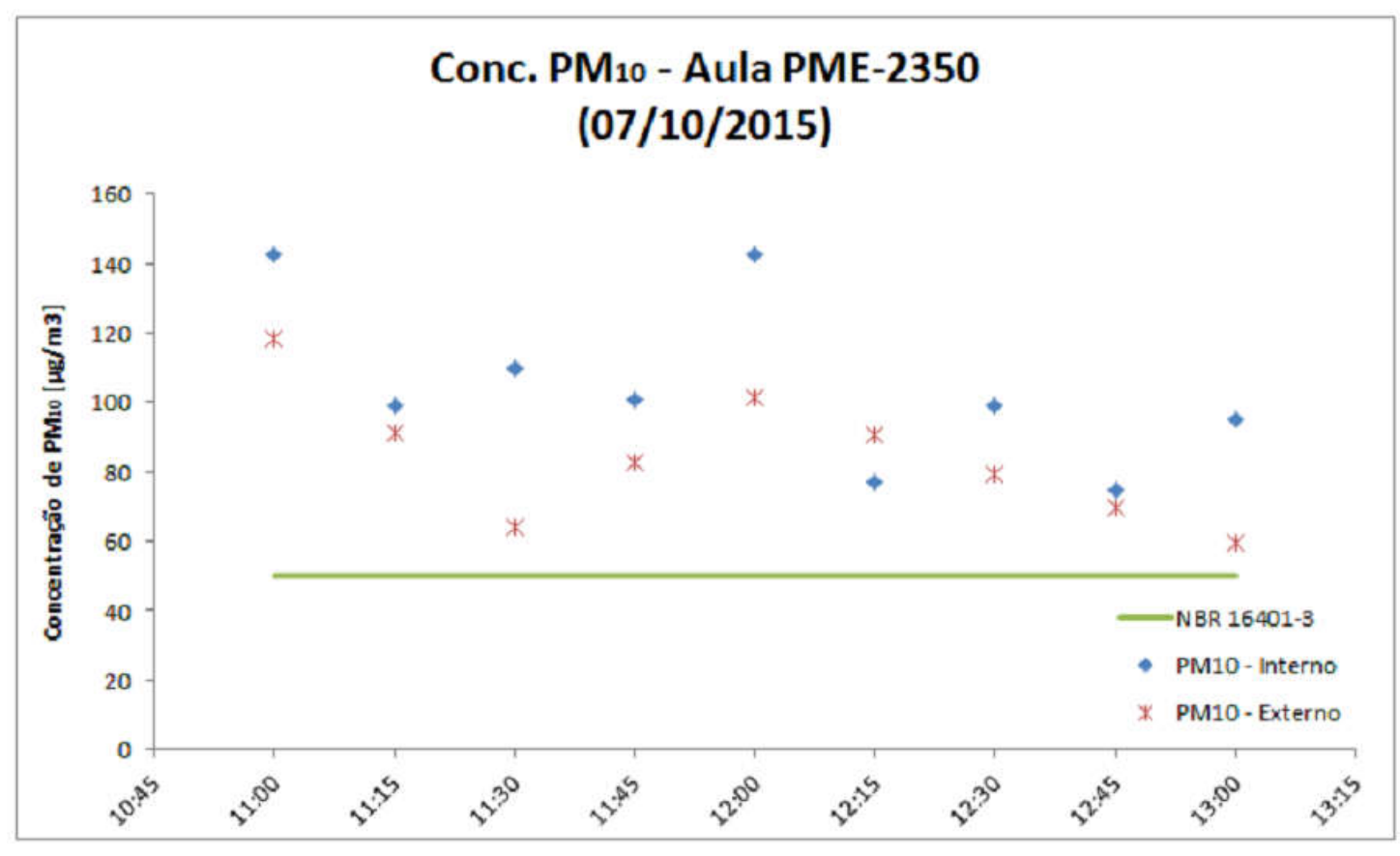




\section{H.3 Concentração de $\mathrm{CO}_{2}$ na sala $\mathrm{A} 2$ durante a Oficina de Carrinhos de Rolimã (BORDINI, 2015)}

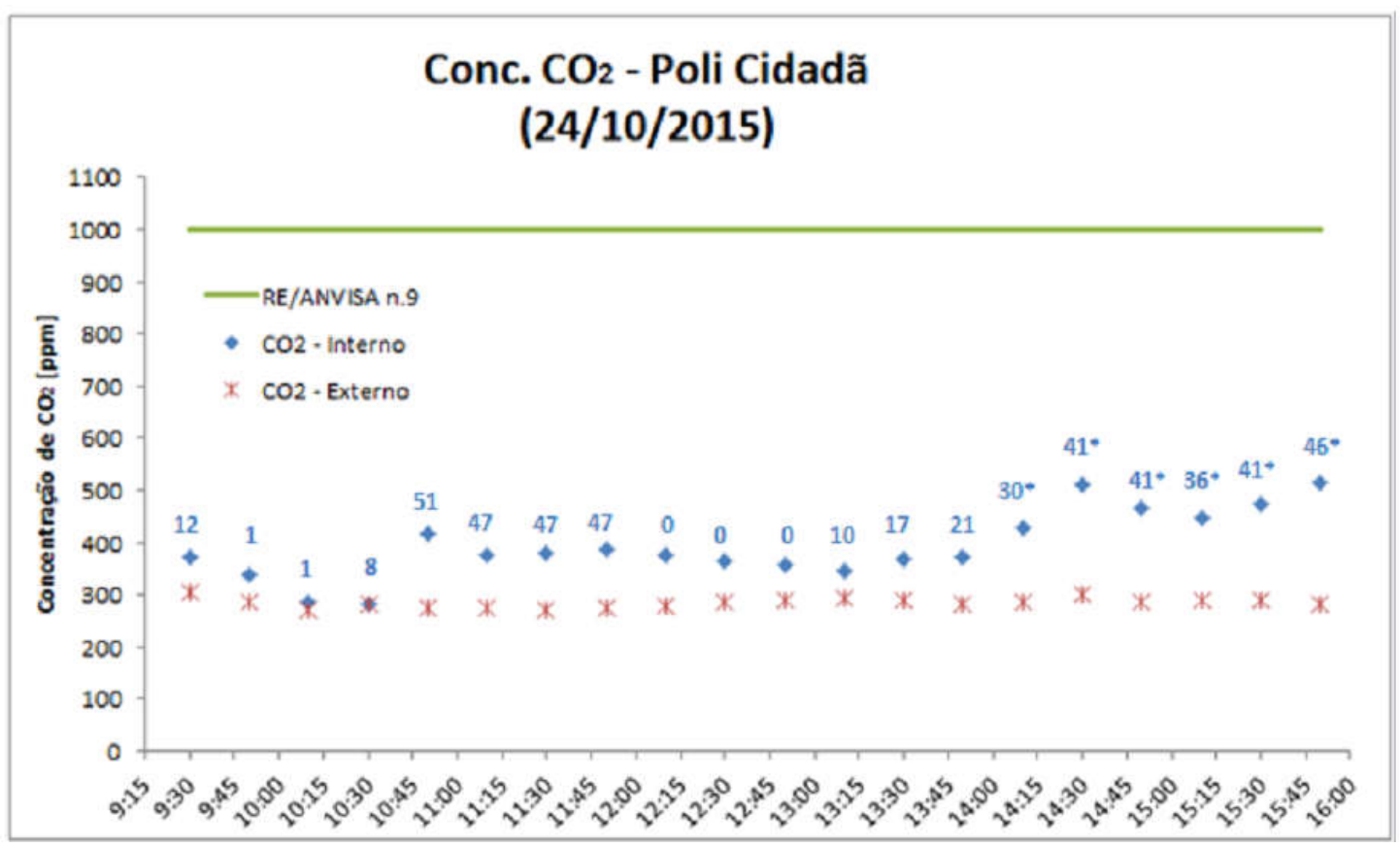


H.4 Concentração de $\mathrm{PM}_{10}$ na sala $\mathrm{A} 2$ durante a Oficina de Carrinhos de Rolimã (BORDINI, 2015)

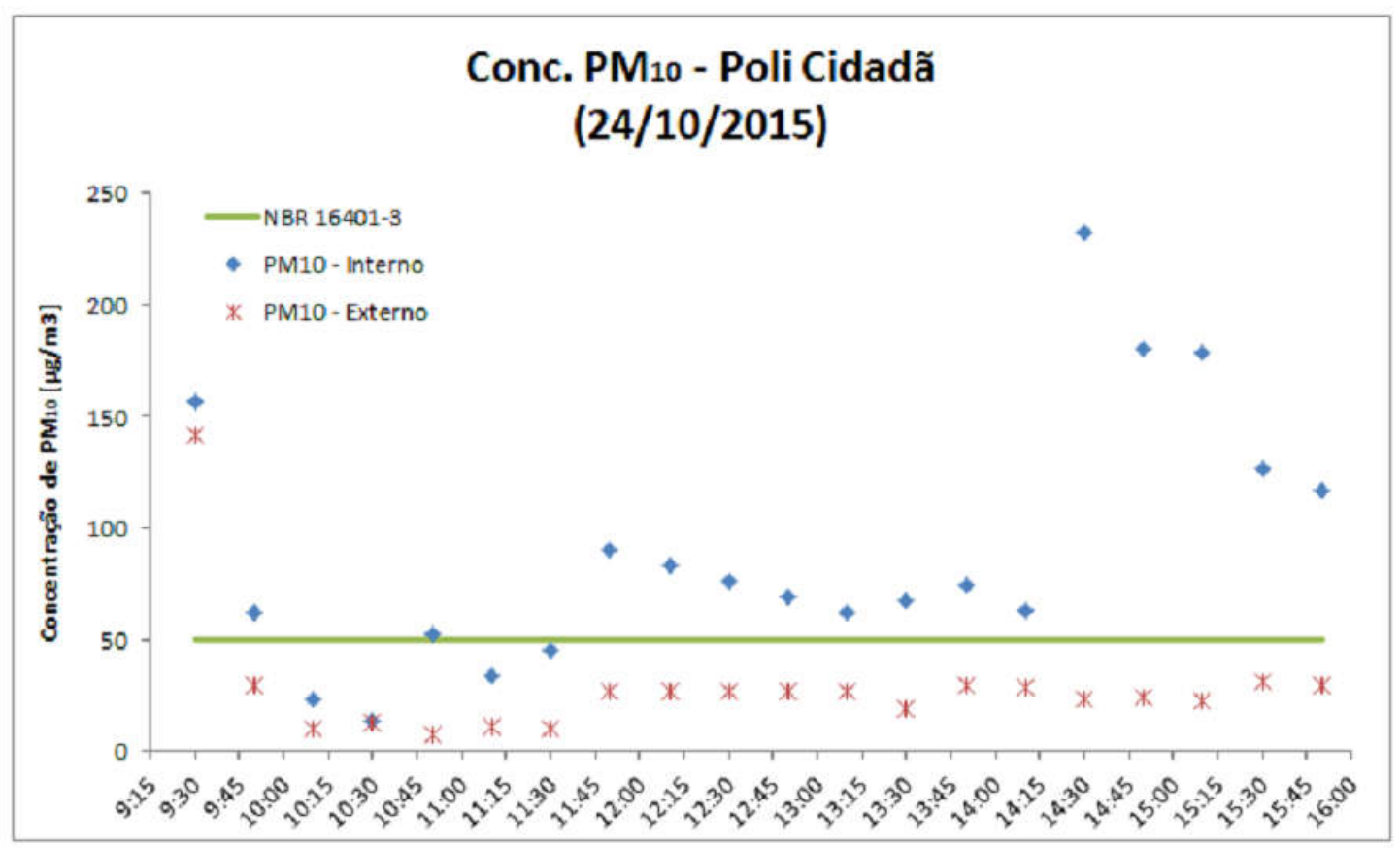

